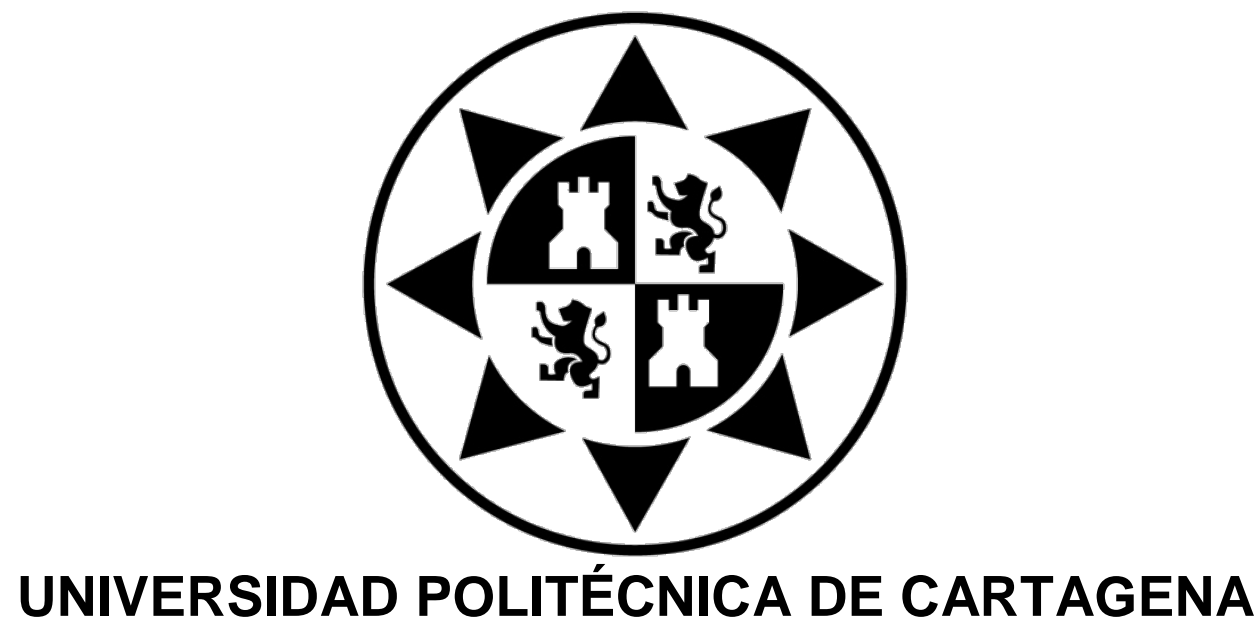

Programa de Doctorado Administración y Dirección de Empresas

TESIS DOCTORAL

LOS FACTORES DEL ÉXITO COMPETITIVO Y LA PROBLEMÁTICA DEL ACCESO A LA FINANCIACIÓN: UN ESTUDIO EMPÍRICO DE LAS MIPYMES EN EL PERÚ

AUTOR:

D. EDUARDO ROCCA ESPINOZA

CARTAGENA 2017 


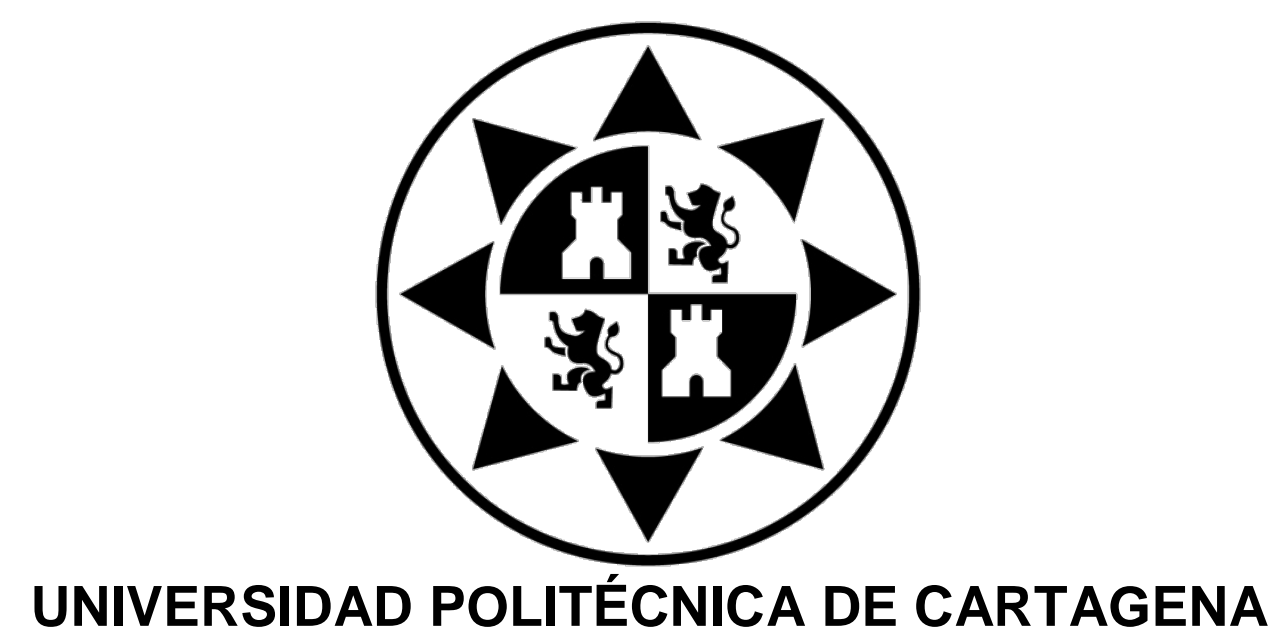

Programa de Doctorado Administración y Dirección de Empresas

TESIS DOCTORAL

\section{LOS FACTORES DEL ÉXITO COMPETITIVO Y LA PROBLEMÁTICA DEL ACCESO A LA FINANCIACIÓN: UN ESTUDIO EMPÍRICO DE LAS MIPYMES EN EL PERÚ}

AUTOR:

D. EDUARDO ROCCA ESPINOZA

DIRIGIDA POR:

DR. D. ANTONIO DURÉNDEZ GÓMEZ-GUILLAMÓN DR. D. DOMINGO GARCÍA PÉREZ DE LEMA 


\section{Dedicatoria}

A mi esposa Martha y a mis hijos Martha Rosa, Arturo y Francisco, quienes son mi motor, mi aliento y motivación.

A mis padres, que con todo su amor me dieron educación, su paciencia, comprensión y amor. 


\section{Agradecimientos}

Mis más sinceros agradecimientos a los Directivos de la Facultad de Ciencias de la Empresa de la Universidad Politécnica de Cartagena (UPCT) por haberme permitido ser alumno del programa de doctorado en Administración y Dirección de Empresas; y al equipo de colaboradores del Departamento de Economía Financiera y Contabilidad por todo el apoyo y facilidades que me brindaron siempre.

Mi profundo reconocimiento, aprecio y gratitud a mis tutores, Dr. Domingo García Pérez de Lema y Dr. Antonio Duréndez Gómez Guillamón que con su profesionalismo, amplia experiencia y acertada orientación, me guiaron, alentaron y orientaron de la mejor forma para culminar con este trabajo de investigación que sin duda han contribuido significativamente a mi formación académica y mi desarrollo personal.

Gracias a mi esposa por su sacrificio, apoyo y extrema paciencia y a mis hijos que han tenido que soportar mis largas ausencias de casa.

Gracias a mis amigos, compañeros de trabajo, colegas y personal administrativo de mi universidad por su apoyo y estímulo para la concreción de este proyecto de tesis. 


\section{RESUMEN}

Las micro, pequeñas y medianas empresas (Mipymes) en la actualidad juegan un importante rol en las economías modernas debido a la riqueza y empleo que generan y se ven afectadas por el rápido cambio tecnológico y la globalización de los mercados. El Perú en la actualidad es un país en vías de desarrollo que está experimentando un importante crecimiento económico y su tejido empresarial está constituido fundamentalmente por microempresas. La Mipyme, en el ámbito del Perú, se configura como el eje central de esta tesis doctoral, siendo su objeto principal estudiar los factores explicativos del éxito empresarial y la problemática del acceso a la financiación, tanto desde la perspectiva del empresario como de las entidades financieras. La tesis doctoral se ha estructurado en tres estudios empíricos con la finalidad de buscar los elementos que ayuden a la Mipyme a mejorar su competitividad, crecimiento y sostenibilidad en el tiempo.

En el primer estudio se analizan los factores asociados al éxito competitivo de las Mipymes peruanas, con una muestra de 94 empresas, con más de 5 trabajadores. Los factores de éxito competitivo se estudian desde la perspectiva de la teoría de los recursos y capacidades de las empresas. Se trata de responder diversas preguntas de investigación como: ¿la posición tecnológica de las empresas influye en su rendimiento?, ¿el hecho que una empresa posea alguna certificación de calidad o esté en proceso de obtenerlo está relacionado con la buena performance de ésta?, ¿las actividades de innovación y la posición tecnológica de la empresa están relacionados con su rendimiento?, ¿los sistemas de control de gestión y las prácticas de recursos humanos en las empresas influyen en su éxito?, ¿la experiencia profesional del gerente influye en el éxito de las organizaciones que conducen? Los resultados muestran que las Mipymes que tengan implantados sistemas de control de gestión más desarrollados y que apliquen prácticas de gestión de sus recursos humanos más eficientes, mayor será la probabilidad de tener éxito en el mercado. Los resultados son especialmente útiles para los gerentes de las Miymes y los organismos de fomento de la Mipyme para que puedan diseñar y promover estrategias y políticas que favorezcan el crecimiento y competitividad de la Miyme.

El segundo estudio analiza las causas del racionamiento de crédito en las Mipymes peruanas. Dado que en Perú se produce un especial problema en el acceso al crédito puesto que el sistema financiero no está plenamente desarrollado y las posibilidades de acceso al crédito bancario son menores que en otras economías. Para 
ello, se desarrolla un estudio empírico mediante una encuesta a una muestra de 158 Mipymes peruanas. Los resultados muestran que factores como las prácticas de innovación en productos, procesos y sistemas de gestión, la situación jurídica formal de la empresa, su buen rendimiento, el que disponga de una posición tecnológica fuerte, que realice un plan estratégico de forma periódica, que tenga departamentos formales dentro en su estructura organizacional, entre otros, hace que tenga una mayor probabilidad de acceso al crédito bancario. La identificación de estos factores que facilitan el acceso al crédito de las empresas ayudará a las mismas en la mejora de su competitividad, así como a los organismos gubernamentales a conocer qué políticas deben desarrollar para facilitar el acceso al crédito y una mayor eficacia del sistema financiero.

Finalmente, en el tercer estudio se analizan los principales criterios que consideran las entidades financieras a la hora de otorgar un crédito a una Mipyme, al objeto de minimizar su riesgo de impago. Para ello, se desarrolla un estudio empírico realizado a 73 analistas de riesgos de entidades financieras peruanas. Los criterios utilizados por las entidades financieras se clasifican en: personalidad y experiencia del empresario; características del producto o servicio que ofrece la empresa y del mercado donde desarrolla su actividad; estrategia y organización de la empresa; y criterios relacionados con la información contable que presentan las empresas. Los resultados muestran que los criterios que los analistas de riesgos consideran más relevantes a la hora de otorgar un crédito son: el conocimiento del sector que tiene el empresario, la honestidad e integridad del empresario, la cartera de clientes con la que cuenta la empresa, y la calificación del personal de la empresa. En cuanto a los criterios relacionados con la información contable, los analistas de riesgos valoran especialmente los ratios de liquidez y de endeudamiento, que las empresas lleven algún sistema de costos fiable y que no aparezcan en registros de impagos como el INFOCORP. Este trabajo es especialmente útil a las entidades financieras para ayudarles a mejorar sus sistemas de calificación y a las Mipymes para favorecer una mejor relación con las entidades financieras. 


\begin{abstract}
Micro, small and medium enterprises (MSMEs) today play an important role in modern economies because of the wealth and employment they generate and are affected by rapid technological change and the globalization of markets. Peru is currently a developing country that is experiencing significant economic growth and its business fabric is mainly microenterprises. MSME, in the Peruvian context, is the central axis of this doctoral thesis, its main objective being to study the factors that explain business success and the problem of access to finance, both from the perspective of the entrepreneur and the financial institutions. The doctoral thesis has been structured in three empirical studies with the purpose of looking for the elements that help the MSME to improve its competitiveness, growth and sustainability over time.

The first study analyzes the factors associated with the competitive success of the Peruvian MSMEs, with a sample of 94 companies, with more than 5 workers. The factors of competitive success are studied from the perspective of the theory of resources and capabilities of companies. It is a question of answering several research questions such as: The technological position of the companies influences its performance?, The fact that a company has some quality certification or is in the process of obtaining it is related to its good performance? Are the innovation activities and the technological position of the company related to its performance? Do management control systems and human resources practices influence business success? The professional experience of the manager influences the success of the organizations that lead?. The results show that MSMEs with more developed management control systems that implement more efficient management practices of their human resources, the greater the probability of success in the market. The results are especially useful for the managers of the MSMEs and the MSME development agencies so that they can design and promote strategies and policies that favor the growth and competitiveness of MSME.

The second study analyzes the causes of credit rationing in Peruvian MSMEs. Given that in Peru there is a special problem in access to credit since the financial system is not fully developed and the possibilities of access to bank credit are lower than in other economies. For this, an empirical study is developed through a survey of a sample of 158 Peruvian MSMEs. The results show that factors such as innovation practices in products, processes and management systems, the formal legal situation of the company, its good performance, the one with a strong technological position, that makes a strategic plan on a regular basis, which has formal departments within its organizational
\end{abstract}


structure, among others, has a greater probability of access to bank credit. Identifying these factors that facilitate access to credit for companies will help them to improve their competitiveness, as well as government agencies to know what policies to develop to facilitate access to credit and greater efficiency of the financial system.

Finally, the third study analyzes the main criteria that financial institutions consider when granting credit to a MSME, in order to minimize their risk of default. For this purpose, an empirical study was carried out on 73 risk analysts from Peruvian financial institutions. The criteria used by financial institutions are classified into: personality and experience of the entrepreneur; characteristics of the product or service offered by the company and the market where it operates; strategy and organization of the company; and criteria related to the accounting information presented by companies. The results show that the criteria that the risk analysts consider most relevant when granting a credit are: knowledge of the sector that has the entrepreneur, honesty and integrity of the entrepreneur, the client portfolio with which the company has, and qualification of the personnel of the company. Regarding the criteria related to accounting information, risk analysts especially value the liquidity and debt ratios, that companies carry some reliable cost system and do not appear in defaults such as INFOCORP. This work is especially useful to financial institutions to help them improve their rating systems and to MSMEs to foster a better relationship with financial institutions. 
ÍNDICE 
ÍNDICE

GLOSARIO

INTRODUCCIÓN

1. LAS MIPYMES EN EL PERÚ. 39

1.1. INTRODUCCIÓN

1.2. SITUACIÓN ECONÓMICA EN EL PERÚ

1.3. PROBLEMAS PENDIENTES EN LA ECONOMÍA PERUANA 43

1.4. CARACTERÍSTICAS E IMPORTANCIA DE LAS MIPYMES EN EL PERÚ ....45

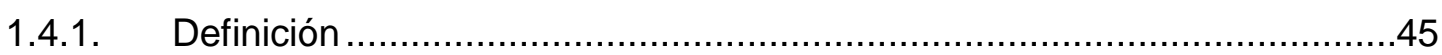

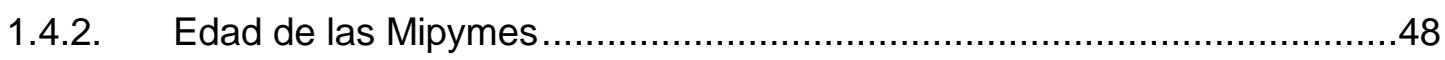

1.4.3. Nivel de formalidad e informalidad .................................................. 49

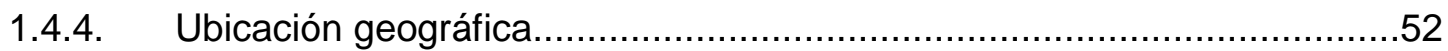

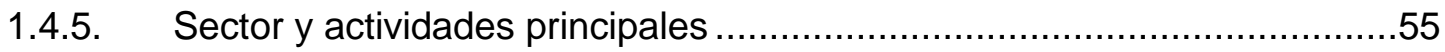

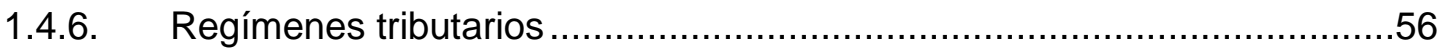

1.5. IMPORTANCIA DE LAS MIPYMES EN LA ECONOMÍA PERUANA..............59

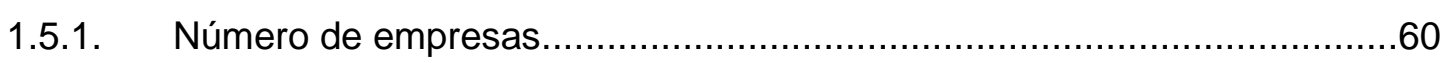

1.5.2. Población económicamente activa (PEA) ocupada .................................60

1.5.3. Volumen de exportaciones..........................................................62

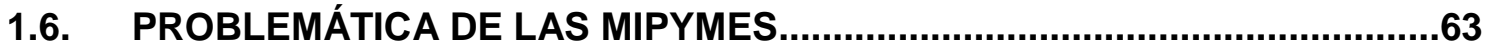

1.7. EL MICROCRÉDITO EN EL PERÚ .......................................................66

2. FACTORES DETERMINANTES DEL ÉXITO COMPETITIVO EN LA MIPYME: UN ESTUDIO EMPÍRICO EN EMPRESAS PERUANAS ........................................73

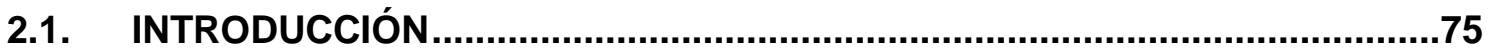

2.2. MARCO TEÓRICO, REVISIÓN DE ESTUDIOS PREVIOS E HIPÓTESIS A

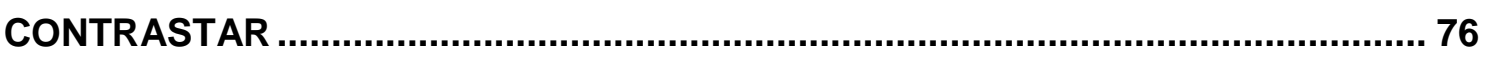

2.2.1. La teoría de los recursos y capacidades de la empresa..........................76 
2.2.2. La planificación, los sistemas de control de gestión y el rendimiento de

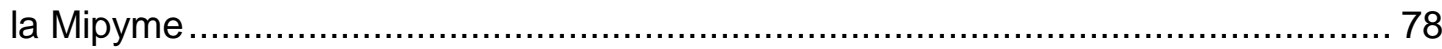

2.2.3. La gestión de la calidad y el rendimiento............................................ 80

2.2.4. La innovación y el rendimiento ........................................................... 81

2.2.5. Los recursos humanos y el rendimiento .......................................... 83

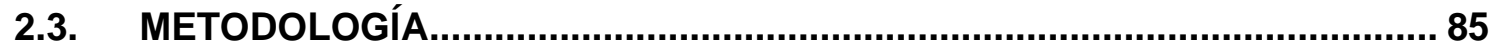

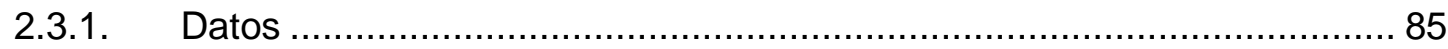

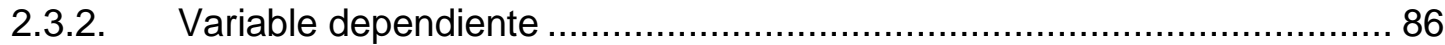

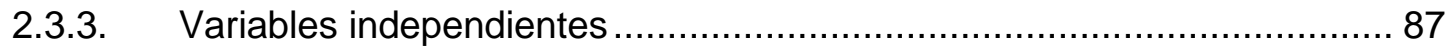

2.3.3.1. Planeación estratégica y sistemas de control comercial ..................... 87

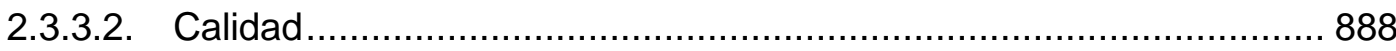

2.3.3.3. Innovación y posición tecnológica ............................................. 88

2.3.3.4. Formación, edad del gerente y prácticas de recursos humanos .......... 89

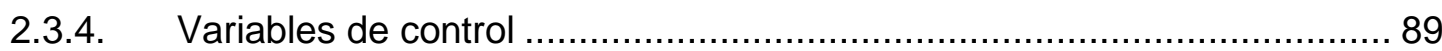

2.3.4.1. Tamaño, edad de la empresa y sector ........................................... 89

2.4. ANÁLISIS DE RESULTADOS............................................................... 89

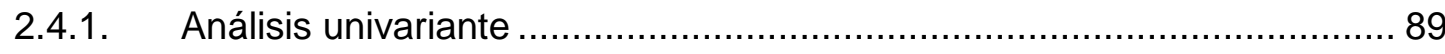

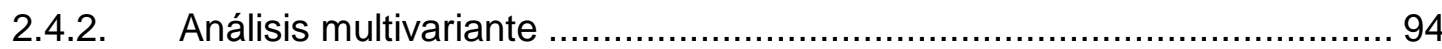

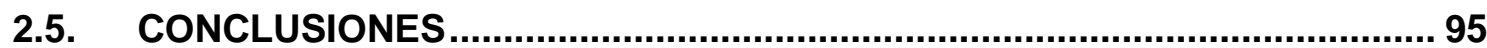

3. FACTORES DETERMINANTES PARA EXPLICAR EL RACIONAMIENTO DE CRÉDITO: UN ESTUDIO EMPÍRICO EN EMPRESAS PERUANAS ..........................97

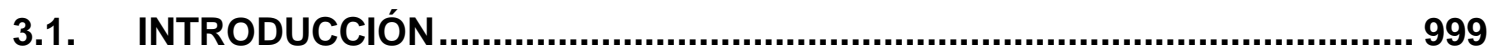

3.2. FACTORES DETERMINANTES DEL RACIONAMIENTO DEL CRÉDITO E

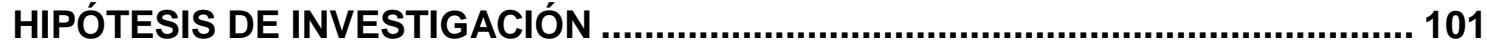

3.2.1. Tamaño y edad de la empresa ....................................................... 103

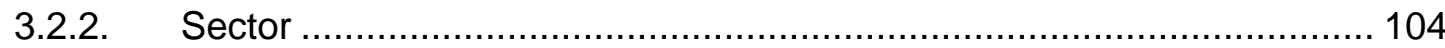

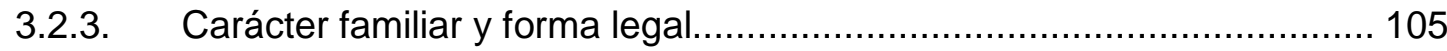

3.2.4. Capital humano: edad, experiencia, nivel de educación y género del

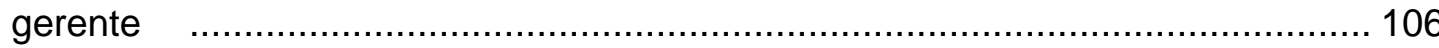

3.2.5. Plan estratégico y estructura organizativa ....................................... 107

3.2.6. Innovación, posición tecnológica, calidad y uso de TIC........................ 108 


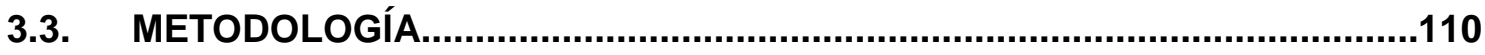

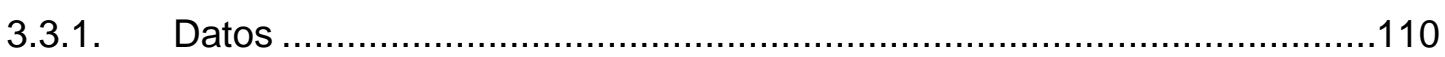

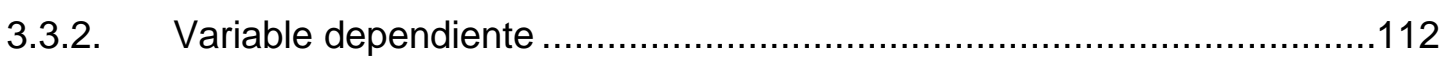

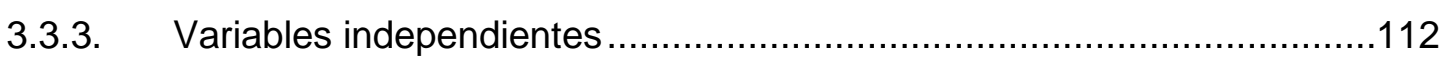

3.3.3.1. Características de la empresa ......................................................112

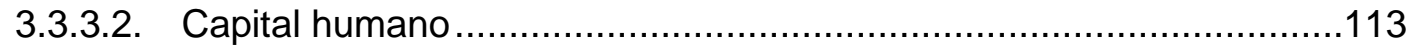

3.3.3.3. Planificación estratégica y estructura organizativa ...........................113

3.3.3.4. Innovación en productos, procesos y gestión ...................................114

3.3.3.5. Posición tecnológica, TIC's y certificación de calidad.........................114

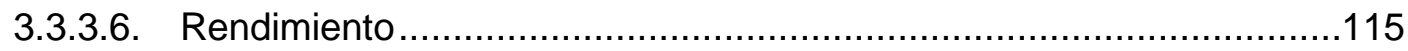

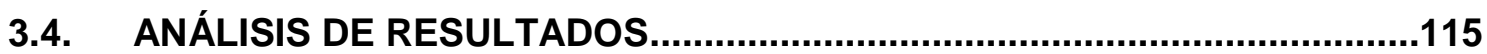

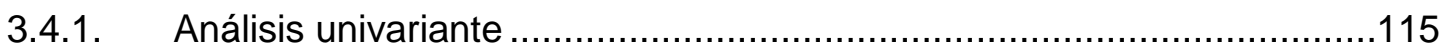

3.4.1.1. Características de la empresa....................................................115

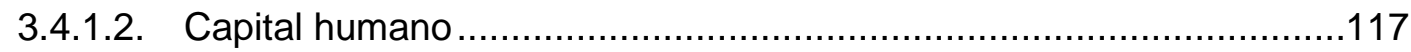

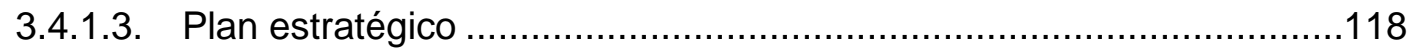

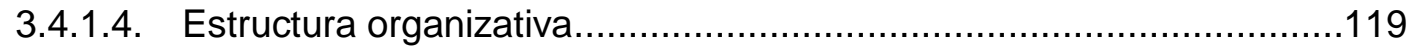

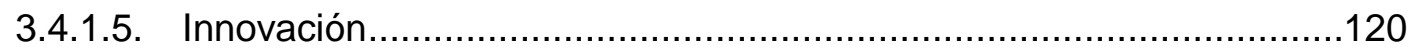

3.4.1.6. Posición tecnológica y certificación de calidad ................................122

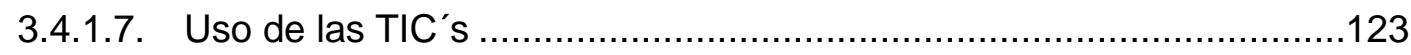

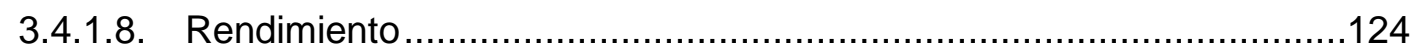

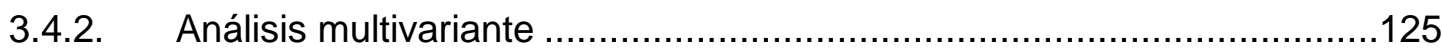

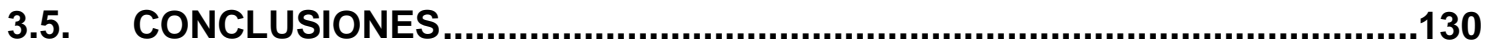

4. FACTORES DETERMINANTES PARA LA CONCESIÓN DE CRÉDITO POR PARTE DE LAS ENTIDADES FINANCIERAS A LAS MIPYMES $\ldots \ldots \ldots \ldots \ldots \ldots \ldots 133$

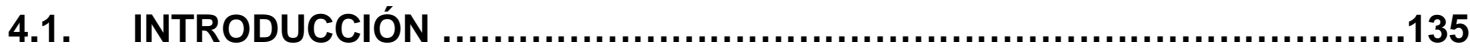

4.2. MARCO TEÓRICO, REVISIÓN DE ESTUDIOS PREVIOS E HIPÓTESIS A

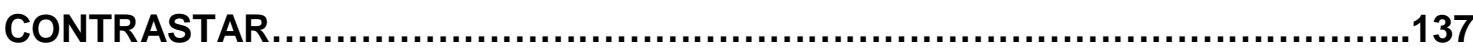

4.3. METODOLOGÍA.................................................................. 141

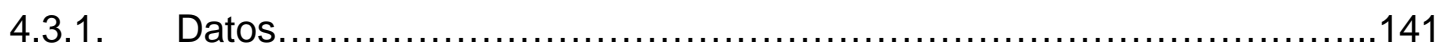


4.4. ANÁLISIS DE RESULTADOS............................................143

4.4.1. Análisis univariante....................................................143

4.4.1.1. Variables acerca de la personalidad y experiencia del empresario....143

4.4.1.2. Variables acerca de las características del producto o servicio que ofrece la empresa y del mercado donde desarrolla su actividad..................145

4.4.1.3. Variables acerca de la estrategia y organización de la empresa.......147

4.4.1.4. Variables acerca de la información contable que presenta la

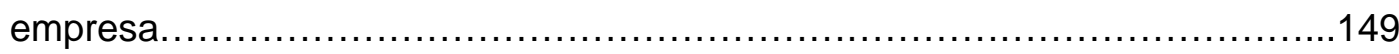

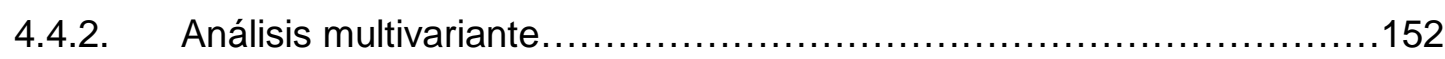

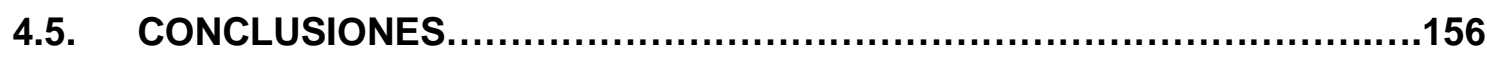

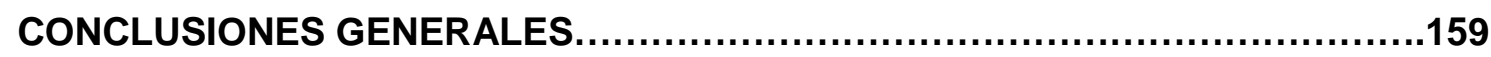

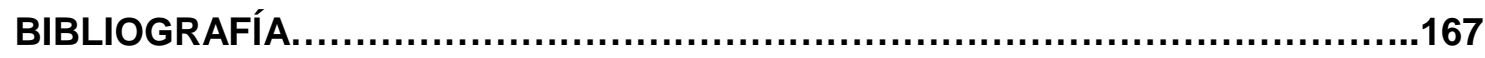




\section{ÍNDICE DE TABLAS}

Tabla 1.1. Definición de la Mipyme en el Perú..................................................46

Tabla 1.2. Definición de la Mipyme en Argentina..................................................47

Tabla 1.3. Definición de la Mipyme en México......................................................... 47

Tabla 1.4. Definición de la Mipyme en Brasil y Panamá ..........................................48

Tabla 1.5. Definición de la Mipyme en Colombia y Costa Rica .................................48

Tabla 1.6. Porcentaje de empresas formales por estrato empresarial ......................49

Tabla 1.7. Número de micro y pequeñas empresas formales y no formales................52

Tabla 1.8. Número de empresas por tamaño y ubicación geográfica .........................54

Tabla 1.9. Número de empresas por sector económico y tamaño ..............................56

Tabla 1.10. Mipymes formales por régimen tributario en el Perú ..............................59

Tabla 1.11. Número de empresas por tamaño en el Perú ............................................60

Tabla 1.12. Número de empresas por tamaño y rango de trabajadores .....................62

Tabla 1.13. Número de empresas exportadoras del sector privado, según tamaño ....63

Tabla 1.14. Factores de la problemática de las Mipymes ........................................64

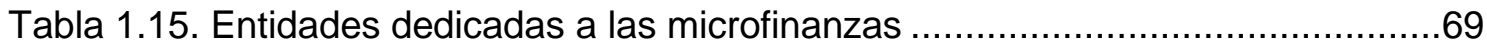

Tabla 2.1. Composición de las empresas de la muestra ........................................86

Tabla 2.2. Validación de las escalas tipo Likert ..................................................... 87

Tabla 2.3. Plan estratégico y sistemas de control de gestión .................................90

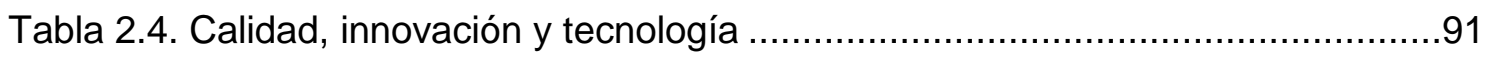

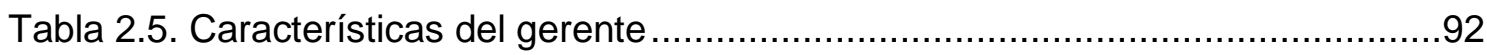

Tabla 2.6. Gestión de recursos humanos ..............................................................93

Tabla 2.7. Tamaño, edad de la empresa y sector................................................93

Tabla 2.8. Regresión logística por el método de Wald.........................................94

Tabla 3.1. Composición de las empresas de la muestra ......................................112

Tabla 3.2. Características de la empresa ...................................................116

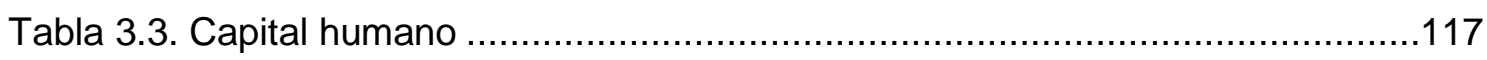

Tabla 3.4. Plan estratégico...................................................................... 118

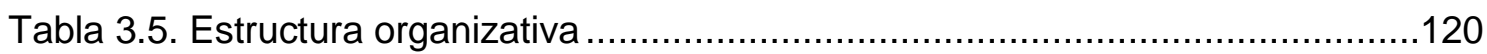

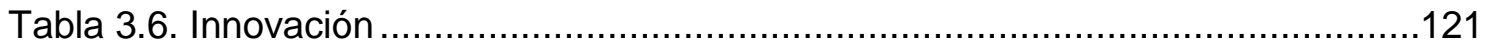

Tabla 3.7. Posición tecnológica y certificación de calidad.......................................122

Tabla 3.8. Uso de tecnologías de información y comunicación .................................124

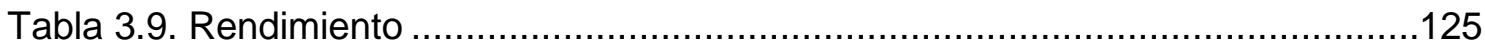

Tabla 3.10. Racionamiento de crédito en la Mipyme ...........................................128

Tabla 3.11. Tabla de Correlaciones de Spearman ..............................................129 
Tabla 4.1. Composición de las entidades financieras de la muestra.

Tabla 4.2. Media y valor de significación de la diferencia entre los ítems asociados con la personalidad y experiencia del empresario

Tabla 4.3. Media y valor de significación de la diferencia entre los ítems asociados con las características del producto o servicio que ofrece la empresa y del mercado donde desarrolla su actividad.

Tabla 4.4. Media y valor de significación de la diferencia entre los ítems asociados con la estrategia y organización de la empresa.

Tabla 4.5. Media y valor de significación de la diferencia entre los ítems asociados con la información contable que presenta la empresa.....

Tabla 4.6. Regresión logística por el método de Wald según el género del analista.153 Tabla 4.7. Regresión logística por el método de Wald según la experiencia del analista....

Tabla 4.8. Regresión logística por el método de Wald según la formación del analista. .155 


\section{ÍNDICE DE GRÁFICOS}

Gráfico 1.1. Promedios de años de funcionamiento de las Mipymes .........................49

Gráfico 1.2. Porcentaje de Mypes formales e informales.......................................50

Gráfico 1.3. Porcentaje de Mipymes por sector económico ......................................55

Gráfico 1.4. Distribución porcentual de la PEA, según número de trabajadores ..........61

Gráfico 1.5. Créditos directos de los Bancos a las Mipymes ...................................70

Gráfico 1.6. Créditos directos de las Cajas Municipales a las Mipymes......................70

Gráfico 1.7. Créditos directos de las Cajas Rurales a las Mipymes ............................71

Gráfico 1.8. Créditos directos de las Edpymes a las Mipymes ................................71

Gráfico 1.9. Créditos directos de las Financieras a las Mipymes ..............................72 


\section{GLOSARIO}


Relación de siglas utilizadas en este documento

\begin{tabular}{|c|c|}
\hline Sigla & Nombre \\
\hline BCRP & Banco Central de Reserva del Perú \\
\hline CEPLAN & Centro Nacional de Planeamiento Estratégico \\
\hline CIIU & Clasificación Internacional Industrial Uniforme \\
\hline CMAC & Caja Municipal de Ahorro y Crédito \\
\hline CRAC & Caja Rural de Ahorro y Crédito \\
\hline EDPYME & Entidad de Desarrollo para la Pequeña y \\
\hline & Microempresa \\
\hline ESSALUD & Seguro Social de Salud del Perú \\
\hline FAEDPYME & $\begin{array}{l}\text { Fundación para el Análisis Estratégico y Desarrollo de } \\
\text { la Pequeña y Mediana Empresa }\end{array}$ \\
\hline IFC & International Finance Corporation \\
\hline INEI & Instituto Nacional de Estadística e Informática \\
\hline INFOCORP & Central de Riesgos más importante de Perú \\
\hline ISO & International Organization for Standardization \\
\hline MIPYME & Micro, Pequeña y Mediana Empresa \\
\hline MYPE & Micro y Pequeña Empresa \\
\hline OECD & $\begin{array}{l}\text { Organisation for Economic Co-operation and } \\
\text { Development }\end{array}$ \\
\hline ONG & Organización no Gubernamental \\
\hline ONU & Organización de las Naciones Unidas \\
\hline PBI & Producto Bruto Interno \\
\hline PEA & Población Económicamente Activa \\
\hline RER & Régimen Especial del Impuesto a la Renta \\
\hline RG & Régimen General del Impuesto a la Renta \\
\hline ROA & Return On Assets \\
\hline RUS & Régimen Único Simplificado \\
\hline SBS & Superintendencia de Banca, Seguros y AFP \\
\hline SUNAT & $\begin{array}{l}\text { Superintendencia Nacional de Aduanas y de } \\
\text { Administración Tributaria }\end{array}$ \\
\hline UE & Unión Europea \\
\hline
\end{tabular}


INTRODUCCIÓN 
Las micro, pequeñas y medianas empresas (Mipymes) en la actualidad juegan un importante rol en las economías modernas debido a la riqueza y empleo que generan (Cravo, Becker, \& Gourlay, 2014; Memili, Fang, Chrisman, \& De Massis, 2015) y se ven afectadas por el rápido cambio tecnológico y la globalización de los mercados (Ahmedova, 2015). También juegan un papel importante en aquellos mercados que demandan productos específicos y que exigen una elevada flexibilidad y en sus procesos productivos hacen más uso intensivo de mano de obra que las empresas grandes (Morsing \& Perrini, 2009), contribuyen en la dinamización de la economía; siendo vista con especial atención debido a su capacidad de adaptarse a la realidad local o regional (Cardozo, Velásquez, \& Rodríguez, 2012). Los gobiernos reconocen cada vez más su importancia como fuente del crecimiento económico creando instituciones y desarrollando políticas de Estado que favorezcan su consolidación y competitividad en el mercado (Gill \& Biger, 2011; Foreman-Peck, 2013; Trang, 2015).

A pesar de la diversidad y heterogeneidad de la Mipyme, éstas comparten ciertos rasgos que las caracterizan (Cocca \& Alberti, 2010). La Mipyme, en general, dispone de recursos limitados y poco especializados, aunque tiene un alto grado de adaptabilidad (Trang, 2015), opera en mercados altamente competitivos y su demanda está conformada por un pequeño portafolio de clientes. Desde el punto de vista del ambiente interno (recursos humanos y financieros, procesos internos, clima y cultura organizacional, etc.), uno de los principales problemas que tiene la Mipyme es la escasez de recursos como la capacidad del personal, la capacidad de gestión empresarial de los dueños del negocio o de los empleados de mayor rango y la estabilidad y seguridad financiera (Arasti, Zandi, \& Bahmani, 2014). Aunque el tamaño de la empresa representa una debilidad por el poco recurso humano disponible para el desarrollo de la actividad de la empresa, representa, por otro lado, una ventaja porque dispone de una estructura organizacional que favorece la flexibilidad, adaptabilidad y rapidez de reacción a los cambios del mercado. Por esta razón, la Mipyme tiene usualmente un alto potencial de innovación para satisfacer nuevos requerimientos de sus clientes. Además, una estructura más sencilla simplifica los procesos de comunicación y ofrece al empresario mejor visibilidad de los procesos de su empresa y la oportunidad de influir directamente en sus empleados. Los pequeños empresarios son generalmente los gerentes generales y de sus competencias en gestión depende el éxito o fracaso organizacional. Sus decisiones se basan usualmente en su intuición y experiencia empresarial antes que en el análisis de información. Tienden a seguir una 
filosofía de reacción y adaptación enfocándose en el corto plazo, desestimando una planificación estratégica de largo plazo (Hudson, Smart, \& Bourne, 2001) .

Además, el contexto económico mundial, ha generado en los últimos años casi una batalla por la sobrevivencia. Dicho contexto está caracterizado por una reducción en el consumo, una competencia mayor de las economías emergentes, una mayor incidencia en la eficiencia y el ahorro de costos, financiación limitada y la disminución de los organismos del Estado (Bianchi, Cosenz, \& Marinković, 2015). Y este marco hace más compleja la conducción, el desarrollo y el desempeño de las Mipymes. La eliminación de las barreras comerciales entre los países y la globalización de la economía hacen que las empresas actúen en un mercado más abierto y más liberal, lo que genera más competitividad y dificulta su supervivencia en el tiempo, obligando a su vez a las empresas a un uso más adecuado de sus recursos y el empleo de la innovación como elemento esencial para lograr ventaja competitiva (Benito-Hernández, PlateroJaime, \& Rodríguez-Duarte, 2012).

El Perú es un país en vías de desarrollo que está experimentando un importante crecimiento económico (Gallo, Garrido, \& Del Pozo, 2015). En los últimos 10 años el PBI real ha crecido a un ritmo del 5,8\% promedio anual (The World Bank, 2016; Instituto Nacional de Estadística e Informática [INEI], 2016c). El tejido empresarial en el Perú está constituido fundamentalmente por microempresas. Del total de empresas formales registradas, las Mipymes concentran el 99,48\% de las empresas en el Perú (de un total de 1.600 .620 empresas formales), de este porcentaje un $94,86 \%$ corresponde a microempresas, un 4,46\% a pequeñas empresas y las medianas constituyen el $0,16 \%$ (Ministerio de la Producción, 2015).

Lo anterior, hace ver la importancia de investigar el contexto de las Mipymes y buscar los elementos que la ayuden a mejorar su competitividad, crecimiento y sostenibilidad en el tiempo. La Mipyme, en el ámbito del Perú, se configura como el eje central de esta tesis doctoral, siendo su objeto principal estudiar los factores explicativos del éxito empresarial y la problemática del acceso a la financiación, tanto desde la perspectiva del empresario como de las entidades financieras. Es importante destacar que la mayoría de investigaciones y resultados que se conocen de las economías desarrolladas no pueden aplicarse directamente en las economías de países emergentes como el Perú, ya que culturalmente el comportamiento de los empresarios frente a cuestiones como la maximización de utilidades, su interés propio y su comportamiento puede ser diferente (Bruton, Ahlstrom, \& Obloj, 2008). 
Los factores de éxito vienen explicados en gran parte por la teoría de los recursos y capacidades, y diferentes recursos internos y externos, usados de manera adecuada, podrían aumentar la competitividad de las empresas. En este sentido, existe una amplia literatura que pone de manifiesto los factores explicativos del éxito empresarial. Las TIC y el uso del comercio electrónico, reduce los costos de transacción y aumenta la eficiencia y velocidad de los diferentes procesos y operaciones de las empresas y favorece el desempeño organizacional (Jones, Motta, \& Alderete, 2016). La innovación es otro factor clave para el éxito y obtener ventajas competitivas (Gibson \& Naquin, 2011). Se debe de innovar en productos y procesos, así como en la formulación de estrategias y el diseño organizacional, siendo un reto importante la adopción de esquemas organizacionales flexibles que les permita operar de manera eficaz en un entorno muy cambiante e incierto (Capó-Vicedo, Expósito-Langa, \& Masiá-Buades, 2007). No obstante, y a pesar de la extensa literatura, aún no está claro qué tipo de innovación tiene efectos directos o indirectos en el rendimiento de la empresa, ya que la evidencia no es consistente y está todavía fragmentada (Vladimirov, 2016). La planificación estratégica permite a las Mipymes proyectarse en el tiempo y tomar medidas que incrementen su competitividad frente a sus competidores (Mora-Riapira, Vera-Colina, \& Melgarejo-Molina, 2015). Biju \& Bhasi (2014) encuentran una relación positiva entre el uso del planeamiento y control en las empresas y su rendimiento. La gestión de la calidad es otro aspecto importante que influye en los resultados de las empresas. Las empresas que adoptan la gestión de la calidad total y buscan la calidad de sus productos o servicios que ofrecen, mejorarán su competitividad, el éxito del negocio y logran diferenciar su producto o servicio de los demás (Prajogo \& Sohal, 2006; Corredor \& Goñi, 2011). Las organizaciones certificadas, son capaces de mejorar su performance en costos y calidad; las ayuda a ser más disciplinadas en sus actividades y las induce a la sistematización y simplificación de sus procesos productivos (Sachdeva, Bhardwaj, \& Sharma, 2007). Finalmente, la gestión de los recursos humanos también ocupa un lugar importante en los trabajos de investigación que buscan su relación con la performance de las empresas. Estos sistemas de gestión son parte de los activos estratégicos que pueden darle ventaja competitiva a la empresa manteniéndolo en el tiempo y agregándole valor; estos activos intangibles son difíciles de reemplazarlos, copiarlos o transferirlos (De Oliveira \& De Oliveira, 2011).

El acceso a la financiación, es una restricción frecuente de las Mipymes en el Perú, y obstaculiza su crecimiento y competitividad. En el Perú es muy común que a las empresas o bien se le deniegan las solicitudes de crédito o les impongan condiciones 
(tasa de interés, garantías) más duras (Mendizabal \& Lertxundi, 2015). El acceso a la financiación se estudia desde una doble perspectiva: (1) se analizan los factores que influyen en el racionamiento de crédito de las empresas peruanas; y (2) se identifican las variables cualitativas y cuantitativas que influyen en el otorgamiento de créditos por parte de las entidades financieras peruanas.

A pesar de la importancia de la Mipyme por su aporte al empleo y a la riqueza económica de un país, una restricción frecuente de las Mipymes es su accesibilidad a la obtención de financiación externa. Las Mipymes en los países en desarrollo tienen un acceso limitado a los servicios financieros formales debido a diversos problemas con las garantías (tenencia, valuación, documentación legal) y el coste relativamente alto de las transacciones de préstamos pequeños (Doan, Gibson, \& Holmes, 2010). En este sentido, es fundamental la disponibilidad de financiación bancaria para asegurar la viabilidad y el crecimiento de la empresa (McCarthy, Oliver, \& Verreynne, 2013), así como la consecución de sus objetivos empresariales. Por ello, las dificultades para conseguir recursos financieros para invertir en nuevos proyectos pueden no solo afectar su crecimiento sino también su supervivencia en el mercado. Las restricciones de financiación tienen por tanto un efecto negativo sobre el crecimiento potencial de las empresas, frenando con ello la diversificación económica y la generación del empleo (Okurut, Olalekan, \& Mangadi, 2011). Así, un sistema financiero eficiente favorece el desarrollo económico de un país a largo plazo. Los países con sistemas financieros más fuertes crecen más rápido y reducen la desigualdad y la pobreza (Montoya, 2016).

La problemática del acceso a la financiación en la Mipyme se explica a través de diferentes teorías financieras clásicas como son la Teoría de la Agencia y la Teoría de la Jerarquía Financiera. Por un lado, el desarrollo de la Teoría de la Agencia permite identificar los costes de agencia, que se materializan en problemas de selección adversa: ante situaciones en las cuales el prestamista de recursos ajenos evidencia mayores riesgos y mayores problemas de información asimétrica endurece las condiciones contractuales de los préstamos, con lo cual se produce un efecto inverso al deseado, ya que esa medida atraerá sobre todo a las empresas que deseen financiar proyectos de inversión más arriesgados y más rentables, al estar en mejores condiciones para hacer frente a la subida del coste de la financiación. Así, cuando el riesgo percibido por los acreedores es potencialmente muy alto, los acreedores pueden preferir restringir su oferta de fondos (Stiglitz \& Weiss, 1981). Esta situación se denomina de "restricciones financieras" o "racionamiento de crédito", y ocasiona que, la mayoría de las veces, la única fuente de financiación disponible para la empresa sean 
los beneficios retenidos. Este problema del racionamiento de crédito se ve atenuado por el tamaño de la empresa, ya que las empresas grandes producen más información contable y financiera para los acreedores e inversores en general y, además, su monitorización supone menores costes (Fama, 1985). Por otro lado, las hipótesis de la Teoría de la Jerarquía Financiera establecen un orden preferencial en las opciones de financiación de la empresa (Myers \& Majluf, 1984). De nuevo, la clave de esta jerarquía es la existencia de información asimétrica que conlleva mayores costes de financiación debido al gap informativo entre agentes externos e internos a la empresa. En concreto, la empresa preferirá financiación interna a deuda, deuda a corto plazo sobre la deuda a largo plazo, y cualquier tipo de deuda frente a ampliaciones de capital.

A la hora de conceder un crédito, en el proceso de intermediación financiera, surge el problema de la información asimétrica, donde normalmente el prestamista no tiene toda la información relevante sobre el prestatario. Este problema no existiría si el prestamista dispusiera de toda la información necesaria o tuviera a su alcance todos los mecanismos de detección y determinación de los riesgos involucrados (EsquivelMartínez \& Hernández-Ramos, 2007). En el caso de las Pymes, este problema es más relevante, debido a la alta opacidad de la información que muchas veces presentan, donde los estados financieros no son totalmente claros, o están desequilibrados y sin el aval de un auditor externo, lo que a su vez hace que los prestamistas sean menos flexibles en la concesión de préstamos a este tipo de empresas (Dayé, Houssa, \& Reding, 2015). Además, esto se agudiza debido a que normalmente las Pymes no cuentan en muchos casos con los activos físicos necesarios para dejarlos como garantía de préstamo (Chen, Huang, Tsai, \& Tzeng, 2013). Toda esta problemática, en el contexto de la Pyme, implica en muchas ocasiones que surjan problemas de restricciones financieras.

Por esta razón es importante en el sistema financiero que las entidades tengan un mecanismo claro y comprensible de cómo gestionar la selección de su cartera de créditos (Iyer, Khwaja, Luttmer, \& Shue, 2014). Las entidades financieras utilizan dos tipos de información para su toma de decisiones: la información dura, de carácter cuantitativo, relativamente fácil de procesar y manejable con grandes magnitudes (Petersen, 2004), puede ser pasado a una escala numérica y es fácilmente verificable (Agarwal, Ambrose, Chomsisengphet, \& Liu, 2011); y la información denominada blanda, de carácter subjetivo o cualitativo, difícil de ser comparable como sí lo puede ser por ejemplo un determinado ingreso por ventas de una empresa (Petersen, 2004). En la literatura financiera existen estudios que apoyan que se privilegie más el uso de 
la información dura, mientras que otros resaltan la complementariedad y muestran que cuando se incluye información blanda a la dura, esto mejora el acierto en la asignación de crédito a las empresas (Grunert, Norden, \& Weber, 2005; Cornée, 2017).

\section{Objetivos de la investigación}

El objetivo de esta tesis es aportar evidencia empírica sobre los factores de gestión que influyen en el éxito competitivo y en el acceso a la financiación de la Mipyme en el ámbito del Perú.

\section{Objetivos Específicos}

- Analizar el contexto de la Mipyme en el Perú y su contribución al crecimiento de la economía.

- Estudiar los factores asociados al éxito competitivo de las Mipymes del Perú, considerando factores como: género del gerente, edad y nivel de formación, tamaño, sector, carácter familiar, estructura organizativa, realización de un plan estratégico, actividad innovadora, posición tecnológica, TICs y gestión de recursos humanos.

- Determinar aquellas variables de gestión que influyen en el racionamiento de crédito de las empresas peruanas.

- Identificar las principales variables cualitativas y cuantitativas que utilizan las entidades financieras para la calificación de las empresas en el otorgamiento de sus créditos.

\section{Estructura de la tesis}

La tesis se configura en cuatro capítulos. En el primer capítulo, se aborda el primer objetivo describiendo las principales características de las micro, pequeñas y medianas empresas en la economía peruana y su contribución a ésta. Asimismo, se describe su nivel de formalidad, su ubicación geográfica y su participación en los diferentes sectores y actividades económicas. También se detalla la PEA ocupada por las Mipymes y se describe los principales problemas que afronta este sector empresarial. Finalmente se hace una pequeña reseña de la evolución del microcrédito en el Perú y su contribución al financiamiento de las Mipymes.

En el segundo capítulo, se analizan los factores asociados al éxito competitivo de las Mipymes peruanas, con una muestra de 94 empresas, con más de 5 trabajadores. Se identifica empíricamente las principales variables de gestión que influyen en el 
rendimiento de las empresas. Los factores de éxito competitivo se estudian desde la perspectiva de la teoría de los recursos y capacidades de las empresas. Las variables consideradas son el plan estratégico, la estructura organizativa, la innovación en sus productos, procesos y en sus sistemas de gestión, su posición tecnológica, si tiene alguna certificación de calidad o está en proceso de obtenerlo y su grado de utilización de Tecnologías de Información y Comunicación. Los resultados muestran que las Mipymes que tengan implantados sistemas de control de gestión más desarrollados y que apliquen prácticas de gestión de sus recursos humanos más eficientes, mayor será la probabilidad de tener éxito en el mercado. Los resultados son especialmente útiles para los gerentes de las Mipymes y los organismos de fomento de la Mipyme, para que puedan diseñar y promover estrategias y políticas que favorezcan el crecimiento y competitividad de la Mipyme.

En el tercer capítulo se analiza las causas del racionamiento de crédito en las micro y pequeñas empresas peruanas. Se identifica empíricamente las principales variables de la empresa y de gestión que influyen en su mayor o menor acceso a la financiación de sus proyectos y operaciones. Dado que en el Perú se produce un especial problema en el acceso al crédito, puesto que el sistema financiero no está plenamente desarrollado y las posibilidades de acceso al crédito bancario son menores que en otras economías. Para ello, se desarrolla un estudio empírico mediante una encuesta a una muestra de 158 micro y pequeñas empresas peruanas. Nuestro trabajo produce robustos resultados en cuanto a factores que influyen en el acceso a la financiación de las micro y pequeñas empresas en Perú. De forma que se identifican factores tangibles e intangibles como la certificación de calidad, el contar con buenos sistemas de gestión, el hacer planeamiento dentro de la empresa, hacer actividades de innovación, contar con directivos altamente calificados y con experiencia que le permitan dar señales a los prestatarios de la buena condición del negocio y de los proyectos que presenta. La identificación de los factores que facilitan el acceso al crédito de las empresas ayudará a las mismas en la mejora de su competitividad, así como a los organismos gubernamentales a conocer qué políticas deben desarrollar para facilitar el acceso al crédito y una mayor eficacia del sistema financiero.

En el cuarto capítulo se determinan las principales variables cualitativas y cuantitativas que consideran los analistas de riesgos de las entidades financieras a la hora de otorgar un crédito a las empresas que lo solicitan. Para ello, se analizan cuatro aspectos referidos a: personalidad y experiencia del empresario; características del producto o servicio que ofrece la empresa y del mercado donde opera; estrategia y 
organización de la empresa; y variables relacionadas con la información contable que presenta la empresa. Asimismo, se analiza si existen diferencias entre los analistas de riesgos teniendo en cuenta factores como el sexo del analista, su nivel de formación y sus años de experiencia. Para ello se desarrolla un estudio empírico en base a una encuesta realizada a 73 analistas de riesgos de entidades financieras peruanas.

\section{Contribución e implicaciones de la tesis}

La presente tesis doctoral contribuye a la literatura académica en varios aspectos relevantes. Podemos mencionar en primer lugar el aporte de la evidencia empírica al contexto de la realidad de la microempresa y de un país en desarrollo como es la República de Perú, levantando sus características específicas y diferenciadoras respecto a empresas de mayor tamaño. Muchos estudios se han centrado en las Mipymes, pero pocos se han concentrado en la micro y pequeña empresa, por lo que se hace muy atractivo su estudio, dado el impacto significativo que tiene la micro y pequeña empresa en su contribución a la generación de empleo y al producto bruto interno del país.

En segundo lugar, las implicaciones de los resultados de esta tesis doctoral son importantes y contribuyen a la discusión de las características del directivo, características de la empresa y las variables de gestión que influyen en su rendimiento. El conocimiento de estas variables determinantes, pueden ser considerados para el diseño y establecimiento de políticas públicas focalizadas a apoyar y contribuir al crecimiento y fortalecimiento de las empresas de este sector que aseguren su sostenibilidad y permanencia en el mercado.

En tercer lugar, se contribuye a determinar las variables de gestión, características de la empresa y de los directivos o emprendedores que favorecen a que puedan acceder al financiamiento por parte de las entidades financieras. Sabemos la importancia relevante que tiene el crédito financiero externo para solventar el buen funcionamiento de sus diversas operaciones de producción, comercialización o de servicios, la adquisición de activos fijos y la ejecución de nuevos proyectos de las organizaciones. En este sentido, las empresas tienen que concentrar sus esfuerzos en desarrollar y fortalecer aquellos aspectos que contribuyan a tener mayor probabilidad de acceso al crédito bancario.

En cuarto lugar, se contribuye a que las empresas conozcan las variables tanto de carácter cualitativo como cuantitativo que los funcionarios de las entidades de crédito 
consideran importantes para la toma de decisiones en el otorgamiento de créditos a ellas.

Los resultados de este trabajo de investigación tienen implicaciones importantes para diferentes entes vinculados al entorno empresarial. Por un lado, ofrecen pautas a los emprendedores y empresarios para que los ayude a identificar los aspectos más resaltantes que pueden contribuir al mayor rendimiento de sus empresas y a los responsables de políticas públicas para que puedan orientar de la mejor forma sus planes de capacitación y programas de apoyo para mejorar la competitividad y productividad de las empresas, asi como políticas que faciliten el financiamiento de estas organizaciones a través de las entidades de crédito del sistema financiero. Por otro lado, aportan informaciones a los directivos de la micro y pequeña empresa para que concentren sus esfuerzos en aquellas actividades de gestión y de organización que les ayude a mejorar su rendimiento y que tengan mayores probabilidades de acceso al crédito.

Finalmente resulta de interés para los académicos e investigadores, al poner de relieve la importancia de las Mipymes y les incentive a seguir en esta línea orientando sus trabajos de investigación, docencia y actividades de extensión para contribuir al desarrollo y consolidación de este dinámico sector empresarial. 
1. LAS MIPYMES EN EL PERÚ 


\subsection{INTRODUCCIÓN}

El Perú con una superficie de 1.285.216 $\mathrm{km}^{2}$, cuenta con una población de 31.151.643 habitantes en el 2015 y se divide en 24 regiones, siendo Lima la de mayor población con 9.835.000 habitantes (INEI, 2015). El Perú es un país en vías de desarrollo y en la última década ha experimentado un importante crecimiento económico (Gallo et al., 2015). En los últimos 10 años el PBI real ha crecido a un ritmo del 5,8\% promedio anual (The World Bank, 2016; INEI, 2016c). Cabe destacar que el sector minero en los últimos 12 años ha sido parte importante del crecimiento económico y el componente más grande de nuestras exportaciones, con un $58 \%$ del total (Bernhardt, 2016). Sin embargo, en el periodo 2013 a 2015 la economía peruana está mostrando signos de desaceleración. En el 2015 el PBI creció un 3,3\%, siendo las actividades extractivas y de servicios las que obtuvieron un mayor crecimiento con un aumento del $7,4 \%$ y 4,2\%, respectivamente. A pesar de esta desaceleración la economía peruana está creciendo a un ritmo superior al de las economías desarrolladas. En 2015, las economías desarrolladas como Estados Unidos y la Eurozona crecieron $2,5 \%$ y $1,5 \%$ respectivamente, mientras que la economía mundial tuvo un crecimiento de 3,1\% (INEI, 2016b). La economía del Perú ha acumulado recursos y tiene tasas de crecimiento positivas que le permiten afrontar retos futuros de una forma equilibrada sin cambios abruptos (Ministerio de Economía y Finanzas, 2015). La deuda pública en el 2015 equivale al 19,5\% del PBI, mientras que en países como México, su deuda pública equivale al 35,5\%, Colombia el 43,9\% y Brasil llega al 66,5\% (CEPAL, 2016).

La estructura productiva del Perú en el periodo de 1980-2014 se ha mantenido estable, concentrada principalmente en los sectores primario y servicios, lo que representó en el último quinquenio el 79,1\% del total de la producción (Bustamante, 2015). También cabe mencionar que en el 2015 el sector manufacturero representó el $13,46 \%$ del PBI total y el sector servicios el $69,08 \%$.

Adicionalmente, la internacionalización de las empresas del Perú ha crecido de una forma muy significativa ${ }^{1}$. Un indicador que da una idea de la apertura comercial externa es la aportación de las exportaciones e importaciones como porcentaje del PBI; este indicador pasó de representar el 30\% del PBI en nuestro país entre 1990 y 2000 a 45,9\% entre 2001 y 2012 (Botello, 2014). Las exportaciones totales en el 2015

\footnotetext{
${ }^{1}$ Minauro, Rafael (Mayo, 2012). "Reflexiones sobre los nuevos negocios internacionales en el Perú” en ORLA-Observatorio de Relaciones con Latinoamérica.
} 
alcanzaron la cifra de 34.157 millones US\$ (casi cinco veces el nivel alcanzado en el año 2000), siendo el sector agroindustrial el que más crecimiento experimentó en este periodo, pasando de US\$394 a US\$ 4.387 millones (más de 11 veces el nivel obtenido en el año 2000) ${ }^{2}$. El Perú cuenta con 7,6 millones de hectáreas con potencial agrícola directo, pero se utilizan menos de 3,6 millones. Con ello, para el 2021, se proyecta la incorporación de 300.000 nuevas hectáreas de cultivo en el Perú, dado el mayor crecimiento de producción de los productos agrícolas tradicionales y no tradicionales (Valenzuela \& Rodríguez, 2015).

\subsection{SITUACIÓN ECONÓMICA EN EL PERÚ}

Una señal de la solidez de la economía peruana y el respaldo para afrontar eventualidades económicas adversas, como cuando hay un fuerte influjo de capitales o para cuando es necesario el ajuste adecuado del tipo de cambio (Banco de España, 2015), lo muestra sus reservas internacionales netas, que al ritmo del crecimiento de la economía, han ido aumentando, encontrándose en la actualidad a niveles altos con respecto al nivel de la región. De 8.180 millones US\$ en el año 2000, pasó a 44.105 millones US\$ en el 2010 y llegando en el 2015 a US\$ 61.485 millones de US\$3 . El Banco Central de Reserva del Perú tuvo el acierto de acumular dichas reservas cuando los precios de los commodities (tales como el oro, cobre, plomo, zinc) estuvieron altos y se dio un mayor ingreso de capitales.

Después de un proceso hiperinflacionario (que llegó en 1990 a 7.650\%) que se dio en los finales de la década de 1980 y principios de 1990, un adecuado manejo de política monetaria hizo que la inflación disminuyera sustancialmente $(139,2 \%, 10,22 \%$ y 3,73\% en los años 1991, 1995 y 2000 respectivamente), siendo la inflación promedio en los últimos 15 años del 2,7\% anual ${ }^{4}$. El 2015 alcanzó el 4,4\% un poco por encima del rango meta del Banco Central (1\%-3\%). Sin embargo, las expectativas de inflación y las medidas adoptadas por el BCRP harán que se sitúe dentro del rango en los próximos dos años.

La economía peruana crecerá a tasas medias más bajas en los próximos años debido a la disminución de los precios de los metales que pesa sobre la inversión privada

\footnotetext{
${ }^{2}$ Calculado en base a las estadísticas del BCRP, tomado de https://estadisticas.bcrp.gob.pe/estadisticas/series/anuales/pbi-por-sectores el 10 de mayo de 2016.

${ }^{3}$ Tomado de Estadísticas del BCRP https://estadisticas.bcrp.gob.pe/estadisticas/series/anuales/reservasinternacionales el 10 de mayo de 2016.

${ }^{4}$ Calculado en base a las estadísticas del BCRP, tomado de https://estadisticas.bcrp.gob.pe/estadisticas/series/anuales/inflacion el 10 de mayo de 2016.
} 
en la minería y los resultados de un menor crecimiento de las exportaciones. Sin embargo, el consumo privado y la inversión pública se mantendrán relativamente sólidos en los próximos años debido a la creciente clase media y una extensa cartera de proyectos de infraestructura (Valenzuela \& Rodríguez, 2015).

EI PBI per cápita del Perú pasó de 6.961 soles en 1990 a 8.552 soles en el 2000, a 12.969 soles en el 2010 y a un estimado de 15.501 soles el 2015 (soles constantes del 2007) ${ }^{5}$. Y el índice global de competitividad alcanzado en el 2015 de 4,2 nos pone en el lugar 69 entre los países en el mundo, habiéndose ubicado los cinco años anteriores entre los puestos 89 y 102 (World Economic Forum, 2016).

\subsection{PROBLEMAS PENDIENTES EN LA ECONOMÍA PERUANA}

No obstante, todavía falta mucho por hacer en determinados sectores económicos y sociales del país. Si bien en el año 2010 el 30,77\% y el 7,63\% de la población total se encontraban en situación de pobreza y pobreza extrema ${ }^{6}$ y en el 2015 se redujo a 21,77\% y 4,07\% respectivamente, falta todavía una mejor distribución de la producción nacional hacia los sectores y regiones menos favorecidos (INEI, 2016a); siendo el más afectado el sector rural. Empleando datos de panel de 1998 a 2002 Calvo (2008) encontró que los hogares rurales son más vulnerables a la pobreza de consumo y menos vulnerables a la pobreza de ocio en comparación con los del área urbana en Perú. En general, la vulnerabilidad a la pobreza de consumo $(0,10)$ es mayor que la vulnerabilidad a la pobreza de ocio $(0,02)$ en el Perú. Del 2007 al 2010 ha habido un logro importante en el aspecto social al haberse reducido la vulnerabilidad severa de 0,123 a 0,074 en dicho periodo, pero se mantuvo casi estable la vulnerabilidad moderada (Gallardo, 2013). En el 2012 aproximadamente el 17,2\% de los jóvenes vulnerables ${ }^{7}$ no estudia ni trabaja (López-Calva, Cruces, Lach, \& Ortiz-Juárez, 2014).

Cuando se toman en cuenta variables como empleo informal, nivel de innovación, institucionalidad, el peso de la industria manufacturera en el PBI total y su estructura productiva, la evolución de la economía peruana no es tan halagadora (Porlles, Cachay, \& Salas, 2015).

En efecto, comparando con otros países de nuestra región, la informalidad sigue siendo un gran problema sobre todo en los independientes. En el 2010 el 50\% de los

\footnotetext{
${ }^{5}$ Tomado de https://www.inei.gob.pe/estadisticas/indice-tematico/economia/ el 5 de julio de 2016.

${ }^{6}$ Se define como pobreza a aquellos que tienen un nivel de gasto inferior al valor de la canasta básica de alimentos y no alimentos y pobreza extrema a los que tienen un gasto inferior al valor de la canasta básica de alimentos.

${ }^{7}$ Pertenecen a familias que tienen ingresos entre 4 a 10 dólares americanos diarios.
} 
informales son mujeres y más del $80 \%$ de la población trabajadora que tiene más de 65 años es informal (Jaramillo \& Sparrow, 2015). En América Latina la producción científica publicada entre el 2000 y 2014 totalizó 1.079 .313 documentos, del cual el Perú contribuyó en esos años con solo 1,08\% de dicha producción en la región (Scimago Journal \& Country Rank, 2016); esta baja producción va a la par con el bajo nivel de inversión en I+D+i (Robles-Alfaro, Vela-Alfaro, Huapaya-Huertas, \& ChacónTorrico, 2015). El Rule of Law (RoL) Index (indicador de institucionalidad) de 1996 al 2012 indica que nuestro país mantiene niveles similares a los de la región y a los países cuyos niveles de ingreso son parecidos, pero no son los adecuados. De ocho aspectos que se evalúan, seis de ellos no muestran un progreso importante en más de diez años, siendo el control de la corrupción y la efectividad del gobierno donde hay que trabajar más (Barrantes \& Grompone, 2015).

En la medida que los estados de América Latina, avancen en negociaciones estratégicas multilaterales de asociación, se mantengan alejados de los conflictos internacionales que se dan fuertemente en otras regiones (Este de Asia, Medio Oriente y Europa del Este) y se adapte de la mejor forma al nuevo escenario mundial, la región ganará y consolidará posiciones. Cada país, y en concreto el Perú, experimenta de acuerdo a su realidad diferentes alternativas para solucionar sus problemas. No se puede saber qué nuevo orden mundial habrá en el futuro ni nuestro rol final, eso dependerá de la evolución de los procesos internos y externos a nuestro país y la región (Llenderrozas, 2016). Las últimas décadas se han caracterizado por un marcado proceso de integración entre los mercados, que es especialmente notorio en los mercados de capital. Este mayor grado de integración afecta tanto a las economías desarrolladas como a las emergentes, aumentando el grado de correlación entre los retornos de los distintos mercados (Valenzuela \& Rodríguez, 2015).

Por ejemplo, la Alianza del Pacífico es sin duda el proceso de integración económico-comercial más dinámico que América Latina ha presentado en mucho tiempo: no solo en la búsqueda por lograr que Chile, Colombia, México y Perú se integren profundamente en miras al mercado asiático, sino también porque logren consolidar economías, y por ende productos de mejor calidad, mayor valor agregado y a menor costo.

Los países de la Alianza del Pacífico suman un Producto Bruto Interno de 2,1 billones de dólares, que representa el 36\% del PBI de América Latina y el Caribe. Los cuatro países conforman un mercado de 214 millones de personas (la tercera parte de la población de la región). La Alianza constituiría la novena economía mundial. En 2013 
generaron el 50\% del comercio exterior de América Latina y el Caribe, con un valor cercano a 1,1 billones de dólares, y estuvieron involucrados en sus economías más de 85 mil millones de dólares en inversión extranjera directa (PWC, 2014; León \& Ramírez, 2014).

Por otro lado, un mayor comercio Sur-Sur podría ser más beneficioso que el tradicional comercio Sur-Norte en tres formas: i) porque implicaría un mayor crecimiento del volumen de exportaciones considerando que el crecimiento económico en los países más pobres del Sur ha sido más dinámico que en los países ricos del Norte, ii) los países involucrados si cambian su canasta tradicional de productos exportables a productos con mayor contenido tecnológico y mayor valor agregado podrían sacar también mayores beneficios y iii) estabilidad macroeconómica de los países en desarrollo al haber una mayor confiabilidad de la demanda para sus exportaciones. Adicionalmente la diversificación de las exportaciones podría disminuir la alta concentración de los productos de exportación como de los mercados a los que se exporta, disminuyendo por ende la dependencia de los países (Bernhardt, 2016)

Se tienen varios retos y se avanzará en la medida que los próximos gobiernos tengan objetivos nacionales claros, de prioridad a los temas que afectan más a la economía y tienen mayor impacto social y las instituciones y poderes del Estado tengan la autonomía y los recursos para planear y ejecutar en concordancia a los intereses nacionales.

\subsection{CARACTERÍSTICAS E IMPORTANCIA DE LAS MIPYMES EN EL PERÚ}

En este apartado describiremos el contexto que enmarca a las Mipymes en el Perú, explicando los conceptos y características principales de este sector del tejido empresarial, a manera de ofrecer un panorama general de este tipo de empresas.

\subsubsection{Definición}

En lo que se refiere a una micro, mediana y pequeña empresa, no se encuentran definiciones de aplicación universal, tanto en el Perú como en otros países del mundo se encuentran distintas opiniones e interpretaciones, debido a que el concepto puede variar en función de los objetivos que persigue cada grupo de interés. Incluso en un mismo país puede cambiar según las diferentes autoridades.

Las definiciones que se adoptan varían según sea el tipo de enfoque. Distintos especialistas destacan la importancia del volumen de ventas, el capital social, el número de personas ocupadas, el valor de la producción, o el de los activos para su 
definición. También se suele utilizar la densidad de capital, como criterio para definir los diferentes tamaños de Mipyme (Yamakawa et al., 2010). Cada grupo de interés plantea su propio enfoque y la define de acuerdo con los objetivos que persigue (Mendiola et al., 2014).

La legislación peruana en la (Ley No. 28015 sobre promoción y formalización de la micro y pequeña empresa, 2013) definió a la Mipyme como:

"La unidad económica constituida por una persona natural o jurídica, bajo cualquier forma de organización o gestión empresarial contemplada, que tiene como objeto desarrollar actividades de extracción, transformación, producción, comercialización de bienes o prestación de servicios."

Se debe resaltar que la legislación peruana con la mencionada Ley sólo define micro y pequeña empresa, dejando un vacío para las medianas y grandes empresas. La (Ley No. 30056 sobre diversas leyes para facilitar la inversión, impulsar el desarrollo productivo y el crecimiento empresarial, 2013) en su artículo 11, que reemplaza al artículo 5 de la anterior Ley, señala que el criterio que las caracteriza es el de su nivel de ventas anuales, extendiendo el volumen de ventas para las pequeñas empresas hasta 1700 unidades impositivas tributarias (UIT); adicionalmente esta última Ley define a la mediana empresa (ver tabla 1.1.).

Tabla 1.1. Definición de la Mipyme en el Perú

\begin{tabular}{|l|c|c|}
\hline $\begin{array}{l}\text { Tipo de } \\
\text { Empresa }\end{array}$ & $\begin{array}{c}\text { Número de } \\
\text { trabajadores }\end{array}$ & $\begin{array}{c}\text { Volumen de } \\
\text { ventas anuales }\end{array}$ \\
\hline Microempresa & $1-10$ & 150 UIT $^{8}$ \\
\hline Pequeña empresa & $1-50$ & $151-1700$ UIT \\
\hline Mediana empresa & $1-100$ & $1701-2300$ UIT \\
\hline $\begin{array}{l}\text { Fuente: Leyes No. 28015 y 30056 - Perú. } \\
\text { Elaboración propia. }\end{array}$ \\
\hline
\end{tabular}

Para poder hacer comparaciones entre los diferentes países se tiene que tener en cuenta sus definiciones de Mipyme que tiene cada uno. En Latinoamérica existe una gran variedad de formas de considerar y definir la micro, pequeña y mediana empresa; no existe homogeneidad al definir a las Mipymes, lo cual dificulta su estudio y análisis. En las tablas 1.2. a 1.5. se muestran las definiciones que dan algunos países de la región. Adicionalmente, debemos señalar que la medición de las empresas de

\footnotetext{
${ }^{8} 1$ UIT año $2016=$ S/. 3.950
} 
pequeña dimensión en el Perú y en buena parte de América Latina, ha estado siempre rodeada de un alto grado de dificultad, pues una porción de este universo se encuentra en la informalidad y por lo tanto, escapa a la medición de los organismos del Estado. Este argumento es mucho más relevante si se trata de microempresas, cuya mayoría está en la informalidad (Villarán \& Mifflin, 2009).

Tabla 1.2. Definición de la Mipyme en Argentina

\begin{tabular}{|l|c|c|c|c|c|}
\hline \multirow{2}{*}{ Tamaño/Sector } & \multicolumn{5}{|c|}{$\begin{array}{c}\text { Ventas anuales } \\
\text { (en dólares americanos) }\end{array}$} \\
\cline { 2 - 6 } & Agropecuario & $\begin{array}{c}\text { Industria } \\
\text { y Minería }\end{array}$ & Comercio & Servicio & Construcción \\
\hline Microempresa & 142.500 & 420.560 & 560.747 & 137.850 & 177.570 \\
\hline Pequeña empresa & 957.944 & 2.406 .542 & 3.271 .028 & 1.004 .673 & 1.124 .495 \\
\hline Mediana empresa & 5.630 .840 & 19.205 .607 & 26.144 .860 & 6.612 .150 & 8.808 .411 \\
\hline $\begin{array}{l}\text { Fuente: Secretaría PYMEYDR, Ministerio de Industria Argentina (2011). } \\
\text { Elaboración propia. }\end{array}$
\end{tabular}

Tabla 1.3. Definición de la Mipyme en México

\begin{tabular}{|c|c|c|c|}
\hline \multirow{2}{*}{ Tamaño/Sector } & \multicolumn{3}{|c|}{ Número de empleados } \\
\hline & Industria & Comercio & Servicios \\
\hline Microempresa & $0-10$ & $0-10$ & $0-10$ \\
\hline Pequeña empresa & $11-50$ & $11-30$ & $11-50$ \\
\hline Mediana empresa & $51-250$ & $31-100$ & $51-100$ \\
\hline \multicolumn{4}{|c|}{$\begin{array}{l}\text { Fuente: Ley para el desarrollo de la competitividad de las micros, pequeñas y } \\
\text { medianas empresas, México (2011). } \\
\text { Elaboración propia. }\end{array}$} \\
\hline
\end{tabular}

\footnotetext{
${ }^{9}$ Convertido a US\$ (T.C.: 4,28)
} 
Tabla 1.4. Definición de la Mipyme en Brasil y Panamá

\begin{tabular}{|c|c|c|}
\hline \multirow[t]{2}{*}{ Tamaño/País } & \multicolumn{2}{|c|}{$\begin{array}{c}\text { Ventas anuales } \\
\text { (en dólares americanos) }\end{array}$} \\
\hline & Brasil (1) & Panamá (2) \\
\hline Microempresa & 100.000 & 150.000 \\
\hline Pequeña empresa & 1.000 .000 & 1.000 .000 \\
\hline Mediana empresa & --- & 2.500 .000 \\
\hline
\end{tabular}

Tabla 1.5. Definición de la Mipyme en Colombia y Costa Rica

\begin{tabular}{|l|c|c|}
\hline \multirow{2}{*}{ Tamaño/País } & \multicolumn{2}{|c|}{$\begin{array}{c}\text { Ventas anuales } \\
\text { (en dólares americanos) }\end{array}$} \\
\cline { 2 - 3 } & Colombia (1) & Costa Rica (2) \\
\hline Microempresa & $1-10$ & $1-5$ \\
\hline Pequeña empresa & $11-50$ & $6-30$ \\
\hline Mediana empresa & $51-200$ & $31-100$ \\
\hline $\begin{array}{l}\text { Fuente: (1) Ministerio de Industria, Turismo y Comercio, Colombia (2011). } \\
\text { (2) Serie Observatorio MIPYMES UNED (2008). } \\
\text { Elaboración propia. }\end{array}$ \\
\hline
\end{tabular}

\subsubsection{Edad de las Mipymes}

En el gráfico 1.1. se puede apreciar la edad promedio y la mediana de las Mipymes del Perú. Conforme aumenta el tamaño de la empresa, su edad promedio aumenta $^{10}$. Las Mipymes peruanas se caracterizan por estar constituidas por empresas jóvenes. La mayor proporción de empresas en cada estrato, como se puede apreciar en la tabla 1.6. tienen hasta 5 años de permanencia en el mercado. Por otro lado, una importante proporción de empresas medianas (14,2\%) tiene más de 20 años de permanencia.

10 Edad considerando el tiempo en años desde el inicio de actividades de la empresa hasta el 2014. 
Gráfico 1.1. Promedios de años de funcionamiento de las Mipymes (2014)

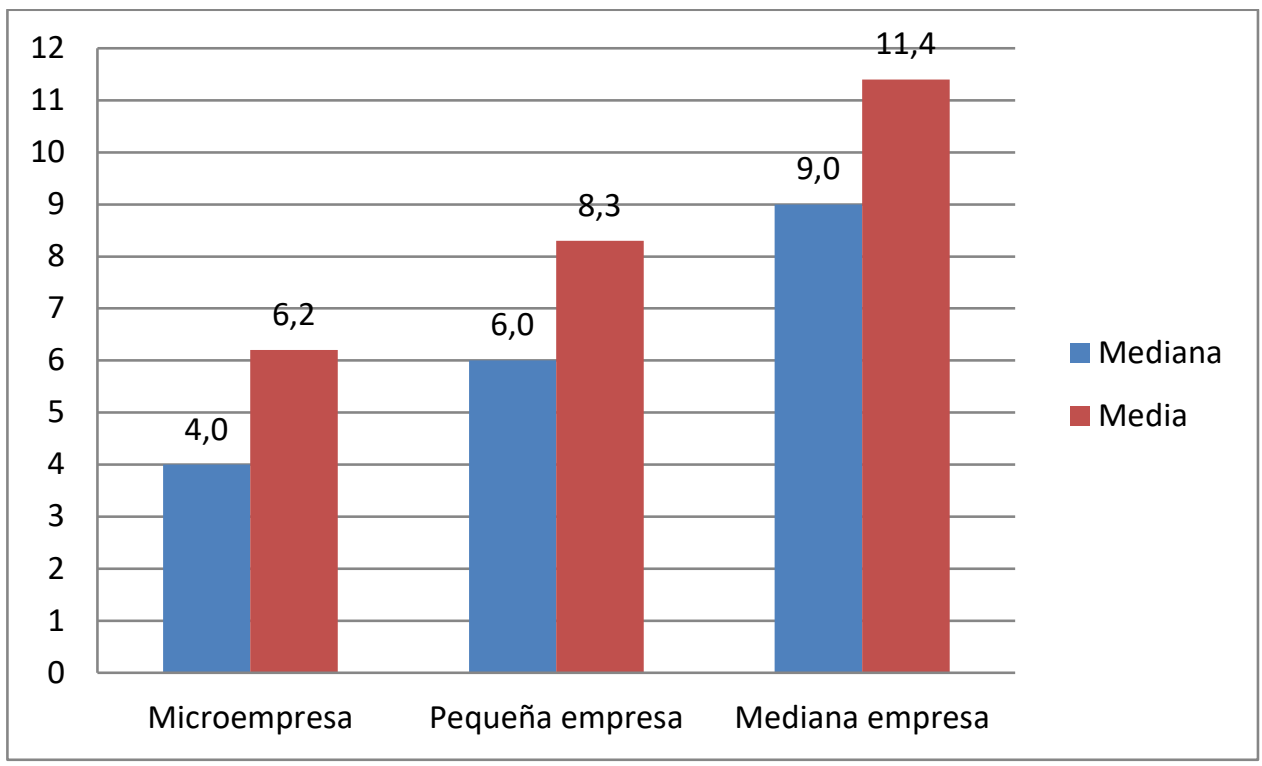

Fuente: PRODUCE (2015).

Elaboración propia.

Tabla 1.6. Porcentaje de empresas formales por estrato empresarial (2014)

\begin{tabular}{|c|c|c|c|}
\hline Rango de edad & Microempresa & Pequeña empresa & Mediana empresa \\
\hline Hasta 5 años & 59,7 & 47,0 & 30,1 \\
\hline De 6 a 10 años & 19,4 & 25,9 & 27,1 \\
\hline De 11 a 15 años & 9,1 & 11,8 & 17,1 \\
\hline De 16 a 20 años & 6,9 & 7,6 & 11,5 \\
\hline Más de 20 años & 4,9 & 7,8 & 14,2 \\
\hline
\end{tabular}

\subsubsection{Nivel de formalidad e informalidad}

En muchas ocasiones es inevitable asociar micro y pequeña empresa con informalidad (Yamakawa et al., 2010). Este criterio no es ajeno a nuestro entorno, según Lévano (2005), estimó que 3 de cada 4 micro o pequeñas empresas en el Perú son informales y que 6 de cada 7 trabajadores ocupados en ellas están en empresas informales, lo que se traduce en un alto grado de informalidad, como característica de 
las Mipymes. Cabe mencionar que, se utiliza el término formal e informal dando especial énfasis en el aspecto legal y tributario.

A continuación, en el gráfico 1.2., se presenta la evolución del porcentaje de micro y pequeñas empresas formales e informales durante los últimos años (2010 al 2014). Se puede observar que el porcentaje de empresas informales ha ido disminuyendo en el transcurso del tiempo siendo en el 2014 un 56,1 el porcentaje de empresas informales. Por lo que la brecha entre las empresas formales e informales es cada vez menor. Esto se debe fundamentalmente a las medidas adoptadas por los diferentes gobiernos para que las empresas de este sector estén conforme a las leyes que la regulan.

\section{Gráfico 1.2. Porcentaje de Mypes formales e informales} (2010-2014)

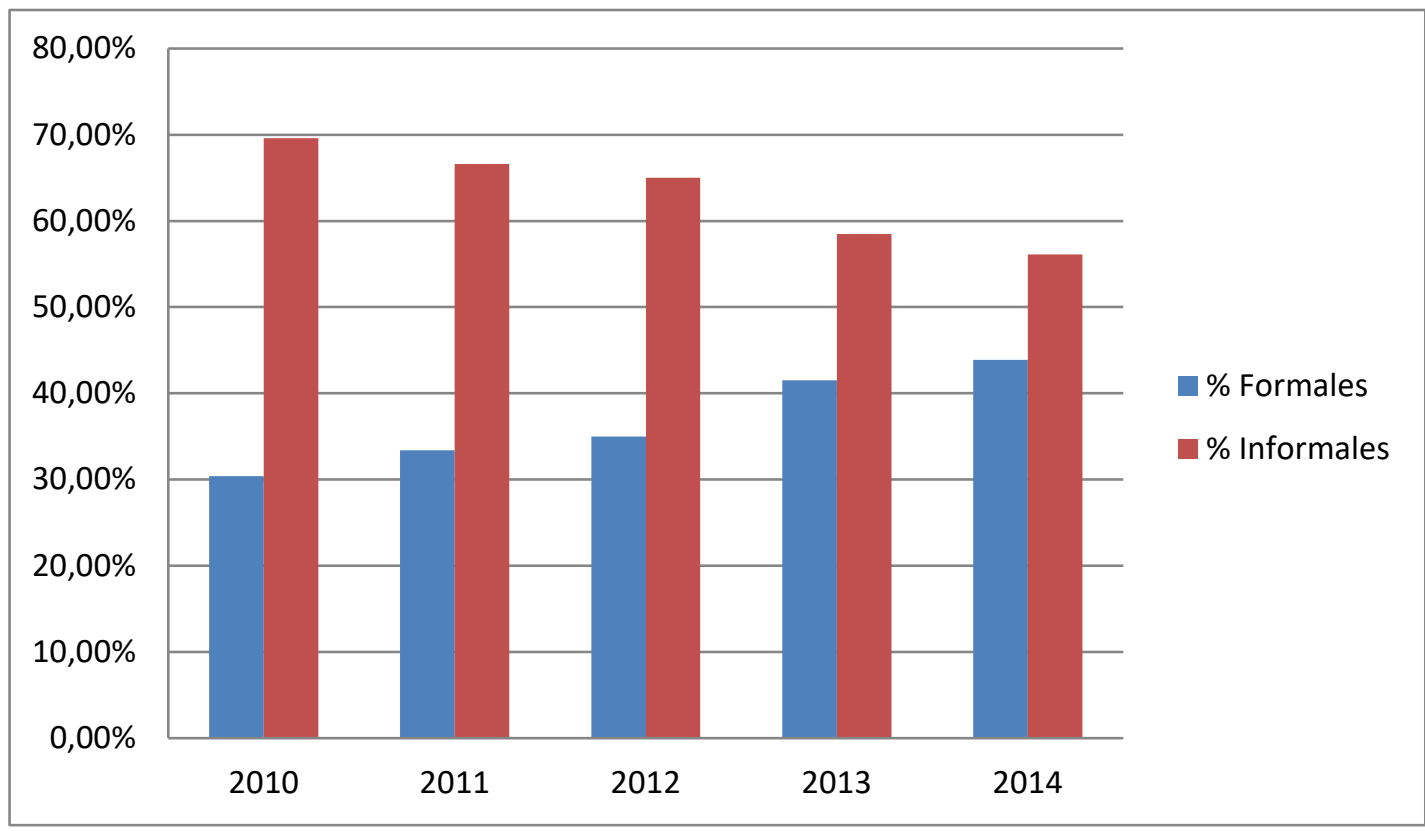

Fuente: PRODUCE (2015).

Elaboración propia.

De acuerdo con la información publicada por el Ministerio de la Producción, en base a las estadísticas de la micro y pequeña empresa para el año 2014, según la tabla 1.7., se puede observar que el número total de empresas informales se reduce en los últimos años, teniendo como resultado que 2.040.659 empresas en el Perú, operan siendo informales, de un total de 3.632.891 estimadas en el 2014.

Esta alta tasa de informalidad $(56,1 \%)$ se atribuye a muchos factores, incluida la carga normativa, la debilidad de las instituciones públicas y la insuficiente percepción 
de los beneficios de ser formal. Estos elementos limitan la productividad y el crecimiento de este tipo de empresas (Banco Mundial, 2007).

La informalidad para las empresas se considera como una opción para evitar las restricciones del mercado formal y se cree que así se puede ser más flexible; por otro lado, la formalidad se vincula con el costo por trámites de formalización de la empresa, como también costos de cumplir con las obligaciones adquiridas en este régimen.

Las Mipymes informales constituyen una importante fuente de generación de empleo; por otro lado, cuanto mayor es el ingreso de los trabajadores la formalidad aumenta y por el contrario disminuye. Además, los costos de formalización son relativamente altos para los empleadores de las Mipymes y las barreras técnicas dadas por los principales países a los que dirigen el comercio exterior. Adicionalmente, los bajos niveles de productividad de las Mipymes informales, los sueldos medios de los trabajadores inferiores al sueldo mínimo y niveles de educación bajos limita la efectividad de las políticas de formalización, de estandarización, uso de normas técnicas y poder superar las trabas comerciales del tipo no arancelario que imponen otros países (Tello, 2011).

Existen distintos atributos de los trabajadores que los hacen finalmente desempeñarse como asalariados, tener su pequeña empresa o trabajar de forma independiente. Tales atributos pueden ser del tipo personales (sexo, edad, escolaridad, estado civil y grupo cultural), ubicación geográfica, acceso al capital (haber recibido una herencia, acceso al financiamiento bancario, número de habitaciones de su vivienda y la posibilidad que el negocio funcione allí), motivación (si está satisfecho en su condición laboral actual, su deseo de ser independiente y su intención de ampliar su empresa en el caso de los que laboran de forma independiente), rama de actividad y el tamaño del negocio (Morales, 2012).

Por otro lado, también se puede entrever en la tabla 1.7. que la proporción del total de micro y pequeñas empresas formales con respecto al total de empresas en los últimos años se ha mantenido; pero el porcentaje de Mypes formales con respecto al total de empresas ha aumentado significativamente, pasando de 33,3\% en el 2011 a 43,7\% en el 2014. Aún así, el aumento de la formalización constituye todavía un reto con el fin de impulsar la inclusión de estas empresas, en el crecimiento económico del país. 
Tabla 1.7. Número de micro y pequeñas empresas formales y no formales (2011-2014)

\begin{tabular}{|c|c|c|c|c|c|c|c|c|}
\hline \multirow[b]{2}{*}{ Tamaño } & \multicolumn{2}{|c|}{2011} & \multicolumn{2}{|c|}{2012} & \multicolumn{2}{|c|}{2013} & \multicolumn{2}{|c|}{2014} \\
\hline & Formales & $\begin{array}{c}\text { No } \\
\text { Formales }\end{array}$ & Formales & $\begin{array}{c}\text { No } \\
\text { Formales }\end{array}$ & Formales & $\begin{array}{c}\text { No } \\
\text { Formales }\end{array}$ & Formales & $\begin{array}{c}\text { No } \\
\text { Formales }\end{array}$ \\
\hline Microempresa & 1.221 .343 & n.d. & 1.270 .009 & n.d. & 1.439 .778 & n.d. & 1.518 .284 & n.d. \\
\hline Pequeña empresa & 61.171 & n.d. & 68.243 & n.d. & 70.708 & n.d. & 71.313 & n.d. \\
\hline Total Mipymes & 1.284 .839 & 2.569 .868 & 1.340 .703 & 2.496.724 & 1.513 .006 & 2.140 .339 & 1.592 .232 & 2.040 .659 \\
\hline
\end{tabular}

\subsubsection{Ubicación geográfica}

Otra característica importante al hablar de las Mipymes, es la ubicación de éstas dentro del territorio nacional, ya que existe una relación directa entre el dinamismo económico de las regiones y la concentración regional, es decir, las regiones que concentran el mayor número de Mipymes, también concentran una mayor participación de producto bruto interno nacional (Ministerio de la Producción, 2013).

Tello (2011) constata que aquellas regiones que tienen un menor índice de informalidad son aquellas que tienen los más altos PBI real per cápita y por el contrario hay mayor informalidad en las regiones con menores niveles de PBI per cápita. Efectivamente, según el INEI, las 10 regiones que más contribuyeron al PBI en el 2014 fueron Lima (49,1\%), Arequipa (5,4\%), La Libertad (4,9\%), Cusco (4,7\%), Piura (4,5\%), Ica (3,6\%), Ancash (3,5\%), Cajamarca (2,9\%), Junín (2,8\%) y Lambayeque (2,5\%); las cuales se encuentran en la lista de las regiones que más Mipymes formales tienen en el mismo año (ver tabla 1.8.).

Cuando en una región se desarrollan actividades innovadoras, éstas tienen un rol importante en el crecimiento de la zona. A su vez factores como la accesibilidad geográfica y la acumulación de capital humano contribuyen a que se den actividades innovadoras en la zona, trayendo a su vez como consecuencia que haya crecimiento económico (Crescenzi, 2005).

También un elemento clave para la competitividad y el éxito de una determinada región son las redes de conocimiento. A pesar que las Mipymes tienden a valorar y a emplear más las redes de conocimiento con entes externos a la región, las más innovadoras guardan un equilibrio con los internos y externos (Huggins \& Johnston, 2009). 
También hay que tener en cuenta que cuando las empresas del mismo sector se concentran en un lugar determinado, se benefician de los efectos indirectos del conocimiento en el área, ya que tienen más fácil acceso a la información, a los nuevos productos desarrollados y precios entre otros (Yurov, Greenstein, Shanley, \& Potter, 2013).

En la tabla 1.8., se muestran el total de Mipymes registradas en el 2014, distribuidas según regiones. Se observa que solo 10 regiones, concentran el 82,16\% de las Mipymes, siendo Lima la región que más empresas presenta, con un total 760.819, que corresponden al 47,78\% de las Mipymes totales registradas, de éstas un $94,15 \%$ son microempresas y el $5,85 \%$ son pequeñas y medianas empresas. 
Tabla 1.8. Número de empresas por tamaño y ubicación geográfica (2014)

\begin{tabular}{|c|c|c|c|c|c|}
\hline Regiones & Microempresa & $\begin{array}{l}\text { Pequeña } \\
\text { empresa }\end{array}$ & $\begin{array}{l}\text { Mediana } \\
\text { empresa }\end{array}$ & $\begin{array}{c}\text { Total } \\
\text { Mipymes }\end{array}$ & Porcentaje \\
\hline Lima & 716.278 & 42.827 & 1.714 & 760.819 & \multirow{10}{*}{$82,16 \%$} \\
\hline Arequipa & 87.371 & 3.408 & 100 & 90.879 & \\
\hline La Libertad & 80.457 & 2.999 & 91 & 83.547 & \\
\hline Cusco & 60.886 & 1.509 & 38 & 62.433 & \\
\hline Piura & 59.927 & 2.193 & 84 & 62.204 & \\
\hline Junín & 55.280 & 1.537 & 43 & 56.860 & \\
\hline Lambayeque & 52.003 & 1.579 & 52 & 53.634 & \\
\hline Callao & 48.892 & 2.231 & 98 & 51.221 & \\
\hline Ancash & 43.112 & 1.584 & 52 & 44.748 & \\
\hline Ica & 40.313 & 1.509 & 39 & 41.861 & \\
\hline Puno & 32.080 & 1.095 & 29 & 33.204 & \multirow{15}{*}{$17,84 \%$} \\
\hline Cajamarca & 31.639 & 1258 & 35 & 32.932 & \\
\hline San Martin & 27.835 & 1.103 & 36 & 28.974 & \\
\hline Loreto & 25.801 & 1.413 & 53 & 27.267 & \\
\hline Tacna & 25.660 & 714 & 21 & 26.395 & \\
\hline Ucayali & 21.859 & 1.020 & 50 & 22.929 & \\
\hline Huánuco & 20.443 & 717 & 17 & 21.177 & \\
\hline Ayacucho & 18.398 & 590 & 22 & 19.010 & \\
\hline Apurímac & 12.950 & 344 & 8 & 13.302 & \\
\hline Tumbes & 11.408 & 334 & 12 & 11.754 & \\
\hline Madre de Dios & 10.978 & 367 & 14 & 11.359 & \\
\hline Moquegua & 10.506 & 253 & 7 & 10.766 & \\
\hline Pasco & 9.525 & 324 & 7 & 9.856 & \\
\hline Amazonas & 8.368 & 287 & 11 & 8.666 & \\
\hline Huancavelica & 6.315 & 118 & 2 & 6.435 & \\
\hline Total & 1.518 .284 & 71.313 & 2.635 & 1.592 .232 & \\
\hline
\end{tabular}




\subsubsection{Sector y actividades principales}

Las actividades económicas detalladas en la Clasificación Internacional Industrial Uniforme (CIIU), son las actividades aceptadas y definidas por la División de Estadísticas de la Organización de las Naciones Unidas. La CIIU, tiene por finalidad establecer una clasificación uniforme de las actividades económicas productivas, ofreciendo un conjunto de categorías de actividades que se usan para generar estadísticas y cuentas nacionales (Ministerio de la Producción, 2013). Cada país, tiene una clasificación industrial propia según las características y el grado de desarrollo de la economía, tomando como base la estructura establecida de la CIIU oficializada por la ONU. En el Perú actualmente se utiliza la CIIU revisión 3.0 (Ministerio de la Producción, 2013).

El gráfico 1.3., muestra el porcentaje de Mipymes, según sector de actividad, siendo el Comercio el sector con mayor concentración de micro, pequeñas y medianas empresas con un $45,20 \%$. Por otro lado, el sector Pesca es el que concentra menor número de Mipymes, ya que se observa que representa solo el 0,20\%.

\section{Gráfico 1.3. Porcentaje de Mipymes por sector económico} (2014)

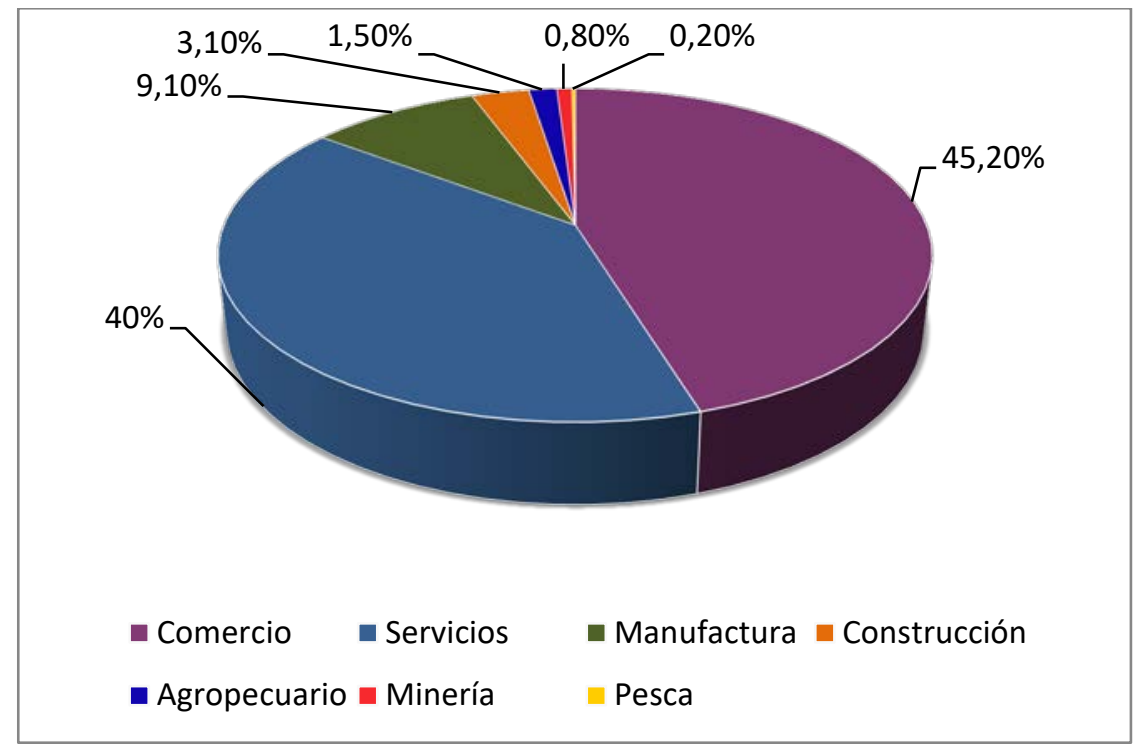

Fuente: PRODUCE (2015).

Elaboración propia.

La tabla 1.9, describe la distribución porcentual de las empresas, según su tamaño y sector de actividad, como se observa, para las microempresas, el 94,64\% de ellas se concentra en los sectores comercio, servicios y manufactura, sumando un total de 1.437.028 empresas; por otro lado, para el caso de las pequeñas empresas, el 
$88,11 \%$ se concentra en los mismos sectores anteriores, totalizando 62.836 empresas.

Tabla 1.9. Número de empresas por sector económico y tamaño (2014)

\begin{tabular}{|l|c|c|c|c|c|c|}
\hline \multirow{2}{*}{ Sector } & \multicolumn{2}{|c|}{ Microempresa } & \multicolumn{2}{c|}{ Pequeña empresa } & \multicolumn{2}{c|}{ Mediana empresa } \\
\cline { 2 - 7 } & Número & Porcentaje & Número & Porcentaje & Número & Porcentaje \\
\hline Comercio & 691.164 & $45,52 \%$ & 28.088 & $39,39 \%$ & 1.047 & $39,73 \%$ \\
\hline Servicios & 608.119 & $40,05 \%$ & 27.291 & $38,27 \%$ & 926 & $35,14 \%$ \\
\hline Manufactura & 137.745 & $9,07 \%$ & 7.457 & $10,46 \%$ & 297 & $11,27 \%$ \\
\hline Construcción & 43.648 & $2,88 \%$ & 5.309 & $7,44 \%$ & 193 & $7,33 \%$ \\
\hline Agropecuario & 21.833 & $1,44 \%$ & 1.943 & $2,72 \%$ & 103 & $3,91 \%$ \\
\hline Minería & 12.764 & $0,84 \%$ & 722 & $1,01 \%$ & 44 & $1,67 \%$ \\
\hline Pesca & 3.011 & $0,20 \%$ & 503 & $0,71 \%$ & 25 & $0,95 \%$ \\
\hline Total & $\mathbf{1 . 5 1 8 . 2 8 4}$ & $\mathbf{1 0 0 \%}$ & $\mathbf{7 1 . 3 1 3}$ & $\mathbf{1 0 0 \%}$ & $\mathbf{2 . 6 3 5}$ & $\mathbf{1 0 0 \%}$ \\
\hline $\begin{array}{l}\text { Fuente: Produce (2015). } \\
\text { Elaboración propia. }\end{array}$ & & & & & \\
\hline
\end{tabular}

CEPLAN (2010) destaca que hay muchas coincidencias en las propuestas de desarrollo productivo que desde la década de los 90 han formulado diversas entidades. Señalan como sectores que se perfilan como importantes de desarrollo de la economía a la agroindustria, la pesca y la acuicultura, la minería, textil y confecciones y el turismo. Menciona también que las propuestas omiten al sector turismo, cuyo crecimiento ha sido muy destacado en los últimos años y que puede convertirse en un sector que dinamice el mercado interno, generando grandes posibilidades de empleo.

García-Vega (2011) plantea que para mejorar la competitividad del país es necesario la innovación como tema pilar en las Mipymes de los sectores minería, agroindustria, y textil, identificando a las que tienen potencial competitivo, agrupándolas para luego capacitarlas, incentivarlas, brindarles asesoría y establecer un plan de colaboración entre la universidad y ellas.

\subsubsection{Regímenes tributarios}

Las Mipymes, pueden elegir entre tres tipos de regímenes tributarios, para cumplir con sus obligaciones ante la SUNAT: Régimen General del Impuesto a la Renta (RG), Régimen Especial del Impuesto a la Renta (RER) y el Régimen Único Simplificado 
$(R U S)^{11}$. Los regímenes especiales, (RER y RUS), fueron creados para facilitar el cumplimiento de las obligaciones tributarias de las Mypes (Ministerio de la Producción, 2015).

EI RER es un régimen tributario establecido para personas naturales y jurídicas, sucesiones indivisas y sociedades conyugales domiciliadas en el país que obtengan renta de tercera categoría generada de actividades de comercio o industria y actividades de servicio.

Para acogerse a este régimen es necesario que:

- Tanto los ingresos netos anuales como el monto acumulado de adquisiciones al año no deben exceder los S/. 525.000.

- No debe superar a los S/. 126.000 el valor de los activos fijos implicados en la actividad exceptuando predios y vehículos.

- El personal implicado en la actividad no debe ser mayor a 10 personas por turno de trabajo ${ }^{12}$.

Los contribuyentes que se acojan al RER, deben cumplir con declarar y pagar mensualmente el Impuesto a la Renta. Pagar como cuota mensual el 1,5\% de los ingresos netos mensuales y el Impuesto General a las Ventas e Impuesto de Promoción Municipal, que es del 18,0\%.

En el caso del RUS, pueden acogerse a este régimen las personas naturales y las sucesiones indivisas, domiciliadas en el país, que tienen un negocio donde los consumidores finales son los clientes y las Empresas Individuales de Responsabilidad Limitada (Ley No. 30056 sobre diversas leyes para facilitar la inversión, impulsar el desarrollo productivo y el crecimiento empresarial, 2013). Este régimen, facilita el cumplimiento de los impuestos a la cual están obligados los pequeños contribuyentes, debido a que proporciona que aporten al fisco de acuerdo a su capacidad de pago de acuerdo a sus ingresos (Villanueva, 2011).

Para acogerse a este régimen es necesario que ${ }^{13}$ :

- El monto tanto de los ingresos brutos, asi como de las adquisiciones y compras no debe sobrepasar de los S/. 360.000 en el transcurso de cada año, o en algún mes no deben exceder a los $\mathrm{S} / .30 .000$.

11 Tomado de http://blog.pucp.edu.pe/blog/agustinacastillo/2008/05/11/regimenes-tributarios-para-mypesnuevo-rus-y-rer-a-proposito-de-la-nueva-ley-mype-vigente-a-partir-del-01-10-2008/ el 19 de abril de 2016 12 Tomado de http://www.sunat.gob.pe/legislacion/renta/ley/capxv.htm el 19 de abril de 2016

13 Tomado de http://www.guiatributaria.sunat.gob.pe/tipos-de-contribuyente/nuevo-rus/19-tipos-decontribuyente/nuevo-rus/37-cuales-son-los-requisitos-para-acogerse-al-nuevo-rus.html el 19 de abril de 2016 
- Realizar actividades en un solo establecimiento que sea de su propiedad o que lo explote bajo cualquier forma de posesión.

- El valor de los activos fijos afectados a la actividad no debe exceder a los S/. 70.000. Los activos fijos, incluyen instalaciones, maquinarias, equipos de cualquier índole, etc. No se considera el valor de los predios ni de los vehículos que se requieran para la ejecución del negocio.

EI RUS reúne un solo pago mensual al impuesto a la renta, impuesto general a las ventas y al impuesto de promoción municipal. Así sustituye con un único tributo, de liquidación mensual, tres impuestos.

El Régimen General está dirigido a personas naturales y jurídicas que generen rentas de tercera categoría. La adopción de este Régimen puede realizarse en cualquier momento del año si el contribuyente proviene del RUS o del RER, o con la inscripción en el RUC de ser el caso, en el mes en que inicie actividades.

El Régimen General comprende los siguientes impuestos:

- IGV: $18 \%$ de las ventas mensuales con derecho al crédito fiscal

- Impuesto a la renta: $30 \%$

- Impuesto Selectivo al Consumo (sólo si estuviera afecto).

- Contribuciones al ESSALUD: 9\%.

Los contribuyentes deben realizar un pago mensual del Impuesto a la Renta de acuerdo a dos métodos establecidos: el método de coeficientes y el método del $2 \%$ de los ingresos netos.

En el Régimen General, los contribuyentes tienen derecho a deducir sus gastos o costos para fines tributarios. Por lo tanto, cuando obtienen bienes y/o servicios necesarios para su actividad, deberán pedir que le otorguen facturas, recibos por honorarios, o ticket que den derecho al crédito fiscal y/o que permitan sustentar sus gastos o costos.

En la tabla 1.10., se presenta el total de Mipymes según régimen tributario registradas en el 2014. Al régimen tributario mediante RUS se acogen únicamente microempresas, siendo estas un total de 610.350 (40,2\% del total de microempresas), mientras que al Régimen General y Régimen Especial se acogen tanto micro como pequeñas empresas según la distribución mostrada en la tabla. 
Tabla 1.10. Mipymes formales por régimen tributario en el Perú (2014)

\begin{tabular}{|l|c|c|c|c|}
\hline Régimen Tributario & Microempresa & $\begin{array}{c}\text { Pequeña } \\
\text { empresa }\end{array}$ & $\begin{array}{c}\text { Mediana } \\
\text { empresa }\end{array}$ & Total \\
\hline Registro Único Simplificado & 610.350 & --- & -- & 610.350 \\
\hline Régimen General & 572.393 & 70.457 & 2.635 & 645.485 \\
\hline Régimen Especial & 335.541 & 856 & --- & 336.397 \\
\hline Total & $\mathbf{1 . 5 1 8 . 2 8 4}$ & $\mathbf{7 1 . 3 1 3}$ & $\mathbf{2 . 6 3 5}$ & $\mathbf{1 . 5 9 2 . 2 3 2}$ \\
\hline $\begin{array}{l}\text { Fuente: Produce (2015). } \\
\text { Elaboración propia. }\end{array}$
\end{tabular}

Se puede entrever también que el 38,33\% del total de las Mipymes, están en el Registro Único Simplificado, un 40,54\% optan por un Régimen General y un 21,13\% se acogen a un Régimen Especial.

Es importante señalar que, dada la alta informalidad en nuestro país, sigue siendo un problema tanto la evasión como la elusión tributaria. Al haber relativamente pocas empresas formales tributando, la recaudación fiscal es insuficiente para que el Estado cubra las necesidades del país, por lo que se ve obligado a subir las tasas de impuestos, lo cual a su vez genera a la larga mayor informalidad (Gordillo, 2015). Orozco, Chávez, \& Yance (2014) mencionan que la informalidad de las Mipymes origina que sus actividades dentro de la organización se muestren poco competitivas con respecto a otras, debido a su vez por las dificultades que tienen al colocar sus productos en el mercado local y a que no ofrecen nuevos productos innovadores y con creatividad.

\subsection{IMPORTANCIA DE LAS MIPYMES EN LA ECONOMÍA PERUANA}

Muchos autores consideran que las Mipymes juegan un papel importante en la economía del país donde operan (Santander, 2013). Dado que su número representa un grupo predominante de empresas que aportan significativamente a la creación de empleo, a la generación de ingresos y a cubrir necesidades en aquellos mercados que resultan poco atrayentes para las empresas de mayor tamaño (Andriani, Biasca \& Martínez, 2003; Hernani \& Hamann, 2013). En términos económicos, la International Finance Corporation (2015) menciona que las Mipymes "representan alrededor del 90\% de los negocios y más del 50\% del empleo en todo el mundo". De todos los países medidos por la Organisation for Economic Co-operation and Development (OECD), las Mipymes en el mundo contribuyen a su tejido empresarial, ya sea definido por el número de empleados o por el monto de la facturación del negocio (OECD, 2015). 
Para apreciar la importancia de las Mipymes en la economía peruana, se hará una descripción cuantitativa de variables como el número de empresas, empleo generado, nivel de producción y nivel de exportaciones.

\subsubsection{Número de empresas}

Al analizar el número de Mipymes registradas se puede medir su participación en el número total de empresas. En este sentido, se observa que del total de empresas formales registradas según la tabla 1.11., las Mipymes, concentran el 99,48\% de las empresas en el Perú (de un total de 1.600 .620 empresas formales existentes al 2014), de este porcentaje un $94,86 \%$ corresponde a microempresas, un $4,46 \%$ a pequeñas empresas y las medianas constituyen el 0,16\% (Ministerio de la Producción, 2015). Por otro lado, cabe mencionar que el 83,0\% de las Mipymes tuvieron en el 2014 ventas anuales menores a las 25 UIT, lo cual indica que la mayoría de ellas tiene el negocio como un medio de subsistencia y sus ganancias no son suficientes para capitalizar la empresa.

Tabla 1.11. Número de empresas por tamaño en el Perú (2014)

\begin{tabular}{|l|c|c|}
\hline Tamaño & Número de empresas & Porcentaje \\
\hline Microempresa & 1.518 .284 & $94,86 \%$ \\
\hline Pequeña empresa & 71.313 & $4,46 \%$ \\
\hline Mediana empresa & 2.635 & $0,16 \%$ \\
\hline Total Mipymes & 1.592 .232 & $99,48 \%$ \\
\hline Gran empresa & 8.388 & $0,52 \%$ \\
\hline Total empresas & $\mathbf{1 . 6 0 0 . 6 2 0}$ & $\mathbf{1 0 0 , 0 0 \%}$ \\
\hline $\begin{array}{l}\text { Fuente: Produce (2015). } \\
\text { Elaboración propia. }\end{array}$ & \\
\hline
\end{tabular}

\subsubsection{Población económicamente activa (PEA) ocupada}

Las Mypes presentan una importante contribución en el empleo en la economía peruana, como muestra el gráfico 1.4., las empresas con menos de 100 trabajadores y los trabajadores independientes representan el $78,5 \%$ del total de empresas formales del Perú. 
Gráfico 1.4. Distribución porcentual de la PEA, según número de trabajadores (2014)

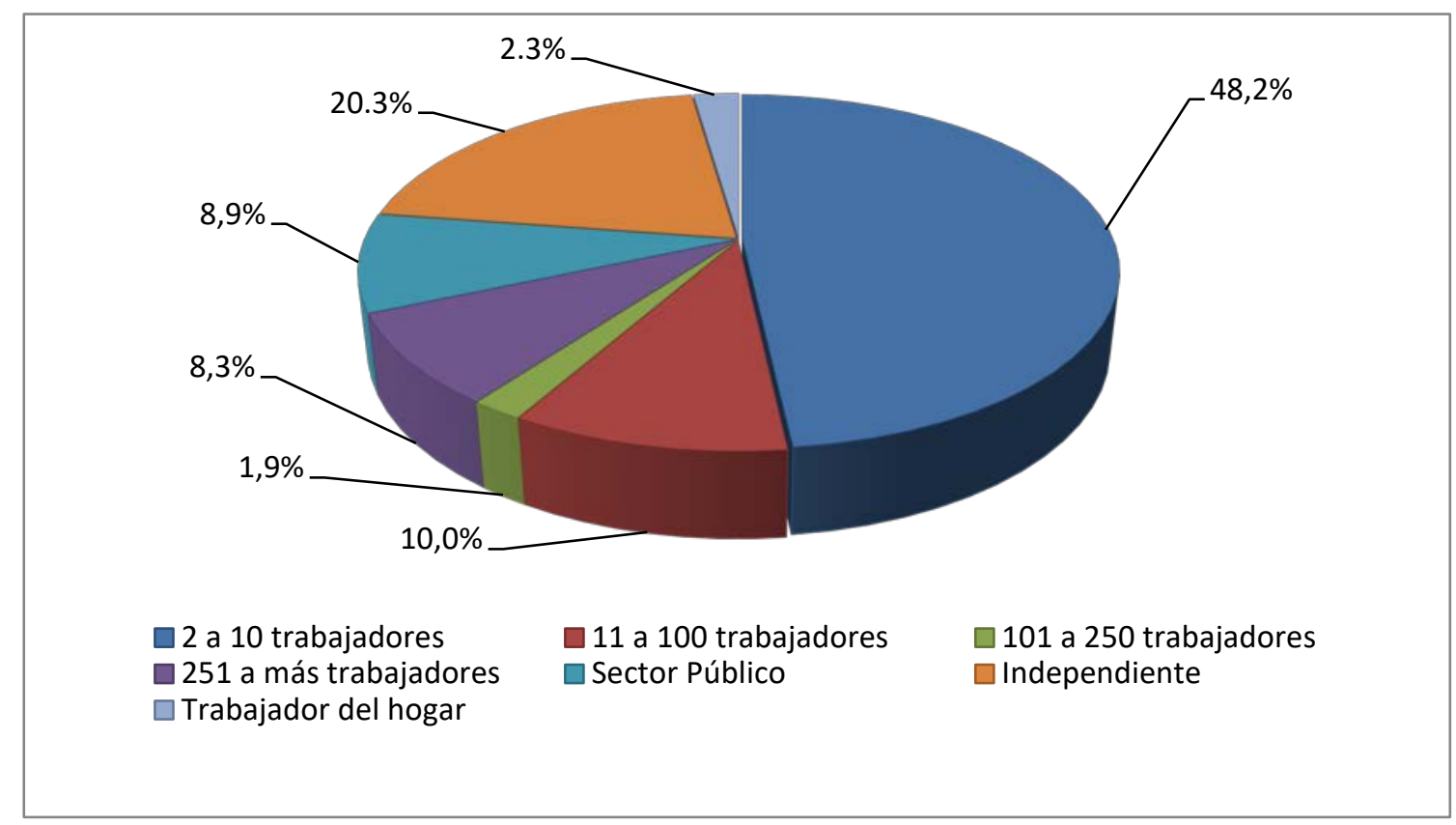

Fuente: PRODUCE (2015).

Elaboración propia.

Se puede apreciar en la tabla 1.12., que el 98,85\% de las microempresas y el $59,13 \%$ de las pequeñas empresas tiene hasta 5 trabajadores, mientras que el $25,96 \%$ de las medianas empresas tiene entre 11 a 20 trabajadores. Las Mipymes generan aproximadamente el $60 \%$ de la PEA ocupada, lo cual hace ver la importancia que tiene en la generación de empleo en nuestro país (Ministerio de la Producción, 2015). Las Mipymes contribuyen de manera importante en la creación de puestos de trabajo, pero se verifica que su aporte disminuye conforme disminuye el desarrollo de la región (Jarosz-Angowska \& Angowski, 2014). 
Tabla 1.12. Número de empresas por tamaño y rango de trabajadores (2014)

\begin{tabular}{|c|c|c|c|c|c|c|}
\hline \multirow{2}{*}{$\begin{array}{l}\text { Rango de } \\
\text { trabajadores }\end{array}$} & \multicolumn{2}{|c|}{ Microempresa } & \multicolumn{2}{|c|}{ Pequeña empresa } & \multicolumn{2}{|c|}{ Mediana empresa } \\
\hline & Número & Porcentaje & Número & Porcentaje & Número & Porcentaje \\
\hline$[0-5]$ & 1.500 .779 & $98,85 \%$ & 42.166 & $59,13 \%$ & 530 & $20,11 \%$ \\
\hline$[6-10]$ & 13.344 & $0,88 \%$ & 12.464 & $17,48 \%$ & 418 & $15,86 \%$ \\
\hline [11-20] & 3.298 & $0,22 \%$ & 9.830 & $13,78 \%$ & 684 & $25,96 \%$ \\
\hline [21-50] & 730 & $0,05 \%$ & 4.892 & $6,86 \%$ & 480 & $18,22 \%$ \\
\hline [51-100] & 100 & $0,01 \%$ & 1.473 & $2,06 \%$ & 332 & $12,60 \%$ \\
\hline [101-200] & 21 & $0,00 \%$ & 369 & $0,52 \%$ & 132 & $5,01 \%$ \\
\hline 201 o más & 12 & $0,00 \%$ & 119 & $0,17 \%$ & 59 & $2,24 \%$ \\
\hline Total & 1.518 .284 & $100,00 \%$ & 71.313 & $100,00 \%$ & 2.635 & $100,00 \%$ \\
\hline
\end{tabular}

\subsubsection{Volumen de exportaciones}

La exportación resulta una actividad sumamente importante para la economía peruana, que se caracteriza por ser pequeña y abierta, ya que va a facilitar el acceso a un mercado mucho más amplio. Por esto, las exportaciones lo consideran como un motor del crecimiento económico y tienen una fuerte relación con el crecimiento del PBI real (Ministerio de la Producción, 2015).

En el 2014, las Mipymes abarcan el 75,8\% del total de empresas exportadoras, como muestra la tabla 1.13. Respecto al 2009, el 2014, el número de Mipymes exportadoras, ha crecido en $10,33 \%$. Por otro lado, haciendo un análisis según tipo de empresa, se puede observar que el número de microempresas exportadoras, ha aumentado en $7,27 \%$ en los últimos 6 años, el número de pequeñas empresas exportadoras se ha incrementado en un $14,11 \%$ y las medianas empresas exportadoras en $8,21 \%$ en el mismo periodo. 
Tabla 1.13. Número de empresas exportadoras del sector privado, según tamaño (2009-2014)

\begin{tabular}{|c|c|c|c|c|c|c|}
\hline \multirow{2}{*}{\multicolumn{2}{|c|}{ Año }} & \multicolumn{4}{|c|}{ Estrato empresarial } & \multirow{3}{*}{$\begin{array}{l}\text { Total } \\
7.072\end{array}$} \\
\hline & & \multirow{2}{*}{$\begin{array}{c}\text { Microempresa } \\
2.831\end{array}$} & \multirow{2}{*}{$\begin{array}{c}\begin{array}{c}\text { Pequeña } \\
\text { empresa }\end{array} \\
2.437\end{array}$} & \multirow{2}{*}{\begin{tabular}{|c|} 
Mediana empresa \\
268
\end{tabular}} & \multirow{2}{*}{$\begin{array}{c}\begin{array}{c}\text { Gran } \\
\text { empresa }\end{array} \\
1.536\end{array}$} & \\
\hline & $\mathbf{N}^{\circ}$ & & & & & \\
\hline 2009 & $\%$ & 40,0 & 34,5 & 3,8 & 21,7 & 100,0 \\
\hline \multirow[b]{2}{*}{2010} & $\mathbf{N}^{\circ}$ & 2.828 & 2.374 & 263 & 1.695 & 7.160 \\
\hline & $\%$ & 39,5 & 33,2 & 3,7 & 23,7 & 100,0 \\
\hline \multirow[b]{2}{*}{2011} & $\mathbf{N}^{\circ}$ & 2.838 & 2.599 & 268 & 1.864 & 7.569 \\
\hline & $\%$ & 37,5 & 34,3 & 3,5 & 24,8 & 100,0 \\
\hline \multirow[b]{2}{*}{2012} & $\mathbf{N}^{\circ}$ & 2.805 & 2.806 & 288 & 1.893 & 7.792 \\
\hline & $\%$ & 36,0 & 36,0 & 3,7 & 24,3 & 100,0 \\
\hline \multirow{2}{*}{2013} & $\mathbf{N}^{\circ}$ & 2.763 & 2.800 & 282 & 1.932 & 7.777 \\
\hline & $\%$ & 35,5 & 36,0 & 3,6 & 24,8 & 100,0 \\
\hline \multirow{2}{*}{2014} & $\mathbf{N}^{\circ}$ & 3.037 & 2.781 & 290 & 1.955 & 8.063 \\
\hline & $\%$ & 37,7 & 34,5 & 3,6 & 24,2 & 100,0 \\
\hline
\end{tabular}

\subsection{PROBLEMÁTICA DE LAS MIPYMES}

Las Mipymes representan un papel muy relevante en la economía peruana. Sin embargo, enfrentan una serie de obstáculos que influyen negativamente en su supervivencia y desarrollo a largo plazo. El terreno donde se desenvuelven todavía es muy frágil. Mediante un modelo matemático de crecimiento de las empresas Cressy (2006) explica por qué "la mayoría de las empresas mueren jóvenes"; esto es, en base al capital inicial, la gestión empresarial y la adversión al riesgo del empresario influyen en sus decisiones y en la ganancias, lo cual a su vez determina su probabilidad de continuar en el mercado. A pesar del apoyo especial que otorgan algunos gobiernos a las Mipymes, no garantizan que alcancen el éxito o que en el tiempo permanezcan en el mercado. De allí que se deben desarrollar e implementar estrategias que faciliten la competitividad a las empresas (López, Tricás, \& Toledano, 2013).

Lederman, Messina, Pienknagura, \& Rigolini (2014) señalan que "la mayoría de las empresas jóvenes son pequeñas, pero hay un porcentaje grande de las empresas 
pequeñas que no son jóvenes", es decir, muchas siguen en el mercado pero no han logrado crecer lo suficiente. Según Sérida, Borda, Nakamatsu, Morales, \& Yamakawa (2005), se estima que 9,2 millones de peruanos están involucrados en una actividad emprendedora, de los cuales el 75\% tiene un periodo de operaciones de entre 0 a 42 meses, y el restante $25 \%$ sobrepasa este periodo, considerándose como empresas consolidadas.

Además Avolio, Mesones, \& Roca (2011) señalan algunos factores que explican a fondo la problemática de las Mipymes en Perú, los cuales se muestran en la tabla 1.14 .

Tabla 1.14. Factores de la problemática de las Mipymes

\begin{tabular}{|c|c|c|}
\hline \multirow{19}{*}{ 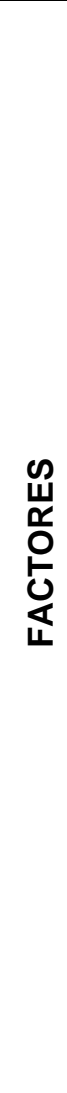 } & \multirow{4}{*}{ Administrativos } & Gestión de recursos humanos \\
\hline & & Temas contables y financieros \\
\hline & & Gestión administrativa \\
\hline & & Capacitación \\
\hline & \multirow{5}{*}{ Operativos } & Estrategia de marketing \\
\hline & & Establecimiento de precios \\
\hline & & Producción \\
\hline & & Control de Inventarios \\
\hline & & Proveedores \\
\hline & \multirow{3}{*}{ Estratégicos } & Acceso a capital \\
\hline & & Investigación de mercados \\
\hline & & Planeamiento a largo plazo \\
\hline & \multirow{4}{*}{ Externos } & Corrupción/ informalidad \\
\hline & & Tecnología \\
\hline & & Competencia \\
\hline & & Estado \\
\hline & \multirow{3}{*}{ Personales } & Motivación de terceros \\
\hline & & Educación \\
\hline & & Experiencia \\
\hline
\end{tabular}

Por otro lado, según el Consejo Nacional para el Desarrollo de la Micro y Pequeña Empresa, las dificultades o limitaciones que se presentan se centran en el acceso al mercado, financiamiento, innovación y transferencia tecnológica, capacitación y asesoría, capacidad gerencial, informalidad, cultura y conocimiento, participación individual y desarticulación empresarial (Codemype, 2006). 
Según Villarán (2001), una de las principales limitaciones del empresario peruano es su falta de métodos y técnicas modernas, para desarrollar cada una de las tareas que confronta en su actividad empresarial. Los empresarios desarrollan maneras de hacer las cosas pero éstas no necesariamente son las más competitivas.

La poca flexibilidad, la resistencia al cambio y sobre todo la ausencia de una oferta formativa atractiva sobre cómo hacer las cosas, hacen que ésta sea una de las principales carencias. El empresario, no tiene métodos eficaces para trabajar en equipo, supervisar, manejar las cuentas, innovar y estudiar el mercado, principalmente (Villarán, 2001).

Al-Hyari (2013) tomando a 241 pymes del sector manufacturero en Jordania, llega a que los cinco principales factores que limitan el desarrollo de las empresas son los altos costos de financiación, la falta de personal calificado, bajo acceso a facilidades de crédito, la fuerte competencia y las normas y reglamentos rígidos.

En base a una muestra de 152 pymes del sector manufacturero en México Fernández, Magdaleno, \& Zesati (2014) concluyen que los recursos financieros (dificultades para obtener financiamiento, costos de la innovación difíciles de controlar), los recursos humanos y las condiciones del ambiente externo (turbulencia económica, carencias de infraestructura y resistencia al cambio de los trabajadores) son barreras a las actividades de innovación. Vasco (2012) menciona que si bien en la región se ha avanzado en el aspecto fiscal en los años de bonanza económica (para 12 países de América Latina pasó de 14,9\% en 1990 a ser 19,2\% como porcentaje del PBI), aún falta llegar a niveles medios de la OCDE, con ingresos cuya magnitud permita cubrir las necesidades del Estado para mejorar sus objetivos y emprender nuevos proyectos de desarrollo. Plantea una reforma tributaria, simplificando aún más las distintas categorías que están sujetas a tributar, cambiando también la estructura de beneficios fiscales, modificando los impuestos sobre consumos y revisando el impuesto general a las ventas.

Loayza (2016), siendo un poco más general, plantea que para mejorar la eficiencia de la economía peruana se requiere llevar a cabo tres grandes procesos de cambio: la transformación estructural, la renovación de empresas y la formalización. El primer proceso se refiere a que es necesario efectuar cambios en la producción hacia sectores de manufactura y servicios con alto valor agregado. El segundo proceso lo considera como un proceso duro pero ineludible, lo cual implica la quiebra de empresas que son deficientes o ineficientes, pero a su vez implica el surgimiento de nuevas empresas más eficientes y el crecimiento de las más productivas. El tercer proceso 
tendría un papel muy importante en el incremento de la productividad; de acuerdo a sus estimaciones la productividad laboral en el sector formal es 2,5 veces más alta que en el informal. El desafío es cómo alcanzar la formalización sin perder la flexibilidad que ha supuesto el estar operando informalmente.

Sabemos que en épocas de crisis económica, las que se ven más afectadas son las Mipymes, pero hay empresas que muestran utilidades importantes, incluso ubicadas en la misma región, perteneciendo al mismo sector y compartiendo el mismo mercado local que las primeras (Bourletidis, 2013).

Respecto a lo analizado por los distintos autores mencionados, se puede concluir que las Mipymes, tienen que mejorar en aspectos como: el acceso al mercado, innovación y tecnología, lo que involucra, tener la disposición de adaptarse al cambio y ser flexibles respecto a las necesidades del mercado, además requieren de una adecuada capacitación, sobre todo gerencial, con el fin de poder adquirir las herramientas que le permitan aplicar estrategias que incrementen la competitividad de la empresa, por último, temas como el acceso al financiamiento y el grado de informalidad, son aspectos, que limitan el crecimiento de las Mipymes, y es por ello que el Estado en conjunto con otras organizaciones realiza esfuerzos para poder reducir estas limitaciones.

\subsection{EL MICROCRÉDITO EN EL PERÚ}

Hasta inicios de la década de los 80 , nuestro país atravesaba un contexto de baja penetración financiera, con una pobre cobertura en la población y concentrado en su capital Lima. Las políticas económicas reforzaron en general dicha situación, que mantenían el sector financiero en un nivel bajo de desarrollo (León \& Jopen, 2011).

El desarrollo de instituciones microfinancieras y de sus tecnologías crediticias se inició en un contexto macroeconómico caracterizado por una alta inflación, el estallido de la crisis de la deuda que generó una abrupta salida de fondos internacionales, el fenómeno de "El Niño" y el bajo dinamismo de la actividad económica. Durante la segunda mitad de la década de 1980, dada la severidad de la crisis del entorno macroeconómico, ocasionó la desaparición de instituciones orientadas al segmento de las microfinanzas como cooperativas de ahorro y crédito, mutuales, programas financieros de reciente creación e incluso la banca de fomento. Las instituciones que subsistieron, resultaban insostenibles en el largo plazo debido al impacto en su capital (Quispe, León, \& Contreras, 2012). 
Durante los primeros años de la década de 1990, se resolvieron los desequilibrios fundamentales mediante un control inflacionario. Este proceso permitió poner en marcha políticas públicas orientadas a la creación de un sector de las microfinanzas, dando lugar, a inicios de esta década, una reforma financiera orientada a hacer más eficiente el mercado financiero y mejorar su capacidad de asignar los recursos en un contexto de una economía abierta de libre mercado, cuyos cambios tuvieron un impacto positivo sobre el sistema bancario (Morris, 2000), generando un entorno normativo sólido y una mayor participación del sector de la microempresa en la estructura económica. En efecto, como resultado de una política de estabilización exitosa y de la implementación de un amplio programa de reformas estructurales, el PBI experimentó un crecimiento promedio anual de 4,7\% y la inflación, una reducción de $6,0 \%$ al año 1998. Al mismo tiempo, consecuente a la fuerte recuperación del ahorro, se amplió significativamente la oferta de fondos (Portocarrero, 2003).

El impacto positivo a partir de la estabilidad económica, tuvo como efecto la mejora en las políticas de promoción del crédito a las Mipymes. Asimismo, en los años 90 se experimentaron diversas estrategias en el desarrollo institucional de las instituciones de microfinanciamiento, sumado a la significativa ampliación de la oferta de microcrédito. Estas entidades, como las Cajas Rurales de Ahorro y Crédito (CRACs), Entidades de Desarrollo para la Pequeña y Microempresa (EDPYMEs) y Mibanco, fueron establecidas entre los años de 1994 y 1998, mientras que las Cajas Municipales de Ahorro y Crédito (CMACs) iniciaron sus actividades en relación a la microempresa a inicios de los años 90 (Portocarrero, 2003).

A fines de 1994, se autorizó la constitución de las EDPYMEs a partir de la formalización de las ONG crediticias, lo cual propició el establecimiento de nuevas empresas orientadas a dicho segmento del mercado y a la promoción del financiamiento del segmento Mipyme. Para su instauración se adoptó requisitos de capital mínimo y, en general, no se desarrollaron fuertes barreras de entrada para su constitución. Con la creación de dichas instituciones, se estableció un tipo de empresa financiera especializada en la intermediación de recursos a este sector, logrando una expansión del crédito a la microempresa (Portocarrero, 2003).

Por su lado, las CRACs no tuvieron el mismo apoyo en cuanto a la tecnología financiera utilizada y en la capacitación de su personal, en comparación con las CMACs. Esto ocasionó que su diseño institucional fomentara a la dispersión de su accionariado y a la confusión entre los roles de un accionista con un prestatario, generando con esto una estructura de propiedad difusa, así como problemas de agencia y riesgo moral. Estos 
problemas se agravaron por el poco selectivo respaldo financiero por parte del sector público a estos intermediarios privados. En el nivel financiero, tuvieron que ampliar sus operaciones mediante el uso de líneas de crédito al sector público, las cuales muchas veces fueron otorgadas con condiciones subsidiadas y una reducida condicionalidad; ocasionando paradójicamente una dependencia marcada de estos intermediarios privados sobre el financiamiento público; la cual no se vio representada de manera significativa en las CMACs (Portocarrero, 2003).

Los diferentes niveles de éxito de las entidades en el sector de microcrédito, fueron muestra del aporte por parte de otras instituciones y, en algunos casos de la actuación internacional en la constitución de estas mismas. A excepción de las CRACs, tal factor no ha estado presente y más aún su relación con el poder político le ha proporcionado más perjuicios que beneficios (Aguilar \& Camargo, 2004).

Mibanco rompe el esquema y empieza revolucionando desde la forma de captar clientes, utilizando un modelo de negocio personalizado, visitando a los potenciales clientes con un equipo de asesores de crédito, capacitados en técnicas de ventas y evaluación crediticia y realizan diversas funciones de promoción, colocación, analistas de créditos y de riesgos y sectoristas (Llosa, 2007). También destaca que el 2003 los grandes bancos comerciales empiezan a incursionar en este sector, al ver las altas rentabilidades de estas instituciones, el incremento de la cartera de créditos de éstas y la baja morosidad que manejan.

Paralelamente y al margen de las instituciones financieras, se han mantenido diversas formas de financiamiento que operan de manera informal, panderos y juntas, prestamistas y se dirigen al segmento de la microempresa y sectores pobres tanto en el ámbito urbano como rural (León \& Jopen, 2011).

Una forma de aproximarnos a la relación entre el crecimiento regional y la expansión de la actividad de las instituciones de microcrédito es analizando el crecimiento económico de las regiones y algunos indicadores de la expansión de la intermediación de estas instituciones en las regiones. La tasa media anual de crecimiento del PBI sin considerar la actividad minera en el periodo 2001-2008 fue de 5,2\% y la mayoría de regiones también tuvieron una mayor actividad productiva no primaria durante la década pasada; adicionalmente en dicho periodo el crecimiento anual de las microempresas a través del Programa de Autoempleo y Microempresa fue del 12\%. Por otro lado, el 2001 las colocaciones de las entidades de microcrédito fueron el $5 \%$ del total de créditos del Sistema Financiero y en el 2009 se incrementa a 15\% (Aguilar, 2013). 
En la tabla 1.15. se puede ver que el total de la cartera de créditos a las Mipymes a diciembre 2015 alcanzó los 73.163 millones de soles, lo cual representó el 28,94\% del total de créditos de estas entidades financieras. Cabe mencionar, que si se considera solo a las entidades no bancarias, su cartera de créditos totalizó 15.754,9 millones de soles, que representó el $60,07 \%$ del total de créditos que otorgaron.

Tabla 1.15. Entidades dedicadas a las microfinanzas (a diciembre 2015)

\begin{tabular}{|l|c|c|c|}
\hline Entidad & Número & $\begin{array}{c}\text { Total de activos } \\
\text { (MM de SI.) }\end{array}$ & $\begin{array}{c}\text { Total de créditos } \\
\text { directos a Mipymes } \\
\text { (MM de SI.) }\end{array}$ \\
\hline Empresas Bancarias & 17 & 358.820 & $57.408,29$ \\
\hline Cajas Municipales & 12 & 18.993 & $9.610,24$ \\
\hline Empresas Financieras & 11 & 11.101 & $5.058,98$ \\
\hline Edpymes & 12 & 2.117 & 732,48 \\
\hline Cajas Rurales de Ahorro y Crédito & 7 & 639 & 353,20 \\
\hline Total & $\mathbf{5 9}$ & $\mathbf{3 9 1 . 6 7 0}$ & $\mathbf{7 3 . 1 6 3 , 1 9}$ \\
\hline $\begin{array}{l}\text { Fuente: Memoria Anual 2015 de la SBS. } \\
\text { Elaboración propia. }\end{array}$
\end{tabular}

El crecimiento de las Mipymes en el Perú ha ido de la mano con el crecimiento del microcrédito. Se puede apreciar en los gráficos 1.5. a 1.9., la evolución del total de la cartera de créditos de las diversas instituciones financieras a las Mipymes en los últimos 6 años. 
Gráfico 1.5. Créditos directos de los Bancos a las Mipymes (en MM de soles)

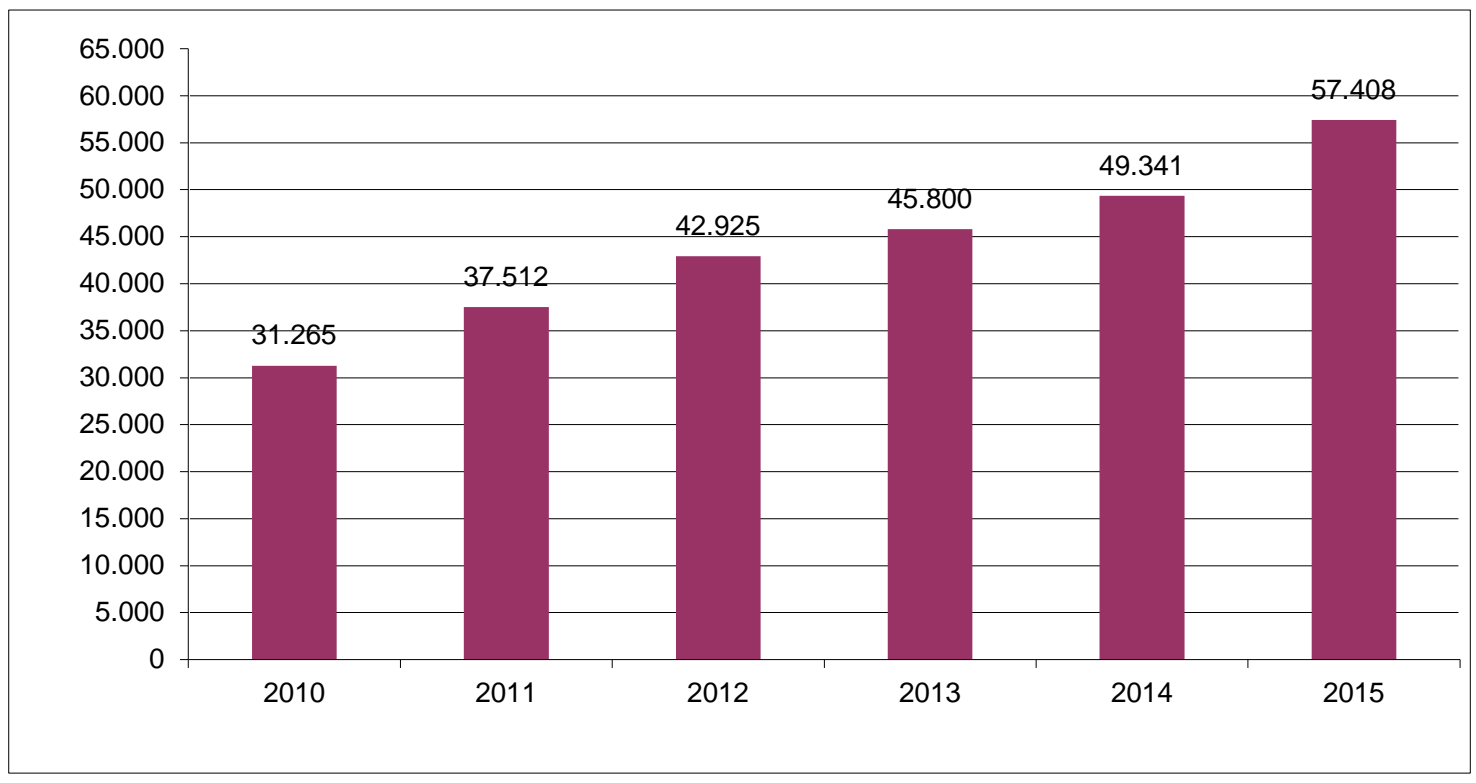

Fuente: Superintendencia de Banca, Seguros y AFP.

Elaboración propia.

Gráfico 1.6. Créditos directos de las Cajas Municipales a las Mipymes

\section{(en MM de soles)}

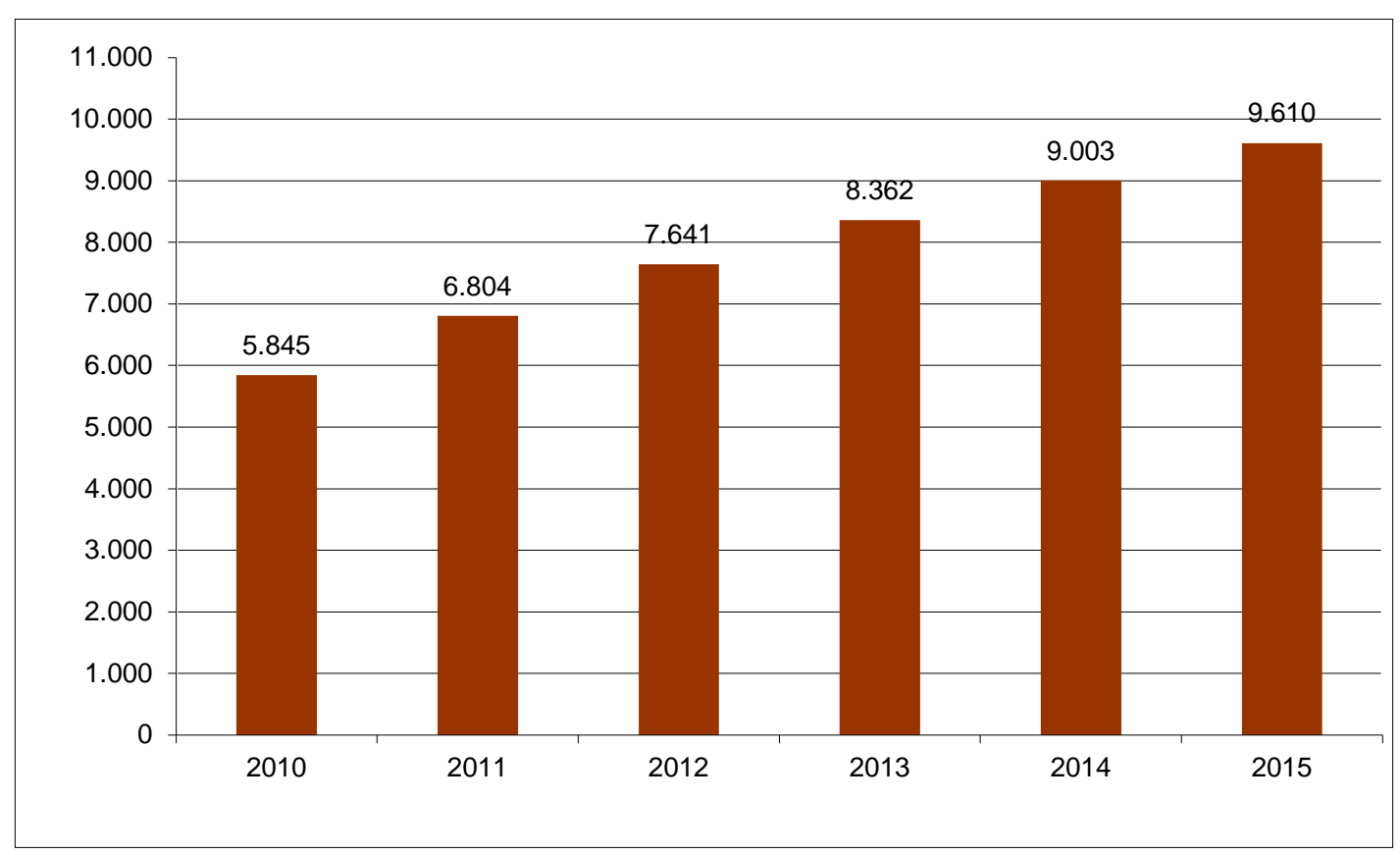

Fuente: Superintendencia de Banca, Seguros y AFP.

Elaboración propia. 
Gráfico 1.7. Créditos directos de las Cajas Rurales a las Mipymes (en MM de soles)

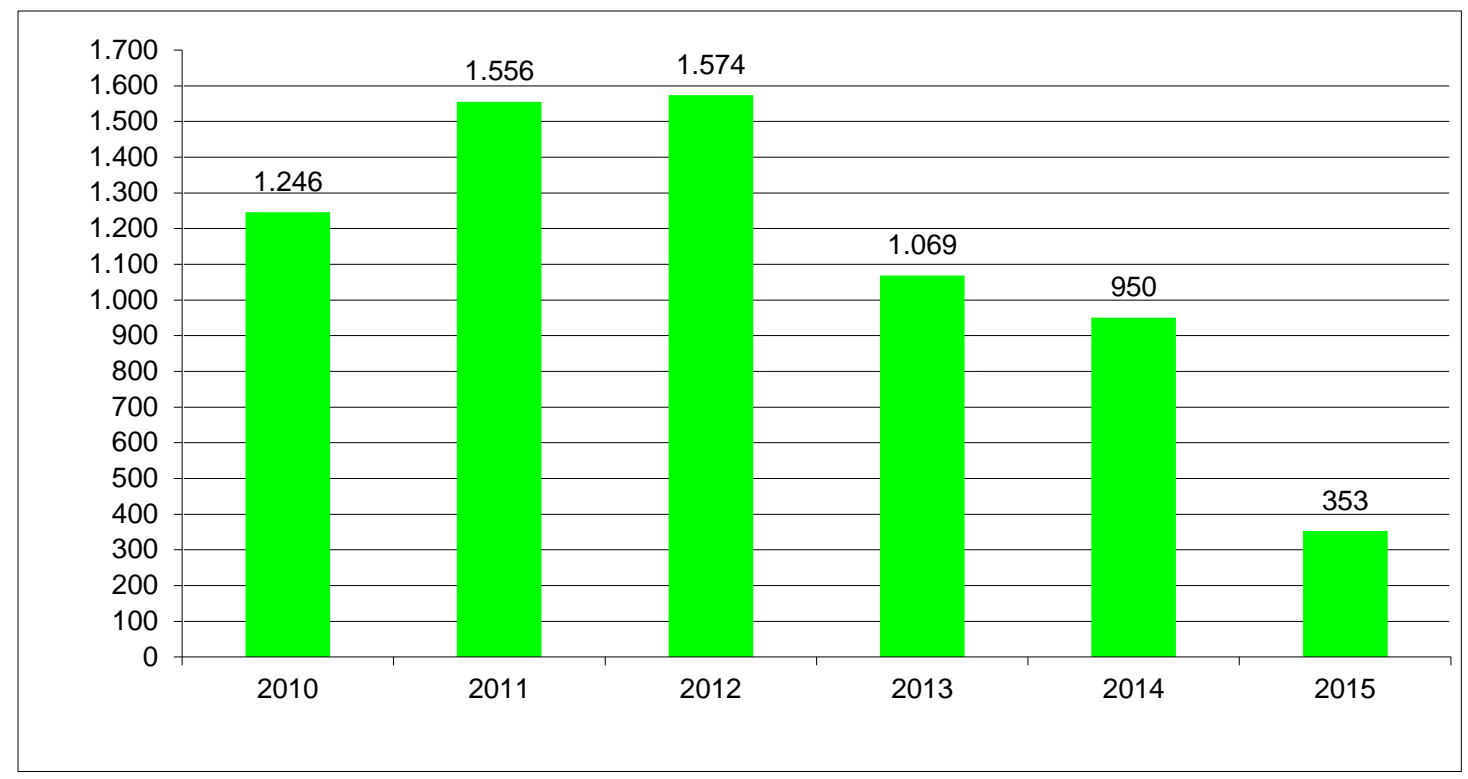

Fuente: Superintendencia de Banca, Seguros y AFP. Elaboración propia.

Gráfico 1.8. Créditos directos de las Edpymes a las Mipymes (en MM de soles)

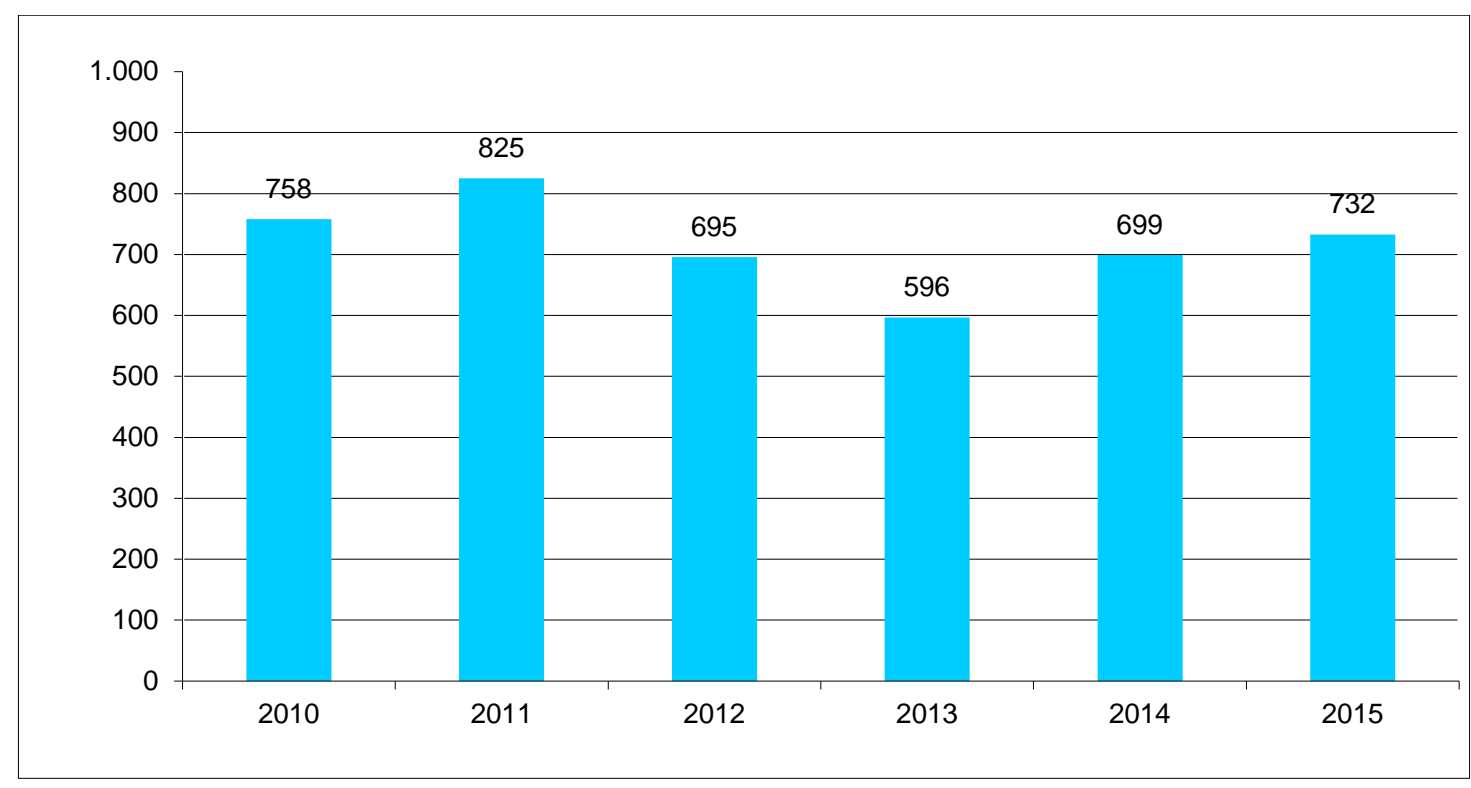

Fuente: Superintendencia de Banca, Seguros y AFP.

Elaboración propia. 
Gráfico 1.9. Créditos directos de las Financieras a las Mipymes (en MM de soles)

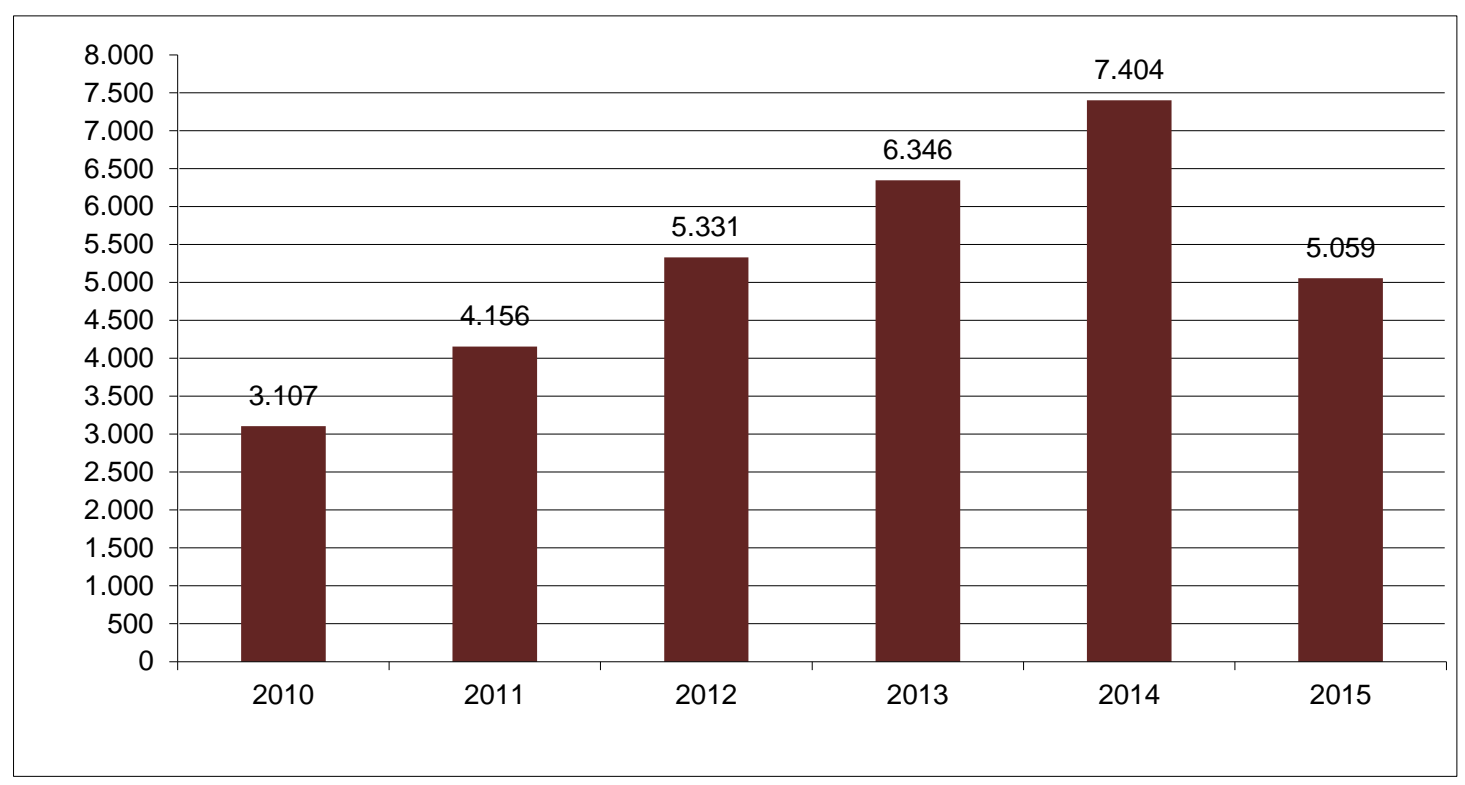

Fuente: Superintendencia de Banca, Seguros y AFP.

Elaboración propia. 
2. FACTORES DETERMINANTES DEL ÉXITO COMPETITIVO EN LA MIPYME: UN ESTUDIO EMPÍRICO EN EMPRESAS PERUANAS 



\subsection{INTRODUCCIÓN}

La literatura sobre los factores explicativos es amplia y generalmente se apoya en la teoría de los recursos y capacidades y en la teoría de organización industrial (Chittithaworn, Islam, Keawchana, \& Yusuf, 2011; Shappo \& Knuth, 2014; Jasra, Hunjra, Rehman, Azam, \& Khan, 2011; Alom, Abdullah, Moten, \& Azam, 2016; Sandada, 2014; Pratono \& Mahmood, 2015; Krejcí, Strielkowski, \& Čabelková, 2015). Sin embargo, en el Perú no existen muchos estudios que analicen la problemática de la Mipyme desde una perspectiva global de la competitividad. El Perú es una economía en desarrollo que forma parte de la Alianza del Pacífico y ha experimentado un importante crecimiento económico, triplicándose el PBI en los últimos 20 años y alcanzando un crecimiento económico promedio de 3,2\% entre 1980 y 2014 (Álvarez, 2014; Shack, 2016;Céspedes, N., Lavado, P., \& Ramírez, 2016). Su tejido empresarial está formado principalmente por micro y pequeñas empresas, (representan más del 99\% de las unidades productivas del país y explican alrededor del 60\% del empleo (Ministerio de la Producción, 2015).

El objeto de este trabajo es analizar los factores que explican el rendimiento de la Mipyme en el contexto de Perú. Para ello se lleva a cabo un estudio empírico a partir de una muestra de 94 Mipymes. Las preguntas de investigación a responder son: ¿cuáles son las diferencias competitivas entre las Mipymes con mayor y menor rendimiento?, ¿la innovación y la tecnología son determinantes del éxito competitivo?, ¿las prácticas de recursos humanos facilitan el rendimiento de la Mipyme?, ¿los sistemas de control de gestión bien implantados favorecen el rendimiento?, ¿qué factores tienen más importancia para la competitividad de la Mipyme?.

Este trabajo es importante desde una doble perspectiva. Por un lado, los resultados son de utilidad al empresario peruano y muestran la necesidad de encontrar procesos de gestión eficientes que puedan ser aplicados dentro de las estrategias de las Mipymes para lograr un mejor desempeño y que puedan ser más competitivas. Por otro lado, desde un punto de vista de política pública los resultados pueden ayudar a los gobiernos a implementar programas económicos que impulsen aquellos factores que incidan de forma más relevante en la competitividad de la Mipyme.

Este estudio se ha estructurado de la siguiente forma: en primer lugar, determinamos el marco teórico, se realiza una revisión de la literatura empírica previa y se delimitan las hipótesis a contrastar; en segundo lugar, exponemos la metodología, las características de la muestra y la justificación de las variables utilizadas; en tercer 
lugar, llevamos a cabo el análisis de los resultados, y finalmente, exponemos las principales conclusiones alcanzadas.

\subsection{MARCO TEÓRICO, REVISIÓN DE ESTUDIOS PREVIOS E HIPÓTESIS A CONTRASTAR}

\subsubsection{La teoría de los recursos y capacidades de la empresa}

La teoría basada en los recursos y capacidades desarrollada por Wernerfelt (1984) y ampliada por diversos autores (Barney, 1991; Grant, 1991) propone que la competitividad de una empresa recae en sus recursos internos de naturaleza intangible. Estos recursos son las capacidades con las que cuenta la empresa, que están debidamente organizadas e integradas para formar un mix de recursos que sea intransferible y único de una empresa. Para poder obtener ventajas competitivas se requiere que estas capacidades tengan un enfoque de largo plazo para que puedan desarrollarse y acentuarse con el tiempo. Esta teoría enfatiza la importancia de los recursos y capacidades internos de la empresa en el entorno competitivo (Collis \& Montgomery, 1999). Así, esta teoría determina que las empresas son entes heterogéneos en idiosincrasia, difícil de imitar en recursos y capacidades (Barney, 1991; Conner, 1991; Rumelt, 1991; Wernerfelt, 1984). La existencia de heterogeneidad entre las empresas en cuanto a los recursos que controlan explican las diferencias en términos de rendimiento (Lippman, McCardle, \& Rumelt, 1991; Barney, 1991).

En este sentido, Amit \& Schoemaker (1993) consideran que la habilidad de la empresa para capturar rentas económicas es una función de cómo tales capacidades son usadas para desplegar y usar los recursos de la empresa. Estos autores definen los recursos como "stocks de factores disponibles que son propiedad o controlados por la empresa". Los recursos son convertidos en productos finales o servicios empleando una variedad de activos y mecanismos de unión (como la tecnología, los sistemas de información gerencial o el sistema de incentivos).

Estos factores son de naturaleza diversa comprendiendo los financieros, físicos, tecnológicos, humanos y organizativos (Cuervo, 1993). Según Barney (1991) los recursos de la empresa pueden agruparse en tres grupos: recursos de capital físico, recursos de capital humano y recursos organizacionales. Los recursos de capital físico incluyen los equipos y la planta, la tecnología usada por la empresa, su ubicación geográfica y su grado de accesibilidad a las materias primas. Los recursos de capital humano incluyen todo lo relativo a los trabajadores y directivos de la empresa como es su preparación, la experiencia, inteligencia, juicio, relaciones e involucramiento dentro 
de la empresa de los administradores y de los trabajadores. Los recursos organizacionales están relacionados con la estructura organizativa formal de la empresa, los sistemas de planificación, control y coordinación formales e informales, así como las relaciones informales entre los distintos grupos dentro de la empresa y entre la empresa, los grupos y su entorno. Por otra parte, Grant (1996) distingue entre recursos tangibles e intangibles y humanos. Esta clasificación es importante puesto que como postula Hall (1993) los recursos intangibles son más difíciles de imitar al estar generados mediante un proceso lento y estar basados en información no codificada y conocimientos tácitos, reportando un mayor potencial competitivo a la empresa. (Fernández, Montes, \& Vázquez, 2000) distinguen cuatro clases de recursos intangibles: capital humano, capital organizativo, capital tecnológico y reputación.

Lieberman \& Montgomery (1998) en vez de recursos utilizan el término activos (stock de elementos tangibles o intangibles de los cuales dispone la empresa incluyendo las habilidades de cada trabajador) y definen las capacidades o competencias como la capacidad colectiva de la organización para llevar a cabo un determinado tipo de actividad. Hablan que la entrada temprana de las empresas tiene el potencial de adquirir mayores recursos y capacidades. Aunque estos recursos pueden quizás no ser los más adecuados, el ser pionero puede hacer obtener ventajas a la organización teniendo por ejemplo una buena ubicación física o una patente.

Las capacidades se basan en el desarrollo e intercambio de información a través del capital humano de la empresa, mediante procesos tangibles o intangibles que son específicos de la empresa y se desarrollan a lo largo del tiempo mediante interacciones complejas entre los recursos (Amit \& Schoemaker, 1993). Las capacidades están basadas en el conocimiento organizacional, siendo una pieza muy importante el aprendizaje dentro de la empresa (Hamel \& Prahalad, 1990). Las capacidades surgen de la utilización de recursos y contribuyen a aumentar la dotación de recursos y capacidades futuras (Idígoras \& Mitxeo, 2000). La ventaja competitiva puede ser derivada de los recursos y capacidades de la empresa debido a su valor (en el sentido que explota oportunidades y/o neutraliza amenazas del entorno), raro (en el sentido que no lo posean muchos competidores), difícilmente imitable y no tener sustitutos estratégicamente equivalentes (Barney, 1991). 


\subsubsection{La planificación, los sistemas de control de gestión y el rendimiento de la Mipyme}

La planificación estratégica es el conjunto de procesos emprendidos para desarrollar una gama de estrategias que contribuyan con el logro de los objetivos y metas planteadas por la administración de una organización. Van Kirk \& Noonan (1982) explican en detalle los pasos que comprende todo proceso de planificación estratégica. En general hay un consenso en que hay cinco pasos principales: fijación de objetivos, análisis de la situación, consideración de alternativas, implementación y evaluación. Adicionalmente, el proceso de la planificación debe ser rápido y flexible para reaccionar ante las amenazas y las oportunidades, reducir la incertidumbre, y ser un dispositivo de integración organizacional y un mecanismo de control. Estas características aseguran respuestas sobre todo cuando el mercado es muy cambiante (Crittenden \& Crittenden, 2000; Tapinos, Dyson, \& Meadows, 2005; Moyer, 1982).

Determinadas empresas llevan a cabo la planificación de manera formal utilizando su estructura organizacional, mientras que otras la realizan sin mayores documentos o reuniones y acuerdos más estructurados y estandarizados. Se observa que las empresas de mayor tamaño realizan en mayor proporción procesos de planificación más formales que las empresas pequeñas; esto tal vez se deba a que estas últimas cuentan con menos recursos, que mayormente demandan un proceso de planificación formal (Ghobadian, O’Regan, Thomas, \& Liu, 2008).

Plantear la misión y visión de la empresa influye positivamente en el rendimiento del negocio (Sandada, 2014). Diversas investigaciones muestran que el uso de la planificación es muy beneficioso para la empresa y que hay una relación muy estrecha con el rendimiento (Sandada, 2014; Wijewardena \& De Zoysa, 2001; Griggs, 2002; Glaister, Dincer, Tatoglu, Demirbag, \& Zaim, 2008; Eddleston, Kellermanns, \& Sarathy, 2008; Aldehayyat \& Twaissi, 2011) y que puede ser un factor básico para su supervivencia (McKiernan \& Morris, 1994).

Aldehayyat \& Twaissi (2011) obtienen una relación significativa entre el planeamiento estratégico y el rendimiento corporativo, mostrando además que las dimensiones del planeamiento estratégico (análisis del entorno, uso de técnicas estratégicas, convergencia de las áreas funcionales de la empresa, la participación de la alta dirección en el planeamiento estratégico, participación de la línea de la administración en el planeamiento) están relacionados con el rendimiento de las empresas. Ogunmokun \& Tang (2012) llegaron a la conclusión de que las organizaciones pequeñas y medianas con un alto nivel de desempeño tienden a tener 
por escrito sus actividades que conforman el plan estratégico de marketing (misión empresarial, sus objetivos de marketing en su participación del mercado, de los productos o servicios y de distribución) y que el grado en que las empresas llevaron a cabo las diversas actividades del proceso del plan de marketing estratégico (como la recolección de información externa, el establecimiento de objetivos de rentabilidad, así como la fijación de objetivos en áreas tales como la participación del mercado, fijación de precios, promoción, distribución, desarrollo de un plan de acción para el logro de los objetivos y el seguimiento de los resultados de la planificación) se relaciona con el rendimiento de las empresas. En otro estudio realizado por Dibrell, Craig, \& Neubaum (2014) vinculan los procesos de planificación estratégica formal, la planificación flexible y la innovación de las empresas con su rendimiento. Confirman que las empresas deben llevar a cabo una planificación flexible en asociación con sus procesos formales de planificación estratégica para optimizar los beneficios de la innovación. Estos argumentos conducen a la formulación de la siguiente hipótesis:

Hipótesis 1: La realización de planificación estratégica influye positivamente en el éxito de la Mipyme.

A partir de ello, es posible afirmar que las Mipymes necesitan cada vez más establecer mecanismos de control que ayuden a la gerencia a tomar correctamente sus decisiones. La fuerte competencia que en la actualidad provoca la globalización de los mercados y el cambio tecnológico está motivando a las Mipymes a desarrollar en el seno de su organización sistemas de control de gestión (AECA, 2005). En ese marco, la contabilidad de costes, la planificación financiera y el diagnóstico económicofinanciero facilitan la toma de decisiones y favorecen el rendimiento de la Mipyme (AECA, 2005; Conde, Sampedro, Feliu, \& Sánchez, 2013; Cosenz \& Noto, 2015).

Ahora es preciso notar que las Mipymes actúan de forma diferente en el control de la gestión de su organización respecto a las empresas de mayor tamaño. Algunas Mipymes se limitan a elaborar los reportes contables exigidos por la normativa contable o fiscal del lugar donde operan; sin embargo, otras prácticas como el análisis financiero efectuado de forma periódica y formalizado está poco extendido (Vărzaru, 2014). Por otro lado, cuando el grado de informatización de la empresa favorece el desarrollo de sus sistemas de control de gestión y el nivel de formación del contador favorece el uso de los datos contables, en el largo plazo, implicará una mejor toma de decisiones y por tanto influirá positivamente en el rendimiento de la empresa. En ese sentido, si la contabilidad de costes y el sistema de fijación de precios están bien diseñados, 
ayudarán en la mejor gestión de la empresa e influenciará sobre su rendimiento financiero (Laitinen, 2014).

En lo que respecta al presupuesto, Sumedrea \& Costin (2014) señalan que un presupuesto flexible se puede utilizar como base para la evaluación del desempeño gerencial, y tiene una gran utilidad principalmente, en la gestión de empresas en rápido crecimiento o en empresas que se desenvuelvan en un entorno organizacional de incertidumbre. Del mismo modo, indican que la práctica de presupuestos tienen una relación directa con la performance del negocio.

A partir de ello, se ha definido la segunda hipótesis:

Hipótesis 2: La utilización de sistemas de control de gestión influye positivamente en el éxito de la Mipyme.

\subsubsection{La gestión de la calidad y el rendimiento}

Son muchos los trabajos que coinciden en que las habilidades relacionadas con la calidad son fundamentales para la competitividad y el éxito de las empresas (Viedma, 1992; Nee \& Wahid, 2010; Lakhal, 2014; Ochieng, Muturi, \& Njihia, 2015). Concretamente, la gestión de la calidad permite a una empresa utilizar los recursos de una forma más eficiente para mejorar su posición en el mercado. No obstante, pocas Mipymes poseen herramientas para la gestión de la calidad, porque esta requiere de la alineación de distintas competencias de las cuales, en algunos casos, carecen por su inexperiencia.

En cuanto a la certificación de calidad las empresas la consideran un factor importante para la permanencia de la empresa en el mercado y esperan que la certificación pueda ayudarlos a mejorar su sistema de gestión. Por ejemplo, la norma ISO 9000 influye en la mejora de la calidad, aumento de los ingresos, reducción de costos y mayores beneficios para la empresa (Ataseven, Prajogo, \& Nair, 2014). De hecho, diversos estudios confirman que la adquisición de la norma de certificación ISO 9000 mejora el rendimiento de las Mipymes (Bayati \& Taghavi, 2007; Romano, 2000; Mokhtar \& Muda, 2012; Starke, Eunni, Dias Fouto, \& De Angelo, 2012). En especial este rendimiento se ve incrementado cuando existe una motivación interna por parte de los empleados y directivos de la empresa (Ilkay \& Aslan, 2012). Un trabajo efectuado a partir de la información de 116 pequeñas empresas de Ghana (África), concluye que la gestión de la calidad cuando se implementa y se practica en las pequeñas empresas, mejora su rendimiento y desarrollo (Fening, 2012). Como la calidad ayuda a ganar ventaja competitiva, implica que la práctica de la gestión de la calidad ayudará a los productos 
locales a ganar ventaja competitiva frente a los productos del exterior. El trabajo de Yee, Yeung, \& Cheng (2010) realizado en empresas de servicios, mostraron cómo la calidad del servicio tiene un impacto positivo con la satisfacción y la lealtad de los clientes, factores que en última instancia mejoran la rentabilidad de la empresa. Adicionalmente, y en relación al TQM, Gadenne \& Sharma (2009), Valmohammadi (2011), y Herzallah, Gutierrez-Gutierrez, \& Munoz Rosas (2014) muestran su importancia para favorecer el incremento de la rentabilidad, la satisfacción del consumidor y el desempeño organizacional. Todos estos argumentos conducen a la formulación de la siguiente hipótesis:

Hipótesis 3: Existe una asociación positiva entre la gestión de la calidad y el éxito de la Mipyme.

\subsubsection{La innovación y el rendimiento}

La innovación es un requisito necesario para el éxito en los mercados que cada vez son más dinámicos y competitivos (Rosenbusch, Brinckmann, \& Bausch, 2008). La innovación tiene un impacto positivo sobre el crecimiento de la empresa (Subrahmanya, 2011; Lecerf, 2012). Sin embargo, en muchas ocasiones la Mipyme no puede seguir una filosofía de innovar constantemente, ya que cuentan con recursos limitados (Nohria, \& Gulati, 1996). De ahí, la necesidad de propiciar una cultura hacia la innovación en la empresa. La comprensión de la cultura de la organización puede ayudar a dar forma al proceso de innovación y a explicar el rendimiento de la empresa (Hogan \& Coote, 2014). La estrategia de innovación y la estructura formal de la empresa son los principales impulsores de la actividad innovadora de la empresa y la adopción de una estrategia económica basada en la innovación aumenta el rendimiento de la empresa (Terziovski, 2010; Leal-Rodriguez, Eldridge, Roldán, Leal-Millán, \& Ortega-Gutiérrez, 2015).

La actual demanda de productos nuevos, diferenciados y de calidad hace que las Mipymes se orienten hacia la innovación como un factor indispensable para su supervivencia (Sok \& O'Cass, 2013). Existen argumentos que respaldan la innovación, ya que puede evitar la competencia de precios por medio de la diferenciación. A través de nuevos productos se puede crear nueva demanda que aumenten las ventas. Un trabajo realizado por Murat \& Baki (2011) efectuado con la información de 270 Mipymes de los parques de ciencia y tecnología de Turquía llegan a mostrar que la innovación en productos y la innovación en procesos está positiva y directamente relacionada con el rendimiento de la empresa (medida a través de las ventas, la rentabilidad y la participación de mercado). La innovación en el producto conlleva a ventas por encima 
de la tasa de crecimiento y se verifica en particular cuando se combinan con la innovación de procesos. La innovación de procesos que no va acompañada de la introducción de nuevos productos corre el riesgo de no ser eficaz para originar un mayor crecimiento y rendimiento (Goedhuysa \& Veugelers, 2012; Atalay, Anafarta, \& Sarvan, 2013). Gunday, Ulusoy, Kilic, \& Alpkan (2011) estudian el impacto de la innovación en productos y procesos sobre el rendimiento de la empresa, en base a 184 empresas manufactureras en Turquía y demuestran que cuando las innovaciones provocan una mejora en la performance de mercado favorece una mejora del rendimiento financiero.

Las empresas orientadas a la tecnología tienen más probabilidades de tener éxito en la innovación y alcanzar un mayor rendimiento superando a sus competidores en condiciones desfavorables de apropiabilidad de la industria (grado en que las empresas pueden apropiarse de los beneficios de sus innovaciones). Sin embargo, cuando los gerentes creen que no pueden explotar de manera suficiente los beneficios de sus innovaciones debido a condiciones de baja apropiabilidad de la industria, no están motivados lo necesario como para destinar recursos en el desarrollo de nuevas ideas y productos (Batra, Sharma, Dixit, Vohra, \& Gupta, 2015). Por ello, es importante resaltar cómo las capacidades de innovación tecnológica (capacidad de aprendizaje, capacidad de asignación de recursos y capacidad de fabricación) y ciertas capacidades de innovación de los negocios (innovación administrativa, prácticas de gestión y la estructura organizativa) se correlacionan positivamente con el rendimiento organizacional (Nor Aziati, Tasmin, Bee Jia, \& Abdullah, 2014). Además, Azubuike (2013) señala que la innovación tecnológica es una importante fuente de crecimiento y un determinante clave de ventaja competitiva para las empresas. Para alcanzar la innovación, se necesita que los diferentes miembros de la empresa coordinen sus esfuerzos e integren las actividades que se derivan de sus funciones. Sus resultados, basados en estudios de empresas de Lagos en Nigeria, evidencian la existencia de correlación entre la innovación tecnológica y el rendimiento de la empresa en el desarrollo de nuevos productos.

Hipótesis 4: Existe una asociación positiva entre la innovación en productos y el éxito de la Mipyme.

Hipótesis 5: Existe una asociación positiva entre la innovación en procesos y el éxito de la Mipyme.

Hipótesis 6: Existe una asociación positiva entre la innovación en gestión y el éxito de la Mipyme. 
Hipótesis 7: Existe una asociación positiva entre la posición tecnológica de la empresa y el éxito de la Mipyme.

\subsubsection{Los recursos humanos y el rendimiento}

Las características individuales de los propietarios o gerentes desempeñan un papel muy relevante en la gestión y rendimiento de la Mipyme. En relación con ello, diversos estudios muestran múltiples factores del empresario que afectan el éxito empresarial de las empresas:

En primer lugar, se encuentra la atención sobre sus productos o servicios, involucrados y dispuestos a continuar con el negocio, y si el empresario tiene claro su mercado y ponen atención a los detalles del mismo (Islam, Khan, Obaidullah, \& Alam, 2011). En segundo lugar, destacan las habilidades de liderazgo, habilidades de toma de decisiones, capacidad de gestión y afiliación profesional con el negocio (Jasra et al., 2011). En tercer lugar, ser un dueño o directivo de mediana edad a cargo de una Mipyme aumenta el éxito de ellas, medido por el aumento de las utilidades por empleado (Strielkowski, Abrhám, \& Herget, 2014). En cuarto lugar, la edad de los empresarios, su educación y su formación empresarial tienen un impacto positivo sobre el crecimiento de las empresas (Alom et al., 2016). La educación superior, en particular, ayuda a estimular al empresario a ejecutar planes de negocio formales y a manejar información clave del negocio. También el nivel educativo tiene un papel importante con respecto a la capacidad de conocimiento empresarial, y la habilidad para acceder y ajustar a los recursos externos y formar la base de un razonamiento analítico o la respuesta racional a los problemas (Tangkittipaporn, 2010). Adicionalmente a la educación, la experiencia de los dueños o administradores también está muy relacionado con el rendimiento de la empresa (Soriano \& Castrogiovanni, 2012). En quinto lugar, las competencias empresariales (que incluye a las habilidades del empresario medida por la capacidad de percepción de los empresarios y de las oportunidades que percibe, y la personalidad del empresario, aspecto en el cual se considera su miedo al fracaso y su modelo de conducta) tienen una relación significativa con el rendimiento del negocio (Barazandeh, Parvizian, Alizadeh, \& Khosravi, 2015). Finalmente, la orientación empresarial puede ayudar a explicar el rendimiento de la empresa, en aspectos como: la innovación, la proactividad y la asunción de riesgos en la actividad empresarial (Price \& Stoica, 2015).

No obstante, estudios como el de Afza (2011) en base a una muestra de 182 empresas familiares de Malasia, revelan que los propietarios jóvenes se desempeñan mejor que los propietarios de mayor edad. Los propietarios jóvenes son más agresivos 
en su intento de incrementar el valor de la empresa. Y el trabajo de Waelchli \& Zeller (2013) encuentra que hay una relación estadística significativa y negativa entre la edad del directivo de la empresa y su rentabilidad. Dicho efecto negativo empieza en torno a los 50 años de edad, cuyo motor es el deterioro de las capacidades cognitivas de la persona y por los cambios importantes en la motivación. A partir de estos argumentos se plantean las siguientes hipótesis:

Hipótesis 8: Existe una relación positiva entre la educación del gerente y el éxito de la Mipyme.

Hipótesis 9: Existe una relación positiva entre la experiencia profesional del gerente y el éxito de la Mipyme.

La buena praxis en la gestión de los recursos humanos influye en el éxito de las empresas. Una adecuada gestión de los recursos humanos incluye desde un sistema de reclutamiento y selección de personal, hasta la política de desarrollo de su personal, además de incluir un sistema de evaluación de puestos y de política salarial y de incentivos, y un sistema de entrenamiento y capacitación del personal, así como sus relaciones individuales y colectivas de trabajo. La Mipyme y en general muchas empresas por la forma como están estructuradas organizacionalmente, por su tamaño o por costos no han implementado en su Área de Recursos Humanos sistemas que incluyan en su totalidad las buenas prácticas de gestión; sin embargo, muchas de ellas tratan de tener lo mínimo indispensable para funcionar y las que incluyen en su gestión muchos de estos tópicos, no identifican o no se concentran en aquellas que pueden influir significativamente en el rendimiento de su organización. La Mipyme más exitosa recurre en mayor medida a determinados grupos de prácticas de gestión de recursos humanos (Fabi, Raymond, \& Lacoursière, 2007). Entre las distintas prácticas aquellas vinculadas con la integración (características del trabajo, reclutamiento y evaluación del desempeño) se relacionan con el crecimiento de las ventas, mientras que las prácticas asociadas con la consulta a los empleados frente a los problemas operacionales están más vinculadas con el desarrollo de la innovación de las empresas (Fabi et al., 2007).

Zheng, O’Neill, \& Morrison (2009) en un estudio de 74 Pymes de China encuentran cómo las prácticas de recursos humanos influyen en el rendimiento de la empresa (incremento de las ventas, incremento de participación en el mercado y potencial de crecimiento). Los resultados que obtienen muestran que en la medida en que las empresas han adoptado prácticas innovadoras de recursos humanos, está estrechamente relacionado con los resultados de los recursos humanos y el rendimiento de la empresa. En el trabajo efectuado por King-Kauanui, Ngoc, \& Ashley-Cotleur (2006) 
en base a Pymes manufactureras de Hanoi, encuentran que existe una relación significativa entre la compensación de incentivos y el rendimiento de la empresa, seguido por el efecto positivo que tiene el entrenamiento de personal en el rendimiento de éstas. También aquellas empresas que tienen desarrollado un sistema de compensación a los empleados tiene relación con su rendimiento (Pratono \& Mahmood, 2015). De esta forma se plantea la siguiente hipótesis:

Hipótesis 10: Existe una relación positiva entre las prácticas de recursos humanos y el éxito de la Mipyme.

\subsection{METODOLOGÍA}

\subsubsection{Datos}

La muestra utilizada, 94 Mipymes de Perú, procede de la base de datos del proyecto "Análisis Estratégico para el Desarrollo de la MPYME en Iberoamérica" realizado por FAEDPYME. El sistema de envío y recogida de información se realizó vía telefónica, utilizando como soporte un cuestionario auto administrado dirigido al gerente de la empresa. Este tipo de encuesta cuenta con la ventaja de la mayor accesibilidad a muestras de ámbito nacional a un coste unitario más reducido (Sarabia, 1999). Los datos fueron extraídos de la Base de Datos de la Superintendencia Nacional de Administración Tributaria (SUNAT). En la muestra no se incluyeron empresas de 5 o menos trabajadores. El trabajo de campo se realizó durante los meses de septiembre a diciembre del 2011. La composición de las empresas que conforman la muestra se puede ver en la Tabla 2.1.

La selección de las variables es fundamental a la hora de configurar el análisis empírico y nos permitirá afrontar adecuadamente el estudio del comportamiento de la Mipyme. Para obtener la información de las variables se elaboró un cuestionario dirigido al director, dueño o gerente de la empresa. Con esta herramienta se ha buscado recoger de forma clara y concisa la información fundamental que constituye el objetivo de esta investigación. En su elaboración se ha cuidado especialmente la estructuración del mismo, una redacción adecuada y sencilla y, sobre todo, un contenido breve. Antes de la aplicación definitiva se llevó a cabo una prueba piloto en siete empresas de distintos sectores, con el propósito de afinar el instrumento de medición para la aplicación definitiva. 
Tabla 2.1. Composición de las empresas de la muestra

\begin{tabular}{|l|c|c|}
\hline \multicolumn{1}{|c|}{ Sector } & $\begin{array}{c}\text { Número de } \\
\text { empresas }\end{array}$ & $\begin{array}{c}\text { Porcentaje de } \\
\text { empresas }\end{array}$ \\
\hline Industria & 63 & 67,0 \\
\hline Comercio & 16 & 17,0 \\
\hline Servicios & 15 & 16,0 \\
\hline Total & $\mathbf{9 4}$ & $\mathbf{1 0 0}$ \\
\hline Fuente: Elaboración propia.
\end{tabular}

\subsubsection{Variable dependiente}

El éxito o rendimiento de la empresa es un concepto amplio y heterogéneo y no existe un claro consenso en la literatura en cuanto a su forma de medición (Estrada, García-Pérez-de-Lema, \& Sánchez, 2009; Venkatraman \& Ramanujam, 1986). La tendencia más extendida es utilizar indicadores de tipo financiero como la rentabilidad, productividad y crecimiento de ventas (Lu \& Beamish, 2006; Hudson et al., 2001; Gómez-Conde, López-Valeiras, \& González-Sánchez, 2014). Sin embargo, estas medidas tienen la dificultad de que las empresas están poco dispuestas a compartir este tipo de información. Para algunos autores el rendimiento medido de forma cualitativa puede mostrar de manera más objetiva la rentabilidad de la empresa (Zahra, Neubaum, \& Naldi, 2007; Okamuro, 2007).

En esta investigación el nivel de rendimiento se midió utilizando una escala de Likert de 5 puntos ( $1=$ total desacuerdo y $5=$ total acuerdo) para definir sobre si la empresa en comparación con sus competidores: a) está creciendo más; b) es más rentable; y c) es más productiva. Para verificar la fiabilidad de esta escala se determinó el alfa de Cronbach, que obtuvo un valor de 0,779. Asimismo, para ver la validez del concepto se realizó un análisis factorial, mediante el cual se observó que las cargas factoriales, el coeficiente KMO y la prueba de esfericidad de Bartlett validan el indicador de rendimiento. Los resultados se observan en la Tabla 2.2.

A partir de esta información se construyó una nueva variable para calcular el promedio de estas tres variables. Posteriormente se realizó un análisis cluster para llevar a cabo una segmentación de esta variable en dos grupos, de forma que fueran significativamente diferentes. Esta variable final de éxito es dicotómica: valor 1= empresas de alto rendimiento y valor $0=$ para empresas de bajo rendimiento. El grupo 1 de empresas de alto rendimiento lo componen 60 empresas y el grupo 0 está compuesto por 34 empresas. 
Tabla 2.2. Validación de las escalas tipo Likert

\begin{tabular}{|l|l|}
\hline Rendimiento & Alfa de Cronbach= 0,779 \\
& Factorial= 1 factor \\
& Varianza explicada= 69,608\% \\
& Sig. Bartlett= ,000 \\
& KMO= 0,579 \\
\hline Prácticas de recursos humanos & Alfa de Cronbach= 0,850 \\
& Factorial= 1 factor \\
& Varianza explicada= 54,323\% \\
& Sig. Bartlett= ,000 \\
& KMO= 0,856 \\
\hline Sistemas de control de gestión & Alfa de Cronbach= ,815 \\
& Factorial= 1 factor \\
& Varianza explicada $=73,549 \%$ \\
& Sig. Bartlett= ,000 \\
& KMO= 0,665 \\
\hline Fuente: Elaboración propia. & \\
\hline
\end{tabular}

\subsubsection{Variables independientes}

\subsubsection{Planeación estratégica y sistemas de control comercial}

La planificación estratégica influye positivamente en el rendimiento de la Mipyme y juega un papel importante para que la empresa logre una ventaja competitiva (Appiah, Pesakovic, \& Amaria, 2008; Idar, Yusoff, \& Mahmood, 2012). Las empresas que hacen esfuerzos por alcanzar una planificación flexible pueden desarrollar una sensibilidad extra y tener una reacción rápida a los diferentes tipos de cambios en el entorno, al margen de la relevancia estratégica que tenga sus esfuerzos. La Mipyme concentrada en lograr beneficios en el presente, deberían centrarse en la noción de adaptabilidad para asegurar su estabilidad y sobrevivencia (Alpkan, Yilmaz, \& Kaya, 2007). En este sentido, las empresas deberían ver a la planificación estratégica más como un proceso que ayuda a los resultados empresariales, que como un proceso deliberado y formal (Glaister et al., 2008).

En el cuestionario se les preguntó a los gerentes si la empresa contaba con un plan estratégico ( $1=$ con plan estratégico y $0=$ sin plan estratégico), esta variable se midió de acuerdo con estudios llevados a cabo anteriormente (Idar et al., 2012). También se preguntó respecto del grado de utilización de sistemas de control de gestión (contabilidad de costes, presupuesto de caja y análisis financiero) usando la escala de Likert de 5 puntos (1= no mucho y $5=$ mucho). A partir de estos conceptos se construyó la variable denominada sistemas de control gestión global utilizada en estudios previos 
(García-Pérez-de-Lema, Marin, \& Martínez, 2006; Esparza, García-Pérez-de-Lema, \& Duréndez, 2009).

\subsubsection{Calidad}

La estrategia de la calidad se ha convertido en la actualidad en un aspecto imprescindible para competir en el mercado y es determinante de la competitividad y el éxito de la empresa (Bayati \& Taghavi, 2007; Aba, Badar, \& Hayden, 2016). La calidad se midió como una variable binaria (dummy), en la que se asignó el valor de 1 cuando la empresa posee certificación de calidad o está en proceso de obtenerla y 0 cuando no dispone de certificación de calidad.

\subsubsection{Innovación y posición tecnológica}

La innovación y la posición tecnológica de la organización son muy importantes para la competitividad y la rentabilidad de la Mipyme. Numerosos estudios han concluido que las empresas que adquieren una tecnología más avanzada y son innovadoras, aumentan su productividad y tienen la posibilidad de competir en un entorno más dinámico (Baldwin \& Sabourin, 2002). En nuestro trabajo la innovación se midió utilizando variables dicotómicas ( $1=$ si y $0=$ no), preguntando a las empresas (1) si realizan cambios o mejoras en productos o servicios; (2) si comercializan nuevos productos/servicios; (3) si realizan cambios o mejoras en los procesos de producción/servicios; (4) si adquieren nuevos bienes de equipo que permiten mejorar los procesos; (5) si realizan cambios sistemas de gestión para la dirección y gestión; (6) si realizan cambios en los sistemas de gestión de compras y aprovisionamientos; y (7) si realizan cambios en los sistemas de gestión de comercial y de ventas.

Respecto de la posición tecnológica se midió utilizando la misma metodología de la AECA (2005). Esta escala se divide en dos categorías: (1) fuerte o buena posición tecnológica (la empresa desarrollada o adquiere tecnología y se esfuerza por lograr mejores resultados que los competidores) y (2) sostenible o débil posición tecnológica (la tecnología utilizada es similar o inferior a la de la competencia). La posición tecnológica es por tanto una variable binaria que asume un valor de 1 cuando la empresa tiene una posición tecnológica fuerte y 0 cuando la empresa tiene una posición tecnológica débil. 


\subsubsection{Formación, edad del gerente y prácticas de recursos humanos}

Muchas características de los directivos están relacionadas con el rendimiento de la empresa, en especial su edad, como proxi de la experiencia, y su nivel de formación ( Biju, Bhasi, \& Madhu, 2012; Molodchik, Jardon, \& Barajas, 2015). La experiencia previa del empresario antes de tener en propiedad una Mipyme y los adquiridos con el paso del tiempo, están positivamente relacionados con la rentabilidad y la productividad de la Mipyme (Soriano \& Castrogiovanni, 2012). Las prácticas de recursos humanos se relacionan positivamente con el clima social de la empresa, facilitan el aprendizaje y permiten lograr un mejor rendimiento de la empresa (Prieto \& Pérez Santana, 2012). La implementación de prácticas de recursos humanos (proceso de contratación, formación, desarrollo profesional y evaluación) mejoran la rentabilidad, la satisfacción del cliente, el crecimiento de las ventas, la moral de los empleados y la participación del mercado (Appiah et al., 2008).

\subsubsection{Variables de control}

\subsubsection{Tamaño, edad de la empresa y sector}

El tamaño de la empresa se mide como el valor medio del número de empleados. Dicho tamaño está significativamente relacionado con la rentabilidad y la productividad de la empresa (Silva \& Maçãs, 2008; Magoutas, Agiomirgianakis, \& Papadogonas, 2011; Soriano \& Castrogiovanni, 2012; Li \& Zhu, 2015). Las empresas grandes son capaces de usar una mayor cantidad de recursos intangibles y de aplicar mayor variedad de herramientas de gestión del conocimiento y capital intelectual y esto conlleva un mayor rendimiento (Molodchik et al., 2015). La edad de la empresa se midió sobre la base del número de años que lleva funcionando la empresa. Soriano \& Castrogiovanni (2012) y Li \& Zhu (2015) muestran cómo la edad de la empresa tiene una relación significativa con la rentabilidad. En el sector de actividad se distinguieron Mipymes de industria manufacturera, comercio y servicios. Determinados autores ponen de manifiesto la existencia de diferencias sectoriales en rendimiento y productividad (Calvo, 2006; Claver, Molina, \& Quer, 2000).

\subsection{ANÁLISIS DE RESULTADOS}

\subsubsection{Análisis univariante}

Al objeto de conocer cuáles son los factores más relevantes para obtener un mayor rendimiento o el éxito competitivo de la Mipyme, analizaremos las diferencias de 
comportamiento entre los grupos de empresas de "alto rendimiento" y "bajo rendimiento". En primer lugar realizaremos un análisis estadístico univariante a través de: (1) un análisis ANOVA para variables continuas y la prueba de Kruskall-Wallis cuando la hipótesis de normalidad y homogeneidad de varianza no fueron encontradas y (2) un análisis de contingencia, basado en la $x^{2}$ de Pearson para las variables categóricas y la prueba de Yates en tablas de $2 \times 2$.

La Tabla 2.3. muestra el análisis para los grupos de "alto rendimiento" y "bajo rendimiento" para las variables "realiza plan estratégico" y "utilización de sistemas de control de gestión". Los resultados muestran que el $71,7 \%$ de las empresas del grupo de alto rendimiento realizan plan estratégico, frente al 58,8\% del grupo de bajo rendimiento. No obstante, esta diferencia no resulta significativa por lo que no podemos confirmar la H1 planteada en la investigación. En relación con el grado de utilización de los sistemas de control de gestión podemos apreciar cómo las Mipymes con mayor rendimiento utilizan en mayor medida tanto los sistemas de contabilidad de costes, como los presupuestos de ingresos y gastos anuales y el diagnóstico económico y financiero (con un nivel de significación del 1\%), por lo que se confirma la H2. Asimismo, se confirma que la utilización de sistemas de control de gestión favorece el éxito de la Mipyme.

Tabla 2.3. Plan estratégico y sistemas de control de gestión $(n=94)$

\begin{tabular}{|c|c|c|c|}
\hline Variables & $\begin{array}{l}\text { Bajo } \\
\text { rendimiento }\end{array}$ & $\begin{array}{l}\text { Alto } \\
\text { rendimiento }\end{array}$ & Significación \\
\hline$\%$ de empresas con plan estratégico & 58,8 & 71,7 & 0,148 \\
\hline $\begin{array}{l}\text { Implantación y control de un sistema de } \\
\text { contabilidad de costos }\end{array}$ & 3,00 & 3,92 & $0,001^{* \star *}$ \\
\hline $\begin{array}{l}\text { Establecimiento de presupuestos de ingresos } \\
\text { y gastos anuales }\end{array}$ & 2,97 & 3,97 & $0,000 * * *$ \\
\hline Análisis de la situación económico-financiera & 3,32 & 4,13 & $0,001^{* * *}$ \\
\hline SISTEMAS DE CONTROL DE GESTIÓN & 3,09 & 4,00 & $0,000 * * *$ \\
\hline \multicolumn{4}{|c|}{$\begin{array}{l}\text { Prueba para verificar la significación de las variables: } \\
\text { Para variable con promedio (escala Likert: } 1=\text { nunca utiliza a } 5=\text { siempre utiliza): F-test (ANOVA) } \\
\text { Para variable categórica: } x^{2} \text { de Pearson (Prueba de Yates en tablas de } 2 \times 2 \text { ) } \\
{ }^{*}: p \leq 0.1 ;{ }^{* *}: p \leq 0.05 ;{ }^{* * *}: p \leq 0.01 \\
\text { Fuente: Elaboración propia. }\end{array}$} \\
\hline
\end{tabular}

En la Tabla 2.4. se analiza el impacto de la certificación de la calidad, de la innovación y la posición tecnológica en el éxito competitivo de la Mipyme. El 40\% de las Mipymes de alto rendimiento certifican calidad o están inmersas en este proceso, frente al $23,5 \%$ del grupo de bajo rendimiento. Esta diferencia resulta significativa al $10 \%$, por 
lo que se acepta la H3, aunque debido al bajo nivel de significación estos datos debamos tomarlos con cautela. En cuanto a la innovación, aunque en todos los tipos de analizados (productos, procesos y gestión) el grupo de Mipymes de alto rendimiento ha realizado en mayor porcentaje estas innovaciones, no se obtienen diferencias estadísticamente significativas por lo que no se pueden validar las $\mathrm{H} 4, \mathrm{H} 5$ e H6. Adicionalmente, los resultados muestran que el factor tecnológico es relevante para la competitividad de la Mipyme. El 71,7\% de las Mipymes de alto rendimiento disponen de una posición tecnológica fuerte o buena, frente al 52,9\% del grupo de bajo rendimiento (nivel de significación: 0,055, significativa al 10\%). A partir de ello, podemos confirmar la $\mathrm{H} 7$.

Tabla 2.4. Calidad, innovación y tecnología $(n=94)$

\begin{tabular}{|c|c|c|c|}
\hline Variables & $\begin{array}{l}\text { Bajo } \\
\text { rendimiento }\end{array}$ & $\begin{array}{l}\text { Alto } \\
\text { rendimiento }\end{array}$ & Significación \\
\hline $\begin{array}{l}\text { \% empresas que tienen certificación de } \\
\text { calidad }\end{array}$ & 23,5 & 40,0 & $0,081^{*}$ \\
\hline $\begin{array}{l}\text { \% empresas que realizan cambios o mejoras } \\
\text { en productos o servicios }\end{array}$ & 77,8 & 80,4 & 0,502 \\
\hline $\begin{array}{l}\text { \% empresas que comercialización nuevos } \\
\text { productos/servicios }\end{array}$ & 66,7 & 78,4 & 0,194 \\
\hline $\begin{array}{l}\text { \% empresas que realizan cambios o mejoras } \\
\text { en los procesos de producción/servicios }\end{array}$ & 78,4 & 85,2 & 0,345 \\
\hline $\begin{array}{l}\text { \% empresas que adquieren nuevos bienes de } \\
\text { equipo que permiten mejorar los procesos }\end{array}$ & 66,7 & 80,4 & 0,143 \\
\hline $\begin{array}{l}\text { \% empresas que realizan cambios sistemas } \\
\text { de gestión para la dirección y gestión }\end{array}$ & 51,9 & 56,9 & 0,426 \\
\hline $\begin{array}{l}\text { \% empresas que realizan cambios en los } \\
\text { sistemas de gestión de compras y } \\
\text { aprovisionamientos }\end{array}$ & 55,6 & 58,8 & 0,484 \\
\hline $\begin{array}{l}\text { \% empresas que realizan cambios en los } \\
\text { sistemas de gestión comercial y de ventas }\end{array}$ & 51,9 & 58,8 & 0,362 \\
\hline $\begin{array}{l}\% \text { empresas que tienen posición tecnológica } \\
\text { fuerte o buena }\end{array}$ & 52,9 & 71,7 & $0,055^{\star}$ \\
\hline \multicolumn{4}{|c|}{$\begin{array}{l}\text { Prueba para verificar la significación de las variables: } \\
\text { Para variable categórica: } x^{2} \text { de Pearson (Prueba de Yates en tablas de } 2 \times 2 \text { ) } \\
{ }^{*}: p \leq 0.1 ;{ }^{* *}: p \leq 0.05 ;{ }^{* * *}: p \leq 0.01 \\
\text { Fuente: Elaboración propia. }\end{array}$} \\
\hline
\end{tabular}

Los resultados que se recogen en la Tabla 2.5. hacen referencia a la formación y la edad del gerente. La formación del gerente no resultó significativa por lo que no encontramos soporte a la H8. Sin embargo, la edad del gerente, como proxy de la experiencia, si arrojan resultados significativos. La edad media del grupo de empresas de alto rendimiento es de 50,8 años frente a las 45,1 del grupo de bajo rendimiento 
(diferencia significativa al 5\%). De esta forma se confirma la $\mathrm{H} 9$ al verificar que la experiencia profesional del gerente explica el éxito de la Mipyme.

Tabla 2.5. Características del gerente $(n=94)$

\begin{tabular}{|l|c|c|c|}
\hline Variables & $\begin{array}{c}\text { Bajo } \\
\text { rendimiento }\end{array}$ & $\begin{array}{c}\text { Alto } \\
\text { rendimiento }\end{array}$ & Significación \\
\hline$\%$ de gerentes que tienen título universitario & 75,8 & 66,1 & 0,234 \\
\hline$\%$ de edad del Director General/Gerente (años) & 45,1 & 50,8 & $0,012^{\star *}$ \\
\hline $\begin{array}{l}\text { Prueba para verificar la significación de las variables: } \\
\text { Para variable con promedio: F-test (ANOVA) } \\
\text { Para variable categórica: } x^{2} \text { de Pearson (Prueba de Yates en tablas de 2x2) } \\
*: p \leq 0.1 ; * \text { : } p \leq 0.05 ; * * *: 0.01 \\
\text { Fuente: Elaboración propia. }\end{array}$ \\
\hline
\end{tabular}

Las prácticas de gestión de recursos humanos (Tabla 2.6.) favorecen la competitividad de la Mipyme. En efecto en casi todas las prácticas analizadas existen diferencias estadísticamente significativas. En especial y significativas al 1\% destacan la planificación de personal, la formación del personal, la evaluación del desempeño y la política retributiva. De esta forma se confirma la $\mathrm{H} 10$ al existir una relación positiva y significativa entre las prácticas de recursos humanos y el éxito competitivo de la Mipyme. 
Tabla 2.6. Gestión de recursos humanos $(n=94)$

\begin{tabular}{|c|c|c|c|}
\hline Variables & $\begin{array}{l}\text { Bajo } \\
\text { rendimiento }\end{array}$ & $\begin{array}{l}\text { Alto } \\
\text { rendimiento }\end{array}$ & Significación \\
\hline Planificación de personal & 2,94 & 4,03 & 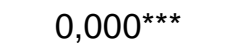 \\
\hline Diseño de puestos de trabajo & 2,94 & 3,58 & $0,031^{\star \star}$ \\
\hline Reclutamiento y selección de personal & 3,21 & 3,83 & $0,024^{\star \star}$ \\
\hline Formación & 3,12 & 4,05 & $0,001^{\star \star \star}$ \\
\hline Desarrollo de carreras profesionales & 2,79 & 3,62 & $0,005^{\star \star \star}$ \\
\hline Evaluación del desempeño & 3,12 & 3,98 & $0,001^{* \star *}$ \\
\hline Política retributiva & 2,82 & 3,70 & $0,003^{\star \star \star}$ \\
\hline $\begin{array}{l}\text { Administración de personal (contratos, } \\
\text { nóminas, ...) }\end{array}$ & 3,44 & 3,87 & 0,118 \\
\hline $\begin{array}{l}\text { Relaciones laborales (negociación del } \\
\text { convenio colectivo, relaciones con los } \\
\text { representantes sindicales) }\end{array}$ & 2,26 & 3,18 & $0,006^{\star \star *}$ \\
\hline $\begin{array}{l}\text { Gestión de la prevención de riesgos laborales, } \\
\text { seguridad y salud laboral }\end{array}$ & 3,32 & 3,87 & $0,051^{*}$ \\
\hline RECURSOS HUMANOS GLOBAL & 2,99 & 3,77 & $0,000 * * *$ \\
\hline \multicolumn{4}{|c|}{$\begin{array}{l}\text { Prueba para verificar la significación de las variables: } \\
\text { Para variable con promedio (escala Likert: 1=Nunca utiliza a } 5=\text { Siempre utiliza): F-test (ANOVA) } \\
*: p \leq 0.1 ; * *: p \leq 0.05 ; * * *: p \leq 0.01\end{array}$} \\
\hline
\end{tabular}

Finalmente, analizamos las variables de control consideradas, tamaño de la empresa, edad y sector de actividad (Tabla 2.7.). El tamaño medido por el promedio de empleados resultó significativo. Las Mipymes de alto rendimiento se caracterizan por ser de mayor tamaño que las de bajo rendimiento (significativa al 90\%), mientras que las variables edad y sector no arrojaron diferencias estadísticamente significativas.

Tabla 2.7. Tamaño, edad de la empresa y sector $(n=94)$

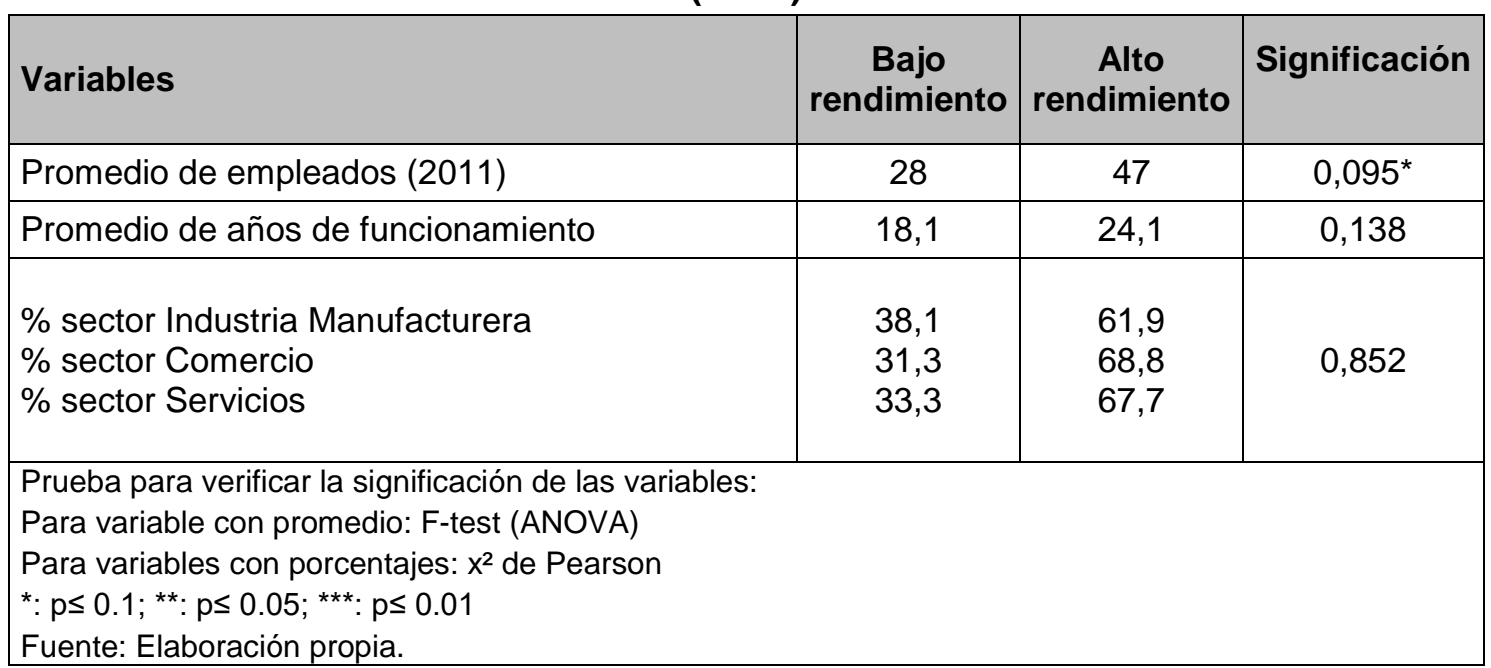




\subsubsection{Análisis multivariante}

Finalmente se llevó a cabo un análisis multivariante con el propósito de estudiar las posibles interrelaciones de las variables analizadas. Para tal efecto, se optó por la regresión logística por el método de Wald. La elección de esta técnica estadística obedece, por una parte, a que la variable dependiente es binaria y cualitativa; y por otra, a que la mayoría de las variables independientes consideradas no siguen una distribución normal. En el modelo de regresión logística se incluyeron las variables que resultaron significativas en el análisis univariante. Para determinar la validez del modelo se calculó el test de verosimilitud, para encontrar la estimación más probable de los coeficientes, la medida de Hosmer y Lemeshow de ajuste global, el porcentaje global de acierto en la clasificación y la bondad del ajuste a través de los estadísticos de $\mathrm{R}^{2}$ alternativos de Cox y Snell y el estadístico de Nagelkerke. Las pruebas estadísticas realizadas confirman la validez de los resultados obtenidos (Tabla 2.8.).

Tabla 2.8. Regresión logística por el método de Wald $(n=94)$

\begin{tabular}{|c|c|c|c|c|c|}
\hline Variables Independientes & B & S.E. & Wald & Sig. & $\operatorname{Exp}(B)$ \\
\hline Recursos humanos global & 0,904 & 0,333 & 7,354 & 0,007 & 2,468 \\
\hline Sistemas de control de gestión & 0,681 & 0,269 & 6,420 & 0,011 & 1,976 \\
\hline Constante & $-4,911$ & 1,296 & 14,361 & 0,000 & 0,007 \\
\hline \multicolumn{6}{|c|}{$\begin{array}{l}\text { Variable introducida en el paso 1: Recursos humanos global } \\
\text { Variable introducida en el paso 2: Sistemas de control de gestión } \\
\text { Variable dependiente (Dummy): Empresas de alto rendimiento=1; empresas de bajo rendimiento= } 0\end{array}$} \\
\hline \multicolumn{6}{|c|}{$\begin{array}{l}\text { Notas: B: Coeficientes logísticos, son empleados para medir los cambios en los ratios de } \\
\text { probabilidades, denominado odds ratio. Un coeficiente positivo incrementa la probabilidad pronosticada, } \\
\text { mientras un valor negativo disminuye la probabilidad predicha. S.E.: error estándar. Wald: estadístico } \\
\text { de Wald. Sig.: nivel de significación. Exp(B): coeficiente exponenciado. La significación estadística del } \\
\text { modelo se ha determinado utilizando la medida de Hosmer Lemeshow de ajuste global donde se obtiene } \\
\text { un contraste estadístico que indica que no existe diferencia estadística significativa entre las } \\
\text { clasificaciones observadas y predichas, ya que el valor de la Chi-cuadrado no es significativo (Chi- } \\
\text { cuadrado: } 7,903 \text {, sig.: } 0,443) \text {. Como medida de calidad de ajuste obtenemos un porcentaje global de } \\
\text { acierto del } 73,4 \% \text { si usamos el modelo con función clasificatoria. Resumen del modelo: }-2 \text { log likelihood: } \\
97,766 ; \mathrm{R}^{2} \text { de Cox y Snell: } 0,236 \text {; } \mathrm{R}^{2} \text { de Nagelkerke: } 0,323 \text {. Adicionalmente, como medida global de } \\
\text { ajuste el valor de la prueba omnibus sobre los coeficientes del modelo es significativa (Chi-cuadrado: } \\
25,260 \text { y sig.: } 0,000 \text { ) }\end{array}$} \\
\hline
\end{tabular}

Los resultados de la regresión logística se presentan en la Tabla 2.8. El modelo estimado por el método de Wald presenta un coeficiente positivo y significativo asociado con la variable prácticas de recursos humanos (Coef. B: 0,904; Exp (B): 2,468; sig: 0,007) y con la variable sistemas de control de gestión (Coef. B: 0,681; Exp (B): 1,976; 
sig: 0,011). Esto implica que a mayor utilización en la Mipyme de prácticas de recursos humanos y de sistemas de control de gestión mayor es la probabilidad de que la Mipyme sea exitosa. Estos resultados consolidan a nivel multivariante las $\mathrm{H} 2 \mathrm{e} \mathrm{H10}$. Ambos factores conjuntamente son los que tienen un mayor poder explicativo del éxito de la Mipyme en Perú.

\subsection{CONCLUSIONES}

El objetivo de este trabajo ha sido analizar los factores determinantes del éxito competitivo de la Mipyme en Perú siguiendo el enfoque de la teoría de los recursos y capacidades. Para ello se ha realizado un estudio empírico sobre 94 Mipymes peruanas. Desde el punto de vista univariante, los resultados muestran que las empresas más exitosas se caracterizan por tener más desarrollados los sistemas de control de gestión, utilizar una tecnología de sus procesos más avanzados, certificar la calidad de sus productos o servicios y aplicar métodos de gestión de recursos humanos más avanzados. Adicionalmente, el tamaño de la Mipyme y la experiencia del gerente tienen una relación positiva con el éxito competitivo. Desde el punto de vista multivariante, las Mipymes peruanas que mayor probabilidad tienen de ser exitosas son las que combinan más apropiadamente la gestión de sus recursos humanos y disponen de sistemas de control de gestión en su organización más desarrollados.

Los resultados del estudio tienen importantes implicaciones y pueden ayudar a los empresarios peruanos para favorecer un entorno que repercuta en una mejora de la competitividad de sus empresas. Conocer los factores de éxito de las organizaciones y las buenas prácticas de gestión marcan el camino a los empresarios para incrementar su rendimiento y favorecer la supervivencia de la Mipyme. También resulta de utilidad a los organismos públicos y privados que fomenten la competitividad de la Mipyme. Los resultados obtenidos en nuestro trabajo pueden servir para incentivar programas de formación gerencial que incluyan aspectos relativos al éxito competitivo o propiciar programas de ayudas públicas orientados hacia los principales factores que expliquen el rendimiento de la Mipyme. En el caso de Perú es especialmente relevante dado el impulso económico que se está produciendo en los últimos años y que la Mipyme ha contribuido especialmente a este fuerte dinamismo.

Este trabajo no está exento de limitaciones que pueden ser potenciales vías de investigación futuras. En primer lugar, la muestra utilizada es muy reducida. Futuros estudios con muestras más amplias deberían permitir reforzar nuestros resultados. En segundo lugar, no se ha considerado aspectos relativos al entorno y el ambiente 
externo. Nuestro trabajo se ha desarrollado desde la perspectiva de la teoría de los recursos y capacidades, pero no hemos considerado la dinámica del entorno y del mercado. Determinados autores encuentran que hay una relación entre el ambiente externo y el éxito de la Mipyme (Chittithaworn et al., 2011; Sandada, 2014). Factores como la regulación del mercado de divisas, las normas fiscales, los procedimientos burocráticos y la protección de los intereses comerciales privados pueden afectar a las empresas y deberían considerarse en futuros trabajos (Shappo \& Knuth, 2014; Jasra et al., 2011). La demanda del producto o servicio, y la disponibilidad de espacio físico para la expansión de los negocios en el área de la ciudad también desempeñan un papel importante a la performance general de estos (Alom et al., 2016). En tercer lugar, otros factores internos a la empresa no han sido considerados y podrían extenderse en futuras investigaciones. Factores internos como las estrategias de marketing y la comercialización de los productos o servicios también contribuyen al éxito de las Mipymes (Jasra et al., 2011). La capacidad de comercialización entendida como la capacidad de manejar estrategias de marketing que abarca la fijación de precios, la venta, la comunicación y el desarrollo de productos tienen efectos positivos sobre la performance de la empresa (Pratono \& Mahmood, 2015). 
3. FACTORES DETERMINANTES PARA EXPLICAR EL RACIONAMIENTO DE CRÉDITO: UN ESTUDIO EMPÍRICO EN EMPRESAS PERUANAS 


\subsection{INTRODUCCIÓN}

Las Mipymes (micro, pequeñas y medianas empresas) en los países en desarrollo tienen un acceso limitado a los servicios financieros formales debido a diversos problemas con las garantías (tenencia, valuación, documentación legal) y el coste relativamente alto de las transacciones de préstamos pequeños (Doan et al., 2010). En este sentido, es fundamental la disponibilidad de financiación bancaria para asegurar la viabilidad y el crecimiento de la empresa (McCarthy et al., 2013), así como la consecución de sus objetivos empresariales. Por ello, las dificultades para conseguir recursos financieros para invertir en nuevos proyectos pueden no solo afectar su crecimiento sino también su supervivencia en el mercado. Las restricciones de financiación tienen por tanto un efecto negativo sobre el crecimiento potencial de las empresas, frenando con ello la diversificación económica y la generación del empleo (Okurut et al., 2011). Así, un sistema financiero eficiente favorece el desarrollo económico de un país a largo plazo. Los países con sistemas financieros más fuertes crecen más rápido y reducen la desigualdad y la pobreza (Montoya, 2016).

La problemática del acceso a la financiación en la Mipyme se explica a través de diferentes teorías financieras clásicas como son la Teoría de la Agencia y la Teoría de la Jerarquía Financiera. Por un lado, el desarrollo de la Teoría de la Agencia permite identificar los costes de agencia, que se materializan en problemas de selección adversa: ante situaciones en las cuales el prestamista de recursos ajenos evidencia mayores riesgos y mayores problemas de información asimétrica endurece las condiciones contractuales de los préstamos, con lo cual se produce un efecto inverso al deseado, ya que esa medida atraerá sobre todo a las empresas que deseen financiar proyectos de inversión más arriesgados y más rentables, al estar en mejores condiciones para hacer frente a la subida del coste de la financiación. Así, cuando el riesgo percibido por los acreedores es potencialmente muy alto, los acreedores pueden preferir restringir su oferta de fondos (Stiglitz \& Weiss, 1981). Esta situación se denomina de "restricciones financieras" o "racionamiento de crédito", y ocasiona que, la mayoría de las veces, la única fuente de financiación disponible para la empresa sean los beneficios retenidos. Este problema de racionamiento de crédito se ve atenuado por el tamaño de la empresa, ya que las empresas grandes producen más información contable y financiera para los acreedores e inversores en general y, además, su monitorización supone menores costes (Fama, 1985). Por otro lado, las hipótesis de la Teoría de la Jerarquía Financiera establecen un orden preferencial en las opciones de financiación de la empresa (Myers \& Majluf, 1984). De nuevo, la clave de esta jerarquía 
es la existencia de información asimétrica que conlleva mayores costes de financiación debido a la brecha informativa entre agentes externos e internos a la empresa. En concreto, la empresa preferirá financiación interna a deuda, deuda a corto plazo sobre la deuda a largo plazo, y cualquier tipo de deuda frente a ampliaciones de capital.

Aunque, existe una amplia evidencia empírica que ha abordado la problemática del acceso a la financiación bancaria en la Mipyme, se produce un importante gap de la literatura en cuanto a estudios realizados en países en desarrollo, donde existe una débil estructura del sistema financiero. Por lo que en este contexto es necesario una mejor comprensión del comportamiento de las empresas en sus decisiones de financiación (Zabri, Ahmad, \& Lean, 2011). En particular, es especialmente interesante analizar el contexto peruano, puesto que se refiere a una economía en desarrollo que forma parte de la Alianza del Pacífico y ha experimentado un importante crecimiento económico en la última década. Su tejido empresarial está formado principalmente por micro y pequeñas empresas, que representan el $98 \%$ de las unidades productivas del país y explican el $80 \%$ del empleo y el $61 \%$ del PIB. Adicionalmente, es interesante, dado que las Mipymes peruanas se han sostenido gracias al desarrollo del microcrédito, habiendo surgido diferentes entidades financieras de apoyo a este sector como son las Cajas Municipales, las Cajas Rurales y las Entidades de Desarrollo de la Pequeña y Microempresa (EDPYMES) junto con la banca tradicional y otras entidades de fomento y de apoyo a Mipymes.

Bajo el marco de las teorías que identifican los problemas de restricciones financieras, el objeto de este trabajo se basa en identificar los principales factores estratégicos de las Mipymes que influyen en el acceso a la financiación bancaria. Para ello se lleva a cabo un estudio empírico, a partir de una muestra de 158 Mipymes peruanas, con las siguientes preguntas de investigación a responder: ¿Existen diferencias entre las empresas que tienen acceso al crédito frente a aquellas que no? ¿Cuáles son las características de las empresas y de los directivos que influyen en el mayor o menor acceso a la financiación bancaria? ¿El que las Mipymes formulen planes estratégicos formales y su estructura organizativa inciden en el racionamiento de crédito? ¿La innovación y la posición tecnológica influyen en su acceso al crédito bancario? ¿Son más rentables aquellas empresas que tienen mayor probabilidad de acceso al crédito bancario? Responder estas cuestiones resulta de especial importancia no solo para conocer los factores principales que inciden en las restricciones de crédito a las Mipymes, sino también para que las empresas identifiquen las variables que las pueda ayudar a conseguir financiación bancaria (McCarthy et al., 2013). 
Este trabajo de investigación es útil para los empresarios, las entidades financieras y el gobierno. A los empresarios les servirá para identificar y mejorar en aquellos aspectos internos al negocio (capital humano, innovación, organización y de gestión estratégica) que le ayuden a tener una mayor probabilidad de acceso a la financiación bancaria (McCarthy et al., 2013). A las entidades financieras les ayudará a comprender el papel crucial que juegan para que las Mipymes operen con normalidad y desarrollen sus proyectos. Por su parte, a los gobiernos les proporcionará un diagnóstico para implementar programas que den un mayor impulso a estas empresas para que se desarrollen y mejoren sus capacidades competitivas, al acceder con mayor probabilidad de éxito a los mercados de créditos formales (Okurut et al., 2011).

El trabajo se ha estructurado de la siguiente forma: en primer lugar, determinamos el marco teórico, se realiza una revisión de la literatura empírica previa y se delimitan las hipótesis a contrastar; en segundo lugar, exponemos la metodología, las características de la muestra y la justificación de las variables utilizadas; en tercer lugar, llevamos a cabo el análisis de los resultados, finalmente, exponemos las principales conclusiones alcanzadas.

\subsection{FACTORES DETERMINANTES DEL RACIONAMIENTO DEL CRÉDITO E HIPÓTESIS DE INVESTIGACIÓN}

Las teorías financieras clásicas como la Teoría de la Agencia y la Teoría de la Jerarquía Financiera, justifican el estudio del comportamiento de la estructura financiera de la empresa y de sus dificultades de acceso a la financiación bancaria, basándose en el paradigma de la información asimétrica, el cual hace referencia al contexto en el que la entidad financiera no cuenta con toda la información relevante en relación con las características del contratante, lo que conlleva a la incertidumbre sobre el resultado del proyecto presentado, perjudicando a la entidad crediticia derivada de su falta de información (Bebczuk, 2003).

El concepto de información asimétrica para analizar los mercados fue introducido por Akerlof (1970), señalando en el mercado crediticio, la importancia de que el acreedor tenga los medios fáciles de tutela del contrato y el conocimiento de las características del prestatario al otorgar un crédito. Asimismo, considera que el riesgo corre a cargo del otorgante y no del adquiriente cuando hay incertidumbre, el cual también se puede explicar en la relación entre prestatario y prestamista en el mercado de crédito. Siguiendo con este planteamiento inicial, autores como Stiglitz \& Weiss (1981) también han extendido el análisis de la información imperfecta en el mercado de crédito. Por un 
lado, señalan que los agentes económicos no tienen información perfecta sobre todas las opciones, y es por esto, que las condiciones de acceso al crédito a los diferentes agentes son heterogéneas. Por otro lado, suponiendo la existencia de información perfecta y gratuita, las entidades financieras podrían estipular con precisión las acciones que el prestatario debería llevar a cabo para obtener el crédito. En este sentido, las entidades financieras al ser conscientes que no son capaces de controlar directamente todas las acciones del prestatario y que no cuentan con toda la información relevante de éste, se cubren de diferentes maneras (Bebczuk, 2003), incurriendo en mayores costes por selección y evaluación de los clientes más arriesgados, así como por el seguimiento de los mismos (Okuyan, 2016). Estos costes los trasladan a los clientes, reflejándose en un aumento de la tasa de interés, lo que podría hacer que algunas empresas de bajo riesgo decidan no solicitar préstamos, ya que para ellos la nueva tasa no se justificaría para el bajo riesgo de incumplimiento del pago de la deuda (Stiglitz \& Weiss, 1981). Bajo este escenario, los prestamistas tienen una mayor preferencia por mantener el crédito racionado debido a que el mercado opera en un entorno donde la falta de información, en cuanto al conocimiento del perfil del solicitante al crédito, es escasa, así como de su proyecto. Con esto las tasas altas de los créditos ahuyentan a los prestatarios más conservadores generando el caso de selección adversa; además de atraer más prestatarios que tengan tendencias por invertir en proyectos más arriesgados, ya que las tasas son muy elevadas induciendo, una vez más al caso de riesgo moral (Holmstrom, 1982).

En particular, la información asimétrica entre prestamista y prestatario es mayor en la Mipyme al disponer de una información más opaca que las empresas de mayor tamaño. Lo que provoca una serie de obstáculos para que los recursos financieros se dirijan a las micro y pequeñas empresas. La información asimétrica induce a los bancos al problema de selección adversa, en tanto que si suben sus tasas de interés, desalientan a buenos clientes con proyectos de bajo riesgo a pedir préstamo y que estaban dispuestos a pagar menores tasas, quedándose con aquellos que presentan un mayor riesgo (Okuyan, 2016). Al conceder préstamos, se origina el problema de riesgo moral por parte de los prestatarios, debido a que al banco muchas veces no le resulta rentable una exhaustiva selección y posterior monitoreo a las empresas, destinando algunos clientes los fondos recién prestados a fines distintos a lo inicialmente acordado. El banco al percibir una mayor opacidad e incertidumbre, opta por el racionamiento de crédito, buscando reducir sus riesgos (Kundid \& Ercegovac, 2011). Ese campo de 
investigación resulta muy relevante para los académicos, empresas y para la políticas públicas (Kirschenmann, 2012).

La disponibilidad de la financiación bancaria es de vital importancia para las Mipymes para garantizar su crecimiento, competitividad y supervivencia. Por ello, se analizan a un nivel micro, las características que pueden influir en la presencia de racionamiento del crédito, tales como la edad y tamaño, la formalidad del negocio, sector al que pertenece, capital humano, estructura organizativa, actividades de innovación, si lleva a cabo planes de negocios, nivel de educación del gerente, capacidad tecnológica, entre otros.

\subsubsection{Tamaño y edad de la empresa}

Diversas investigaciones relacionan el tamaño y la edad de la empresa para explicar el racionamiento de crédito que padecen las Mipymes (Hoque, Sultana, \& Thalil, 2016; McCarthy et al., 2013; Freel, Carter, Tagg, \& Mason, 2012; Angelini, Salvo, \& Ferri, 1998).

Así, se considera ampliamente aceptado que las pequeñas empresas afrontan mayores dificultades que las grandes empresas en el mercado de crédito. Canton, Grilo, Monteagudo, \& Van der Zwan (2013), empleando datos de cerca de 3500 Mipymes de 25 países de la Unión Europea, señalan que las empresas más jóvenes y pequeñas perciben que es más difícil conseguir préstamos de los bancos que las más grandes y antiguas. Por su parte, Toçi \& Hashi (2009) sugieren que las empresas más grandes son menos propensas a que les nieguen un préstamo y afrontan menos obstáculos para obtener préstamos de corto y largo plazo. Martínez \& Londoño (2004) mencionan que los bancos al disponer de poca información sobre los prestatarios, y debido a la mayor solidez que muestran generalmente las empresas grandes frente a las pequeñas, son estas últimas son las que tienen menos acceso al crédito. Otros estudios como los de Freel (2007), Kira \& He (2012) y de Farinha \& Félix (2015) muestran que las empresas más pequeñas afrontan más restricciones de crédito que las empresas más grandes.

Por otro lado, en la literatura financiera se observa que el racionamiento de crédito es menor cuando las empresas tienen más edad. En general, la justificación se basa en el hecho que conforme la empresa madura, se reduce la información asimétrica (McCarthy et al., 2013). En este mismo sentido Kirschenmann (2012) indica que el racionamiento del crédito es mayor para las empresas más jóvenes y cuando comienzan las relaciones de la empresa con el banco. Sin embargo, según transcurra el tiempo, la relación prestatario-prestamista se fortalece por la reducción de la asimetría de 
información. Las asimetrías de información decrecen a medida que las empresas crecen en tamaño y edad, permitiendo acceder más fácilmente al crédito (Briozzo, Vigier, Castillo, Pesce, \& Speroni, 2016). Roman \& Rusu (2011) resaltan en su trabajo que algunos bancos se niegan a conceder préstamos para las Mipymes que no ofrecen las garantías debidas o que no tienen un historial de crédito, puesto que son muy jóvenes o tienen un grado de solvencia que está fuera de lo que exigen los bancos.

Según estos argumentos planteamos las siguientes hipótesis:

H1: El tamaño de la empresa influye en el acceso a la financiación de las Mipymes.

H2: Las empresas jóvenes sufren más restricciones en el acceso a la financiación que las empresas maduras.

\subsubsection{Sector}

Los diferentes sectores económicos se caracterizan por requerir diferentes estructuras de activos y capital, enfrentándose a diferentes entornos competitivos (Freel et al., 2012). Así, el sector de la industria en el que opera una empresa puede proporcionar información sobre el nivel de riesgo del futuro de la empresa. Ferri \& Jones (1979) señalan que empresas ubicadas en el mismo sector deberían afrontar similares riesgos del negocio. Además, como el entorno y las situaciones económicas externas son también similares, la influencia de estos aspectos tanto en el crecimiento como en las utilidades del negocio son semejantes (Kira \& He, 2012). Por tanto, los bancos pueden restringir más el crédito a empresas de determinados sectores que a otros. De forma que, la heterogeneidad de las empresas tiene un considerable impacto sobre los mecanismos de racionamiento de crédito (Ata, Korpi, Ugurlu, \& Sahin, 2015).

En este sentido, Kira \& He (2012) encuentran que hay una relación significativa entre el sector al que pertenece la empresa y el acceso a la financiación. Por su parte, Briozzo et al. (2016) muestran que el sector servicios tiene en su estructura de activos una menor proporción de activos tangibles que el resto de sectores. Por ello, al contar con diferentes recursos, las instituciones financieras pueden ver distintos efectos en las empresas de cada sector e influir en sus decisiones de otorgamiento de préstamos y por ende en un probable racionamiento a empresas de determinado un sector. McCarthy et al. (2013) muestran la existencia de una relación significativa diferenciada en las empresas que se dedican a la agricultura frente a los sectores industria y servicios, en referencia al éxito de obtener un préstamo. Okurut et al. (2011) encuentran que las empresas del sector bienes raíces, servicios financieros y de hotelería tienen mayor 
probabilidad de tener racionamiento de crédito. Freel et al. (2012) sugieren que las empresas del sector de servicios más intensivas en conocimiento tienen un mayor racionamiento de crédito. Una explicación a este hecho se puede basar en que las empresas de producción y del sector mayorista y minorista poseen tradicionalmente más activos físicos que puedan servir como garantías, mientras que los de servicios intensivos en conocimientos poseen recursos más de tipo intangible (Tether, 2005).

Según los argumentos planteamos la siguiente hipótesis a contrastar es:

H3: El sector al cual pertenece la empresa influye en su acceso a la financiación bancaria.

\subsubsection{Carácter familiar y forma legal}

Barton \& Matthews (1989) comprueban que las empresas familiares se financian de forma preferente con beneficios no distribuidos, más que con endeudamiento externo o con la entrada de nuevos accionistas. El origen de esta preferencia hay que buscarlo en la aversión al riesgo, por el miedo de la familia a perder el control de la empresa, cuando no se puede hacer frente a la deuda o cuando entran a formar parte del capital nuevos accionistas (Romano, Tanewski, \& Smyrnios, 2000; Upton \& Petty, 2000; Mishra \& McConaughy, 1999). Hamilton \& Fox (1998) han constatado que en el caso de las pequeñas empresas, ni siquiera se planifica la obtención de un ratio óptimo entre recursos ajenos y propios, por el citado miedo a perder el control del negocio. López \& Sánchez (2007) confirman, con empresas familiares españolas, que éstas siguen una política financiera basada en la generación de financiación propia, aun renunciando al crecimiento con el fin de garantizar el control de la empresa.

Estudios empíricos previos que han comparado empresas familiares y no familiares concluyen que las empresas familiares mantienen menores niveles de deuda que las empresas no familiares (Mishra \& McConaughy, 1999; Gallo, Tápies, \& Cappuyns, 2000; McConaughy, Matthews, \& Fialko, 2001). En este sentido, la reticencia a usar ampliaciones de capital con socios nuevos es una característica propia de la empresa familiar, puesto que estas ampliaciones de capital diluyen el control familiar (Gallo \& Vilaseca, 1996). De forma que, el conservadurismo financiero que caracteriza a la empresa familiar la hace preferir la financiación propia frente a la ajena, aún a costa de obtener un menor crecimiento o rentabilidad, siempre que permita asegurar la continuidad de la misma.

Según lo expuesto se espera que las Mipymes empresas familiares puedan estar más auto racionadas por su mayor conservadurismo financiero que las no familiares: 
H4: Las Mipymes no familiares tienen menores probabilidades de racionamiento de crédito que las Mipymes familiares.

Por otra parte, es probable que la situación legal de una empresa tenga efectos sobre las conductas de ahorro y préstamo (Freel et al., 2012). Cuando los bancos van a dar crédito a las Mipymes se basan en las garantías y el marco regulatorio existente. El banco trata de evitar que no haya un debido registro de las garantías y propiedades del negocio, evitan los vacíos legales que vayan en contra de la recuperación de la deuda y toman en cuenta el aspecto legal en caso de quiebra de la empresa (Zhang, $\mathrm{Hu}, \&$ Zhang, 2011). Esto muestra la importancia que tiene el hecho que la empresa que va a solicitar financiación al banco, esté formalmente constituida, para tener mayor o menor probabilidad de que se lo otorguen.

Esto nos conduce a plantear la siguiente hipótesis:

H5: La situación jurídica formal de la empresa influye positivamente en el acceso a la financiación.

\subsubsection{Capital humano: edad, experiencia, nivel de educación y género del gerente}

El capital humano de la empresa (el dueño, el gerente y los empleados) juega un rol diferente en las diversas etapas del ciclo de vida del negocio. Las contribuciones del capital humano en las primeras etapas son más importantes que en las etapas posteriores (Muda \& Rahman, 2016) y contribuirá a la consolidación y supervivencia en el mercado. Åstebro \& Bernhardt (2005) analizan el efecto del capital humano (edad y experiencia del dueño) y la capacidad empresarial para flexibilizar las restricciones de capital, ellos encuentran que las empresas que poseen un alto capital humano son las que tienen menos restricciones de financiación para iniciar nuevos negocios.

Diversos estudios han tratado de encontrar relaciones entre el racionamiento de crédito a las empresas y la edad, el género y el nivel de instrucción del gerente (Hoque et al., 2016; Freel et al., 2012). En concreto, Hoque et al. (2016) hallan que la edad y el sexo del dueño principal de la empresa tienen un impacto significativo sobre el racionamiento de crédito. Robson, Akuetteh, Stone, Westhead, \& Wright (2013) concluyen que la experiencia del empresario reduce la probabilidad de que sus créditos sean racionados. Los resultados de Ahiawodzi \& Sackey (2013) muestran que los directivos de sexo masculino y los que tienen más años de experiencia en el negocio tienen mayor probabilidad de acceso al crédito por parte del sector bancario. McCarthy et al. (2013) encuentran que existe una relación positiva entre las empresas conducidas por hombres y la proporción de deuda bancaria que obtuvieron. También muestran que 
las empresas dirigidas por mujeres no tienden a buscar más financiación que sus pares masculinos, pero sí son más propensas a ser racionadas. Drakos \& Giannakopoulos (2011) verifican que las empresas cuyos dueños principales son de sexo femenino tiene mayor probabilidad de sufrir racionamiento de crédito; afirman que, excluyendo la presencia de discriminación, el racionamiento aumenta con la aversión al riesgo que en mayor medida presenta el sexo femenino.

Adicionalmente, Briozzo et al. (2016) llegan a la conclusión de que la educación tiene un impacto positivo en el que las pequeñas empresas tengan menos restricciones de financiación. El mayor nivel educativo, hace que los empresarios tengan mayores conocimientos de carácter técnico, lo que les da mayor capacidad para poder afrontar de una forma más satisfactoria las limitaciones financieras de las empresas, lo cual a su vez tiene un impacto positivo en la reducción de restricciones de financiación. La formación del empresario puede ayudarlo a formular buenos proyectos y a mejorar sus habilidades con el mercado financiero, por lo que las restricciones de crédito podrían ser de un bajo nivel (Hoque et al., 2016). También para acceder a fuentes de financiación formales se requiere, entre otros aspectos, que el directivo conozca el manejo de las cuentas bancarias y los libros del negocio y entender los requisitos y pasos a seguir para la obtención de financiamiento de diversas fuentes (G. Zhang, 2008), y esto requiere cierto nivel de preparación y experiencia.

Todo lo anterior nos lleva a plantear las siguientes hipótesis:

H6a: La edad del directivo influye en el acceso a la financiación de la empresa.

H6b: La experiencia del directivo influye en el acceso a la financiación de la empresa.

H6c: El nivel de educación del directivo influye en el acceso a la financiación de la empresa.

H6d: El género del directivo influye en el acceso a la financiación de la empresa.

\subsubsection{Plan estratégico y estructura organizativa}

Determinadas empresas hacen planificación de manera formal utilizando su estructura organizacional y otras lo realizan sin mayores documentos o reuniones y acuerdos más estructurados y estandarizados. Se observa que las empresas de mayor tamaño realizan en mayor proporción procesos de planificación más formales que las empresas pequeñas, esto tal vez se deba a que las últimas cuentan con menos recursos, los cuales mayormente demandan un proceso de planificación formal (Ghobadian et al., 2008). Además, la orientación estratégica consume muchos recursos, 
siendo los financieros de especial importancia para las pequeñas empresas (Wiklund \& Shepherd, 2005).

Aunque se parta de la base de que las micro y pequeñas empresas deben tener menos formalizada su estructura, se plantea que el uso de estrategias formales y procedimientos de planificación financiera por parte de las Mipymes, no solo les da oportunidades para mejorar en la conducción de estas empresas, sino que los lleva a mejores condiciones de acceso a fuentes de financiamiento (Vera-Colina, RodriguezAedina, \& Melgarejo-Molina, 2011). Vera-Colina et al. (2011) en su estudio dirigido a Mipymes hallan relaciones positivas entre el hecho que la empresa planifique y su acceso al crédito bancario, de proveedores y financiación exterior.

En relación con la planificación estratégica y la estructura organizativa, se plantean las siguientes hipótesis de investigación:

H7: Las empresas que realizan planificación estratégica tienen un menor racionamiento en el acceso a la financiación.

H8: Las empresas que tienen un mayor número de departamentos formales en su organización tienen un menor racionamiento de crédito.

\subsubsection{Innovación, posición tecnológica, calidad y uso de TIC}

Recientes estudios han señalado que la probabilidad de racionamiento de crédito se incrementa para las compañías innovadoras (Ata et al., 2015). Bellucci, Favaretto, \& Giombini (2014) mencionan que el mayor o menor racionamiento de crédito que afronten las empresas innovadoras se da en la medida que en estas empresas prevalezcan sus puntos débiles o fuertes. Las primeras podrían afrontar mayores costes de financiación y tiene una mayor probabilidad de ser racionadas financieramente; en cambio las segundas podrían conseguir mejores condiciones de crédito. Sin embargo, los autores consideran que los bancos evalúan a las más innovadoras como más arriesgadas y les cobran tasas de interés más altas y, al mismo tiempo, les imponen menos límites a los créditos, ya que las consideran más rentables. Adicionalmente, McCarthy et al. (2013) concluyen en su modelo que las empresas que realizan pequeñas innovaciones sobre sus productos, tienden a experimentar un mayor éxito en el préstamo solicitado. Robson et al. (2013) llegan al resultado de que cuando el empresario está involucrado en su negocio con la innovación, en nuevos productos o servicios y en la innovación de procesos de producción, se es menos propenso al racionamiento de crédito.

En relación con la tecnología y TIC's, Botello (2015), en base a un análisis acerca de la financiación a 110 mil empresas industriales y de servicios de Latinoamérica, 
elaborada por el Banco Mundial, muestra que son los factores internos los que más influyen en su probabilidad de acceso al crédito: capacidad tecnológica (si tiene web, mail, certificaciones de calidad, entrenamiento a trabajadores en cursos de calidad), tamaño de la empresa ( $n^{\circ}$ empleados y nivel de ventas) y la formalidad (si es único accionista o es sociedad limitada). Precisa que estos factores incrementan su competitividad en el mercado y aseguran la generación de flujos de caja sostenibles, aspectos básicos que los bancos consideran usualmente para dar préstamos. En este sentido, Guiso (1998) por su lado encuentra que las empresas de alta tecnología tienen mayor probabilidad de que se le deniegue el crédito que las empresas de baja tecnología. Por su parte, Kossaï \& Piget (2012) en su trabajo hallan que hay una relación estadísticamente significativa entre el nivel de uso de las TIC por parte de las Mipymes y su rendimiento y, como sabemos, este indicador es uno de los factores que los bancos consideran al evaluar los créditos y tomar la decisión de aprobación.

Respecto a la calidad, Ullah, Wei, \& Xie (2014), con base a 21.852 encuestas efectuadas por el Banco Mundial a empresas de 31 países de América Latina y el Caribe, muestran que las empresas con certificación ISO exhiben significativamente menor nivel de limitaciones financieras que las empresas que no cuentan con ISO. Así, manifiestan que estos resultados apoyan en general la conjetura de que la adopción de una certificación ISO desempeña un papel de "garantía" y da señales de fortaleza financiera de la empresa. Por tanto, la acreditación por un tercero reduce la asimetría de información entre las empresas y acreedores/inversores.

El anterior razonamiento, nos lleva a plantear las siguientes hipótesis:

H9: Las empresas que realizan más innovaciones en sus productos/servicios y procesos tienen un menor racionamiento de crédito.

H10: Las empresas que realizan más innovaciones en sus sistemas de gestión tienen un menor racionamiento de crédito.

H11: Las empresas que tienen certificación de calidad presentan un menor racionamiento financiero.

H12: Las empresas que tienen una posición tecnológica fuerte tienen más facilidad de acceso a la financiación.

H13: Las empresas que hacen un mayor uso de las TIC's tienen más facilidad de acceso a la financiación. 


\subsubsection{Rendimiento}

Freel et al. (2012) indican que existe un amplio consenso sobre que el crecimiento de las pequeñas empresas está directamente relacionado a su capacidad para acceder a recursos en general, particularmente los financieros. Hace distinción entre aquellas empresas que en el pasado han crecido de aquellas que proyectan crecer en el futuro; considerando que los resultados del primer grupo de empresas obedecen más a factores estructurales como las características del negocio, mientras que las del segundo grupo su expectativa es un componente estratégico. Considera que se asocian más con el éxito a estos últimos, ya que envían una señal positiva a los prestamistas. En este sentido, la falta de acceso a la financiación impide el crecimiento de la empresa, ya que muchos proyectos de inversión rentables quedan sin financiación afectando, negativamente al rendimiento de la empresa (Beck, Demirgüç-Kunt, \& Martínez, 2008).

Kremp \& Sevestre (2013) en base a una muestra de 60.000 Mipymes, señalan que la rentabilidad de la empresa juega un papel importante en el racionamiento de crédito; los negocios que obtienen una buena rentabilidad tiene un mayor acceso al crédito bancario, ya que están en una mejor situación para cumplir con el pago posterior de la deuda a contraer. En este sentido, Ahiawodzi \& Sackey (2013) obtienen una relación significativa y positiva entre los beneficios y la determinación de los préstamos a las empresas. Por su parte, Toçi \& Hashi (2009) observan que la rentabilidad y el uso de algunas normas contables disminuyen de modo importante la probabilidad de racionamiento de crédito de las empresas. Estudios posteriores como Cenni, Monferrà, Salotti, Sangiorgi, \& Torluccio (2015), en base a una muestra de 4.289 empresas, encuentran que aquellas que tienen un mayor rendimiento (ROA) hace que disminuya moderadamente la probabilidad de racionamiento.

El razonamiento anterior implica plantear la siguiente hipótesis:

H14: El rendimiento de la empresa influye en el racionamiento de crédito que pueda sufrir.

\subsection{METODOLOGÍA}

\subsubsection{Datos}

Para el estudio se ha empleado una muestra de 158 micro y pequeñas empresas de Perú, obtenidas de la base de datos del proyecto "Análisis Estratégico para el Desarrollo de la Mipyme en Iberoamérica", de la Fundación para el Análisis Estratégico y Desarrollo de la Pequeña y Mediana Empresa (2014). Para definir el concepto de 
Mipyme se ha seguido el criterio aprobado por la Unión Europea, que clasifica a las empresas por tamaño atendiendo al número de empleados (Anexo I del reglamento (UE) $n^{\circ}$ 651/2014 de la Comisión). De forma que, se consideran microempresas aquellas con menos de 10 trabajadores; pequeñas aquellas que se encuentran en el intervalo más de 10 a 50.

El sistema de envío y recogida de información se realizó vía telefónica, utilizando como soporte un cuestionario auto administrado dirigido al gerente de la empresa. Este tipo de encuesta cuenta con la ventaja de la mayor accesibilidad a muestras de ámbito nacional a un coste unitario más reducido (Sarabia, 1999). La fuente estadística para la población se basó en la Base de Datos de la Superintendencia Nacional de Administración Tributaria (SUNAT).

Con el fin de obtener una muestra representativa de las Mipymes de Perú, el diseño de la muestra se basó en los principios del muestreo estratificado, así partiendo de la población de empresas contenidas en la base oficial SUNAT se fijaron tres estratos: 4 sectores (industria, comercio, servicios y construcción), 2 tamaños (micro y pequeña empresa) y 3 regiones de Perú (Lima, Trujillo y Arequipa). Dentro de cada estrato la selección se realizó mediante un muestreo aleatorio simple. Dado que el cuestionario incluye una tipología de preguntas muy variada, tanto cuantitativas como cualitativas, se ha determinado el tamaño muestral tomando como criterio de calidad el control sobre el error máximo a priori en la estimación de la proporción de la respuesta a una pregunta dicotómica. En concreto, se fijó como objetivo inicial que el error máximo de estimación no superase el 5\% con un nivel de confianza del 95\% para el conjunto de la muestra.

El trabajo de campo se realizó entre los meses de septiembre a diciembre del 2011. La composición de las empresas que conforman la muestra se puede ver en la Tabla 3.1.

La selección de las variables es fundamental a la hora de configurar el análisis empírico y nos permitirá afrontar adecuadamente el estudio del comportamiento de la Mipyme. Para obtener la información de las variables se elaboró un cuestionario dirigido al director, dueño o gerente de la empresa. Con esta herramienta se ha buscado recoger de forma clara y concisa la información fundamental que constituye el objetivo de esta investigación. En su elaboración se ha cuidado especialmente la estructuración del mismo, una redacción adecuada y sencilla y, sobre todo, un contenido breve. Antes de la aplicación definitiva se llevó a cabo una prueba piloto en siete empresas de distintos 
sectores, con el propósito de afinar el instrumento de medición para la aplicación definitiva.

Tabla 3.1. Composición de las empresas de la muestra

\begin{tabular}{|l|c|c|}
\hline Sector & $\begin{array}{c}\text { Número de } \\
\text { empresas }\end{array}$ & $\begin{array}{c}\text { Porcentaje de } \\
\text { empresas }\end{array}$ \\
\hline Industria + Construcción & 67 & 42,4 \\
\hline Comercio + Servicios & 91 & 57,6 \\
\hline Total & $\mathbf{1 5 8}$ & 100 \\
\hline Fuente: Elaboración propia
\end{tabular}

\subsubsection{Variable dependiente}

Racionamiento de crédito

El racionamiento de crédito se ha medido mediante una pregunta cualitativa "dummy" que recoge un valor binario $(0 ; 1)$ en función de que la empresa haya intentado o no acceder a líneas de financiación de entidades de crédito en los últimos meses. Dicha medida ha sido utilizada en otros estudios previos como los de HernándezCánovas \& Martínez-Solano (2010).

\subsubsection{Variables independientes}

\subsubsection{Características de la empresa}

Se incluye en el análisis medidas caracterizadoras de las empresas como son el tamaño, la edad, el sector de actividad, la forma jurídica o el carácter familiar. Respecto al tamaño de la empresa, es comúnmente estimada por los activos totales, ventas netas o por el nivel de empleo (Bellier, Sayeh, \& Serve, 2012). Para la medición de la variable tamaño de la empresa (TAMAÑO) se empleará el número de empleados que la empresa disponía en el momento de la encuesta (2012) y es una variable continua. Esta variable ha sido empleada en trabajos como los de Briozzo et al. (2016), Hoque et al. (2016) y M. Freel et al. (2012).

La variable edad de la empresa (EDAD_EMP) también es una variable continua que se refiere al número de años que lleva funcionando la empresa desde su formación. Dicha variable ha sido utilizada, entre otros, por Briozzo et al. (2016), Hoque et al. (2016) y Freel et al. (2012). En relación con el sector, se tiene en cuenta el sector al que pertenece la empresa (SECTOR), siendo una variable categórica conformada por cuatro 
sectores donde 1=Industria, 2=Construcción, 3=Comercio y 4=Servicios. El sector en el que se desenvuelve el negocio ha sido analizado en Briozzo et al. (2016), Freel et al. (2012) y Okurut et al. (2011).

La forma jurídica de la empresa como sociedad empresarial (LEGAL) se considera como una variable binaria, donde el valor 1 denota que el negocio está constituido formalmente como sociedad empresarial y 0 si no lo está. Investigadores como Briozzo et al. (2016) y Freel et al. (2012) usan la misma medición de esta variable.

Para analizar si una empresa es de carácter familiar o no (FAMILIAR), se tomará una variable binaria, donde el valor $=1$ si el control mayoritario de la empresa (el grupo familiar tiene más del $50 \%$ del capital) es familiar, $=0$ si el control mayoritario de la empresa no es de carácter familiar. Al respecto los autores Freel et al. (2012) toman en cuenta esta variable dentro del análisis de sus empresas.

\subsubsection{Capital humano}

Para medir el capital humano utilizaremos las siguientes variables: (1) Como proxis de la experiencia, utilizamos las variables "edad del gerente" (EDAD_GRTE) y "años que lleva en la gerencia de la empresa" (EXPERIENCIA). Ambas son variables continuas. Estas variables han sido utilizadas en los trabajos previos de Freel et al. (2012), Zabri et al. (2011) y Okurut et al. (2011); (2) Nivel de educación del gerente (EDUCACION): toma valor $1=$ Nivel de formación universitaria y $0=$ Formación no universitaria (Briozzo et al., 2016; Hoque et al., 2016) y (3) Género del gerente (GENERO): toma valor 1 cuando es hombre y 0 cuando es mujer (Hoque et al., 2016; Zabri et al., 2011).

\subsubsection{Planificación estratégica y estructura organizativa}

La variable plan estratégico (ESTRATEGIA) es una variable binaria donde toma el valor 1 si la empresa realiza procesos formales de planeación estratégica, y 0 si no lo hace. Esta variable se midió de acuerdo con estudios llevados a cabo anteriormente Idar et al. (2012).

Para el análisis de la estructura organizativa de la empresa utilizamos variables binarias que miden la existencia formalizada o no de los diferentes departamentos de la empresa. En concreto, si posee departamento de comercialización/ventas, departamento de recursos humanos, departamento de investigación y desarrollo, departamento de operaciones/compras, departamento de administración/contabilidad y 
departamento de calidad (=1 si existe formalmente dentro de la estructura organizativa de la empresa, 0 en otro caso).

La variable GLOBAL ORGANIZACION, es una variable aditiva de los ítems que miden el número de departamentos formalmente establecidos.

\subsubsection{Innovación en productos, procesos y gestión}

Aquí tomaremos las variables binarias (dummy) que se refieren a cambios o mejoras en productos/servicios existentes, en la comercialización de nuevos productos/servicios, cambios o mejoras en los procesos de producción/servicios, si ha realizado adquisición de nuevos bienes de equipos, si ha realizado cambios o mejoras en dirección y gestión, si ha realizado cambios o mejoras en compras y aprovisionamientos y si ha realizado cambios o mejoras en el área comercial/ventas (=1 si ha realizado innovación, =0 si no ha realizado).

También aquí se consideran para cada una de las 7 opciones, variables cuyas medidas se realizan usando la escala Likert (donde 1=si la innovación que se ha realizado es poco importante, 5=si la innovación que ha realizado es muy importante).

La variable global IPROCESOS, es una variable aditiva de los ítems que miden innovación en productos y procesos; la variable global IGESTION, es una variable aditiva de los ítems que miden innovación en gestión.

\subsubsection{Posición tecnológica, TIC's y certificación de calidad}

La variable posición tecnológica (TECNOLOGIA) es una variable binaria que toma el valor 1 si la empresa tiene una posición tecnológica fuerte y 0 si posee una tecnología sostenible, siguiendo el planteamiento de estudios previos como AECA (2005).

Para analizar si el hecho de que la empresa tenga o no, o esté en proceso de obtención de una certificación de calidad influye en las restricciones de crédito que sufra la empresa, se toma la variable categórica certificación de calidad (CALIDAD) que es =1 si la empresa dispone de una certificación ISO de la serie 9000 o equivalentes, =2 si la empresa no dispone de una certificación de calidad, pero está en el proceso previo para obtenerlo e $=3$ si la empresa no dispone de una certificación de calidad ni está en el proceso para obtenerlo.

Se emplearán las variables binarias relacionadas con: el correo electrónico, la página Web, el comercio electrónico, la banca electrónica, marketing por Internet, intranet corporativa, uso de redes sociales y trámite de impuestos (=1 si la empresa 
hace uso de la herramienta, $=0$ si no). La variable global TIC's, es una variable aditiva de los ítems que miden el grado de uso de las tecnologías de la información y comunicación.

\subsubsection{Rendimiento}

Para el análisis del rendimiento utilizamos las variables "ofrece productos de mayor calidad", "dispone de procesos internos más eficientes", "cuenta con clientes más satisfechos", "se adapta antes a los cambios en el mercado", "está creciendo más", "es más rentable", "tiene empleados más satisfechos" y "tiene un menor absentismo laboral". Las medidas de todas las variables se realizan usando la escala Likert (donde 1=si están en total desacuerdo que su empresa tiene ese indicador y 5=si están en total acuerdo que su empresa tiene ese indicador).

La variable global RENDIMIENTO, es una variable aditiva de los ítems que miden el desempeño.

Con el fin de descartar problemas de multicolinealidad en el análisis de regresión logística, se adjunta, en la tabla 3.11., la tabla de correlaciones bivariantes siguiendo la prueba no paramétrica de Spearman, cuyos valores justifican la hipótesis inicial de ausencia de colinealidad.

\subsection{ANÁLISIS DE RESULTADOS}

\subsubsection{Análisis univariante}

Al objeto de conocer cuáles son los factores más relevantes que determinan el racionamiento de crédito que soportan las micro y pequeñas empresas peruanas, se ha comenzado con el análisis univariante. En primer lugar, realizaremos un análisis estadístico univariante a través de: (1) Un análisis ANOVA para variables continuas y la prueba de Kruskall-Wallis cuando la hipótesis de normalidad y homogeneidad de varianza no se cumplen y (2) Un análisis de contingencia, basado en la $x^{2}$ de Pearson para las variables categóricas, así como la prueba de Yates en tablas de 2x2.

\subsubsection{Características de la empresa}

La tabla 3.2. recoge y compara el racionamiento de crédito según las características propias de la muestra de estudio. En concreto, no se encuentran relaciones significativas entre el tamaño y la edad de la empresa con el hecho que sean racionadas en el crédito o no; por lo que no se confirman las hipótesis 1 y 2 . Se hallan valores significativos en la tabla de contingencia en relación con la pertenencia al sector 
de actividad, de forma que las empresas pertenecientes al sector industrial (industria + construcción) reflejan un mayor racionamiento financiero, el 59,4\% están racionadas, frente a aquellas que pertenecen al sector servicios (comerciales + servicios) cuyo valor desciende al 40,9\% (significativo al 5\%). Estos resultados permiten confirmar la hipótesis 3 , en relación a que no todos los sectores económicos presentan los mismos problemas de racionamiento de crédito, en consonancia con los estudios previos realizados por McCarthy et al. (2013) y Kira \& He (2012).

Tabla 3.2. Características de la empresa

$(n=158)$

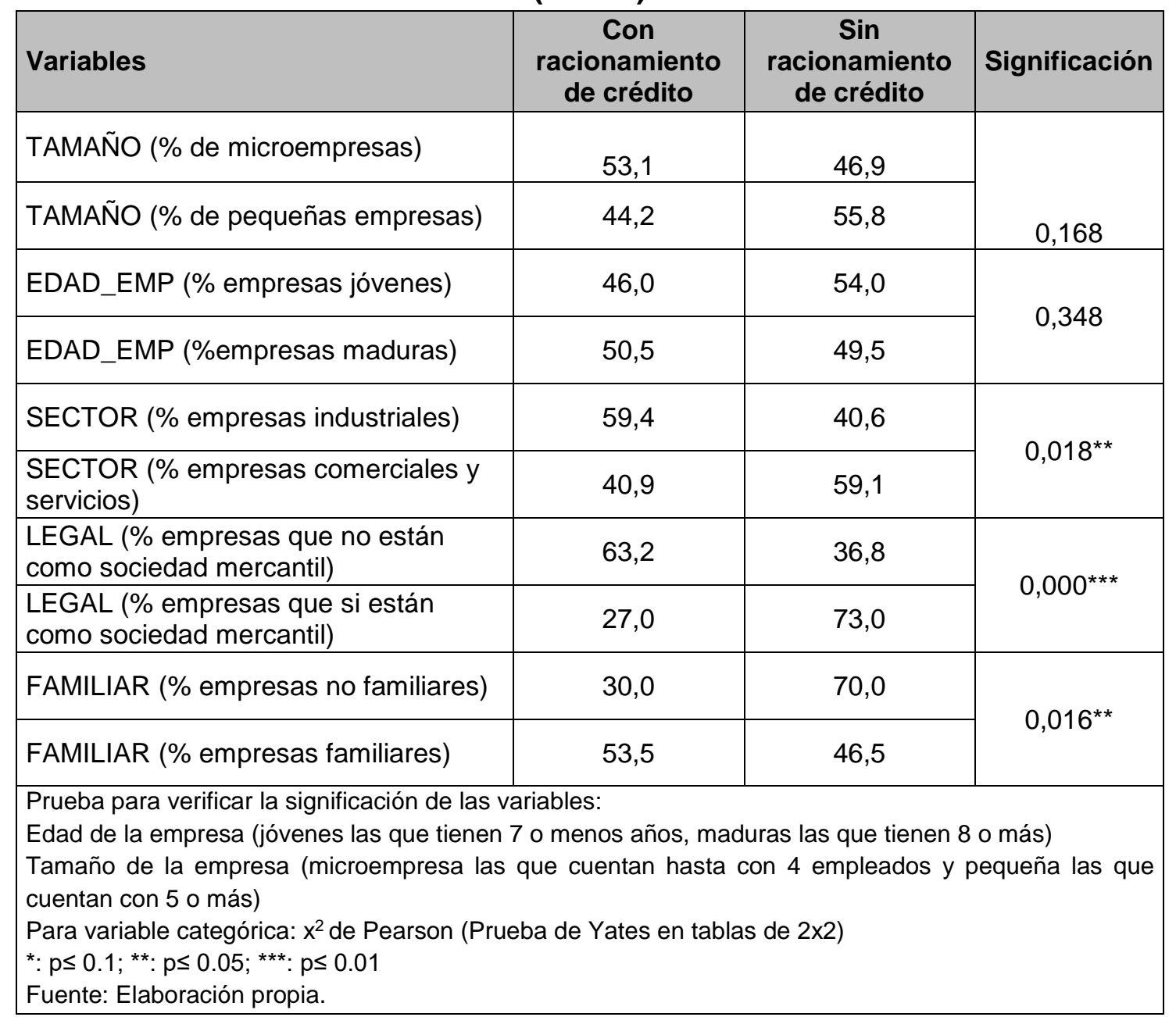

Cuando analizamos la forma legal de la empresa, se observa que aquellas que están constituidas como sociedad formalmente presentan un menor racionamiento en el acceso al crédito. Sólo el $27 \%$ están racionadas frente al 63,2\% de aquellas que no están constituidas formalmente (significativo al 1\%). En este caso, se confirma la 
hipótesis 5, la cual refleja que las empresas constituidas bajo una forma jurídica formalmente se encuentran menos racionadas.

Por último, al estudiar el carácter familiar o no de la empresa, se comprueba cómo las empresas familiares reflejan unos mayores valores de racionamiento de crédito que las no familiares, presentando un valor del 53,5\% las familiares frente al $30 \%$ de las no familiares (significativo al 5\%). Por su parte, se cumpliría la hipótesis 4, puesto que las pequeñas y medianas empresas familiares se hallan más racionadas que las no familiares. Este resultado estaría acorde con el estudio de Larrán, García-Borbolla, \& Giner (2010), que encuentran que las empresas en las que el propietario es también gerente de la misma se exigían mayores garantías para el acceso a crédito bancario.

\subsubsection{Capital humano}

Tabla 3.3. Capital humano

\begin{tabular}{|c|c|c|c|}
\hline \multicolumn{4}{|c|}{$(n=158)$} \\
\hline Variables & $\begin{array}{l}\text { Con } \\
\text { racionamiento } \\
\text { de crédito }\end{array}$ & $\begin{array}{l}\text { Sin } \\
\text { racionamiento } \\
\text { de crédito }\end{array}$ & Significación \\
\hline $\begin{array}{l}\text { EDAD_GRTE (\% de empresas con } \\
\text { gerentes jóvenes) }\end{array}$ & 45,9 & 54,1 & \multirow{2}{*}{0,270} \\
\hline $\begin{array}{l}\text { EDAD_GRTE (\% de empresas con } \\
\text { gerentes mayores) }\end{array}$ & 52,1 & 47,9 & \\
\hline $\begin{array}{l}\text { EXPERIENCIA (\% de empresas con } \\
\text { gerentes con poca experiencia) }\end{array}$ & 48,9 & 51,1 & \multirow{2}{*}{0,546} \\
\hline $\begin{array}{l}\text { EXPERIENCIA (\% de empresas con } \\
\text { gerentes con mucha experiencia) }\end{array}$ & 48,5 & 51,5 & \\
\hline $\begin{array}{l}\text { EDUCACION (\% de empresas con } \\
\text { gerentes de nivel de educación } \\
\text { básico) }\end{array}$ & 62,5 & 37,5 & \multirow{2}{*}{$0,000^{\star \star \star}$} \\
\hline $\begin{array}{l}\text { EDUCACION (\% de empresas con } \\
\text { gerentes de nivel de educación } \\
\text { superior) }\end{array}$ & 15,2 & 84,8 & \\
\hline GENERO (\% género femenino) & 47,8 & 52,2 & \multirow{2}{*}{0,478} \\
\hline GENERO (\% género masculino) & 50,0 & 50,0 & \\
\hline \multicolumn{4}{|c|}{$\begin{array}{l}\text { Prueba para verificar la significación de las variables: } \\
\text { Edad del gerente (jóvenes los que tienen hasta la edad promedio, mayores los que tienen edad mayor } \\
\text { al promedio) } \\
\text { Años que lleva gerenciando (gerentes con poca experiencia son aquellos que tienen laborando menos } \\
\text { que el tiempo promedio y gerentes con mucha experiencia son los llevan laborando más que el tiempo } \\
\text { promedio) } \\
\text { Formación Gerente (1 Estudios Básicos; } 2 \text { Estudios Superiores) } \\
\text { Para variable categórica: } x^{2} \text { de Pearson (Prueba de Yates en tablas de } 2 \times 2 \text { ) } \\
\text { *: } p \leq 0.1 ;{ }^{* *:} p \leq 0.05 ;{ }^{* * *}: p \leq 0.01 \\
\text { Fuente: Elaboración propia. }\end{array}$} \\
\hline
\end{tabular}


Los resultados que se recogen en la tabla 3.3. hacen referencia a la edad, el número de años que se lleva como gerente en la empresa, el nivel de educación y el género del gerente. Tanto la edad, los años que lleva conduciendo la empresa y su género no resultaron significativas; por lo que no se confirman las hipótesis $6 a, 6 b$ y $6 \mathrm{~d}$. Sin embargo, su nivel de formación si arroja resultados muy significativos. El 84,8\% de las empresas que son conducidas por gerentes con un nivel de educación superior tienen un menor racionamiento de crédito, mientras que sólo el 37,5\% de ellas cuyos directivos tienen un nivel de educación básico no están racionadas (significativo al 1\%). De esta forma, se confirma la hipótesis $6 c$ al existir una relación negativa y muy significativa entre el nivel de formación del gerente de la empresa y el racionamiento de crédito, en el sentido de que cuanto mayor es la formación del gerente de la empresa, menor será el racionamiento de crédito que soporte. Así, los resultados están en la línea de estudios previos como el de Briozzo et al. (2016) que obtuvo que la educación del gerente tiene un impacto positivo al reducir las restricciones de financiación de la empresa.

\subsubsection{Plan estratégico}

La tabla 3.4. muestra el análisis para los grupos "con racionamiento de crédito" y "sin racionamiento de crédito" para la variable "realiza plan estratégico" (ESTRATEGIA). Los resultados muestran que el 71,4\% de las empresas que realizan planeamiento estratégico son del grupo sin racionamiento de crédito, mientras que sólo el $44,0 \%$ de las empresas que no realizan planeamiento estratégico se encuentran sin problemas de acceso al crédito. Esta diferencia resulta muy significativa al 1\%, por lo que se confirma la hipótesis 7 en el sentido de que la realización de planeamiento estratégico por parte de las empresas favorece un menor racionamiento de crédito.

Tabla 3.4. Plan estratégico

\begin{tabular}{|c|c|c|c|}
\hline Variables & $\begin{array}{c}\text { Con } \\
\text { racionamiento } \\
\text { de crédito }\end{array}$ & $\begin{array}{c}\text { Sin } \\
\text { racionamiento } \\
\text { de crédito }\end{array}$ & Significación \\
\hline $\begin{array}{l}\text { ESTRATEGIA (\% de empresas no } \\
\text { realizan plan estratégico) }\end{array}$ & 56,0 & 44,0 & \multirow{2}{*}{$0,002^{\star \star *}$} \\
\hline $\begin{array}{l}\text { ESTRATEGIA (\% de empresas si } \\
\text { realizan plan estratégico) }\end{array}$ & 28,6 & 71,4 & \\
\hline \multicolumn{4}{|c|}{$\begin{array}{l}\text { Prueba para verificar la significación de las variables: } \\
\text { Para variable con promedio (escala Likert: } 1=\text { Poco uso a } 5=\text { Mucho uso): F-test (ANOVA) } \\
\text { Para variable categórica: } x^{2} \text { de Pearson (Prueba de Yates en tablas de } 2 \times 2 \text { ) } \\
{ }^{*}: p \leq 0.1 ;{ }^{* *}: p \leq 0.05 ;{ }^{* * *}: p \leq 0.01 \\
\text { Fuente: Elaboración propia. }\end{array}$} \\
\hline
\end{tabular}




\subsubsection{Estructura organizativa}

La mayor estructura organizativa que tengan las Mipymes (Tabla 3.5.) favorece que tengan un menor racionamiento de crédito. Analizando cada variable, se observa que el $81,4 \%$ de las empresas que cuenta con un dpto. de comercialización/ventas no están racionadas, frente a solo el $33,3 \%$ de las empresas que no tienen este dpto. (diferencia muy significativa al 1\%). Las empresas que cuentan con un dpto. de recursos humanos presentan un menor racionamiento en el acceso al crédito; solo el 16,7\% están racionadas frente al $51,4 \%$ de aquellas empresas que no cuentan con este dpto. (diferencia significativa al 5\%). Las empresas que disponen de un dpto. de operaciones/compras tienen un mayor acceso al crédito bancario; solo el 18,4\% están racionadas frente al $63,0 \%$ de aquellas empresas que no tienen este dpto. (diferencia muy significativa al 1\%). Las empresas que cuentan con un dpto. de calidad presentan un menor racionamiento de crédito; en efecto, el $77,6 \%$ de las empresas que tienen un dpto. de calidad enfrentan un menor racionamiento financiero frente a solo un $39,4 \%$ de aquellas empresas que no cuentan con este dpto. en su estructura organizativa (diferencia muy significativa al 1\%).

Analizando la variable GLOBAL ORGANIZACION, el número promedio de departamentos con los que cuenta el grupo de empresas sin racionamiento es de 2,50 frente al 1,11 del grupo con racionamiento de crédito (esta diferencia es muy significativa al 1\%). De este modo se confirma la hipótesis 8 , al verificar que tener un mayor número de departamentos como estructura formal dentro de las Mipymes influye en el menor racionamiento en su acceso al crédito. 
Tabla 3.5. Estructura organizativa

\begin{tabular}{|c|c|c|c|}
\hline \multicolumn{4}{|c|}{$(n=158)$} \\
\hline Variables & $\begin{array}{c}\text { Con } \\
\text { racionamiento } \\
\text { de crédito }\end{array}$ & $\begin{array}{l}\text { Sin } \\
\text { racionamiento } \\
\text { de crédito }\end{array}$ & Significación \\
\hline $\begin{array}{l}\text { No tiene Dpto. de } \\
\text { Comercialización/Ventas }\end{array}$ & 66,7 & 33,3 & \multirow[b]{2}{*}{$0,000^{\star * * *}$} \\
\hline $\begin{array}{l}\text { Si tiene Dpto. de } \\
\text { Comercialización/Ventas }\end{array}$ & 18,6 & 81,4 & \\
\hline $\begin{array}{l}\text { No tiene Dpto. de Recursos } \\
\text { Humanos }\end{array}$ & 51,4 & 48,6 & \multirow[b]{2}{*}{$0,020^{* *}$} \\
\hline $\begin{array}{l}\text { Si tiene Dpto. de Recursos } \\
\text { Humanos }\end{array}$ & 16,7 & 83,3 & \\
\hline $\begin{array}{l}\text { No tiene Dpto. de } \\
\text { Operaciones/Compras }\end{array}$ & 63,0 & 37,0 & \multirow{2}{*}{$0,000^{\star \star \star}$} \\
\hline $\begin{array}{l}\text { Si tiene Dpto. de } \\
\text { Operaciones/Compras }\end{array}$ & $18,4 \%$ & $81,6 \%$ & \\
\hline $\begin{array}{l}\text { No tiene Dpto. de } \\
\text { Contabilidad/Finanzas }\end{array}$ & 57,1 & 42,9 & \multirow{2}{*}{0,137} \\
\hline $\begin{array}{l}\text { Si tiene Dpto. de } \\
\text { Contabilidad/Finanzas }\end{array}$ & 45,7 & 54,3 & \\
\hline No tiene Dpto. de Calidad & 60,6 & 39,4 & \multirow{2}{*}{$0,000^{\star \star \star}$} \\
\hline Si tiene Dpto. de Calidad & $22,4 \%$ & $77,6 \%$ & \\
\hline GLOBAL ORGANIZACION (1) & 1,11 & 2,50 & $0,000 * \star *$ \\
\hline \multicolumn{4}{|c|}{$\begin{array}{l}\text { Prueba para verificar la significación de las variables: } \\
\text { Para variable categórica: } x^{2} \text { de Pearson (Prueba de Yates en tablas de } 2 \times 2 \text { ) } \\
\text { (1) Variable aditiva de los diferentes ítems que miden la implantación de Departamentos en escala } \\
0-1 . \\
\text { *: } p \leq 0.1 ;{ }^{* *}: p \leq 0.05 ;{ }^{* * *}: p \leq 0.01 \\
\text { Fuente: Elaboración propia. }\end{array}$} \\
\hline
\end{tabular}

\subsubsection{Innovación}

En la Tabla 3.6. se analiza el impacto de la innovación en el racionamiento de crédito de las Mipymes. La realización de actividades de innovación favorece un menor racionamiento financiero. Aunque en todos los tipos analizados (productos, procesos y gestión) el grupo de Mipymes sin racionamiento de crédito han realizado actividades de innovación más importantes, no se obtienen diferencias estadísticamente significativas en las actividades referidas a la innovación en productos. En todas las actividades relacionadas con la innovación en procesos se encuentran resultados significativos. Resulta significativa al 5\% las actividades que se refieren a la adquisición de equipos que permiten mejorar sus procesos, y poco significativa (al 10\%) las actividades relacionadas con la realización de cambios o mejoras en sus procesos de producción/servicios. En todas las actividades relacionadas con la innovación en los sistemas de gestión de las empresas se hallan resultados relevantes, excepto en las 
actividades relacionadas con la realización de cambios o mejoras en dirección y gestión. En especial, y muy relevantes al 1\%, destacan las que efectúan cambios o mejoras tanto en sus sistemas de gestión de compras y aprovisionamiento como en sus sistemas de gestión del área comercial y de ventas.

Tabla 3.6. Innovación

$(n=158)$

\begin{tabular}{|c|c|c|c|}
\hline Variables & $\begin{array}{l}\text { Con } \\
\text { racionamiento } \\
\text { de crédito }\end{array}$ & $\begin{array}{l}\text { Sin } \\
\text { racionamiento } \\
\text { de crédito }\end{array}$ & Significación \\
\hline \multicolumn{4}{|l|}{ Innovación en productos/servicios } \\
\hline $\begin{array}{l}\text { Empresas que realizan cambios o } \\
\text { mejoras en productos/servicios } \\
\text { existentes }\end{array}$ & 3,13 & 3,40 & 0,361 \\
\hline $\begin{array}{l}\text { Empresas que comercializan nuevos } \\
\text { productos/servicios }\end{array}$ & 2,52 & 2,78 & 0,424 \\
\hline \multicolumn{4}{|l|}{ Innovación en procesos } \\
\hline $\begin{array}{l}\text { Empresas que realizan cambios o } \\
\text { mejoras en los procesos de } \\
\text { producción/servicios }\end{array}$ & 1,90 & 2,52 & $0,058^{*}$ \\
\hline $\begin{array}{l}\text { Empresas que adquieren nuevos } \\
\text { bienes de equipo que permiten } \\
\text { mejorar los procesos }\end{array}$ & 2,13 & 2,88 & $0,021^{\star \star}$ \\
\hline $\begin{array}{l}\text { IPROCESOS (Global innovación } \\
\text { productos+procesos) (1) }\end{array}$ & 9,67 & 11,56 & $0,065^{*}$ \\
\hline \multicolumn{4}{|l|}{ Innovación sistemas de gestión } \\
\hline $\begin{array}{l}\text { Empresas que realizan cambios o } \\
\text { mejoras en dirección y gestión }\end{array}$ & 0,97 & 1,14 & 0,576 \\
\hline $\begin{array}{l}\text { Empresas que realizan cambios o } \\
\text { mejoras en los sistemas de gestión de } \\
\text { compras y aprovisionamientos }\end{array}$ & 0,82 & 2,05 & $0,000^{* * *}$ \\
\hline $\begin{array}{l}\text { Empresas que realizan cambios o } \\
\text { mejoras en los sistemas de gestión de } \\
\text { comercial y de ventas }\end{array}$ & 0,81 & 1,98 & $0,000^{* \star *}$ \\
\hline $\begin{array}{l}\text { IGESTION (Global innovación } \\
\text { gestión) (2) }\end{array}$ & 2,59 & 5,16 & $0.001^{* * *}$ \\
\hline \multicolumn{4}{|c|}{$\begin{array}{l}\text { Prueba para verificar la significación de las variables: } \\
\text { Para variable con promedio (escala Likert: } 1=\text { Poco importante a } 5=\text { Muy importante): F-test (ANOVA) } \\
\text { (1) Variable aditiva de los diferentes ítems de innovación en productos y procesos en escala } 0-1 \\
\text { (2) Variable aditiva de los diferentes ítems de innovación en gestión en escala } 0-1 \\
{ }^{*}: p \leq 0.1 ;{ }^{* *}: p \leq 0.05 ;{ }^{* * *}: p \leq 0.01 \\
\text { Fuente: Elaboración propia. }\end{array}$} \\
\hline
\end{tabular}

Analizando la variable IPROCESOS, el grupo de empresas que efectúan en promedio más actividades de innovación en sus productos y procesos, presentan un menor racionamiento en el acceso al crédito. De este modo, se confirma la hipótesis 9 al verificar que la realización importante de actividades de innovación en productos y procesos influye en el menor racionamiento de crédito de las Mipymes (significativa al $10 \%)$. 
Analizando la variable IGESTION, el grupo de empresas que efectúa, en promedio, más actividades de innovación en sus sistemas de gestión y de mayor importancia, presentan un menor racionamiento financiero. De este modo se confirma la $\mathrm{H} 10$ al verificar que la realización de actividades de innovación en gestión influye de manera muy significativa (significativa al 1\%) en el menor racionamiento de crédito de las Mipymes.

\subsubsection{Posición tecnológica y certificación de calidad}

La tabla 3.7. muestra el análisis para los grupos "con racionamiento de crédito" y "sin racionamiento de crédito" para la variable "posición tecnológica". Los resultados muestran que el $74,1 \%$ de las empresas que tienen una posición tecnológica fuerte presentan menor racionamiento financiero, mientras que solo el 38,0\% de las empresas que tienen una posición tecnológica sostenible son de este grupo. Esta diferencia resulta muy significativa, por lo que se confirma la H12 con un nivel de significación del 1\%. Los resultados confirman que contar con una capacidad tecnológica fuerte favorece un menor racionamiento en el acceso al crédito.

Tabla 3.7. Posición tecnológica y certificación de calidad $(n=158)$

\begin{tabular}{|c|c|c|c|}
\hline Variables & $\begin{array}{l}\text { Con } \\
\text { racionamiento } \\
\text { de crédito }\end{array}$ & $\begin{array}{l}\text { Sin } \\
\text { racionamiento } \\
\text { de crédito }\end{array}$ & Significación \\
\hline TECNOLOGIA (tipo A Fuerte) & 25,9 & 74,1 & \multirow[b]{2}{*}{$0,000^{\star \star \star}$} \\
\hline $\begin{array}{l}\text { TECNOLOGIA (tipo B y C } \\
\text { Sostenible) }\end{array}$ & 62,0 & 38,0 & \\
\hline $\begin{array}{l}\text { CALIDAD (no dispone de } \\
\text { certificación de calidad) }\end{array}$ & 52,1 & 47,9 & \multirow{2}{*}{$0,003^{\star \star *}$} \\
\hline $\begin{array}{l}\text { CALIDAD (dispone de certificación } \\
\text { de calidad) (1) }\end{array}$ & 8,3 & 91,7 & \\
\hline \multicolumn{4}{|c|}{$\begin{array}{l}\text { Prueba para verificar la significación de las variables: } \\
\text { Para variable categórica: } x^{2} \text { de Pearson (Prueba de Yates en tablas de } 2 \times 2 \text { ) } \\
\text { (1) Son los que disponen de una certificación de calidad o están en el proceso previo para ello } \\
{ }^{*}: p \leq 0.1 ;{ }^{* *}: p \leq 0.05 ;{ }^{* * *}: p \leq 0.01 \\
\text { Fuente: Elaboración propia. }\end{array}$} \\
\hline
\end{tabular}

También se puede apreciar que el 91,7\% de las empresas que tiene o está en proceso de obtener una certificación de calidad presentan un menor racionamiento de crédito, mientras que solo el $47,9 \%$ de las empresas que no cuentan con una certificación de calidad son de este grupo. Esta diferencia resulta muy significativa, por lo que se confirma la H11 con un nivel de significación del 1\%. De forma que contar con 
una certificación de calidad o estar en proceso de obtenerla influye en un menor racionamiento en el acceso al crédito.

\subsubsection{Uso de las TIC's}

Los resultados que se recogen en la Tabla 3.8. hacen referencia al uso de diferentes herramientas relacionadas con las tecnologías de información y comunicación por parte de las Mipymes. Aunque en todas las TIC's el grupo de Mipymes sin racionamiento de crédito tienen o usan en mayor porcentaje estas tecnologías, solo en cinco de ellas se tienen diferencias significativas, destacando el uso de correo electrónico, la realización de marketing por internet y la utilización de redes sociales como variables significativas al $1 \%$.

Analizando la variable global TIC's, el número promedio de TIC's que usan o tienen del grupo de empresas sin racionamiento es de 2,06 frente al 1,03 del grupo con racionamiento de crédito (diferencia significativa al 1\%). De este modo, se confirma la $\mathrm{H} 13$ al verificar que el mayor uso de TIC's influye en el menor racionamiento de crédito de las Mipymes. 
Tabla 3.8. Uso de tecnologías de información y comunicación $(n=158)$

\begin{tabular}{|c|c|c|c|}
\hline Variables & $\begin{array}{c}\text { Con } \\
\text { racionamiento } \\
\text { de crédito }\end{array}$ & $\begin{array}{c}\text { Sin } \\
\text { racionamiento } \\
\text { de crédito }\end{array}$ & Significación \\
\hline No usa correo electrónico & 60,9 & 39,1 & \multirow[b]{2}{*}{$0,000 * \star *$} \\
\hline Usa correo electrónico & 31,8 & 68,2 & \\
\hline No tiene página web & 50,9 & 49,1 & \multirow[b]{2}{*}{0,239} \\
\hline Tiene página web & 42,9 & 57,1 & \\
\hline $\begin{array}{l}\text { No realiza Compras y/o } \\
\text { ventas electrónicas usando } \\
\text { internet }\end{array}$ & 51,1 & 48,9 & \multirow{2}{*}{$0,088^{*}$} \\
\hline $\begin{array}{l}\text { Realiza Compras y/o ventas } \\
\text { electrónicas usando internet }\end{array}$ & 31,6 & 68,4 & \\
\hline No utiliza banca electrónica & 50,7 & 49,3 & \multirow{2}{*}{0,154} \\
\hline Utiliza banca electrónica & 36,4 & 63,6 & \\
\hline $\begin{array}{l}\text { No realiza mercadeo a través } \\
\text { de internet }\end{array}$ & 52,9 & 47,1 & \multirow{2}{*}{$0,007^{\star \star \star}$} \\
\hline $\begin{array}{l}\text { Realiza mercadeo a través de } \\
\text { internet }\end{array}$ & 22,7 & 77,3 & \\
\hline No tiene intranet & 49,3 & 50,7 & \multirow{2}{*}{0,405} \\
\hline Tiene intranet & 40,0 & 60,0 & \\
\hline No utiliza redes sociales & 56,3 & 43,7 & \multirow{2}{*}{$0,001^{\star \star \star}$} \\
\hline Utiliza redes sociales & $25,6 \%$ & $74,4 \%$ & \\
\hline $\begin{array}{l}\text { No tramita impuesto a través } \\
\text { de la web }\end{array}$ & 52,7 & 47,3 & \multirow{2}{*}{$0,024^{\star \star}$} \\
\hline $\begin{array}{l}\text { Tramita impuesto a través de } \\
\text { la web }\end{array}$ & $29,6 \%$ & $70,4 \%$ & \\
\hline TIC's (Global uso TIC's) (1) & 1,03 & 2,06 & $0,003^{* * *}$ \\
\hline \multicolumn{4}{|c|}{$\begin{array}{l}\text { Prueba para verificar la significación de las variables: } \\
\text { Para variable categórica: } x^{2} \text { de Pearson (Prueba de Yates en tablas de } 2 \times 2 \text { ) } \\
\text { (1) Variable aditiva de los diferentes ítems sobre uso de TIC's en escala } 0-1 \text {. } \\
{ }^{*}: p \leq 0.1 ;{ }^{* *}: p \leq 0.05 ; *{ }^{* *}: p \leq 0.01 \\
\text { Fuente: Elaboración propia. }\end{array}$} \\
\hline
\end{tabular}

\subsubsection{Rendimiento}

Los resultados que se recogen en la Tabla 3.9. hacen referencia a indicadores de rendimiento de las micro y pequeñas empresas: si ofrece productos de mayor calidad, si cuenta con clientes más satisfechos, si la empresa está creciendo más, si es más rentable, si tiene trabajadores más satisfechos y motivados y si posee un menor 
absentismo laboral. En todos los indicadores de rendimiento existen diferencias estadísticamente significativas. En especial y significativas al $1 \%$ destacan el crecimiento, la rentabilidad, satisfacción de los trabajadores y el absentismo laboral.

Analizando la variable global RENDIMIENTO, la puntuación promedio alcanzada por el grupo de empresas sin racionamiento es de 32,44 frente al 30,19 del grupo con racionamiento (esta diferencia es muy significativa al 1\%). De este modo, se confirma la $\mathrm{H} 14$ al verificar que el tener un mayor número de indicadores a favor del rendimiento de las Mipymes influye en el menor racionamiento de su acceso al crédito.

Tabla 3.9. Rendimiento

\begin{tabular}{|c|c|c|c|}
\hline \multicolumn{4}{|c|}{$(n=158)$} \\
\hline Variables & $\begin{array}{c}\text { Con } \\
\text { racionamiento } \\
\text { de crédito }\end{array}$ & $\begin{array}{c}\text { Sin } \\
\text { racionamiento } \\
\text { de crédito }\end{array}$ & Significación \\
\hline Ofrece productos mayor calidad & 4,01 & 4,23 & $0,065^{\star}$ \\
\hline Cuenta con clientes más satisfechos & 3,95 & 4,19 & $0,044^{\star \star}$ \\
\hline Está creciendo más & 3,73 & 4,10 & $0,001^{\star * *}$ \\
\hline Es más rentable & 3,61 & 4,03 & $0,000 * * *$ \\
\hline $\begin{array}{l}\text { Tiene empleados más } \\
\text { satisfechos/motivados }\end{array}$ & 3,65 & 4,01 & $0,002^{\star \star *}$ \\
\hline Tiene un menor absentismo laboral & 3,55 & 3,86 & $0,005^{\star \star *}$ \\
\hline $\begin{array}{l}\text { RENDIMIENTO (Global rendimiento) } \\
\text { (1) }\end{array}$ & 30,19 & 32,44 & $0,005^{\star \star \star}$ \\
\hline $\begin{array}{l}\text { Prueba para verificar la significación de las } \\
\text { Para variable con promedio (escala Likert: } \\
(1) \text { Variable aditiva de los diferentes ítems } s \\
{ }^{*}: p \leq 0.1 ;{ }^{* *}: p \leq 0.05 ;{ }^{* * *}: p \leq 0.01 \\
\text { Fuente: Elaboración propia. }\end{array}$ & $\begin{array}{l}\text { bles: } \\
\text { tal Desacuerdo a } \\
\text { rendimiento en }\end{array}$ & $\begin{array}{l}\text { =Total Acuerdo): F- } \\
\text { sala Likert de } 1 \text { a } 5\end{array}$ & test (ANOVA) \\
\hline
\end{tabular}

\subsubsection{Análisis multivariante}

Finalmente, se llevó a cabo un análisis multivariante para cada una de las variables significativas obtenidas mediante el análisis univariante, con el propósito de estudiar las posibles interrelaciones de las variables analizadas. Para tal efecto se optó por la regresión logística del método de Wald. La elección de esta técnica estadística obedece, por una parte, a que la variable dependiente es binaria y cualitativa, y además, a que la mayoría de las variables independientes consideradas no siguen una distribución normal.

En el modelo de regresión logística se incluyeron las variables que definen las características principales de las empresas junto con las variables que resultaron significativas en el análisis univariante. Para determinar la validez del modelo se calculó 
el test de verosimilitud, para encontrar la estimación más probable de los coeficientes, la medida de Hosmer y Lemeshow de ajuste global, el porcentaje global de acierto en la clasificación y la bondad del ajuste a través de los estadísticos de $\mathrm{R}^{2}$ alternativos de Cox y Snell y el estadístico de Nagelkerke. Las pruebas estadísticas realizadas confirman la validez de los resultados obtenidos en cada modelo (tabla 3.10.).

En la Tabla 3.10. se muestran los diferentes modelos construidos. El primer modelo (I) Características, contrasta las características esenciales de las empresas. En concreto, se analizan las hipótesis sobre tamaño, antigüedad de la empresa, sector de actividad, situación jurídica formal y carácter familiar. En relación con las hipótesis H1, TAMAÑO ( $\beta$ : 0,$304 ; N S$ ) y H2, EDAD ( $\beta$ : $-0,245 ; N S)$ que consideran el tamaño y la antigüedad de las empresas analizadas no se obtienen valores significativos que permitan corroborar los resultados del análisis univariante. Respecto al sector económico H3, SECTOR ( $\beta$ : 0,$921 ; p \leq 0,05$ ), se observa un coeficiente positivo y significativo que confirma el análisis univariante, en el sentido de que las pertenecientes a los sectores comercial y servicios están menos racionadas que las de los sectores industria y construcción. Por su parte, los resultados del modelo (I) en relación con la hipótesis H5, LEGAL ( $\beta$ : 1,585; $p \leq 0,01)$ son coherentes con los obtenidos en el análisis univariante, confirmando que la constitución formal de la empresa influye en forma positiva en la probabilidad de su acceso al crédito. Por último, la variable FAMILIAR comprueba la hipótesis $\mathrm{H} 4(\beta$ : $-0,952 ; p \leq 0,1)$, hallándose un valor significativo y negativo que confirma que las empresas familiares están más racionadas que las no familiares.

En relación con el modelo (II) Formación, los resultados son coherentes con los obtenidos previamente, en el análisis univariante, resultando muy significativa al 1\% la variable FORMACION, que confirma la $\mathrm{H} 6 \mathrm{c}(\beta: 1,608 ; p \leq 0,01)$ en el sentido que el mayor nivel de formación académica del gerente de la empresa influye en el menor racionamiento de crédito.

Los resultados del modelo (III) Estrategia también resultan coherentes con los resultados del análisis univariante, confirmando la H7 ESTRATEGIA $(\beta: 0,752 ; p \leq 0,1)$, a un nivel de significación del $10 \%$. De forma que si la empresa realiza procesos formales de planeación estratégica dentro de ella tendrá un mayor acceso a la financiación bancaria.

Los resultados del modelo sobre (IV) Innovación en procesos y/o productos son también coherentes con los resultados obtenidos en el análisis univariante, confirmando la H9, IPROCESOS $(\beta$ : 0,055; $p \leq 0,1)$ a un nivel de significación del 10\%. De modo que 
las empresas que realizan más actividades de innovación en sus productos/servicios y procesos afrontan una menor dificultad en el acceso a la financiación bancaria.

Los resultados del modelo (V) Innovación en gestión son significativos al 5\%, y validan la $H 10$, IGESTION ( $\beta$ : 0,$101 ; p \leq 0,05)$, en el sentido que las empresas que realizan más actividades de innovación en sus sistemas de gestión están menos racionadas en los créditos que solicitan.

En los resultados del modelo (VI), Uso de TIC's, no se obtienen valores significativos para la hipótesis H13, TIC's ( $\beta$ : 0,101 ; NS), lo cual no permite confirmar los resultados previos del análisis univariante.

En el modelo (VII) Estructura Organizativa, se obtiene un valor positivo y significativo en relación con la variable racionamiento de crédito. Esto permite confirmar la hipótesis H8, ORGANIZACION $(\beta$ : 0,761; $p \leq 0,01)$ en el sentido de que las empresas que cuentan con un mayor número de departamentos dentro de su estructura organizativa, tendrán mejores facilidades de acceso a la financiación que aquellas empresas que tienen una estructura organizativa que no se desarrolla formalmente.

Respecto al modelo (VIII) Rendimiento, se obtiene también una relación significativa (5\%) con el racionamiento de crédito, en el sentido que las empresas más rentables serán las que tengan menores dificultades en el acceso a la financiación, validando la $\mathrm{H} 14$, RENDIMIENTO ( $\beta$ : 0,083; $p \leq 0,05)$.

Por último, el modelo (IX) Posición Tecnológica, los resultados son positivos y significativos, lo que permite confirmar la hipótesis H12, TECNOLOGIA ( $\beta$ : 1,694; $p \leq 0,01$ ) de forma que las empresas que tienen una posición tecnológica fuerte tendrán mejores facilidades de acceso a la financiación que aquellas empresas que cuentan con una posición tecnológica sostenible. 
Tabla 3.10. Racionamiento de crédito en la Mipyme

\begin{tabular}{|c|c|c|c|c|c|c|c|c|c|}
\hline MODELOS & (I) & (II) & (III) & (IV) & (V) & (VI) & (VII) & (VIII) & (IX) \\
\hline & Características & Formación & $\begin{array}{c}\text { Plan } \\
\text { Estratégico }\end{array}$ & $\begin{array}{l}\text { Innovación } \\
\text { Procesos y } \\
\text { Productos }\end{array}$ & $\begin{array}{c}\text { Innovación } \\
\text { Gestión }\end{array}$ & $\begin{array}{l}\text { Uso de } \\
\text { TIC's }\end{array}$ & $\begin{array}{c}\text { Estructura } \\
\text { Organizativa }\end{array}$ & Rendimiento & $\begin{array}{c}\text { Posición } \\
\text { Tecnológica }\end{array}$ \\
\hline \multicolumn{10}{|l|}{ Variables } \\
\hline FORMACION & & $\begin{array}{l}1,608^{\star \star *} \\
(10,549)\end{array}$ & & & & & & & \\
\hline ESTRATEGIA & & & $\begin{array}{l}0,752^{*} \\
(2,906)\end{array}$ & & & & & & \\
\hline IPROCESOS & & & & $\begin{array}{l}0,055^{\star} \\
(3,431)\end{array}$ & & & & & \\
\hline IGESTION & & & & & $\begin{array}{l}0,101^{\star *} \\
(5,732)\end{array}$ & & & & \\
\hline TIC'S & & & & & & $\begin{array}{c}0,101 \\
(1,064) \\
\end{array}$ & & & \\
\hline ORGANIZACION & & & & & & & $\begin{array}{l}0,761^{\star \star \star} \\
(20,391)\end{array}$ & & \\
\hline RENDIMIENTO & & & & & & & & $\begin{array}{l}0,083^{\star *} \\
(4,336)\end{array}$ & \\
\hline TECNOLOGIA & & & & & & & & & $\begin{array}{l}1,694^{\star \star \star} \\
(15,840)\end{array}$ \\
\hline \multicolumn{10}{|l|}{$\begin{array}{l}\text { Características } \\
\text { de la empresa }\end{array}$} \\
\hline FAMILIAR & $\begin{array}{l}-0,952^{*} \\
(3,665) \\
\end{array}$ & $\begin{array}{l}-0,640 \\
(1,458) \\
\end{array}$ & $\begin{array}{l}-0,886^{\star} \\
(3,065) \\
\end{array}$ & $\begin{array}{c}-1,103^{\star \star} \\
(4,635) \\
\end{array}$ & $\begin{array}{l}-0,940^{\star} \\
(5,435) \\
\end{array}$ & $\begin{array}{l}-0,936^{\star} \\
(3,561) \\
\end{array}$ & $\begin{array}{l}-0,871 \\
(2,550) \\
\end{array}$ & $\begin{array}{l}-0,900^{*} \\
(3,095) \\
\end{array}$ & $\begin{array}{l}-1,211^{\star \star} \\
(5,340)\end{array}$ \\
\hline LEGAL & $\begin{array}{l}1,585^{\star \star \star} \\
(17,005)\end{array}$ & $\begin{array}{l}1,190^{\star \star \star} \\
(8.329)\end{array}$ & $\begin{array}{l}1,433^{\star \star \star} \\
(13,173)\end{array}$ & $\begin{array}{l}1,506^{\star \star \star} \\
(14,823)\end{array}$ & $\begin{array}{l}1,401^{\star \star \star} \\
(12,466)\end{array}$ & $\begin{array}{l}1,408^{\star \star \star} \\
(11,401)\end{array}$ & $\begin{array}{l}0,808^{*} \\
(3,301)\end{array}$ & $\begin{array}{l}1,652^{\star \star \star} \\
(17,412)\end{array}$ & $\begin{array}{l}1,553^{\star \star \star} \\
(14,237)\end{array}$ \\
\hline EDAD & $\begin{array}{l}-0.245 \\
(0,452)\end{array}$ & $\begin{array}{l}-0,239 \\
(0,398)\end{array}$ & $\begin{array}{l}-0,301 \\
(0,666)\end{array}$ & $\begin{array}{l}-0,281 \\
(0,583)\end{array}$ & $\begin{array}{l}-0,307 \\
(0,679)\end{array}$ & $\begin{array}{l}-0,261 \\
(0,507)\end{array}$ & $\begin{array}{l}-0,314 \\
(0,617)\end{array}$ & $\begin{array}{l}-0,395 \\
(1,091)\end{array}$ & $\begin{array}{c}0,027 \\
(0,005)\end{array}$ \\
\hline SECTOR & $\begin{array}{l}0.921^{\star *} \\
(5,985)\end{array}$ & $\begin{array}{l}0,836^{\star *} \\
(4,573)\end{array}$ & $\begin{array}{c}0,924^{\star *} \\
5,915\end{array}$ & $\begin{array}{c}1,021^{\star \star \star} \\
(6,950)\end{array}$ & $\begin{array}{l}0,959^{* *} \\
(6,188)\end{array}$ & $\begin{array}{l}0,964^{\star *} \\
(6,418)\end{array}$ & $\begin{array}{l}0,991^{* *} \\
(5,591)\end{array}$ & $\begin{array}{l}0,893^{\star *} \\
(5,346)\end{array}$ & $\begin{array}{l}0,799^{* *} \\
(4,006)\end{array}$ \\
\hline TAMAÑO & $\begin{array}{c}0.304 \\
(0,679)\end{array}$ & $\begin{array}{c}0,225 \\
(0,342)\end{array}$ & $\begin{array}{c}0,231 \\
(0,382)\end{array}$ & $\begin{array}{c}0,237 \\
(0,399)\end{array}$ & $\begin{array}{c}0,197 \\
(0,272)\end{array}$ & $\begin{array}{c}0,205 \\
(0,290)\end{array}$ & $\begin{array}{l}-0,045 \\
(0,012)\end{array}$ & $\begin{array}{c}0,081 \\
(0,043)\end{array}$ & $\begin{array}{c}0,088 \\
(0,049)\end{array}$ \\
\hline CONSTANTE & $\begin{array}{c}-0,998 \\
(1,057)\end{array}$ & $\begin{array}{l}-2,935^{\star} \\
(6,115)\end{array}$ & $\begin{array}{l}-1,071 \\
(1,198)\end{array}$ & $\begin{array}{l}-1,487 \\
(2,149)\end{array}$ & $\begin{array}{l}-1,213 \\
(1,512)\end{array}$ & $\begin{array}{l}-1,094 \\
(1,242)\end{array}$ & $\begin{array}{l}-1,952^{\star} \\
(3,167)\end{array}$ & $\begin{array}{c}-3,321^{\star *} \\
(4,380)\end{array}$ & $\begin{array}{c}-3,173^{* \star \star} \\
(7,077)\end{array}$ \\
\hline Chi-cuadrado & $29,976^{\star \star \star}$ & $41,781^{\star \star \star}$ & $32,926^{\star \star \star}$ & $33,483^{\star \star \star}$ & 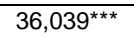 & $31,066^{\star \star \star}$ & $55,331^{\star \star \star}$ & $35,748^{\star \star \star}$ & $47,467^{\star \star \star}$ \\
\hline Hosmer-L. & $\begin{array}{c}4,625 \\
(0,797)\end{array}$ & $\begin{array}{c}3,722 \\
(0,881)\end{array}$ & $\begin{array}{c}4,124 \\
(0,846)\end{array}$ & $\begin{array}{c}7,463 \\
(0,488)\end{array}$ & $\begin{array}{c}6,301 \\
(0,614)\end{array}$ & $\begin{array}{l}11,798 \\
(0,160)\end{array}$ & $\begin{array}{c}4,032 \\
(0,854)\end{array}$ & $\begin{array}{c}4,182 \\
(0,840)\end{array}$ & $\begin{array}{c}7,641 \\
(0,469)\end{array}$ \\
\hline $\mathrm{R}^{2} \operatorname{Cox}$ & 0,180 & 0,242 & 0,196 & 0,199 & 0,212 & 0,186 & 0,307 & 0,213 & 0,270 \\
\hline $\mathrm{R}^{2}$ Nagelkerke & 0,240 & 0,322 & 0,261 & 0,265 & 0,283 & 0,248 & 0,409 & 0,284 & 0,360 \\
\hline
\end{tabular}

Notas: B: Coeficientes logísticos, son empleados para medir los cambios en los ratios de probabilidades, denominado odds ratio. Un coeficiente positivo incrementa la probabilidad pronosticada, mientras un valor negativo disminuye la probabilidad predicha. Wald:estadístico de Wald, entre paréntesis.Sig.:nivel de significación. ${ }^{*}$ : $\leq 0.1 ;{ }^{* *}$ : $p \leq 0.05 ;{ }^{* *}$ : $p \leq 0.01$. La significación estadística del modelo se ha determinado utilizando la medida de Hosmer-Lemeshow de ajuste global donde se obtiene un contraste estadístico que indica que no existe diferencia estadística significativa entre las clasificaciones observadas y predichas, ya que el valor de la Chi-cuadrado no es significativo. Como resumen del modelo se ofrece el -2 log likelihood; $\mathrm{R}^{2}$ de Cox y Snell; $\mathrm{R}^{2}$ de Nagelkerke. Adicionalmente, como medida global de ajuste el valor de la prueba omnibus sobre los coeficientes del modelo se incluye la prueba Chi-cuadrado con su nivel de significación. La definición de las variables es la siguiente: FORMACIÓN, se mide como una dummy según se tengan o no estudios universitarios y/o posgrado; ESTRATEGIA, según la empresa desarrolle o no un plan estratégico; IPROCESOS, variable aditiva de los ítems que miden innovación en productos y procesos; IGESTION, variable aditiva de los ítems que miden innovación en gestión; TIC'S, variable aditiva de los ítems que miden el grado de uso de las tecnologías de la información; ORGANIZACIÓN, variable aditiva de los ítems que miden el número de departamentos formalmente establecidos; RENDIMIENTO, variable aditiva de los ítems que miden e desempeño; TECNOLOGÍA, variable dummy que mide si la empresa desarrolla una tecnología fuerte o sostenible; FAMILIAR, variable dummy que mide si el control mayoritario de la empresa es familiar; LEGAL, variable dummy que mide si la empresa está legalmente constituida; EDAD, dummy que toma la mediana de la antigüedad de las empresas, menor o igual que 7 años; SECTOR, variable dummy que divide a las empresas en dos grupos, industrial y construcción frente a servicios y comerciales; TAMAÑO, dummy que divide a la muestra entre empresas menores o iguales a 4 trabajadores y el resto.

Fuente: Elaboración propia. 
Tabla 3.11. Tabla de Correlaciones de Spearman

\begin{tabular}{|c|c|c|c|c|c|c|c|c|c|c|c|c|c|}
\hline & 1 & 2 & 3 & 4 & 5 & 6 & 7 & 8 & 9 & 10 & 11 & 12 & 13 \\
\hline 1 FORMACION & 1.00 & & & & & & & & & & & & \\
\hline 2 ESTRATEGIA & $0.31 \mathrm{a}$ & 1.00 & & & & & & & & & & & \\
\hline 3 IPROCESOS & $0.17 a$ & $0.22 \mathrm{a}$ & 1.00 & & & & & & & & & & \\
\hline 4 IGESTION & $0.22 \mathrm{a}$ & $0.34 a$ & $0.54 a$ & 1.00 & & & & & & & & & \\
\hline 5 TIC'S & $0.44 a$ & $0.28 a$ & $0.28 a$ & $0.26 \mathrm{a}$ & 1.00 & & & & & & & & \\
\hline 6 ORGANIZACION & $0.30 \mathrm{a}$ & $0.41 a$ & $0.22 a$ & $0.30 \mathrm{a}$ & $0.28 \mathrm{a}$ & 1.00 & & & & & & & \\
\hline 7 RENDIMIENTO & $0.21 \mathrm{a}$ & $0.21 \mathrm{a}$ & $0.15 a$ & $0.20 \mathrm{a}$ & $0.24 a$ & $0.11 \mathrm{a}$ & 1.00 & & & & & & \\
\hline 8 TECNOLOGIA & $0.15 a$ & 0.09 & 0.09 & $0.16 \mathrm{a}$ & $0.16 \mathrm{a}$ & $0.11 \mathrm{a}$ & $0.22 \mathrm{a}$ & 1.00 & & & & & \\
\hline $\begin{array}{ll}9 & \text { FAMILIAR } \\
\end{array}$ & -0.01 & -0.04 & 0.06 & -0.06 & 0.08 & -0.00 & -0.01 & 0.08 & 1.00 & & & & \\
\hline 10 LEGAL & $0.33 a$ & $0.20 \mathrm{a}$ & 0.08 & $0.10 \mathrm{a}$ & $0.43 a$ & $0.32 a$ & 0.09 & 0.08 & 0.06 & 1.00 & & & \\
\hline 11 EDAD & -0.06 & 0.01 & 0.03 & 0.02 & 0.05 & 0.01 & -0.02 & -0.06 & -0.03 & 0.04 & 1.00 & & \\
\hline 12 SECTOR & 0.06 & -0.04 & $-0.14 a$ & 0.10 & $-0.17 a$ & 0.01 & -0.06 & 0.08 & -0.05 & -0.02 & -0.06 & 1.00 & \\
\hline 13 TAMAÑO & $0.18 \mathrm{a}$ & $0.17 a$ & $0.19 a$ & $0.17 a$ & $0.32 a$ & $0.14 a$ & $0.20 \mathrm{a}$ & 0.02 & 0.03 & $0.17 a$ & 0.09 & $0.18 \mathrm{a}$ & 1.00 \\
\hline
\end{tabular}

Notas: Se muestra el coeficiente de correlación de Spearman: a Coeficientes significativos al 0.01; b Coeficientes significativos al 0.05 Fuente: Elaboración propia. 


\subsection{CONCLUSIONES}

Dentro de la línea de investigación sobre dificultades de acceso al crédito y las causas de racionamiento, siguiendo los estudios previos de McCarthy et al. (2013) y Okuyan (2016), hemos desarrollado el presente estudio analizando las causas del racionamiento de crédito en las micro y pequeñas empresas peruanas. Dado que en Perú se produce un especial problema en el acceso al crédito puesto que el sistema financiero no está plenamente desarrollado y las posibilidades de acceso al crédito bancario son menores que en otras economías.

Nuestro trabajo produce robustos resultados en cuanto a factores que influyen en el acceso a la financiación de las micro y pequeñas empresas en Perú. Dichas variables son la innovación en procesos y sistemas de gestión de la empresa, tipo de tecnología que utiliza, nivel de formación del gerente, forma jurídica, carácter familiar, así como el sector al que pertenece la empresa. Esto puede servir de referencia a los empresarios para que centralicen sus esfuerzos en aquellos factores internos a la empresa que le permitan un mayor y mejor acceso a la obtención de fondos de los bancos. Adicionalmente, se identifican factores tangibles y no tangibles como la certificación de calidad, el contar con buenos sistemas de gestión, hacer planeamiento dentro de la empresa, realizar actividades de innovación, contar con directivos altamente calificados y con experiencia que le permitan dar señales a los prestatarios de la buena condición del negocio y de los proyectos que presenta.

Dado que las micro y pequeñas empresas peruanas con frecuencia desconocen las fuentes de financiación disponibles, así como la forma de negociación que las posicione adecuadamente para ser vistas favorablemente por los prestamistas (Abor \& Biekpe, 2007), nuestro trabajo puede ayudar a las Mipymes a dar señales positivas a los bancos que le permitan una mejor evaluación crediticia y por ende facilite su acceso a la financiación.

En relación con las instituciones gubernamentales, y en línea con lo mantenido por Al-Hyari (2013), el gobierno peruano debería considerar la promoción de acciones que mejoren la competitividad de la Mipyme y mejoren la economía del país. En esta línea, nuestro trabajo también puede ser útil para los responsables de tomar e implementar políticas que tengan que ver con la regulación, creación, sostenibilidad y desarrollo de las Mipymes.

El estudio presenta limitaciones que generan la necesidad de profundizar en esta misma línea de investigación. Así, la cantidad y calidad de información disponible en 
Perú limita la posibilidad de ampliar los datos de corte transversal y continuar con un análisis y seguimiento longitudinal. Adicionalmente, dado el escaso desarrollo y consolidación del sistema financiero no se dispone de información de acceso al crédito que permita añadir al análisis microeconómico, variables macro y de uso y disponibilidad de recursos bancarios. En este sentido, diversos autores utilizan bases de datos de organismos e instituciones relacionadas con el sistema financiero de su país o de la región (Mijid, 2015; Xiao-hong \& Yang-jie, 2013; Larrán et al., 2010; Angelini et al., 1998). Futuros trabajos de investigación podrían analizar el efecto que sobre el racionamiento tienen los programas financiados en parte por el gobierno y extender el efecto del racionamiento a las empresas informales como lo realiza Mushinski \& Pickering (2007). Por último, dado que se trata de una investigación con carácter exploratorio, no hemos realizado un control de la endogeneidad y causalidad en la relación entre las variables analizadas, esto supone una limitación del trabajo que abre líneas de investigación futuras para el análisis individualizado de cada una de dichas relaciones. 
4. FACTORES DETERMINANTES PARA LA CONCESIÓN DE CRÉDITO POR PARTE DE LAS ENTIDADES FINANCIERAS A

LAS MIPYMES 


\subsection{INTRODUCCIÓN}

A la hora de conceder un crédito, en el proceso de intermediación financiera, surge el problema de la información asimétrica, donde normalmente el prestamista no tiene toda la información relevante sobre el prestatario. Este problema no existiría si el prestamista dispusiera de toda la información necesaria o tuviera a su alcance todos los mecanismos de detección y determinación de los riesgos involucrados (EsquivelMartínez \& Hernández-Ramos, 2007). En el caso de las Mipymes, este problema es más relevante, debido a la alta opacidad de la información que muchas veces presentan, donde los estados financieros no son totalmente claros, o están desequilibrados y sin el aval de un auditor externo, lo que a su vez hace que los prestamistas sean menos flexibles en la concesión de préstamos a este tipo de empresas (Dayé, Houssa, \& Reding, 2015). Además, esto se agudiza debido a que normalmente las Mipymes no cuentan en muchos casos con los activos físicos necesarios para dejarlos como garantía de préstamo (Chen, Huang, Tsai, \& Tzeng, 2013). Toda esta problemática, en el contexto de la Mipyme, implica en muchas ocasiones que surjan problemas de restricciones financieras.

Por esta razón es importante en el sistema financiero que las entidades tengan un mecanismo claro y comprensible de cómo gestionar la selección de su cartera de créditos (Iyer, Khwaja, Luttmer, \& Shue, 2014). Las entidades financieras utilizan dos tipos de información para su toma de decisiones: la información dura, de carácter cuantitativo, relativamente fácil de procesar y manejable con grandes magnitudes (Petersen, 2004), puede ser pasado a una escala numérica y es fácilmente verificable (Agarwal, Ambrose, Chomsisengphet, \& Liu, 2011); y la información denominada blanda, de carácter subjetivo o cualitativo, difícil de ser comparable como sí lo puede ser por ejemplo un determinado ingreso por ventas de una empresa (Petersen, 2004). En la literatura financiera existen estudios que apoyan que se privilegie más el uso de la información dura, mientras que otros resaltan la complementariedad y muestran que cuando se incluye información blanda a la dura, esto mejora el acierto en la asignación de crédito a las empresas (Grunert, Norden, \& Weber, 2005; Cornée, 2017).

El objetivo de este trabajo es analizar los criterios que utilizan las entidades financieras a la hora de otorgar un crédito a una Mipyme. Para ello se realiza un estudio empírico a partir de la información suministrada por 73 responsables de las áreas de créditos y riesgos de las principales entidades financieras peruanas. Las cuestiones de investigación que se tratan de responder son: ¿Cuáles son los criterios más relevantes para las entidades financieras a la hora de conceder un crédito?, 
¿Predomina la información dura o la información blanda a la hora de conceder un crédito?, ¿Existen diferencias entre las entidades financieras en los criterios utilizados?, ¿Se dan diferencias de criterios según las características personales del analista de riesgos? La respuesta a estas cuestiones tiene importantes implicaciones. Por un lado, ayudan al gestor de la Mipyme a conocer la importancia de los distintos criterios que utilizan las entidades financieras para otorgar un crédito, y así pueden enfocar con mayor claridad la información que estas entidades requieren. Y por otra parte permite a los responsables de riesgos de las entidades financieras favorecer mecanismos de gestión de la información para su toma de decisiones. El caso peruano es especialmente interesante debido a que el Perú es una economía en desarrollo que forma parte de la Alianza del Pacífico y ha tenido un crecimiento económico importante en la última década y las micro y pequeñas empresas representan el $98 \%$ de las unidades productivas del país e integran el $80 \%$ del empleo y el $61 \%$ del PIB. La demanda de crédito en Perú a las entidades financieras por parte de las micro y pequeñas empresas se ha ido incrementando, y surge con frecuencia problemas de asimetría de información, siendo necesario favorecer la relación entre prestamista y prestatario.

Este trabajo es de utilidad para los analistas de créditos, para los empresarios y para las entidades financieras. Los resultados de este trabajo pueden ayudar a los analistas de créditos a conocer las variables más relevantes en la toma de decisiones en el otorgamiento de préstamos a las empresas. Puede ser de utilidad también a los empresarios, para que centren sus esfuerzos en ciertos aspectos que le ayuden a tener mayor probabilidad para que le aprueben sus solicitudes de créditos. Finalmente, a las entidades financieras, quienes pueden utilizar estos resultados para mejorar sus modelos de riesgo para evaluar sus operaciones crediticias.

El artículo está organizado como se describe a continuación. La sección 2 hace una revisión del marco teórico y estudios previos acerca de los criterios que utilizan las entidades crediticias para la selección de sus clientes. La sección 3 describe el cuestionario utilizado, la recolección de la información y los métodos de análisis. La sección 4 presenta los resultados obtenidos y la sección 5 las conclusiones del trabajo. 


\subsection{MARCO TEÓRICO, REVISIÓN DE ESTUDIOS PREVIOS E HIPÓTESIS A CONTRASTAR}

El crecimiento y consolidación de las empresas está muy relacionado con su capacidad para acceder a los recursos financieros (Montoya, 2016; Rodríguez, 2012). El crédito bancario es una importante fuente de financiamiento para las Mipymes. $Y$ en general las Mipymes se enfrentan, por una parte, al problema de información asimétrica, y a la mayor sensibilidad ante los cambios que puedan darse en el sistema financiero local. A diferencia de las empresas de mayor tamaño, que pueden recurrir con relativa facilidad a otras fuentes como a los bancos del exterior o al mercado de capitales utilizando instrumentos financieros sofisticados (Bellina, 2004). El problema de información asimétrica, se refiere como es conocido, a que los clientes tienen una mayor y mejor información que las entidades de crédito en lo referente a la calidad y riesgo de los proyectos que trata de financiar, así como de la capacidad de gestión de sus directivos y de sus motivaciones internas para el pago de la deuda que van a asumir. Los prestamistas al tratar de disminuir el problema terminan otorgando préstamos de mayor riesgo (selección adversa) y los malos prestatarios pueden utilizar los recursos prestados a otros proyectos y existir incumplimientos con los pagos (riesgo moral) (Dayé et al., 2015).

La relativa opacidad de la información que presentan las pequeñas empresas hace que influya en el rechazo a los requerimientos de préstamos por parte de las entidades financieras. Las empresas presentan proyectos que son difíciles de monitorear y evaluar, o están manejadas por directivos con historial muy reciente y presentan garantías muy limitadas (Freel et al., 2012). Esta opacidad de la información agudiza los problemas de asimetría de información, ocasionado por la presentación de estados financieros no muy claros, no equilibrados y sin auditar (Dayé et al., 2015).

La actividad más conocida de las entidades financieras, como son la captación y colocación de fondos, tiene varios riesgos relacionados con el no cumplimiento de los compromisos del préstamo y lo que se refiere a la solvencia de los prestatarios (Alexandre \& Smondel, 2012). Las entidades financieras para tomar la decisión acerca de la aprobación de los créditos a los potenciales prestatarios emplean diversos tipos de información, así como definen las características del contrato de crédito a pactar con los clientes (Agarwal et al., 2011). Por tanto, la adquisición de información es una función básica por parte de los intermediarios financieros, que los conduce a un mejor y mayor conocimiento de sus prestatarios para descartar los proyectos de menor calidad (Karapetyan \& Stacescu, 2014). 
Las entidades financieras utilizan diversas herramientas que les permite una mejor evaluación, medición y control de sus clientes (Alexandre \& Smondel, 2012). Muchos bancos tratan de conseguir más información a través de las centrales de información de créditos y van acumulando información que les ayude para crear un modelo de credit scoring para seleccionar a los mejores prestatarios. Este modelo debe ser fácil de modificar ante cambios en la información proveniente de las centrales de crédito y en el entorno del negocio de las empresas (Tsaih, Liu, Liu, \& Lien, 2004). Existe un amplio consenso en clasificar a la información que manejan las entidades de crédito en dos tipos: información blanda e información dura. Alexandre \& Smondel (2012) definen la información blanda como todos aquellos datos cualitativos, que se reducen a un pequeño texto escrito y que reflejan las opiniones y los juicios de la persona que los recopiló, quien a su vez es el que debe tener una relación directa y cercana con el prestatario; mientras que la información dura lo constituyen los datos cuantitativos, que tienen un menor contenido impersonal y son independientes del contexto en el que fue recolectado.

Se puede mencionar como ejemplos de información blanda las calificaciones que se realizan a los créditos de consumo y a los bonos corporativos (Agarwal et al., 2011). Petersen (2004) agrega que también son parte de la información considerada como blanda aspectos como la honestidad del cliente, su capacidad de gestión y su comportamiento ante situaciones bajo presión, la percepción del mercado, la situación de los planes futuros de la empresa y las proyecciones económicas. Como ejemplos de información dura menciona a la información contenida en los estados financieros auditados, el historial de pagos de los clientes y el rendimiento de las acciones de la empresa.

La información blanda puede obtenerse a través de los analistas de créditos de las instituciones financieras contando con la solicitud de préstamo del potencial cliente o por medio de las relaciones que establecen con los empresarios (Agarwal et al., 2011). También se puede obtener haciendo que determinados empleados de los bancos realicen visitas a las empresas de los prestatarios, entrevisten al personal relevante de ésta, para posteriormente emitir su opinión con una calificación numérica acerca del nivel de solvencia de la empresa (Chen et al., 2013).

En las últimas décadas la información dura ha sido utilizada intensamente por los bancos para sus procesos de selección de clientes y fijación de precios (tasa de interés activa). A partir de los trabajos pioneros de Beaver y Altman en la década de los 60 , se desarrollaron modelos de riesgos de crédito que usan en forma privilegiada 
datos cuantitativos extraídos de la información de la empresa o del mercado en el que operan (Cornée, 2017). Sin embargo, diversos estudios han mostrado la importancia de la información blanda. Chang, Liao, Yu, \& Ni (2014) mencionan que la información blanda que acompaña a la información dura empleada en una calificación de crédito interno de la institución financiera en base por ejemplo a los ratios financieros de la empresa, ayuda a mejorar la calidad de la evaluación del crédito solicitado. Más aún, en concreto, al evaluar la morosidad, la información blanda que se capta a través de una relación de préstamo sostenida, hace que la información blanda sea más que un complemento, un sustituto del papel que hace la información dura; en especial si esta información dura es relativamente fácil de manipular.

La información blanda puede también ser de mucha utilidad para el analista de crédito en la toma de decisiones en el otorgamiento de préstamos, al darle información adicional relacionada a la disponibilidad del empresario para pagar el préstamo (Agarwal et al., 2011). Las instituciones de crédito están dispuestas a afrontar mayores costos por la obtención de información blanda relacionada con los prestatarios. Karapetyan \& Stacescu (2014) llegaron a la conclusión de que los prestamistas se ven incentivados a invertir en información blanda cuando las agencias de crédito ponen a disposición de todas las entidades financieras del sistema acerca del historial de crédito, la morosidad y otros datos de los potenciales prestatarios. Esto es debido a que la inversión en la obtención de información blanda es menor a la utilidad marginal que se obtendrá como resultado de una menor pérdida por el otorgamiento de préstamos a malos clientes.

La información blanda es más completa y puede darnos una mejor idea de la situación real de la empresa al integrar los datos relacionados con la situación de la economía, características generales del conductor del negocio y otros factores que estén afectando su operatividad. En este sentido es más rica esta información que la dura y la entidad financiera puede tomar decisiones de mayor calidad utilizando de forma complementaria ambos tipos de información (Alexandre \& Smondel, 2012).

Para procesar el grueso de la información dura no se necesita de personas altamente cualificadas, más si para el análisis de la información blanda (Alexandre \& Smondel, 2012). Contar con personal con más experiencia y competencia involucra mayores costos en la recopilación y análisis de la información blanda debido al nivel salarial que normalmente exige este tipo de analistas de las instituciones financieras. En el caso del tratamiento de la información dura, al ser procesada por personal más operativo, los costos son menores y la toma de decisiones con la información 
procesada se centraliza en los niveles altos de la organización crediticia (Alexandre \& Smondel, 2012). Scott (2006) llega a mostrar la importancia de los analistas de crédito sobre la disponibilidad de crédito para las pequeñas empresas. Cuanto más importante es el papel de la información blanda en la decisión del otorgamiento de crédito, la rotación de los analistas afecta de forma adversa sobre la disponibilidad de crédito.

El papel del analista de crédito parece relativamente sencillo, pero como cualquier persona, sus decisiones y actuaciones varían y se ven influenciadas de acuerdo a los cambios en el entorno. El analista tiene que recoger información muy variable en el tiempo y hacer un esfuerzo de análisis para ver en qué medida estos cambios afectan a su relación con los prestatarios, y por ende al coste y disponibilidad de los créditos (Alexandre \& Smondel, 2012). Holod \& Peek (2013) sugieren que los bancos que establecen relaciones duraderas a través del tiempo con sus clientes, pueden de manera relativamente fácil y poco costosa ir recolectando información blanda aparte de la dura que les permita controlar y monitorear mejor sus préstamos y tomar mejores decisiones de los créditos que otorgan.

La cantidad de información que disponen los bancos acerca de los prestatarios es cada vez mayor, facilitada por el progreso en las tecnologías de información y comunicación, así como por la mayor capacidad para el procesamiento y análisis de la información y la existencia de agencias especializadas que proporcionan información de crédito. Este progreso ha facilitado la reducción de las visitas a las empresas por parte de los analistas de crédito y el control y seguimiento de los clientes, aumentando la productividad del personal involucrado (DeYoung, Glennon, \& Nigro, 2008). Además, la informática que puede procesar altos volúmenes de información a muy bajo costo, ha hecho que la información dura haya sido el tipo de información de más amplio uso por las instituciones financieras, debido a su facilidad para su almacenamiento y comunicación (Alexandre \& Smondel, 2012).

Varios autores resaltan los principales criterios que se deben utilizar al evaluar la posibilidad de otorgar créditos a empresas que presentan nuevos proyectos. Zhang (2012) considera 5 aspectos de evaluación: 1) La evaluación de la gestión de la empresa abarca la calidad de la gestión y del personal clave, la planificación y la rendición de cuentas, la gestión de la información y la presentación de informes relevantes de ventas, rentabilidades de los productos y precios; y la compensación al personal. 2) evaluación de la operación (plan de ingresos, gestión de los gastos, los planes operacionales y la eficiencia y calidad del proceso. 3) Evaluación de la 
estrategia que incluye las tendencias del mercado, su posición competitiva, su estrategia de crecimiento y la gestión de los clientes. 4) Evaluación de las transacciones que incluye el valor de realización de la empresa y su tiempo de salida. 5) Evaluación de costos (de financiación, la relación de ingresos y gastos y la estructura de sus activos). Adicionalmente, Streletzki \& Schulte (2013) resaltan que son importantes aspectos como: - la etapa de desarrollo en la que se encuentra la empresa solicitante de crédito, - la ubicación de la empresa y su cercanía a su potencial cartera, - su capacidad de asociación para establecer alianzas, redes o asesoría técnica, financiera o legal, - patentes, - prueba de su concepto de negocio cuando se aplica la inversión inicial, - diversidad de productos/servicios que ofrecen, segmento del mercado al que apuntan y - estrategia para entrar al mercado.

Otros trabajos como el de Mishra (2004) analiza factores referentes a la personalidad y experiencia del empresario, características del producto o servicio y del mercado, en la evaluación de las inversiones. En base a una encuesta a 40 altos ejecutivos de empresas de capital riesgo de la India, encuentra que las 10 principales variables que consideran para la evaluación de las inversiones son: integridad del empresario, tasa de crecimiento del mercado, visión a largo plazo, necesidad de crecer de la empresa, capacidad de atención a los detalles por parte del empresario, su familiaridad con el mercado meta, si cuenta con un equipo equilibrado, capacidad del empresario de sostener un esfuerzo intenso, y las habilidades técnicas y financieras del equipo de gestión. Ge, Mahoney, \& Mahoney (2005) consideran ochos aspectos: diferenciación del producto, tasa de crecimiento de la demanda, experiencia previa del emprendedor en el sector, experiencia previa del empresario en alta dirección, experiencia en el emprendimiento previo de otros negocios, si el fundador del negocio es único o es un equipo, si la empresa cuenta con un equipo de gestión y si cuenta con vínculos externos. Uchida (2011) en base a 1040 encuestas a los principales bancos en Japón obtiene que toman decisiones sobre el otorgamiento de créditos: tipo de negocio, capacidad de gestión del empresario y la fuerza operacional de la pyme (creatividad y capacidad técnica).

\subsection{METODOLOGÍA}

\subsubsection{Datos}

Para llevar a cabo el estudio, se adaptó el cuestionario utilizado por Hernández-Cánovas, Madrid-Guijarro, \& Van Auken (2010) y Pintado, García Pérez de 
Lema, \& Van Auken (2007). El trabajo de campo fue realizado en el primer semestre de 2016. Dicho cuestionario estuvo dirigido a los analistas de las áreas de créditos y riesgos de las principales entidades financieras peruanas que otorgan préstamos a empresas. Los contactos fueron realizados por llamada telefónica y enviando una carta de presentación y el cuestionario por e-mail. En varios casos la encuesta también se realizó directamente a través de contactos de algunas de las entidades crediticias. La composición de las entidades que conforman la muestra se puede ver en la tabla 4.1.

La selección de las variables es fundamental a la hora de configurar el análisis empírico y nos permitirá afrontar adecuadamente el estudio de las principales variables que toman en cuenta las entidades financieras peruanas para la toma de decisiones en el otorgamiento de financiación de proyectos que presentan las empresas. Para obtener la información de las variables se elaboró un cuestionario dirigido a los analistas de estas instituciones financieras. Con esta herramienta se ha buscado recoger de forma clara y concisa la información fundamental que constituye el objetivo de esta investigación. En su elaboración se ha cuidado especialmente la estructuración del mismo, una redacción adecuada y sencilla y, sobre todo, un contenido breve. Antes de la aplicación definitiva se llevó a cabo una prueba piloto a 5 analistas de distintas entidades financieras, con el propósito de afinar el instrumento de medición para la aplicación definitiva.

Tabla 4.1. Composición de las entidades financieras de la muestra

\begin{tabular}{|l|c|c|}
\hline Entidad financiera & $\begin{array}{c}\text { Número de } \\
\text { encuestas }\end{array}$ & $\begin{array}{c}\text { Porcentaje de } \\
\text { encuestas }\end{array}$ \\
\hline Banco 1: Banco de Crédito & 15 & $20,5 \%$ \\
\hline Banco 2: BBVA & 19 & $26,0 \%$ \\
\hline Banco 3: Scotiabank & 9 & $12,3 \%$ \\
\hline Banco 4: Banco Cencosud & 8 & $11,0 \%$ \\
\hline Banco 5: Banco Financiero & 14 & $19,2 \%$ \\
\hline Banco 6: Interbank & 2 & $2,7 \%$ \\
\hline Banco 7: BANBIF (Banco Interamericano de Finanzas) & 1 & $1,4 \%$ \\
\hline Financiera Confianza & 5 & $6,9 \%$ \\
\hline Total & 73 & $\mathbf{1 0 0 \%}$ \\
\hline Fuente: Elaboración propia. & \multicolumn{2}{|l}{} \\
\hline
\end{tabular}


El cuestionario está constituido por cinco bloques. El primer bloque solicita información general del analista encuestado: edad, sexo, años de experiencia como analista de riesgos, nivel de formación y el puesto que ocupa actualmente. Los cuatro bloques restantes solicitan al encuestado para que de una valoración acerca de los siguientes aspectos:

1. Personalidad y experiencia del empresario.

2. Características del producto o servicio que ofrece la empresa y del mercado donde desarrolla su actividad.

3. Estrategia y organización de la empresa.

4. Información contable que presenta la empresa.

Las medidas de todas las variables consideradas en cada bloque se realizan usando la escala Likert (donde 1=si consideran a la variable como poco importante para la toma de decisiones en la financiación a las empresas y $5=s i$ consideran muy importante a la variable en cuestión). Ver en las tablas 4.2., 4.3. y 4.4. la relación de variables incluidas en cada bloque.

\subsection{ANÁLISIS DE RESULTADOS}

\subsubsection{Análisis univariante}

\subsubsection{Variables acerca de la personalidad y experiencia del empresario}

La tabla 4.2. incluye el análisis univariante relacionado con las variables que miden la influencia de la personalidad y la experiencia del empresario que solicita financiación en las decisiones de crédito que toman los analistas de riesgos de las entidades de crédito. 
Tabla 4.2. Media y valor de significación de la diferencia entre los ítems asociados con la personalidad y experiencia del empresario

\begin{tabular}{|c|c|c|c|c|c|c|c|c|c|c|}
\hline \multirow{2}{*}{$\begin{array}{l}\text { Personalidad y experiencia del } \\
\text { empresario }(n=73)\end{array}$} & \multirow{2}{*}{$\begin{array}{l}\text { Valor } \\
\text { de la } \\
\text { media }\end{array}$} & \multicolumn{3}{|c|}{ Sexo } & \multicolumn{3}{|c|}{ Experiencia } & \multicolumn{3}{|c|}{$\begin{array}{l}\text { Formación } \\
\text { Universitaria }\end{array}$} \\
\hline & & Masc & Fem & Sig & - & + & Sig & - & + & Sig \\
\hline $\begin{array}{l}\text { Capacidad de reacción/evaluación de } \\
\text { riesgos }\end{array}$ & 4,05 & 3,95 & 4,24 & n.s. & 4,01 & 4,16 & n.s. & 4,00 & 4,08 & n.s. \\
\hline Honestidad e integridad & 4,28 & 4,08 & 4,68 & ** & 4,24 & 4,38 & n.s. & 4,15 & 4,36 & n.s. \\
\hline $\begin{array}{l}\text { Capacidad de realizar esfuerzo } \\
\text { sostenido/intenso }\end{array}$ & 3,58 & 3,41 & 3,92 & * & 3,50 & 3,83 & n.s. & 3,50 & 3,63 & n.s. \\
\hline Habilidad analítica & 4,02 & 3,93 & 4,20 & n.s. & 4,00 & 4,11 & n.s. & 4,00 & 4,04 & n.s. \\
\hline Deseo de ganar dinero & 3,31 & 3,25 & 3,44 & n.s. & 3,31 & 3,27 & n.s. & 3,34 & 3,29 & n.s. \\
\hline Facilidad de palabra & 3,19 & 3,06 & 3,44 & n.s. & 3,25 & 2,94 & n.s. & 3,15 & 3,21 & n.s. \\
\hline Organización de su equipo & 3,84 & 3,79 & 3,96 & n.s. & 3,81 & 3,94 & n.s. & 3,76 & 3,89 & n.s. \\
\hline Es meticuloso y detallista & 3,86 & 3,85 & 3,88 & n.s. & 3,90 & 3,66 & n.s. & 3,84 & 3,87 & n.s. \\
\hline Su búsqueda de independencia & 3,12 & 3,02 & 3,32 & n.s. & 3,12 & 3,05 & n.s. & 3,19 & 3,08 & n.s. \\
\hline Capacidad de gestión & 4,04 & 3,89 & 4,32 & n.s. & 4,01 & 4,05 & n.s. & 3,80 & 4,17 & n.s. \\
\hline Experiencia profesional & 3,93 & 3,81 & 4,16 & n.s. & 3,88 & 4,00 & n.s. & 3,76 & 4,02 & n.s. \\
\hline Conocimiento del sector & 4,41 & 4,39 & 4,44 & n.s. & 4,33 & 4,66 & * & 4,38 & 4,42 & n.s. \\
\hline Capacidad de liderazgo demostrada & 3,83 & 3,68 & 4,12 & * & 3,75 & 4,05 & n.s. & 3,61 & 3,95 & n.s. \\
\hline Grado de vínculo con el sector & 4,20 & 4,18 & 4,24 & n.s. & 4,12 & 4,38 & n.s. & 4,11 & 4,25 & n.s. \\
\hline $\begin{array}{l}\text { Continuidad del negocio si se produce } \\
\text { pérdida súbita del líder }\end{array}$ & 4,24 & 4,14 & 4,44 & n.s. & 4,35 & 3,94 & ** & 4,23 & 4,25 & n.s. \\
\hline \multicolumn{11}{|c|}{ Escala Likert: 1=Poco importante a 5=Muy importante: } \\
\hline \multicolumn{11}{|c|}{ Test para verificar la significación entre los grupos: F-test (ANOVA) } \\
\hline${ }^{*}: p \leq 0.1 ;{ }^{* *}: p \leq 0.05 ;{ }^{* * *}: p \leq 0.01 ;$ n.s: & 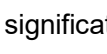 & & & & & & & & & \\
\hline
\end{tabular}

En concreto, los factores que los analistas de riesgos consideran más relevantes ante las decisiones de concesión de créditos, son por este orden el "conocimiento del sector" $(4,41)$, seguido por la "honestidad e integridad" $(4,28)$, la "continuidad del negocio si se produce pérdida súbita del líder" $(4,24)$, el "grado de vínculo con el sector" $(4,20)$ y, por último, la "capacidad de reacción/evaluación de riesgos" $(4,05)$. En sentido contrario, los factores menos valorados por los analistas de riesgos de las entidades financieras fueron "su búsqueda de independencia" $(3,12)$, la "facilidad de palabra" $(3,19)$ y el "deseo de ganar dinero" $(3,31)$. La importancia de los factores cualitativos (información blanda) en las decisiones de los analistas de riesgos también ha sido contrastada en otros estudios previos como Chang et al. (2014), Alexandre \& Smondel (2012) y Grunert et al. (2005). 
Adicionalmente, se analizan variables caracterizadoras del analista de riesgos con el fin de detectar los determinantes de las decisiones de financiación de las entidades bancarias. En este sentido, se analiza si el sexo, experiencia y formación universitaria del analista de riesgos entrevistado influye en la valoración dada a los diversos factores. En los resultados de la tabla 4.2., se encuentran diferencias estadísticamente significativas, en relación con el género del analista, respecto que los analistas de sexo femenino valoran más el factor "honestidad e integridad" que sus pares de sexo masculino (4,68 versus 4,08). También se observa que los analistas de sexo femenino conceden mayor importancia a los factores "capacidad de realizar esfuerzo sostenido/intenso" (3,92 versus 3,41$)$ y "capacidad de liderazgo demostrada" $(4,12$ versus 3,68$)$ que los analistas de riesgo de género masculino.

Otra variable incluida en el análisis es la experiencia del analista en las decisiones de financiación. En este sentido, los resultados demuestran diferencias estadísticamente significativas en relación con que los analistas con mayor experiencia valoran más en promedio al factor "conocimiento del sector" que aquellos que tienen menos años de experiencia profesional (4,66 versus 4,33). Por el contrario, los analistas que tienen más años de experiencia valoran en promedio menos el factor "continuidad del negocio si se produce pérdida súbita del líder" que aquellos analistas con menos años de experiencia (3,94 versus 4,35).

Por último, se analiza la importancia que puede tener el nivel de formación universitaria del analista ante las decisiones de concesión de créditos a empresas. Sin embargo, tal y como se aprecia en la tabla 4.2., no se obtienen diferencias estadísticamente significativas en ninguno de los ítems analizados.

\subsubsection{Variables acerca de las características del producto o servicio que ofrece la empresa y del mercado donde desarrolla su actividad}

La tabla 4.3. incluye el análisis univariante relacionado con las variables que miden la influencia de las características del producto o servicio que ofrece la empresa, junto al mercado donde se desarrolla la actividad en la toma de decisiones de los analistas de riesgos. 
Tabla 4.3. Media y valor de significación de la diferencia entre los ítems asociados con las características del producto o servicio que ofrece la empresa y del mercado donde desarrolla su actividad

\begin{tabular}{|c|c|c|c|c|c|c|c|c|c|c|}
\hline \multirow{2}{*}{$\begin{array}{l}\text { Características del producto o servicio } \\
\text { que ofrece la empresa y del mercado } \\
\text { donde desarrolla su actividad }(n=73)\end{array}$} & \multirow{2}{*}{$\begin{array}{l}\text { Valor } \\
\text { de la } \\
\text { media }\end{array}$} & \multicolumn{3}{|c|}{ Sexo } & \multicolumn{3}{|c|}{ Experiencia } & \multicolumn{3}{|c|}{$\begin{array}{l}\text { Formación } \\
\text { Universitaria }\end{array}$} \\
\hline & & Masc & Fem & Sig & - & + & Sig & - & + & Sig \\
\hline $\begin{array}{l}\text { Producto/servicio aceptado en el } \\
\text { Mercado }\end{array}$ & 4,27 & 4,27 & 4,28 & n.s. & 4,31 & 4,16 & n.s. & 4,42 & 4,19 & n.s. \\
\hline Producto/servicio de alta tecnología & 3,52 & 3,43 & 3,68 & n.s. & 3,48 & 3,61 & n.s. & 3,46 & 3,55 & n.s. \\
\hline Empresa exportadora & 3,28 & 3,20 & 3,44 & n.s. & 3,29 & 3,16 & n.s. & 3,11 & 3,38 & n.s. \\
\hline $\begin{array}{l}\text { Producto/servicio nuevo desarrollado } \\
\text { hasta el punto de tener un modelo en } \\
\text { funcionamiento }\end{array}$ & 3,56 & 3,58 & 3,52 & n.s. & 3,55 & 3,55 & n.s. & 3,69 & 3,48 & n.s. \\
\hline Ciclo de vida del producto/servicio & 3,90 & 3,77 & 4,16 & * & 3,90 & 3,88 & n.s. & 3,88 & 3,91 & n.s. \\
\hline Estrategia de marketing & 3,69 & 3,58 & 3,92 & n.s. & 3,64 & 3,77 & n.s. & 3,84 & 3,61 & n.s. \\
\hline Red de distribución & 4,04 & 3,95 & 4,20 & n.s. & 3,90 & 4,38 & ** & 4,07 & 4,02 & n.s. \\
\hline Cartera de clientes & 4,45 & 4,43 & 4,48 & n.s. & 4,37 & 4,66 & n.s. & 4,46 & 4,44 & n.s. \\
\hline Cartera de proveedores & 4,09 & 4,10 & 4,08 & n.s. & 4,01 & 4,27 & n.s. & 4,00 & 4,14 & n.s. \\
\hline $\begin{array}{l}\text { Mercado objetivo con una tasa de } \\
\text { crecimiento significativa }\end{array}$ & 4,00 & 3,93 & 4,12 & n.s. & 4,00 & 4,00 & n.s. & 4,03 & 3,97 & n.s. \\
\hline $\begin{array}{l}\text { Es fácil que nuevas empresas entren } \\
\text { en el sector }\end{array}$ & 3,45 & 3,33 & 3,68 & n.s. & 3,40 & 3,50 & n.s. & 3,42 & 3,46 & n.s. \\
\hline $\begin{array}{l}\text { Existe una alta competencia entre las } \\
\text { empresas del sector }\end{array}$ & 3,86 & 3,79 & 4,00 & n.s. & 3,88 & 3,77 & n.s. & 3,96 & 3,80 & n.s. \\
\hline $\begin{array}{l}\text { Los clientes tienen un poder de } \\
\text { negociación más elevado que las } \\
\text { empresas del sector }\end{array}$ & 3,71 & 3,58 & 3,96 & n.s. & 3,62 & 3,94 & n.s. & 3,69 & 3,72 & n.s. \\
\hline $\begin{array}{l}\text { Los proveedores tienen un poder de } \\
\text { negociación más elevado que las } \\
\text { empresas del sector }\end{array}$ & 3,60 & 3,52 & 3,76 & n.s. & 3,55 & 3,77 & n.s. & 3,65 & 3,57 & n.s. \\
\hline $\begin{array}{l}\text { Es fácil crear productos sustitutos a los } \\
\text { fabricados por el sector }\end{array}$ & 3,60 & 3,47 & 3,84 & n.s. & 3,59 & 3,66 & n.s. & 3,50 & 3,65 & n.s. \\
\hline \multicolumn{11}{|c|}{ Escala Likert: 1=Poco importante a 5=Muy importante: } \\
\hline $\begin{array}{l}\text { Test para verificar la significación entre } \\
{ }^{*}: p \leq 0.1 ;{ }^{* *}: p \leq 0.05 ;{ }^{* *}: p \leq 0.01 ; n . s .: n \\
\text { Fuente: Elaboración propia. }\end{array}$ & $\begin{array}{l}\text { s grupos: } \\
\text { significat }\end{array}$ & test (Al & OVA) & & & & & & & \\
\hline
\end{tabular}

En relación con los factores más relevantes en las decisiones de financiación referentes a las características del producto-servicio y el mercado de actividad, se comprueba, en la tabla 4.3., que lo más tenido en cuenta es por este orden la "cartera de clientes" $(4,45)$, seguido por el grado en que el "producto/servicio está aceptado en el mercado" $(4,27)$, la "cartera de proveedores" $(4,09)$, la "red de distribución" $(4,04)$ y que el "mercado objetivo tenga una tasa de crecimiento significativa" $(4,00)$. En sentido 
contrario, los factores que obtienen una menor valoración en las decisiones de los analistas han sido la "empresa exportadora" $(3,28)$, si "es fácil que nuevas empresas entren en el sector" $(3,45)$ y que la empresa tenga un "producto/servicio de alta tecnología" $(3,52)$.

Además, en la tabla 4.3. se analiza cómo influyen las características personales de los analistas de riesgo de las entidades de crédito en las decisiones de financiación ajena. En concreto, de todos los ítems analizados sólo se han encontrado diferencias estadísticamente significativas en relación con el género de los analistas en lo referido al ciclo de vida del producto/servicio del solicitante del crédito. Así, se comprueba que los analistas de sexo femenino valoran más en promedio el factor "ciclo de vida del producto/servicio" que sus equivalentes de sexo masculino $(4,16$ versus 3,77$)$.

Otra variable analizada como factor de influencia en las decisiones de los analistas, en relación con el ciclo de vida del producto-servicio y el mercado, es su mayor o menor experiencia profesional. En este caso, sólo se encuentran diferencias estadísticamente significativas en relación con la mayor valoración en promedio que le dan al factor "red de distribución" los analistas con mayor experiencia con respecto a los que tienen una menor experiencia profesional $(4,38$ versus 3,90$)$.

Por último, se analiza si el nivel de formación universitaria de los analistas es un factor a considerar en sus decisiones cuando valoran las características del producto-servicio o mercado del prestatario que solicita la financiación. En este caso, no se hallan diferencias estadísticamente significativas en ninguno de los ítems analizados.

\subsubsection{Variables acerca de la estrategia y organización de la empresa}

En la tabla 4.4. se incluye el análisis univariante relacionado con las variables que miden la influencia de la estrategia y la organización de la empresa solicitante del crédito en la toma de decisiones de los analistas de riesgos. 
Tabla 4.4. Media y valor de significación de la diferencia entre los ítems asociados con la estrategia y organización de la empresa

\begin{tabular}{|c|c|c|c|c|c|c|c|c|c|c|}
\hline \multirow{2}{*}{$\begin{array}{l}\text { Estrategia y organización de la } \\
\text { empresa }(n=73)\end{array}$} & \multirow{2}{*}{$\begin{array}{l}\text { Valor } \\
\text { de la } \\
\text { media }\end{array}$} & \multicolumn{3}{|c|}{ Sexo } & \multicolumn{3}{|c|}{ Experiencia } & \multicolumn{3}{|c|}{$\begin{array}{l}\text { Formación } \\
\text { Universitaria }\end{array}$} \\
\hline & & Masc & Fem & Sig & - & + & Sig & - & + & Sig \\
\hline Empresa con certificado de calidad & 3,87 & 3,72 & 4,16 & * & 3,83 & 3,94 & n.s. & 3,96 & 3,82 & n.s. \\
\hline $\begin{array}{l}\text { Instalaciones donde se desarrolla la } \\
\text { actividad son de la empresa }\end{array}$ & 3,72 & 3,62 & 3,92 & n.s. & 3,74 & 3,66 & n.s. & 3,96 & 3,59 & * \\
\hline $\begin{array}{l}\text { Realizar inventarios por lo menos una } \\
\text { vez al año }\end{array}$ & 3,93 & 3,81 & 4,16 & n.s. & 3,88 & 4,05 & n.s. & 3,88 & 3,95 & n.s. \\
\hline Personal calificado & 4,16 & 4,04 & 4,40 & * & 4,16 & 4,16 & n.s. & 4,19 & 4,14 & n.s. \\
\hline $\begin{array}{l}\text { Tienen establecido una política de } \\
\text { precios coherente }\end{array}$ & 3,90 & 3,77 & 4,16 & * & 3,88 & 3,94 & n.s. & 3,92 & 3,89 & n.s. \\
\hline Controlan la calidad de los productos & 4,15 & 4,02 & 4,40 & * & 4,16 & 4,16 & n.s. & 4,19 & 4,12 & n.s. \\
\hline $\begin{array}{l}\text { El ambiente de trabajo es bueno. } \\
\text { Están contentos los empleados }\end{array}$ & 3,53 & 3,35 & 3,88 & * & 3,50 & 3,66 & n.s. & 3,57 & 3,51 & n.s. \\
\hline $\begin{array}{l}\text { Tecnología de las instalaciones } \\
\text { productivas }\end{array}$ & 3,85 & 3,78 & 4,00 & n.s. & 3,88 & 3,77 & n.s. & 4,15 & 3,68 & ** \\
\hline $\begin{array}{l}\text { Empresa informatizada y utiliza las } \\
\text { TIC's }\end{array}$ & 3,84 & 3,79 & 3,96 & n.s. & 3,79 & 4,00 & n.s. & 4,07 & 3,72 & * \\
\hline Ubicación del negocio & 3,93 & 3,83 & 4,12 & n.s. & 3,83 & 4,22 & n.s. & 4,00 & 3,89 & n.s. \\
\hline $\begin{array}{l}\text { Impresión causada del negocio en la } \\
\text { visita }\end{array}$ & 4,15 & 4,06 & 4,32 & n.s. & 4,12 & 4,22 & n.s. & 4,11 & 4,17 & n.s. \\
\hline \multicolumn{11}{|c|}{ Escala Likert: 1=Poco importante a 5=Muy importante: } \\
\hline $\begin{array}{l}\text { Test para verificar la significación entr } \\
{ }^{*}: p \leq 0.1 ;{ }^{* *}: p \leq 0.05 ;{ }^{* * *}: p \leq 0.01 ; n . s . \\
\text { Fuente: Elaboración propia. }\end{array}$ & $\begin{array}{l}\text { os grupo } \\
\text { o signific }\end{array}$ & $\begin{array}{l}\text { F-test }( \\
\text { va }\end{array}$ & NOVA) & & & & & & & \\
\hline
\end{tabular}

En la tabla 4.4., se comprueba que los factores más relevantes en las decisiones de financiación que toman los analistas de riesgos en relación con la estrategia y la organización interna de la empresa solicitante del crédito son el "personal cualificado" $(4,16)$, seguido por "controlan la calidad de los productos" $(4,15)$, la "impresión causada del negocio en la visita" $(4,15)$, el hecho de "realizar inventarios por lo menos una vez al año" $(3,93)$, así como la "ubicación del negocio" $(3,93)$. En sentido contrario, los factores que aparecen como menos valorados en la toma de decisiones de los analistas son "el ambiente de trabajo es bueno. Están contentos los empleados" $(3,53)$, las "instalaciones donde se desarrolla la actividad son de la empresa" $(3,72)$ y la "empresa informatizada y utiliza las TIC's" $(3,84)$. La importancia de los factores cualitativos en las decisiones de los analistas de riesgos también ha sido contrastada en otros estudios previos como Grunert et al. (2005). 
Al evaluar los resultados atendiendo a las características de los analistas de riesgos, encontramos diferencias estadísticamente significativas en la evaluación realizada según el género (ver tabla 4.4.). En este sentido, los evaluadores de género femenino les asignan mayor importancia a los siguientes factores en comparación con sus equivalentes de sexo masculino: "empresa con certificado de calidad" (4,16 versus 3,72 ), "personal calificado" (4,40 versus 4,04), "tienen establecido una política de precios coherente" (4,16 versus 3,77$)$, "controlan la calidad de los productos" $(4,40$ versus 4,02$)$ y "el ambiente de trabajo es bueno. Están contentos los empleados" $(3,88$ versus 3,35$)$.

Adicionalmente, en la tabla 4.4. cuando se analiza cómo afecta la experiencia de los analistas al valorar las decisiones de financiación cuando se consideran variables relacionadas con la estrategia y la estructura organizativa de la empresa, se comprueba que no existen diferencias estadísticamente significativas en ninguno de los ítems estudiados.

Por último, en relación con la influencia del nivel de formación de los analistas en sus decisiones con respecto a los factores derivados de la estructura organizativa y la estrategia empresarial, se hallan diferencias estadísticamente significativas en la evaluación realizada por los profesionales con mayor nivel de formación universitaria con respecto a los de menor formación. En este sentido, los analistas de mayor nivel de formación les asignan menos peso a los siguientes factores en comparación con aquellos otros que poseen una menor formación: "instalaciones donde se desarrolla la actividad son de la empresa" (3,59 versus 3,96), "tecnología de las instalaciones productivas" $(3,68$ versus 4,15$)$ y "empresa informatizada y utiliza las TIC's" $(3,72$ versus 4,07).

\subsubsection{Variables acerca de la información contable que presenta la empresa}

A continuación, en la tabla 4.5., se incluye el análisis univariante relacionado con las variables que miden la influencia de la situación económico-financiera de la sociedad y el uso de herramientas financieras de gestión en la empresa solicitante del crédito en la toma de decisiones de los analistas de riesgos. 
Tabla 4.5. Media y valor de significación de la diferencia entre los ítems asociados con la información contable que presenta la empresa

\begin{tabular}{|c|c|c|c|c|c|c|c|c|c|c|}
\hline \multirow[t]{2}{*}{ Información Contable $(n=73)$} & & \multicolumn{3}{|c|}{ Sexo } & \multicolumn{3}{|c|}{ Experiencia } & \multicolumn{3}{|c|}{$\begin{array}{c}\text { Formación } \\
\text { Universitaria }\end{array}$} \\
\hline & $\begin{array}{l}\text { de la } \\
\text { media }\end{array}$ & Masc & Fem & Sig & - & + & Sig & - & + & Sig \\
\hline Empresa auditada & 4,21 & 4,22 & 4,20 & n.s. & 4,12 & 4,44 & n.s. & 4,26 & 4,19 & n.s. \\
\hline $\begin{array}{l}\text { Volumen de existencias en } \\
\text { almacén acordes con el balance }\end{array}$ & 4,05 & 3,93 & 4,28 & n.s. & 4,05 & 4,05 & n.s. & 4,11 & 4,02 & n.s. \\
\hline $\begin{array}{l}\text { Llevar algún sistema de costos } \\
\text { fiable }\end{array}$ & 4,22 & 4,08 & 4,50 & * & 4,18 & 4,35 & n.s. & 4,26 & 4,19 & n.s. \\
\hline $\begin{array}{l}\text { Exista control sistemático de } \\
\text { impagados }\end{array}$ & 4,06 & 3,97 & 4,25 & n.s. & 4,05 & 4,11 & n.s. & 4,30 & 3,93 & n.s. \\
\hline $\begin{array}{l}\text { Seguir criterios de valoración y } \\
\text { principios contables claros, } \\
\text { definidos y uniformes en el tiempo }\end{array}$ & 4,23 & 4,16 & 4,36 & n.s. & 4,22 & 4,22 & n.s. & 4,30 & 4,19 & n.s. \\
\hline Analizan frecuentemente la & & & & & & & & & & \\
\hline $\begin{array}{l}\text { situación económica y financiera de } \\
\text { la empresa }\end{array}$ & 4,50 & 4,50 & 4,52 & n.s. & 4,51 & 4,44 & n.s. & 4,46 & 4,53 & n.s. \\
\hline $\begin{array}{l}\text { Inexistencia de apariciones en } \\
\text { INFOCORP }\end{array}$ & 4,22 & 4,04 & 4,56 & ** & 4,32 & 3,94 & n.s. & 4,52 & 4,06 & ** \\
\hline $\begin{array}{l}\text { Situación de endeudamiento } \\
\text { personal del empresario }\end{array}$ & 4,16 & 4,02 & 4,44 & * & 4,29 & 3,83 & * & 4,50 & 3,97 & $\star *$ \\
\hline $\begin{array}{l}\text { Ratios de crecimiento (ventas, } \\
\text { inversión, valor añadido) }\end{array}$ & 4,65 & 4,66 & 4,64 & n.s. & 4,74 & 4,38 & ** & 4,88 & 4,53 & $\star *$ \\
\hline Ratios de liquidez & 4,68 & 4,72 & 4,60 & n.s. & 4,70 & 4,61 & n.s. & 4,88 & 4,57 & ** \\
\hline Ratios de endeudamiento & 4,67 & 4,70 & 4,60 & n.s. & 4,74 & 4,44 & * & 4,92 & 4,53 & *** \\
\hline Ratios de rentabilidad & 4,63 & 4,66 & 4,56 & n.s. & 4,66 & 4,50 & n.s. & 4,84 & 4,51 & ** \\
\hline $\begin{array}{l}\text { Capacidad de retorno en base al } \\
\text { Plan de Negocios }\end{array}$ & 4,49 & 4,22 & 4,20 & n.s. & 4,55 & 4,27 & n.s. & 4,61 & 4,42 & n.s. \\
\hline $\begin{array}{l}\text { Aporte de capital propio en la } \\
\text { inversión }\end{array}$ & 4,41 & 3,93 & 4,28 & n.s. & 4,44 & 4,27 & n.s. & 4,65 & 4,27 & * \\
\hline Capital de Trabajo & 4,50 & 4,08 & 4,50 & n.s. & 4,53 & 4,38 & n.s. & 4,76 & 4,36 & ** \\
\hline \multicolumn{11}{|c|}{ Escala Likert: 1=Poco importante a 5=Muy importante: } \\
\hline \multicolumn{11}{|c|}{$\begin{array}{l}\text { Test para verificar la significación entre los grupos: F-test (ANOVA) } \\
{ }^{*}: p \leq 0.1 ;{ }^{* *}: p \leq 0.05 ;{ }^{* *}: p \leq 0.01 ; \text { n.s.: no significativa }\end{array}$} \\
\hline Fuente: Elaboración propia. & & & & & & & & & & \\
\hline
\end{tabular}

De la tabla 4.5. se desprende que los factores más valorados por los analistas de riesgos de cara a su toma de decisiones, y en relación con la situación económicofinanciera de la empresa solicitante, son por este orden: la situación que marca el "ratio de liquidez" $(4,68)$, seguido por el apalancamiento medido mediante el "ratio de endeudamiento" $(4,67)$, el potencial de crecimiento que marca el "ratio de crecimiento (ventas, inversión, valor añadido)" (4,65), la rentabilidad de la empresa en su "ratio de 
rentabilidad" $(4,63)$, el hecho de que "analizan frecuentemente la situación económica y financiera de la empresa" $(4,50)$ y el "capital de trabajo" $(4,50)$. En el lado opuesto, los factores de menor importancia para los analistas de riesgos son que el "volumen de existencias en almacén acordes con el balance" $(4,05)$, "exista control sistemático de impagados" $(4,06)$ y la "situación de endeudamiento personal del empresario" $(4,16)$. Estos resultados son coincidentes con Petersen (2004) y Agarwal (2011), que identifican la importancia de la información cuantitativa en la toma de decisiones.

Por su parte, profundizando en el análisis de las características asociadas a los propios analistas cuando estudian la posición económico-financiera de la empresa solicitante del crédito, encontramos que hay diferencias estadísticamente significativas en cuanto al género del analista. En este sentido, los analistas de género femenino le otorgan mayor importancia a "llevar algún sistema de costos fiable" (4,50 versus 4,08), "inexistencia de apariciones en INFOCORP" (4,56 versus 4,04) y respecto a la "situación de endeudamiento personal del empresario" (4,44 versus 4,02).

Adicionalmente y cuando se considera la experiencia del analista de riesgos en sus decisiones de financiación empresarial, se observa, ver tabla 4.5., que la experiencia es un factor que condiciona la forma en que se tiene en cuenta la posición económico-financiera de la empresa ante las solicitudes de financiación. En particular, los analistas de mayor experiencia valoran menos los siguientes factores: la "situación de endeudamiento personal del empresario" (3,83 versus 4,29), el "ratio de crecimiento (ventas, inversión, valor añadido)" (4,38 versus 4,74$)$ y el "ratio de endeudamiento" $(4,44$ versus 4,74$)$.

En último lugar, y en relación con el efecto que puede tener en sus decisiones financieras el hecho de que los analistas de riesgos posean o no mayor nivel de formación universitaria, se obtiene que los analistas con mayor grado de formación le dan menor peso que sus homólogos con formación universitaria básica a los siguientes factores: "inexistencia de apariciones en INFOCORP" (4,06 versus 4,52), "situación de endeudamiento personal del empresario" (3,97 versus 4,50), "ratios de crecimiento (ventas, inversión, valor añadido)" (4,53 versus 4,88), "ratios de liquidez" $(4,57$ versus 4,88$)$, "ratios de endeudamiento" (4,53 versus 4,92$)$, "ratios de rentabilidad" (4,51 versus 4,84), "aporte de capital propio en la inversión" (4,27 versus $4,65)$ y "capital de trabajo" (4,36 versus 4,76$)$. 


\subsubsection{Análisis multivariante}

Finalmente, se llevó a cabo un análisis multivariante con el fin de considerar de forma conjunta el efecto de las características de los analistas de riesgos (sexo del analista, experiencia del analista y formación del analista) en el proceso de toma de decisiones de financiación, con el propósito de estudiar las posibles interrelaciones de las variables analizadas. Con este fin se optó por la regresión logística por el método de Wald. La elección de esta técnica estadística obedece, por una parte, a que la variable dependiente es binaria y cualitativa; y por otra, a que la mayoría de las variables independientes consideradas no siguen una distribución normal.

En el modelo de regresión logística se incluyeron las variables que resultaron significativas en el análisis univariante. Adicionalmente, en la construcción del modelo, se consideró la no normalidad de las variables independientes y las características binaria y cualitativa de la variable dependiente. Para determinar la validez del modelo se calculó el test de verosimilitud, con la finalidad de encontrar la estimación más probable de los coeficientes, la medida de Hosmer y Lemeshow de ajuste global del modelo, el porcentaje global de acierto en la clasificación y la bondad del ajuste a través de los estadísticos de $\mathrm{R}^{2}$ alternativos de Cox y Snell y el estadístico de Nagelkerke. Las pruebas estadísticas realizadas confirman la validez de los resultados obtenidos en el análisis univariante (tablas 4.6. a 4.8.). 
Tabla 4.6. Regresión logística por el método de Wald según el género del analista

$(n=73)$

\begin{tabular}{|c|c|c|c|c|c|}
\hline Variables independientes & B & S.E. & Wald & Sig. & $\operatorname{Exp}(B)$ \\
\hline Su honestidad e integridad & 0,846 & 0,413 & 4,194 & 0,041 & 2,331 \\
\hline $\begin{array}{l}\text { Llevar algún sistema de costos } \\
\text { fiable }\end{array}$ & 0,704 & 0,380 & 3,445 & 0,063 & 2,023 \\
\hline $\begin{array}{l}\text { Inexistencia de apariciones en } \\
\text { INFOCORP }\end{array}$ & 0,895 & 0,418 & 4,597 & 0,032 & 2,448 \\
\hline Constante & $-11,386$ & 3,336 & 11,652 & 0,001 & 0,000 \\
\hline \multicolumn{6}{|c|}{ Variable dependiente (dummy): Sexo del analista: Mujer=1; Hombre=0 } \\
\hline \multicolumn{6}{|c|}{$\begin{array}{l}\text { Notas: B: Coeficientes logísticos, son empleados para medir los cambios en los ratios de probabilidades, } \\
\text { denominado odds ratio. Un coeficiente positivo incrementa la probabilidad pronosticada, mientras un valor negativo } \\
\text { disminuye la probabilidad predicha. S.E.: error estándar. Wald: estadístico de Wald. Sig.: nivel de significación. } \\
\text { Exp(B): coeficiente exponenciado. La prueba omnibus sobre los coeficientes del modelo ofrece un valor de } \\
\text { la Chi-cuadrado: } \mathbf{1 6 , 7 1 8 , ~ s i g : ~} \mathbf{0 , 0 0 1 .} \text { Por lo que el modelo resulta significativo. La significación estadística del } \\
\text { modelo se ha determinado utilizando la medida de Hosmer Lemeshow de ajuste global donde se obtiene un } \\
\text { contraste estadístico que indica que no existe diferencia estadística significativa entre las clasificaciones } \\
\text { observadas y predichas, ya que el valor de la Chi-cuadrado no es significativo (Chi-cuadrado:5,139, sig.: 0,743). } \\
\text { Como medida de calidad de ajuste obtenemos un porcentaje global de acierto del } 70,4 \% \text { si usamos el modelo con } \\
\text { función clasificatoria. Resumen del modelo: }-2 \text { log likelihood: } 74,122 ; R^{2} \text { de Cox y Snell: } 0,210 ; R^{2} \text { de Nagelkerke: } \\
0,291 . \\
\text { Fuente: Elaboración propia. }\end{array}$} \\
\hline
\end{tabular}

En la tabla 4.6., se analiza el efecto multivariante entre las características de género de los analistas de riesgos y los factores significativos que influyen en sus decisiones de concesión de créditos. Los resultados estadísticamente significativos ponen de manifiesto que el género del analista es determinante durante el proceso de toma de decisiones. En concreto, los analistas de género femenino valoran más que los de género masculino en su proceso decisorio, la honestidad e integridad del empresario demandante de fondos financieros $(\beta: 0,846 ; p \leq 0,05)$, el hecho de que la empresa tenga implementado con fiabilidad un sistema de gestión de costes ( $\beta$ : 0,704; $p \leq 0,1)$, así como que la empresa no aparezca en el listado de entidades con impagos INFOCORP $(\beta: 0,895 ; p \leq 0,05)$. Estos resultados confirman para las pymes peruanas los resultados de estudios previos realizados en otros contextos socio-económicos, en relación con la importancia de factores tanto cuantitativos como también cualitativos en los procesos de decisión de los analistas de riesgos (Petersen, 2004; Grunert et al., 2005; Chang et al., 2014). 
Tabla 4.7. Regresión logística por el método de Wald según la experiencia del analista

$(n=73)$

\begin{tabular}{|l|c|c|c|c|c|}
\hline Variables & B & S.E. & Wald & Sig. & Exp (B) \\
\hline Red de distribución & 1,394 & 0,516 & 7,308 & 0,007 & 4,031 \\
\hline $\begin{array}{l}\text { Situación de endeudamiento } \\
\text { personal del empresario }\end{array}$ & $-0,775$ & 0,331 & 5,500 & 0,019 & 0,461 \\
\hline $\begin{array}{l}\text { Ratios de crecimiento (ventas, } \\
\text { inversión, valor añadido) }\end{array}$ & $-1,708$ & 0,673 & 6,430 & 0,011 & 0,181 \\
\hline Constante & 4,116 & 3,098 & 1,765 & 0,184 & 61,337 \\
\hline
\end{tabular}

Variable dependiente (dummy): Experiencia del analista: Alta=1; Baja $=0$

Notas: B: Coeficientes logísticos, son empleados para medir los cambios en los ratios de probabilidades, denominado odds ratio. Un coeficiente positivo incrementa la probabilidad pronosticada, mientras un valor negativo disminuye la probabilidad predicha. S.E.: error estándar. Wald: estadístico de Wald. Sig.: nivel de significación. $\operatorname{Exp(B):~coeficiente~exponenciado.~La~prueba~omnibus~sobre~los~coeficientes~del~modelo~ofrece~un~valor~de~}$ la Chi-cuadrado: 18,642, sig: $\mathbf{0 , 0 0 0}$. Por lo que el modelo resulta significativo. La significación estadística del modelo se ha determinado utilizando la medida de Hosmer Lemeshow de ajuste global donde se obtiene un contraste estadístico que indica que no existe diferencia estadística significativa entre las clasificaciones observadas y predichas, ya que el valor de la Chi-cuadrado no es significativo (Chi-cuadrado:4,451, sig.: 0,616). Como medida de calidad de ajuste obtenemos un porcentaje global de acierto del 81,9\% si usamos el modelo con función clasificatoria. Resumen del modelo: -2 log likelihood: 62,335 ; $R^{2}$ de Cox y Snell: 0,228; $R^{2}$ de $N^{2}$ gelkerke: 0,338 .

Fuente: Elaboración propia.

Por otra parte, en la tabla 4.7., se analiza el efecto multivariante entre la experiencia previa profesional que tienen los analistas de riesgos y los factores significativos que influyen en sus decisiones de concesión de créditos a empresas. Los resultados estadísticamente significativos ponen de manifiesto que la experiencia del analista es determinante durante el proceso de toma de decisiones.

En concreto, los analistas de riesgos con mayor experiencia valoran más que los de menor experiencia en su proceso decisorio, el hecho de que la empresa cuente con una buena red de distribución $(\beta: 1,394 ; p \leq 0,01)$. Este resultado implica que cuanto mayor es la experiencia del evaluador de riesgos más importancia le concede en su decisión a la capacidad potencial con la que cuenta la empresa para poder vender, es decir, valora sobre todo la faceta comercial del empresario en sus decisiones financieras. Sin embargo, y, al contrario, lo menos valorado por los analistas de mayor experiencia, es decir, los factores que presentan una relación inversa con la experiencia del analista, son la situación de endeudamiento personal del empresario que solicita la financiación $(\beta:-0,775 ; p \leq 0,05)$ y el crecimiento que tenga la 
empresa solicitante del crédito en el momento de la solicitud, medido por las ratios de crecimiento de ventas, inversión y valor añadido $(\beta:-1,708 ; p \leq 0,05)$. Estos resultados confirman para las pymes peruanas los resultados de estudios previos realizados en otros contextos socio-económicos, en relación con la importancia de factores cuantitativos en los procesos de toma de decisión de los analistas de riesgos (Petersen, 2004).

Tabla 4.8. Regresión logística por el método de Wald según la formación del analista

$(n=73)$

\begin{tabular}{|c|c|c|c|c|c|}
\hline Variables & B & S.E. & Wald & Sig. & $\operatorname{Exp}(B)$ \\
\hline $\begin{array}{l}\text { Situación de endeudamiento } \\
\text { personal del empresario }\end{array}$ & $-0,740$ & 0,334 & 4,911 & 0,027 & 0,477 \\
\hline Ratios de endeudamiento & $-2,106$ & 0,806 & 6,829 & 0,009 & 0,122 \\
\hline Constante & 13,768 & 4,231 & 10,592 & 0,001 & 954053,0 \\
\hline \multicolumn{6}{|c|}{$\begin{array}{l}\text { Variable dependiente (dummy): Nivel de formación universitaria del analista: } \\
\text { Alta=1; Baja=0 }\end{array}$} \\
\hline \multicolumn{6}{|c|}{$\begin{array}{l}\text { Notas: B: Coeficientes logísticos, son empleados para medir los cambios en los ratios de probabilidades, } \\
\text { denominado odds ratio. Un coeficiente positivo incrementa la probabilidad pronosticada, mientras un valor } \\
\text { negativo disminuye la probabilidad predicha. S.E.: error estándar. Wald: estadístico de Wald. Sig.: nivel de } \\
\text { significación. Exp(B): coeficiente exponenciado. La prueba omnibus sobre los coeficientes del modelo } \\
\text { ofrece un valor de la Chi-cuadrado: } \mathbf{1 7 , 1 7 7} \text {, sig: } \mathbf{0 , 0 0 0} \text {. Por lo que el modelo resulta significativo. La } \\
\text { significación estadística del modelo se ha determinado utilizando la medida de Hosmer Lemeshow de ajuste } \\
\text { global donde se obtiene un contraste estadístico que indica que no existe diferencia estadística significativa } \\
\text { entre las clasificaciones observadas y predichas, ya que el valor de la Chi-cuadrado no es significativo (Chi- } \\
\text { cuadrado: } 4,038 \text {, sig.: } 0,401 \text { ). Como medida de calidad de ajuste obtenemos un porcentaje global de acierto } \\
\text { del } 70,0 \% \text { si usamos el modelo con función clasificatoria. Resumen del modelo: }-2 \text { log likelihood: } 74,069 ; R^{2} \text { de } \\
\text { Cox y Snell: } 0,218 ; R^{2} \text { de Nagelkerke: } 0,299 \text {. } \\
\text { Fuente: Elaboración propia. }\end{array}$} \\
\hline
\end{tabular}

En la tabla 4.8., se analiza el efecto multivariante entre las características formativas de los analistas de riesgos y los factores significativos que influyen en sus decisiones de concesión de créditos. Los resultados estadísticamente significativos ponen de manifiesto que el nivel de formación universitaria del analista es determinante durante el proceso de toma de decisiones. En concreto, se aprecia una relación inversa entre el hecho de tener mayor nivel de formación universitaria y la situación de endeudamiento personal del empresario que solicita la financiación $(\beta:-0,740 ; p \leq 0,05)$ y el grado de apalancamiento que tenga la empresa solicitante del 
crédito en el momento de la solicitud, medido por el ratio de endeudamiento $(\beta:-2,106 ; p \leq 0,01)$.

\subsection{CONCLUSIONES}

El objetivo de este trabajo ha sido analizar los criterios que utilizan las entidades financieras a la hora de otorgar un crédito a una Mipyme, considerando el sexo, experiencia y formación universitaria del analista de riesgos. Para ello se ha realizado un estudio empírico a partir de la información suministrada por 73 responsables de las áreas de créditos y riesgos de las principales entidades financieras peruanas. El contexto de Perú es especialmente relevante dado que su sistema financiero no está plenamente desarrollado y las posibilidades de acceso por parte de las empresas son menores que en otras economías. Los criterios utilizados se clasifican en: personalidad y experiencia del empresario; características del producto o servicio que ofrece la empresa y del mercado donde desarrolla su actividad; estrategia y organización de la empresa; y criterios relacionados con la información contable que presentan las empresas.

Los resultados muestran que los criterios más valorados por los analistas de riesgos a la hora de otorgar un crédito son: el conocimiento del sector que tiene el empresario, la honestidad e integridad del empresario, la cartera de clientes con la que cuenta la empresa, y calificación del personal de la empresa. Asimismo, consideran importante diversas variables relacionadas con la información contable como los ratios de liquidez, endeudamiento, de crecimiento del negocio y de rentabilidad. Si consideramos las diferencias según el sexo, la experiencia y la formación del analista de riesgos, los resultados obtenidos ponen de manifiesto: (1) los analistas de sexo femenino valoran en mayor medida que los hombres la honestidad e integridad del empresario, que la empresa tenga implementado con fiabilidad un sistema de gestión de costes y que la empresa no aparezca en el listado de entidades con impagos INFOCORP; (2) los analistas con mayor experiencia valoran más que los analistas con menos experiencia, que las empresas dispongan de una buena red de distribución de sus productos o servicios y le dan menos importancia a la situación de endeudamiento personal del empresario y la posición de crecimiento que tenga la empresa solicitante del crédito en el momento de la solicitud; (3) los analistas que disponen de un menor nivel de formación universitaria le dan más importancia a la situación de endeudamiento personal del empresario y al grado de apalancamiento que tenga la 
empresa, en relación a los analistas que disponen de mayor nivel de formación universitaria.

Los resultados obtenidos en este trabajo tienen importantes implicaciones teóricas y prácticas. Conocer los criterios de decisión de inversión más acertados reduce el riesgo de selección adversa (Mishra, 2004). Entre estos criterios la evaluación de las capacidades de gestión de la empresa resulta extremadamente importante (Mishra, 2004). En contextos económicos como el de Perú con un sistema financiero incipiente en cuanto al suministro de crédito a la Mipyme, las entidades financieras deben optimizar su gestión de créditos, y minimizar los problemas de la asimetría de información. En este sentido la información "suave" que las entidades recogen a lo largo de su relación con la Mipyme resulta imprescindible para reducir el problema de la asimetría de información (Alexandre \& Smondel, 2012; Chen et al., 2013). Adicionalmente, una mejora de los sistemas de gestión de riesgos puede generar efectos indirectos positivos para toda la economía, ya que las entidades financieras canalizan sus inversiones hacia proyectos más seguros y eficientes (Cornée, 2017). Desde una perspectiva práctica los resultados de este trabajo son especialmente útiles a las entidades financieras para ayudarles a mejorar sus sistemas de calificación y a las Mipymes para favorecer una mejor relación con las entidades financieras y poder mejorar sus habilidades de gestión para conseguir préstamos más favorables (Grunert \& Norden, 2012). También resultan de utilidad práctica a los organismos de supervisión bancaria para que aconsejen o potencien modelos de calificaciones de crédito mixtos para abordar las calificaciones de riesgos en las operaciones con las Mipymes (Matias \& Amaral, 2012). 
CONCLUSIONES GENERALES 
El objetivo de este trabajo de tesis ha sido aportar evidencia empírica sobre los factores de gestión que tienen influencia en el éxito competitivo y la problemática del acceso a la financiación de las micro y pequeñas empresas de Perú. La realidad propia del sector micro y pequeño empresario peruano, con mucha informalidad, recelosos de dar datos concretos y reales a las instituciones que lo solicitan, hacen difícil la realización de investigaciones empíricas en este sector. Sin embargo, sí proporcionan información general que han permitido llevar a cabo esta investigación, con el apoyo de empresas especializadas en estas labores.

Para dar respuesta al objetivo general se plantearon tres objetivos específicos. El primero ha sido estudiar los factores que inciden en el rendimiento de las micro y pequeñas empresas, precisando que para el rendimiento o éxito competitivo se ha considerado como variable proxy la tendencia del aumento de las ventas de la empresa. A partir del análisis de factores como si la empresa realiza actividades de planificación; si hace uso de sistemas de control de gestión; si tiene buenas prácticas de gestión de la calidad; su posición tecnológica respecto a sus competidores; el grado de formación y experiencia profesional del gerente conductor de la empresa y si la organización realiza buenas prácticas de recursos humanos. A partir del análisis de estos factores se llega a que las empresas que tienen implantados en su organización sistemas de control de gestión (sistema de contabilidad de costos, de presupuestos de ingresos y gastos anuales, de análisis de situación económica-financiera) tienen mayor probabilidad que tengan éxito frente a aquellas que no lo hacen o lo tienen en menor grado. También se muestra que las empresas que tienen certificación de calidad tienen mayores oportunidades de tener éxito que aquellas que no poseen alguna certificación o que no están en proceso de obtenerla. Otro factor importante que influye en el éxito de las empresas es el hecho que su posición tecnológica frente a sus competidores sea fuerte o buena. Adicionalmente, se ve que la experiencia profesional del gerente de la empresa también influye en la buena performance de la empresa. Finalmente, las buenas prácticas en recursos humanos tales como el diseño de puestos, el reclutamiento y selección del personal, actividades de formación, evaluación del desempeño y una buena política retributiva contribuyen a que la empresa tenga mayor probabilidad de éxito que aquellas que realizan actividades en esta área en menor grado o no lo hacen.

El segundo objetivo fue identificar aquellos factores de gestión que contribuyen a que la empresa tenga mayor probabilidad de acceso a la financiación bancaria. Los resultados arrojaron que las empresas que tienen la posibilidad de un mayor acceso al 
crédito por parte de las entidades financieras son aquellas que pertenecen a determinados sectores, son no familiares y tiene una situación jurídica formal de constitución. Asimismo, aquellas empresas que son conducidas por gerentes con mayor formación, realizan planes estratégicos periódicamente y cuentan con departamentos formales dentro de su organización sufren un menor racionamiento de crédito. También, aquellas que realizan actividades de innovación en sus procesos y sus sistemas de gestión tienen un menor racionamiento. El mayor uso de TIC's por parte de las empresas también es un elemento que influye en que las entidades financieras les den un mayor acceso al crédito. Adicionalmente, la empresa que tiene o está en proceso de obtener alguna certificación de calidad y aquella que tiene una posición tecnológica fuerte también tiene mayor probabilidad de acceso al crédito. Indicadores de rendimiento o buena performance de la empresa como el que ofrezca productos de mayor calidad, que cuente con clientes más satisfechos, esté creciendo más, sea más rentable y que tenga un menor absentismo laboral contribuyen a que la empresa tenga la posibilidad de mayor acceso a la financiación.

El tercer objetivo ha sido identificar aquellos factores tanto cualitativos como cuantitativos que toman en cuenta los analistas de riesgo de las entidades financieras peruanas para el otorgamiento de créditos. Los hallazgos revelaron que el conocimiento que tenga del sector el empresario y su honestidad e integridad son los aspectos que más valoran los analistas de crédito en su toma de decisiones para otorgamiento de préstamos. Asimismo, cuentan para ellos la calidad de la cartera de clientes con que cuente la empresa, así como el grado de aceptación que tiene el producto o servicio que ofrece en el mercado. Un personal calificado dentro de la organización, el que la empresa tenga mecanismos del control de la calidad de sus productos o servicios y la impresión que se llevan los analistas en la visita del negocio también son factores muy importantes para la concesión de créditos a las empresas. De igual manera, los funcionarios de crédito le dan bastante peso a los ratios de liquidez y de endeudamiento en base a los estados financieros que presente la empresa. También se halla que hay diferencias significativas entre la valoración que le dan los analistas de sexo femenino frente a sus pares masculinos a determinados factores: las mujeres valoran más la honestidad e integridad del empresario, si las empresas llevan algún sistema de costos fiable y que la empresa a calificar no aparezca en INFOCORP. Los analistas de riesgo con mayor experiencia le dan mayor importancia a que la empresa tenga una red de distribución, a que el empresario se encuentre en una situación de endeudamiento menor y a los ratios de crecimiento del 
solicitante de crédito. Asimismo, los analistas que tienen un mayor nivel de formación le dan menos peso a la situación de endeudamiento personal del empresario y a los ratios de endeudamiento de la empresa al otorgar crédito.

Los resultados obtenidos tienen importantes implicaciones tanto para el empresariado peruano, organismos públicos como para las entidades financieras y analistas de créditos que laboran calificando las solicitudes de crédito de las micro, pequeñas y medianas empresas.

A los directivos y empresarios de las empresas les pueden dar pautas para concentrar sus esfuerzos de gestión en aquellos aspectos que favorecen el éxito empresarial. Debe el empresariado poner mayor énfasis a la gestión de la calidad y el uso de sistemas de apoyo al control de gestión. También es importante que trate de tener una posición tecnológica fuerte frente a sus competidores y que tenga especial cuidado en el manejo de los recursos humanos que lo apoyan; así como seleccionar en la conducción de sus negocios a directivos que tengan vasta experiencia profesional.

También a los empresarios les puede servir para que refuercen su gestión en aquellos aspectos que pueden influir decisivamente a su acceso a la financiación bancaria. En este sentido el empresariado debe colocar a directivos con alta formación académica, que realicen planeamiento formal estratégico, que definan en su organización departamentos formales, que realicen prácticas de innovación en los productos, procesos y sistemas de gestión que utilicen y que se esfuercen por tener una posición tecnológica fuerte y que reflejen sus esfuerzos en diversos indicadores de rendimiento que favorezcan su acceso al crédito.

A los organismos públicos, especialmente a los responsables de regular e incentivar este sector del tejido empresarial, les puede orientar para implementar programas que le ayuden al empresario a desarrollar sus capacidades de gestión, les facilite su consolidación en el mercado e incentive a las buenas prácticas de innovación y desarrollo para mejorar su competitividad y rendimiento.

A las entidades financieras les puede ayudar a mejorar sus modelos de credit scoring incorporando nuevas variables tanto cualitativas como cuantitativas consideradas en el estudio de investigación.

A los analistas de riesgos que trabajan en las entidades financieras les puede servir como referencia para revisar el peso relativo que le dan a determinados factores en el momento de evaluar la posibilidad de otorgar financiación a las empresas que lo solicitan, así como también incorporar nuevas variables para su proceso de toma de 
decisiones en la concesión de préstamos. A los mismos empresarios, les puede ser de utilidad para mejorar y/o focalizar sus esfuerzos para mejorar en aquellos aspectos que las entidades financieras toman en cuenta de los prestatarios que les permita tener menores posibilidades de racionamiento de crédito.

El trabajo de investigación presenta limitaciones. Una de ellas se refiere a la cantidad y calidad de la información que se puede extraer de las empresas peruanas, lo cual limita la posibilidad de poder hacer análisis con datos de corte transversal y poder proseguir con un análisis y seguimiento longitudinal. Otra limitación se debe a que el escaso desarrollo y consolidación del sistema financiero peruano, no se dispone de información relacionada al acceso crediticio que posibilite adicionar variables del tipo macro al análisis micro y lo que se refiere al uso y disponibilidad de los recursos bancarios por parte de las empresas. Tampoco se ha tomado en cuenta para el trabajo aspectos relacionados al entorno y al ambiente externo a la empresa; ni se ha realizado un estudio que efectúe un control de la endogeneidad y causalidad en la relación entre las variables que se analice.

Futuros trabajos de investigación deberían considerar factores externos a la empresa que pueden influir en el éxito competitivo de las empresas como las leyes fiscales, los procedimientos burocráticos, los incentivos al sector privado, entre otros. También podrían considerarse aspectos como la regulación del mercado cambiario y las políticas de apoyo a las empresas por parte del Estado.

Factores internos a la empresa como las estrategias de marketing, la forma de comercialización y las alianzas estratégicas que realice. También aspectos cuantitativos concretos como cierta información crediticia, información proveniente de sus estados financieros y su historial de crédito.

También posteriores trabajos de investigación podrían analizar el efecto que sobre el racionamiento de crédito pueden tener los programas financiados por el Estado. Se puede focalizar también futuros estudios en las empresas informales o a un solo sector muy significativo del empresariado peruano como son los microempresarios.

Finalmente, conviene precisar algunos temas relacionados que pueden ser tomados por trabajos futuros como son: el efecto que sobre el rendimiento de las empresas puede tener el nivel de emprendedurismo del directivo de la empresa o el grado en que la empresa copia o desarrolla su producto o servicio que ofrece. También se puede analizar el grado en que la misma empresa se auto raciona y qué factores influyen en esto. 
Al analizar los factores que toman en cuenta las entidades financieras para el otorgamiento de créditos se puede estudiar si tiene influencia la relación que en el tiempo establecen las empresas peruanas con los bancos que trabajan y si tanto la cantidad de préstamos como los montos prestados influyen sobre las decisiones de futuros préstamos. 
BIBLIOGRAFÍA 
Aba, E. K., Badar, M. A., \& Hayden, M. A. (2016). Impact of ISO 9001 certification on firms financial operating performance. International Journal of Quality \& Reliability Management, 33(1), 78-89.

Abor, J., \& Biekpe, N. (2007). Corporate governance, ownership structure and performance of SMEs in Ghana: Implications for financing opportunities. Corporate Governance: The International Journal of Business in Society, 7(3), 288-300.

AECA (2005). Estrategia e innovación de la Pyme industrial en España, Estudios empíricos. Asociación Española de Contabilidad y Administración de Empresas: Madrid.

Afza, N. (2011). The effect of owner's gender and age to firm performance: A review on Malaysian public listed family business. Journal of Global Business and Economics, 2(1), 104-116.

Agarwal, S., Ambrose, B. W., Chomsisengphet, S., \& Liu, C. (2011). The role of soft information in a dynamic contract setting: Evidence from the home equity credit market. Journal of Money, Credit and Banking, 43(4), 633-655.

Aguilar, G. (2013). Microfinanzas y crecimiento regional en el Perú. Economía, XXXVI(72), 143-173.

Aguilar, G., \& Camargo, G. (2004). Análisis de la morosidad de las instituciones microfinancieras (IMF) en el Perú. Documento de Trabajo No. 133. Lima, Perú: Instituto de Estudios Peruanos.

Ahiawodzi, a K., \& Sackey, F. G. (2013). Determinants of credit rationing to the private sector in Ghana. African Journal of Business Management, 7(38), 3864-3874.

Ahmedova, S. (2015). Factors for increasing the competitiveness of small and mediumsized enterprises (SMEs) in Bulgaria. Procedia - Social and Behavioral Sciences, 195, 1104-1112.

Akerlof, G. A. (1970). The market for "lemons": Quality uncertainty and the market mechanism. Quarterly Journal of Economics, 84(3), 488-500. 
Aldehayyat, J., \& Twaissi, N. (2011). Strategic planning and corporate performance relationship in small business firms: Evidence from a middle east country context. International Journal of Business and Management, 6(8), 255-263.

Alexandre, H., \& Smondel, A. (2012). Substitution or complementarity between "soft" and information "hard": Why and which effect on bank profitability? Journal of Modern Accounting and Auditing, 8(6), 6-15.

Al-Hyari, K. (2013). Identification of barrier factors and potential solutions to SMEs development among Jordanian manufacturing sector. International Journal of Business and Management, 8(24), 132-141.

Alom, F., Abdullah, M. A., Moten, A. R., \& Azam, S. M. F. (2016). Success factors of overall improvement of microenterprises in Malaysia: An empirical study. Journal of Global Entrepreneurship Research, 6(1), 1-13.

Alpkan, L., Yilmaz, C., \& Kaya, N. (2007). Market orientation and planning flexibility in SMEs. International Small Biusiness Journal, 25(2), 152-172.

Álvarez, C. (2014). Crecimiento, innovación, competitividad y sostenibilidad de la economía peruana. Revista de Economía y Derecho, 7(28), 107-150.

Amit, R., \& Schoemaker, P. J. (1993). Strategic assets and organizational rent. Strategic Management Journal, 14(1), 33-46.

Andriani, C., Biasca, R., \& Martínez, M. (2003). El nuevo sistema de gestión para las pymes: Un reto para las empresas latinoamericanas, México: Editorial Norma.

Angelini, P., Salvo, R. Di, \& Ferri, G. (1998). Availability and cost of credit for small businesses: Customer relationships and credit cooperatives. Journal of Banking \& Finance, 22(6-8), 925-954.

Appiah, F., Pesakovic, G., \& Amaria, P. (2008). Relationship between quality management practices and the performance of small and medium size enterprises (SMEs) in Ghana. International Journal of Quality \& Reliability Management, 25(7), 694-708.

Arasti, Z., Zandi, F., \& Bahmani, N. (2014). Business failure factors in Iranian SMEs: Do successful and unsuccessful entrepreneurs have different viewpoints? Journal of Global Entrepreneurship Research, 4(1), 1-14. 
Åstebro, T., \& Bernhardt, I. (2005). The winner's curse of human capital. Small Business Economics, 24(1), 63-78.

Ata, H. A., Korpi, M., Ugurlu, M., \& Sahin, F. (2015). Factors influencing the credit rationing on the commercial lending process. Journal of Business Economics and Finance, 4(2), 250-267.

Atalay, M., Anafarta, N., \& Sarvan, F. (2013). The relationship between Innovation and firm performance: An empirical evidence from Turkish automotive supplier industry. Procedia-Social and Behavioral Sciences, 75, 226-235.

Ataseven, C., Prajogo, D. I., \& Nair, A. (2014). ISO 9000 Internalization and organizational commitment - Implications for process improvement and operational performance. IEEE Transactions on Engineering Management, 61(1), 5-17.

Avolio, B., Mesones, A., \& Roca, E. (2011). Factores que limitan el crecimiento de las micro y pequeñas empresas en el Perú (Mypes). Strategia, 22, 70-80.

Azubuike, V. M. U. (2013). Technological innovation capability and firm's performance in new product development. Communications of the IIMA, 13(1), 43-56.

Baldwin, J. R., \& Sabourin, D. (2002). Advanced technology use and firm performance in Canadian manufacturing in the 1990s. Industrial \& Corporate Change, 11(4), 761-789.

Banco de España. (2015). Informe de economía Latinoamericana: Primer semestre de 2015. Boletín Económico, (4), 61-88.

Banco Mundial. (2007). Cómo ser más formal y productivo, Políticas para fortalecer las empresas. Bolivia.

Barazandeh, M., Parvizian, K., Alizadeh, M., \& Khosravi, S. (2015). Investigating the effect of entrepreneurial competencies on business performance among early stage entrepreneurs Global Entrepreneurship Monitor (GEM 2010 survey data). Journal of Global Entrepreneurship Research, 5(1), 18.

Barney, J. (1991). Firm resources and sustained competitive advantage. Journal of Management, 17(1), 99-120. 
Barrantes, R., \& Grompone, A. (2015). ¿Entrampados o encauzados?: Los retos del crecimiento económico en el Perú del siglo XXI. Documento de Trabajo No. 223. Lima, Perú: Instituto de Estudios Peruanos.

Barton, S. L., \& Matthews, C. H. (1989). Small firm financing: implications from a strategic management perspective. Journal of Small Business Management, 27(1), 1-7.

Batra, S., Sharma, S., Dixit, M. R., Vohra, N., \& Gupta, V. K. (2015). Performance implications of industry appropriability for manufacturing SMEs, The role of technology orientation. Journal of Manufacturing Technology Management, 26(5), 660-677.

Bayati, A., \& Taghavi, A. (2007). The impacts of acquiring ISO 9000 certification on the performance of SMEs in Tehran. The TQM Magazine, 19(2), 140-149.

Bebczuk, R. N. (2003). Asymmetric information in financial markets: Introduction and applications. Cambridge, United Kingdom: Cambridge University Press.

Beck, T., Demirgüç-Kunt, A., \& Martínez, M. S. (2008). "Bancarizando a las pymes alrededor del mundo: Determinantes, obstáculos, modelos de negocios y prácticas de financiamiento", presentación en el X Foro de la Microempresa, BID/FOMIN, Asunción.

Bellier, A., Sayeh, W., \& Serve, S. (2012). What lies behind credit rationing ? A survey of the literature. Thema Working paper, No. 2012-39. Cergy-Pontoise, France: Université de Cergy-Pontoise.

Bellina, J. (2004). Dificultades crediticias de las pymes derivados de la información asimétrica. Invenio, 7(13), 103-126.

Bellucci, A., Favaretto, I., \& Giombini, G. (2014). Does innovation affect credit access? New empirical evidence from Italian small business lending. Tûbingen, Germany. IAW-Diskussionspapiere, Working paper No. 104, 1-26.

Benito-Hernández, S., Platero-Jaime, M., \& Rodríguez-Duarte, A. (2012). Factores determinantes de la innovación en las microempresas españolas: La importancia de los factores internos. Universia Business Review, 33, 104-121. 
Bernhardt, T. (2016). El comercio Sur-Sur y Sur-Norte: ¿Cuál contribuye más al desarrollo de Asia y América del Sur? Ideas a partir de la estimación de elasticidades-ingreso de la demanda de importaciones. Revista CEPAL, 118, 101120.

Bianchi, C., Cosenz, F., \& Marinković, M. (2015). Designing dynamic performance management systems to foster SME competitiveness according to a sustainable development perspective: Empirical evidences from a case-study. International Journal of Business Performance Management, 16(1), 84-108.

Biju, A., Bhasi, M., \& Madhu, G. (2012). Linking SME performance with the use of forecasting planning and control: Empirical findings from Indian firms. European Journal of Scientific Research, 73(1), 86-105.

Biju, P. A., \& Bhasi, M. (2014). A structural equation model linking forecasting, planning and controlling with SME performance. In 2014 IEEE International Conference on Industrial Engineering and Engineering Management (531-535).

Botello, H. A. (2014). Condiciones y determinantes de la internacionalización de las empresas industriales latinoamericanas. Apuntes, 41(75), 47-78.

Botello, H. A. (2015). Determinants of access to credit for SMEs: evidence at the level of the firm in Latin America. Apuntes del Cenes, 34(60), 247-276.

Bourletidis, K. (2013). The strategic management of market information to SMEs during economic crisis. Procedia - Social and Behavioral Sciences, 73, 598-606.

Briozzo, A., Vigier, H., Castillo, N., Pesce, G., \& Speroni, M. C. (2016). Decisiones de financiamiento en pymes: ¿Existen diferencias en función del tamaño y la forma legal? Estudios Gerenciales, 32(138), 71-81.

Bruton, G. D., Ahlstrom, D., \& Obloj, K. (2008). Entrepreneurship in emerging economies: The research go in the future. Entrepreneurship Theory and Practice, 32(1), 1-14.

Bustamante, R. (2015). Características Estilizadas de los Ciclos Económicos de la Economía Peruana: 1980-2014. Revista de Economía San Marcos, 2(1), 72-95.

Calvo, C. (2008). Vulnerability to multidimensional poverty: Peru, 1998-2002. World Development, 36(6), 1011-1020. 
Calvo, J. L. (2006). Testing Gibrat's law for small, young and innovating firms. Small Business Economics, 26(2), 117-123.

Canton, E., Grilo, I., Monteagudo, J., \& Van der Zwan, P. (2013). Perceived credit constraints in the European Union. Small Business Economics, 41(3), 701-715.

Capó-Vicedo, J., Expósito-Langa, M., \& Masiá-Buades, E. (2007). La importancia de los clusters para la competitividad de las PYME en una economía global. EURE, 33(98), 119-133.

Cardozo, E., Velásquez, Y., \& Rodríguez, C. (2012). El concepto y la clasificación de PYME en America Latina. Global Conference on Business and Financing Proceedings, 7(2), 1630-1641.

Cenni, S., Monferrà, S., Salotti, V., Sangiorgi, M., \& Torluccio, G. (2015). Credit rationing and relationship lending. Does firm size matter? Journal of Banking and Finance, 53, 249-265.

CEPAL (2016). Estudio Económico de América Latina y el Caribe: La agenda 2030 para el desarrollo sostenible y los desafíos del financiamiento para el desarrollo. Santiago: Naciones Unidas.

CEPLAN (2010). Plan Perú al 2021. Plan estratégico de desarrollo nacional. Biblioteca Nacional del Perú N²010-03114 ISBN, Lima, Perú: Editora Diskcopy S.A.C.

Céspedes, N., Lavado, P., \& Ramírez, N. (2016). Productividad en el Perú: Medición, determinantes e implicancias. Lima, Perú: Universidad del Pacífico.

Chang, C., Liao, G., Yu, X., \& Ni, Z. (2014). Information from relationship lending: Evidence from loan defaults in China. Journal of Money, Credit and Banking, 46(6), 1225-1257.

Chen, Y., Huang, R. J., Tsai, J., \& Tzeng, L. Y. (2013). Soft information and small business lending. Journal of Financial Services Research, 47, 115-133.

Chittithaworn, C., Islam, M. A., Keawchana, T., \& Yusuf, D. H. M. (2011). Factors affecting business success of small \& medium enterprises (SMEs) in Thailand. Asian Social Science, 7(5), 180-190. 
Claver, E., Molina, J., \& Quer, D. (2000). Incidencia comparada del «efecto empresa» y el «efecto sector» en la rentabilidad económica. Aplicación a una muestra de empresas de Alicante 1994-1998. Economía Industrial, 334(4), 143-152.

Cocca, P., \& Alberti, M. (2010). A framework to assess performance measurement systems in SMEs. International Journal of Productivity and Performance Management, 59(2), 186-200.

Codemype. (2006). Plan nacional de promoción y formalización para la competitividad y desarrollo de la micro y pequeña empresa 2005-2009. Lima, Perú.

Collis, D., \& Montgomery, C. A. (1999). Competing on resources: Strategy in the 1990s. Harvard Business Review, July-August, 118-128.

Conde, J. G., Sampedro, E. L. V., Feliu, V. R., \& Sánchez, M. B. G. (2013). Management control systems and ISO certification as resources to enhance internationalization and their effect on organizational performance. Agribusiness, 29(3), 392-405.

Conner, K. R. (1991). A historical comparison of resource-based theory and five schools of thought within industrial organization economics: Do we have a new theory of the firm? Journal of Management, 17(1), 121-154.

Cornée, S. (2017). The relevance of soft information for predicting small business credit default: Evidence from a social bank. Journal of Small Business Management, forthcoming.

Corredor, P., \& Goñi, S. (2011). TQM and performance: Is the relationship so obvious? Journal of Business Research, 64(8), 830-838.

Cosenz, F., \& Noto, L. (2015). Combining system dynamics modelling and management control systems to support strategic learning processes in SMEs: A dynamic performance management approach. Journal of Management Control, 26(2-3), 225-248.

Cravo, T. a., Becker, B., \& Gourlay, A. (2014). Regional growth and SMEs in Brazil: A spatial panel approach. Regional Studies, 49(12), 1995-2016. 
Crescenzi, R. (2005). Innovation and regional growth in the enlarged Europe: The role of local innovative capabilities, peripherality, and education. Growth and Change, 36(4), 471-507.

Cressy, R. (2006). Why do most firms die young? Small Business Economics, 26(2), 103-116.

Crittenden, W. F., \& Crittenden, V. L. (2000). Relationships between organizational characteristics and strategic planning processes in nonprofit organizations. Journal of Managerial Issues, 12(2), 150-168.

Cuervo, A. (1993). El papel de la empresa en la competitividad. Papeles de Economía Española, 56, 363-378.

Dayé, M., Houssa, R., \& Reding, P. (2015). Policy instruments to improve MSMEs access to external financing in developing countries: A survey (No. 6). University of Namur, Department of Economics..

De Oliveira, A. M. B., \& De Oliveira, A. J. (2011). Gestão de recursos humanos: Uma metanálise de seus efeitos sobre desempenho organizacional. RAC-Revista de Administração Contemporânea, 15(4), 650-669.

DeYoung, R., Glennon, D., \& Nigro, P. (2008). Borrower-lender distance, credit scoring, and loan performance: Evidence from informational-opaque small business borrowers. Journal of Financial Intermediation, 17(1), 113-143.

Dibrell, C., Craig, J. B., \& Neubaum, D. O. (2014). Linking the formal strategic planning process, planning flexibility, and innovativeness to firm performance. Journal of Business Research, 67(9), 2000-2007.

Doan, T., Gibson, J., \& Holmes, M. (2010). What determines credit participation and credit constraints of the poor in peri-urban areas, Vietnam?. MPRA Paper No. 27509, Muenchen, Germany.

Drakos, K., \& Giannakopoulos, N. (2011). On the determinants of credit rationing: Firmlevel evidence from transition countries. Journal of International Money and Finance, 30(8), 1773-1790. 
Eddleston, K. A., Kellermanns, F. W., \& Sarathy, R. (2008). Resource configuration in family firms: Linking resources, strategic planning and technological opportunities to performance. Journal of Management Studies, 45(1), 26-50.

Esparza, J. L., García-Perez-de-Lema, D., \& Duréndez, A. (2009). Gestión estratégica y competitiva de las empresas familiares turisticas mexicanas: Un estudio empírico. Revista Escuela de Administración de Negocios, 66, 5-29.

Esquivel-Martínez, H., \& Hernández-Ramos, U. (2007). Crecimiento económico, información asimétrica en mercados financieros y microcréditos. Economía, Sociedad y Territorio, 6(23), 773-805.

Estrada, R., García-Pérez-de-Lema, D., \& Sánchez, V. (2009). Factores determinantes del éxito competitivo en la Pyme: Estudio empírico en México. Revista Venezolana de Gerencia, 14(46), 169-182.

Fabi, B., Raymond, L., \& Lacoursière, R. (2007). HRM Practice clusters in relation to size and performance: An empirical investigation in Canadian manufacturing SMEs. Journal of Small Business and Entrepreneurship, 20(1), 25-40.

Fama, E. F. (1985). What's different about banks? Journal of Monetary Economics, 15(1), 29-39.

Farinha, L., \& Félix, S. (2015). Credit rationing for Portuguese SMEs. Finance Research Letters, 14, 167-177.

Fening, F. (2012). Impact of quality management practices on the performance and growth of small and medium sized enterprises (Smes) in Ghana. International Journal of Business and Social Science, 3(13), 1-13.

Fernández, E., Montes, J. M., \& Vázquez, C. J. (2000). Typology and strategic analysis of intangible resources: A resource-based approach. Technovation, 20(2), 81-92.

Fernández, S. P., Magdaleno, J. A. R., \& Zesati, R. E. F. (2014). La influencia de las barreras a la innovación que limitan la competitividad y el crecimiento de las pymes manufactureras. Administración y Organizaciones, 33, 33-57.

Ferri, M. G., \& Jones, W. H. (1979). Determinants of financial structure: A new methodological approach. The Journal of Finance, 34(3), 631-644. 
Foreman-Peck, J. (2013). Effectiveness and efficiency of SME innovation policy. Small Business Economics, 41(1), 55-70.

Freel, M. (2007). Are small innovators credit rationed? Small Business Economics, 28(1), 23-35.

Freel, M., Carter, S., Tagg, S., \& Mason, C. (2012). The latent demand for bank debt: Characterizing "discouraged borrowers." Small Business Economics, 38(4), 399_ 418.

Fundación para el Análisis Estratégico y Desarrollo de la Pequeña y Mediana Empresa (2014). Análisis estratégico para el desarrollo de la Mipyme en Iberoamérica: Informe Mipyme Perú 2013. Lima, Perú.

Gadenne, D. y Sharma, B. (2009). An investigation of the hard and soft quality management factors of Australian SMEs and their association with firm performance. International Journal of Quality \& Reliability Management, 26(9), 865880.

Gallardo, M. (2013). Vulnerabilidad a la pobreza: Aplicaciones para América Latina (Disertación doctoral, Universidad Nacional de La Plata, Facultad de Ciencias Económicas, 2013).

Gallo, M. A., Tápies, J., \& Cappuyns, K. (2000). Comparación entre empresas familiares y no familiares: Lógicas financieras y preferencias personales, Documento de Investigación 406, IESE, Pamplona, España: Universidad de Navarra.

Gallo, M. A., \& Vilaseca, A. (1996). Finance in Family Business. Family Business Review, 9(4), 387-401.

Gallo, M., Garrido, R., \& Del Pozo, J. (2015). La cara amarga del crecimiento económico peruano: persistencia de la desigualdad y divergencia territorial. Documentos de Trabajo IELAT No. 75, Universidad de Alcalá.

García-Pérez-de-Lema, D., Marin, S., \& Martínez, F. J. (2006). La contabilidad de costos y rentabilidad en la Pyme. Contaduría y Administración, (218), 39-59. 
García-Vega, E. H. (2011). Competitividad en el Perú: Diagnóstico, sectores a priorizar y lineamientos a seguir para el período 2011-2016. Revista de Globalización, Competitividad y Gobernabilidad, 5(1), 112-141.

Ge, D., Mahoney, J. M., \& Mahoney, J. T. (2005). New venture valuation by venture capitalists: An integrative approach. University of Illinois at Urban Champaign Working Paper, 124, 05-0124.

Ghobadian, A., O'Regan, N., Thomas, H., \& Liu, J. (2008). Formal strategic planning, operating environment, size, sector and performance. Journal of General Management, 34(2), 1-19.

Gibson, D. V., \& Naquin, H. (2011). Investing in innovation to enable global competitiveness: The case of Portugal. Technological Forecasting and Social Change, 78(8), 1299-1309.

Gill, A., \& Biger, N. (2011). Barriers to small business creations in Canada. Journal of Small Business and Enterprise Development, 19(4), 656-668.

Glaister, K. W., Dincer, O., Tatoglu, E., Demirbag, M., \& Zaim, S. (2008). A causal analysis of formal strategic planning and firm performance: Evidence from an emerging country. Management Decision, 46(3), 365-391.

Goedhuysa, M., \& Veugelers, R. (2012). Innovation strategies, process and product innovations and growth: Firm-level evidence from Brazil. Structural Change and Economic Dynamics, 23(4), 516-529.

Gómez-Conde, J., López-Valeiras, E., \& González-Sánchez, M. B. (2014). Sistemas de control de gestión, rendimiento de la capacidad innovadora y certificaciones ISO: Modelando sus efectos sobre el rendimiento organizacional. Revista Galega de Economía, 23(1), 245-270.

Gordillo, M. A. M. (2015). La evasión y elusión tributaria de las mype en las empresas del sector comercio-rubro abarrotes del distrito de Chimbote, 2014. In Crescendo Derecho y Ciencia Política, 2(2), 19-27.

Grant, R. M. (1991). The resource-based theory of competitive advantage: Implications for strategy formulation. California Management Review, 33(3), 114-135. 
Grant, R. M. (1996). Dirección Estratégica. Conceptos, Técnicas y Aplicaciones. Madrid, España: S. L. Civitas Ediciones.

Griggs, H. E. (2002). Strategic planning system characteristics and organisational effectiveness in Australian small-scale firms. The Irish Journal of Management, 23(1), 23-51.

Grunert, J., \& Norden, L. (2012). Bargaining power and information in SME lending. Small Business Economics, 39(2), 401-417.

Grunert, J., Norden, L., \& Weber, M. (2005). The role of non-financial factors in internal credit ratings. Journal of Banking \& Finance, 29(2), 509-531.

Guiso, L. (1998). High-tech firms and credit rationing. Journal of Economic Behavior \& Organization, 35(1), 39-59.

Gunday, G., Ulusoy, G., Kilic, K., \& Alpkan, L. (2011). Effects of innovation types on firm performance. Journal of Production Economics, 133(2), 662-676.

Hall, R. (1993). A framework linking intangible resources and capabiliites to sustainable competitive advantage. Strategic Management Journal, 14(8), 607-618.

Hamel, G., \& Prahalad, C. K. (1990). Corporate imagination and expeditionary marketing. Harvard Business Review, 69(4), 81-92.

Hamilton, R. T., \& Fox, M. A. (1998). The financing preferences of small firm owners. International Journal of Entrepreneurial Behaviour \& Research, 4(3), 239-248.

Hernández-Cánovas, G., Madrid-Guijarro, A., \& Van Auken, H. (2010). Role of information in the debt financing of technology-based firms in Spain. The Entrepreneurial Society: How to Fill the Gap Between Knowledge and Innovation. Edward Elgar Publishing Inc., 79-103.

Hernández-Cánovas, G., \& Martínez-Solano, P. (2010). Relationship lending and SME financing in the continental European bank-based system. Small Business Economics, 34(4), 465-482.

Hernani, M., \& Hamann, A. (2013). Percepción sobre el desarrollo sostenible de las mype en el Perú. Rae, 53(3), 290-302. 
Herzallah, A. M., Gutierrez-Gutierrez, L., \& Munoz Rosas, J. F. (2014). Total quality management practices, competitive strategies and financial performance: The case of the Palestinian industrial SMEs. Total Quality Management \& Business Excellence, 25(5-6), 635-649.

Hogan, S. J., \& Coote, L. V. (2014). Organizational culture, innovation, and performance: A test of Schein's model. Journal of Business Research, 67(8), 1609-1621.

Holmstrom, B. (1982). Moral hazard in teams. The Bell Journal of Economics, 13(2), 324-340.

Holod, D., \& Peek, J. (2013). The value to banks of small business lending. Working Papers, Federal Reserve Bank of Boston, No. 13-7.

Hoque, M. Z., Sultana, N., \& Thalil, T. (2016). Credit rationing's determinants of small and medium enterprises (SMEs) in Chittagong, Bangladesh. Journal of Global Entrepreneurship Research, 6(1), 1.

Hudson, M., Smart, A., \& Bourne, M. (2001). Theory and practice in SME performance measurement systems. International Journal of Operations \& Production Management, 21(8), 1096-1115.

Huggins, R., \& Johnston, A. (2009). Knowledge networks in an uncompetetive region: SME innovation and growth. Growth and Change, 40(2), 227-259.

Idar, R., Yusoff, Y., \& Mahmood, R. (2012). The effect of market orientation as mediator to strategic planning practices and performance relationship: Evidence from Malaysian SMEs. Procedia Economics and Finance, 4, 68-75.

Idígoras, I. M., \& Mitxeo, J. (2000). La gestión del conocimiento como base de la estrategia basada en los recursos y capacidades de la empresa. Revista de Dirección y Administración de Empresas, 8, 61-75.

Ilkay, M. S., \& Aslan, E. (2012). The effect of the ISO 9001 quality management system on the performance of SMEs. International Journal of Quality \& Reliability Management, 29(7), 753-778.

Instituto Nacional de Estadística e Informática. (2015). 11 de julio Día Mundial de la Población. Lima, Perú. 
Instituto Nacional de Estadística e Informática. (2016a). Evolución de la pobreza monetaria 2009-2015. Lima, Perú.

Instituto Nacional de Estadística e Informática. (2016b). Panorama de la Economía Peruana: 1950-2015. Lima, Perú.

Instituto Nacional de Estadística e Informática. (2016c). Producto Bruto Interno Trimestral. Lima, Perú.

Instituto Nacional de Estadística e Informática. (2015). 11 de julio Día Mundial de la Población. Lima, Perú.

International Finance Corporation. (2015). Informe Anual 2015. Washington, EE.UU.

Islam, A., Khan, M., Obaidullah, A. y Alam, M. (2011). Effect of entrepreneur and firm characteristics on the business success of small and medium enterprises (SMEs) in Bangladesh. International Journal of Business and Management, 6(3), 289-299.

Iyer, R., Khwaja, A. I., Luttmer, E. F. P., \& Shue, K. (2014). Screening peers softly: Inferring the quality of small borrowers. National Bureau of Economic Research Working Paper Series, (15242), 1-65.

Jaramillo, M., \& Sparrow, B. (2015). Crecimiento y segmentación en el Perú. Análisis y Propuestas, 29, 1-4.

Jarosz-Angowska, A., \& Angowski, M. (2014). The importance of the small and mediumsized enterprise sector of the voivodeships of Eastern Poland. Acta Scientiarum Polonorum. Oeconomia, 13(4), 67-78.

Jasra, J. M., Hunjra, A. I., Rehman, A. U., Azam, R. I., \& Khan, M. A. (2011). Determinants of business success of small and medium enterprises. International Journal of Business and Social Science, 2(20), 274-280.

Jones, C., Motta, J., \& Alderete, M. V. (2016). Gestión estratégica de tecnologías de información y comunicación y adopción del comercio electrónico en Mipymes de Córdoba, Argentina. Estudios Gerenciales, 32(138), 4-13.

Karapetyan, A., \& Stacescu, B. (2014). Information sharing and information acquisition in credit markets. Review of Finance, 18(4), 1583-1615. 
King-Kauanui, S., Ngoc, S. D., \& Ashley-Cotleur, C. (2006). Impact of human resource management: SME performance in Vietnam. Journal of Developmental Entrepreneurship, 11(1), 79-95.

Kira, A. R., \& He, Z. (2012). The impact of firm characteristics in access of financing by small and medium-sized enterprises in Tanzania. International Journal of Business and Management, 7(24), 108-119.

Kirschenmann, K. (2012, July). Credit rationing in small business bank relationships. Helsinki, Finland: Aalto University School of Business.

Kossaï, M., \& Piget, E. P. (2012). Utilisation des technologies de l'information et des communications (Tic) et performance economique des Pme Tunisiennes: Une etude econometrique. Brussels economic review, 55(3).

Krejcí, M., Strielkowski, W., \& Čabelková, I. (2015). Factors that influence the success of small and medium enterprises in ICT: A case study from the Czech Republic. Business: Theory and Practice/Verslas: Teorija Ir Praktika, 16(3), 304-315.

Kremp, E., \& Sevestre, P. (2013). Did the crisis induce credit rationing for French SMEs? Journal of Banking and Finance, 37(10), 3757-3772.

Kundid, A., \& Ercegovac, R. (2011). Credit rationing in financial distress: Croatia SMEs' finance approach. International Journal of Law and Management, 53(1), 62-84.

Laitinen, E. K. (2014). Influence of cost accounting change on performance of manufacturing firms. Advances in Accounting, 30(1), 230-240.

Lakhal, L. (2014). The relationship between ISO 9000 certification, TQM practices, and organizational performance. The Quality Management Journal, 21(3), 38-48.

Larrán, M., García-Borbolla, A., \& Giner, Y. (2010). Factores determinantes del racionamiento de crédito a las pymes: Un estudio empírico en Andalucía. Investigaciones Europeas de Dirección y Economía de la Empresa, 16(2), 63-82.

Leal-Rodriguez, A. L., Eldridge, S., Roldán, J. L., Leal-Millán, A. G., \& Ortega-Gutiérrez, J. (2015). Organizational unlearning, innovation outcomes, and performance: The moderating effect of firm size. Journal of Business Research, 68(4), 803-809. 
Lecerf, M. (2012). Internationalization and Innovation: The effects of a strategy mix on the economic performance of French SMEs. International Business Research, 5(6), $2-13$.

Lederman, D., Messina, J., Pienknagura, S., \& Rigolini, J. (2014). El emprendimiento en América Latina: Muchas empresas y poca innovación. Washington, DC: Banco Mundial.

León, J., \& Jopen, G. (2011). La heterogeneidad del microcrédito en el sector financiero regulado peruano. En J. León \& J. Iguíñiz (Eds.), Desigualdad distributiva en el Perú: dimensiones (pp. 291-320). Lima, Perú: Pontificia Universidad Católica del Perú.

León, J., \& Ramírez, J. (2014). La Alianza del Pacífico. Alcances, competitividad e implicaciones para América Latina. Análisis No. 5, Fundación Friedrich Ebert Stiftung.

Lévano, C. (2005). Elaboración de estadísticas de la micro y pequeña empresa. Lima, Perú: Dirección Nacional de la Micro y Pequeña Empresa del Ministerio de Trabajo y Promoción del Empleo.

Ley No. 28015 sobre promoción y formalización de la micro y pequeña empresa (2013). En Diario Oficial El Peruano. Perú.

Ley No. 30056 sobre diversas leyes para facilitar la inversión, impulsar el desarrollo productivo y el crecimiento empresarial (2013). En Diario Oficial El Peruano. Perú.

Li, L., \& Zhu, B. (2015). Family involvement, firm size, and performance of private-owned enterprises. The Journal of Chinese Sociology, 2(1), 1-18.

Lieberman, M. B., \& Montgomery, D. B. (1998). First-mover (dis)advantages: Retrospective and link with the resource-based view. Strategic Management Journal, 19, 1111-1125.

Lippman, S. A., McCardle, K. F., \& Rumelt, R. P. (1991). Heterogeneity under competition. Economic Inquiry, 29(4), 774-782. 
Llenderrozas, E. (2016). América Latina: Fin de ciclo y transición regional. En A. Serbin (coordinador), ¿Fin de ciclo y reconfiguración regional? América Latina y las relaciones entre Cuba y los Estados Unidos (pp. 51-64). Buenos Aires, Argentina: Coordinadora Regional de Investigaciones Económicas y Sociales.

Llosa, R. (2007). La importancia de las microfinanzas, el microcrédito y los empresarios de la microempresa. THEMIS: Revista de Derecho, 54, 253-260.

Loayza, N. V. (2016). La productividad como clave del crecimiento y el desarrollo: En el Perú y el mundo. Revista Estudios Económicos, 31, 9-28.

López, J., \& Sánchez, S. (2007). Financial structure of the family business: Evidence from a group of small spanish firms. Family Business Review, 20(4), 269-287.

López, L., Tricás, J., \& Toledano, R. (2013). Principales prácticas de recursos humanos de las pymes industriales exitosas. Revista Universidad \& Empresa, 23, 19-43.

López-Calva, L., Cruces, G., Lach, S., \& Ortiz-Juárez, E. (2014). Clases medias y vulnerabilidad a la pobreza: Reflexiones desde América Latina. El Trimestre Económico, LXXXI(2, número 322), 281-307.

Lu, J. W., \& Beamish, P. W. (2006). SME internationalization and performance: Growth vs . profitability. Journal of International Entrepreneurship, 4(1), 27-48.

Magoutas, A., Agiomirgianakis, G., \& Papadogonas, T. (2011). Education and firm performance. Empirical evidence from Greece. International Journal of Economic Research, 8(2), 141-152.

Matias, A., \& Amaral, H. (2012). Credit risk assessment and the impact of the New Basel Capital Accord on small and medium-sized enterprises. Management Research Review, 35(8), 727-749.

McCarthy, S., Oliver, B. R., \& Verreynne, M. L. (2013). Bank financing and credit rationing of Australian SMEs. Australian Journal of Management, 42(1), 58-85.

McConaughy, D. L., Matthews, C. H., \& Fialko, A. S. (2001). Founding family controlled firms: Performance, risk, and value. Journal of Small Business Management, 39(1), 31-49. 
McKiernan, P., \& Morris, C. (1994). Strategic planning and financial performance in UK SMEs: Does formality matter? British Journal of Management, 5(s1), S31-S41.

Memili, E., Fang, H., Chrisman, J. J., \& De Massis, A. (2015). The impact of small-and medium-sized family firms on economic growth. Small Business Economics, 45(4), 771-785.

Mendiola, A., Aguirre, C., Chuica, S., Palacios, R., Peralta, M., Rodríguez, J., \& Suárez, E. (2014). Factores críticos de éxito para la creación de un mercado alternativo de emisión de valores para las pymes en el Perú. Lima, Perú: Universidad ESAN.

Mendizabal, A., \& Lertxundi, A. (2015). Crisis financiera, racionamiento de crédito y relación bancaria de las pyme españolas. Cuadernos de Administración, 28(50), 39-59.

Mijid, N. (2015). Gender differences in Type 1 credit rationing of small businesses in the US. General \& Applied Economics, 3(1), 1-14.

Ministerio de Economía y Finanzas (2015). Marco Macroeconómico Multianual 20162018. Lima: Ministerio de Economía y Finanzas. Disponible en: http://www.bcrp.gob.pe/docs/Publicaciones/Programa-Economico/mmm-20162018-abril.pdf

Ministerio de la Producción. (2013). Mipyme 2012. Estadísticas de la micro, pequeña y mediana empresa. Lima, Perú.

Ministerio de la Producción. (2015). Las Mipyme en cifras 2014. Lima, Perú.

Mishra, A. K. (2004). Indian venture capitalists (VCs) investment evaluation criteria. ICFAI Journal of Applied Finance, 10(7), 71-93.

Mishra, C. S., \& McConaughy, D. L. (1999). Founding family control and capital structure: the risk of loss of control and the aversion to debt. Entrepreneurship: Theory \& Practice, 23(4), 53-64.

Mokhtar, M. Z., \& Muda, M. S. (2012). Comparative study on performance measures and attributes between ISO and non-ISO certification companies. International Journal of Business and Management, 7(3), 185-193. 
Molodchik, M., Jardon, C., \& Barajas, A. (2015). The firm size effect on performance due to intangible resources. Higher School of Economics Research. Paper No. WP $B R P, 35,1-17$.

Montoya, J. J. (2016). El desarrollo financiero y el crecimiento económico. REICE: Revista electrónica de investigación en Ciencias Económicas, 4(7), 325-349.

Morales, R. (2012). Entre la formalidad y la informalidad. ¿Opciones e ingresos diferentes? Revista Latinoamericana de Desarrollo Económico, (17), 7-52.

Mora-Riapira, E. H., Vera-Colina, M. A., \& Melgarejo-Molina, Z. A. (2015). Planificación estratégica y niveles de competitividad de las Mipymes del sector comercio en Bogotá. Estudios Gerenciales, 31(134), 79-87.

Morris, F. (2000). La reforma del sistema financiero. En R. Abusada, F. Dubois, E. Morón \& J. Valderrama (Eds.), La reforma incompleta (pp. 313-342). Lima, Perú: Universidad del Pacífico e Instituto Peruano de Economía.

Morsing, M., \& Perrini, F. (2009). CSR in SMEs: Do SMEs matter for the CSR agenda? Business Ethics: A European Review, 18(1), 1-6.

Moyer, R. (1982). Strategic planning for the small firm. Journal of Small Business Management (Pre-1986), 20(3), 8-14.

Muda, S., \& Rahman, M. R. C. A. (2016). Human capital in SMEs life cycle perspective. Procedia Economics and Finance, 35, 683-689.

Murat Ar, I., \& Baki, B. (2011). Antecedents and performance impacts of product versus process innovation: Empirical evidence from SMEs located in Turkish science and technology parks. European Journal of Innovation Management, 14(2), 172-206.

Mushinski, D. W., \& Pickering, K. A. (2007). Heterogeneity in informal sector mitigation of micro-enterprise credit rationing. Journal of International Development, 19(5), $567-581$.

Myers, S. C., \& Majluf, N. S. (1984). Corporate financing and investment decisions when firms have information that investors do not have. Journal of Financial Economics, 13(2), 187-221. 
Nee, G. Y., \& Wahid, N. A. (2010). The effect of ISO 14001 environmental management system implementation on SMEs performance: An empirical study in Malaysia. Journal of Sustainable Development, 3(2), 215-220.

Nohria, N., y Gulati, R. (1996). Is slack good or bad for innovation? Academy of Management Journal, 39(5), 1245-1264.

Nor Aziati, A. H., Tasmin, R. H., Bee Jia, L., \& Abdullah, N. H. (2014). The relationship of technological innovation capabilities and business innovation capabilities on organization performance: Preliminary findings of Malaysian food processing SMEs. 2014 International Conference on Engineering, Technology and Innovation.

Ochieng, J., Muturi, D., \& Njihia, S. N. (2015). The impact of ISO 9001 implementation on organizational performance in Kenya. The TQM Journal, 27(6), 761-771.

Ogunmokun, G. O., \& Tang, E. C. H. (2012). The effect of strategic marketing planning behaviour on the performance of small-to medium-sized firms. International Journal of Management, 29(1), 159-170.

Okamuro, H. (2007). Determinants of successful R\&D cooperation in Japanese small businesses: The impact of organizational and contractual characteristics. Research Policy, 36(10), 1529-1544.

Okurut, F. N., Olalekan, Y., \& Mangadi, K. (2011). Credit rationing and SME development in Botswana: Implications for economic diversification. Botswana Journal of Economics, 8(12), 62-85.

Okuyan, H. A. (2016). The effect of asymmetric information on Turkish banking sector and credit markets. Revue Économique, 65(5), 699-708.

Organisation for Economic Co-operation and Development. (2015). Taxation of SMEs in OECD and G20 Countries. OECD Tax Policy Studies. ( $\left.\mathrm{N}^{\circ} 23\right)$. OECD Publishing, París.

Orozco, J., Chávez, G., \& Yance, C. (2014). Informalidad en la gestión de las Pymes y su efecto en la competitividad. Fenopina, 4(7), 44-48. 
Petersen, M. A. (2004). Information: Hard and soft. Working paper. USA: Northwestern University. Recuperado el 10 de febrero de 2016, de https://www.scholars.northwestern.edu/en/publications/information-hard-and-soft

Pintado, T. R., García Pérez de Lema, D., \& Van Auken, H. (2007). Venture capital in Spain by stage of development. Journal of Small Business Management, 45(1), 6888.

Porlles, J., Cachay, O., \& Salas, G. (2015). ¿Qué requerimos para una industrialización sostenible del Perú? Una propuesta del modelo industrial. Industrial Data, 18(2), 89-98.

Portocarrero, F. (2003). Microfinanzas en el Perú: experiencias y perspectivas. Lima, Perú: Centro de Investigación de la Universidad del Pacífico-PROPYME.

Prajogo, D. I., \& Sohal, A. S. (2006). The relationship between organization strategy, total quality management (TQM) and organization performance - The mediating role of TQM. European Journal of Operational Research, 168(1), 35-50.

Pratono, A. H., \& Mahmood, R. (2015). Mediating effect of marketing capability and reward philosophy in the relationship between entrepreneurial orientation and firm performance. Journal of Global Entrepreneurship Research, 5(1), 1-12.

Price, D., \& Stoica, M. (2015). The relationship between resources and firm performance: Factors that influence SMEs. Academy of Entrepreneurship Journal, 21(2), 87-98.

Prieto, I. M., \& Pérez Santana, M. (2012). Building ambidexterity: The role of human resource practices in the performance of firms from Spain. Human Resource Management, 51(2), 189-211.

PWC. (2014). La Alianza del Pacífico, Una nueva era para América Latina. México.

Quispe, Z., León, D., \& Contreras, A. (2012). El exitoso desarrollo de las microfinanzas en el Perú. Revista Moneda, (151), 13-18.

Robles-Alfaro, R., Vela-Alfaro, F., Huapaya-Huertas, O., \& Chacón-Torrico, H. (2015). Relación entre el gasto en investigación y desarrollo con la producción científica en el Perú. En Anales de la Facultad de Medicina, 76(4), 469-470. 
Robson, P., Akuetteh, C., Stone, I., Westhead, P., \& Wright, M. (2013). Credit-rationing and entrepreneurial experience: Evidence from a resource deficit context. Entrepreneurship \& Regional Development, 25(5-6), 349-370.

Rodríguez, M. (2012). Mecanismos de financiación empresarial en Colombia. Derecho y Realidad, 2(19), 107-116.

Roman, A., \& Rusu, V. D. (2011). Constraints on bank lending to SMEs from Romania and supportive measures. EuroEconomica, 30(5), 21-38.

Romano, C., Tanewski, G., \& Smyrnios, K. (2000). Capital structure decision making: A model for family business. Journal of Business Venturing, 16(3), 285-310.

Romano, P. (2000). ISO 9000: What is its impact on performance? Quality Management Journal, 7(3), 38-56.

Rosenbusch, N., Brinckmann, J., \& Bausch, A. (2008). Is innovation always beneficial? A meta-analysis of the relationship between innovation and performance in SMEs. Journal of Business Venturing, 26(4), 441-457.

Rumelt, R. P. (1991). How much does industry matter? Strategic Management Journal, 12(3), 167-185.

Sachdeva, A., Bhardwaj, A., \& Sharma, V. S. (2007). Impact of ISO 9000 certification on performance of SMEs: A study of Indian industry. International Journal of Management Practice, 2(3), 226-239.

Sandada, M. (2014). Mission and vision, environmental scanning and formality of strategic planning as predictors of the performance of small and medium enterprises (Smes) in the Gauteng province of South Africa. Ecoforum Journal, 3(2), 59-67.

Martínez, A., \& Londoño, H. (2004). El racionamiento del crédito en los mercados financieros. Revista de Economía y Administración, 1, 145-184.

Santander, C. (2013). Estrategias para inducir la formalidad de la mype de la industria gráfica-offset por medio de gestión competitiva (Tesis de Maestría, Pontificia Universidad Católica del Perú, 2013). Recuperado el 10 de abril de 2016, de http://tesis.pucp.edu.pe/repositorio/handle/123456789/4961 
Sarabia, F. (1999). Metodología para la investigación en marketing y dirección de empresas. Madrid, España: Pirámide.

Scimago Journal \& Country Rank. (2016). Consultado el 10 de mayo de 2016, de http://www.scimagojr.com

Scott, J. A. (2006). Loan officer turnover and credit availability for small firms. Journal of Small Business Management, 44(4), 544-562.

Sérida, J., Borda, A., Nakamatsu, K., Morales, O., \& Yamakawa, P. (2005). Global Entrepreneurship Monitor: Perú 2004-2005. Lima.

Shack, N. (2016). Reformas de gasto público y crecimiento económico: El caso de las Asociaciones Público-Privadas en el Perú y la inversión "impulsada". CEPAL. Serie Macroeconomía del Desarrollo No. 171.

Shappo, M., \& Knuth, A. (2014). Empirical factors of SME development in Belarus: Analysis and recommendations. Get Belarus, 4, 1-22.

Silva, Z., \& Maçãs, P. (2008). Performance and size: Empirical evidence from Portuguese SMEs. Small Business Economics, 31, 195-217.

Sok, P., \& O'Cass, A. (2013). Examining the new product innovation - performance relationship: Optimizing the role of individual-level creativity and attention-to-detail. Industrial Marketing Management, 47, 156-165.

Soriano, D. R., \& Castrogiovanni, G. J. (2012). The impact of education, experience and inner circle advisors on SME performance: Insights from a study of public development centers. Small Business Economics, 38(3), 333-349.

Starke, F., Eunni, R. V., Dias Fouto, N. M., \& De Angelo, C. (2012). Impact of ISO 9000 certification on firm performance: Evidence from Brazil. Management Research Review, 35(10), 974-997.

Stiglitz, J. E., \& Weiss, A. (1981). Credit rationing in markets with imperfect information. American Economic Review, 71(3), 393-410.

Streletzki, J.-G., \& Schulte, R. (2013). Which venture capital selection criteria distinguish high-flyer investments? Venture Capital, 15(1), 29-52. 
Strielkowski, W., Abrhám, J., \& Herget, J. (2014). Success factors of growth and development for small and medium enterprises in tourism sector. Journal of Applied Economic Sciences, IX(1,27), 101-109.

Subrahmanya, M. B. (2011). Technological innovations and firm performance of manufacturing SMEs: Determinants and outcomes. Journal of Management, 41(1), 109-122.

Sumedrea, S., \& Costin, V. (2014). Managing through budgets for increasing firms' performances in a dynamic and globalized economy. Bulletin of the Transilvania University of Brasov. Economic Sciences. Series V, 7(2), 159-164.

Tangkittipaporn, J. (2010). Factors predicting small and medium-sized enterprises' success. International Journal of Sustainable Economy, 2(1), 113-126.

Tapinos, E., Dyson, R. G., \& Meadows, M. (2005). The impact of performance measurement in strategic planning. International Journal of Productivity and Performance Management, 54(5/6), 370-384.

Tello, M. (2011). Indicadores del sector Mype informal en el Perú: Valor agregado, potencial exportador, capacidad de formalizarse y requerimientos de normas técnicas peruanas de sus productos. Documento de Trabajo No. 310, Lima, Perú: Departamento de Economía de la Pontificia Universidad Católica del Perú.

Terziovski, M. (2010). Innovation practice and its performance implications in small and medium enterprises (SMEs) in the manufacturing sector: a resource-based view. Strategic Management Journal, 31(8), 892-902.

Tether, B. S. (2005). Do services innovate (differently)? Insights from the European innobarometer survey. Industry \& Innovation, 12(2), 153-184.

The World Bank (2016). [Archivo de datos]. Disponible en el sitio web de http://databank.worldbank.org/data/home.aspx

Toçi, V. Z., \& Hashi, I. (2009). Financing constraints and credit rationing: Evidence from south-east Europe. Challenges of Europe: Financial crisis and climate changes Proceedings of the International Conference in Split-Bol, Split-Bol, Croatia, (211234). 
Trang, T. K. (2015). Key success factors of SME entrepreneurs: Empirical study in Vietnam. International Journal of Business and Management, 11(1), 136-143.

Tsaih, R., Liu, Y. J., Liu, W., \& Lien, Y. L. (2004). Credit scoring system for small business loans. Decision Support Systems, 38(1), 91-99.

Uchida, H. (2011). What do banks evaluate when they screen borrowers? Soft information, hard information and collateral. Journal of Financial Services Research, 40(1-2), 29-48.

Ullah, B., Wei, Z., \& Xie, F. (2014). ISO certification, financial constraints, and firm performance in Latin American and Caribbean countries. Global Finance Journal, 25(3), 203-228.

Upton, N., \& Petty, W. (2000). Venture capital investment and US family business. Venture Capital: An International Journal of Entrepreneurial Finance, 2(1), 27-39.

Valenzuela, G., \& Rodríguez, A. (2015). Interdependencia de mercados y transmisión de volatilidad en Latinoamérica. Innovar, 25(55), 157-170.

Valmohammadi, C. (2011). The impact of TQM implementation on the organizational performance of Iranian manufacturing SMEs. The TQM Journal, 23(5), 496-509.

Van Kirk, J. E., \& Noonan, K. (1982). Key factors in strategic planning. Journal of Small Business Management (Pre-1986), 20(3), 1-7.

Vărzaru, L. A. A. (2014). Control performance through the design and implementtion of a budgetary system in SMEs in the region south-west Oltenia. Annals of the University of Craiova, Economic Sciences Series, 1(42), 178-188.

Vasco, D. C. (2012). Reforma fiscal y nuevo modelo de desarrollo de América Latina: Los casos de Perú y Colombia. Documento de Trabajo 70/2012. Fundación Alternativas.

Venkatraman, N., \& Ramanujam, V. (1986). Measurement of business performance in strategy research: A comparison of approaches. The Academy of Management Review, 11(4), 801-814. 
Vera-Colina, M. A., Rodriguez-Aedina, G., \& Melgarejo-Molina, Z. (2011). Financial planning and access to financing in small and medium-sized companies in the Venezuelan manufacturing sector. Innovar-Revista de Ciencias Administrativas y Sociales, 21(42), 99-112.

Viedma, J. M. (1992). La excelencia empresarial española. (2ª ed.). México: McGrawHill.

Villanueva, C. (2011). Tratamiento tributario en el Régimen Único Simplificado. Actualidad y Aplicación Práctica, 244, 12-14.

Villarán, F. (2001). Participación de las empresas en la formación de recursos humanos. Documento de Trabajo 3, MECEP. Lima, Perú: Proyecto Mejoramiento de la Calidad de la Educación Peruana.

Villarán, F., \& Mifflin, I. (2009). Creando riqueza desde abajo: Las micro y pequeñas empresas en el Perú. Lima, Perú: Fondo Editorial del Congreso del Perú.

Vladimirov, Z. (2016). SME innovations and performance: The mediating role of product innovation. International Review of Entrepreneurship, 14(2), 209-233.

Waelchli, U., \& Zeller, J. (2013). Old captains at the helm: Chairman age and firm performance. Journal of Banking \& Finance, 37, 1612-1628.

Wernerfelt, B. (1984). A resource-based view of the firm. Strategic Management Journal, 5(2), 171-180.

Wijewardena, H., \& De Zoysa, A. (2001). The impact of financial planning and control on performance of SMEs in Austrialia. Journal of Enterprising Culture, 9(04), 353-365.

Wiklund, J., \& Shepherd, D. (2005). Entrepreneurial orientation and small business performance: A configurational approach. Journal of Business Venturing, 20(1), 7191.

World Economic Forum. (2016). The Global Competitiveness Index Historical Dataset, [Archivo de datos]. Disponible en el sitio web de http://www3.weforum.org/docs/ gcr/2015-2016/GCl_Dataset_2006-2015.xIsx 
Xiao-hong, C., \& Yang-jie, G. (2013). Impact of demographic traits of entrepreneurs on financing constraints of SMEs. International Conference on Management Science and Engineering - Annual Conference Proceedings (1815-1822).

Yamakawa, P., Del Castillo, C., Baldeón, J., Espinoza, L. M., Granda, J. C., \& Vega, L. (2010). Modelo tecnológico de integración de servicios para la mype peruana. Lima, Perú: Universidad ESAN. Serie Gerencia para el Desarrollo.

Yee, R. W., Yeung, A. C., \& Cheng, T. E. (2010). An empirical study of employee loyalty, service quality and firm performance in the service industry. International Journal of Production Economics, 124(1), 109-120.

Yurov, K. M., Greenstein, S. M., Shanley, M. T., \& Potter, R. E. (2013). The role of geographic location in the acquisition strategies of high technology firms: Evidence from computer networking equipment industry. Thunderbird International Business Review, 55(4), 371-385.

Zabri, S. M., Ahmad, K., \& Lean, J. (2011). Understanding owner-managers' preferences towards different sources of financing: The case of successful SMEs in Malaysia. Advanced Science Letters, 4, 400-407.

Zahra, S., Neubaum, D., \& Naldi, L. (2007). The Effects of ownership and governance on SMEs' international knowledge-based resources. Small Business Economics, 29(3), 309-327.

Zhang, D., Hu, H., \& Zhang, H. (2011). Risk analysis of credit rating business for commercial banks on small and medium-sized enterprise. Proceedings - 2011 4th International Conference on Information Management, Innovation Management and Industrial Engineering, ICIII 2011, 3, 312-315.

Zhang, G. (2008). The choice of formal or informal finance: Evidence from Chengdu, China. China Economic Review, 19(4), 659-678.

Zhang, X. (2012). Venture capital investment selection decision-making base on fuzzy theory. Physics Procedia, 25, 1369-1375.

Zheng, C., O'Neill, G., \& Morrison, M. (2009). Enhancing Chinese SME performance through innovative HR practices. Personnel Review, 38(2), 175-194. 